UNIVERSIDAD POLITÉCNICA DE MADRID

Escuela Técnica Superior de Ingenieros de

Caminos, Canales y Puertos

\title{
NUEVO PROCEDIMIENTO DE ENSAYO PARA \\ DETERMINAR EL COEFICIENTE DE PULIMENTO \\ ACELERADO DE MEZCLAS BITUMINOSAS
}

\section{TESIS DOCTORAL}

\author{
Antonio Ramírez Rodríguez \\ Ingeniero de Caminos, Canales y Puertos
}

Madrid, 2017 

DEPARTAMENTO DE INGENIERÍA CIVIL: TRANSPORTE Y TERRITORIO

Escuela Técnica Superior de Ingenieros de Caminos, Canales y Puertos

TESIS DOCTORAL

\title{
NUEVO PROCEDIMIENTO DE ENSAYO PARA DETERMINAR EL COEFICIENTE DE PULIMENTO ACELERADO DE MEZCLAS BITUMINOSAS
}

por

\author{
Antonio Ramírez Rodríguez \\ Ingeniero de Caminos, Canales y Puertos \\ Director: \\ Juan Gallego Medina \\ Dr. Ingeniero de Caminos, Canales y Puertos
}

Madrid, 2017 



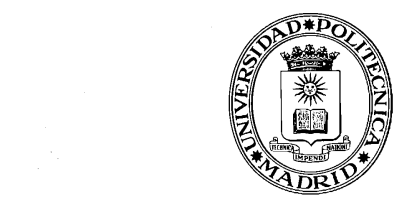

UNIVERSIDAD POLITECNICA DE MADRID

\section{D.15}

Tribunal nombrado por el Mgfco. y Excmo. Sr. Rector de la Universidad Politécnica de Madrid, el día.

Presidente

Vocal

Vocal

Vocal

Secretario

Realizado el acto de defensa y lectura de la Tesis el día..........de de 2015 en la E.T.S. de Ingenieros de Caminos, Canales y Puertos de la U.P.M.

Calificación:

EL PRESIDENTE LOS VOCALES

EL SECRETARIO 



\section{AGRADECIMIENTOS}

Voy a empezar, como no podía ser de otra forma, por mi director de tesis, Juan Gallego, que ha sabido guiarme durante todos estos años, darme sabios consejos, por su gran conocimiento en la materia sobre la que versa esta tesis y darme el ánimo que necesitaba cuando ya pensaba que no podía acabar el trabajo.

A mi antiguo jefe, Jacinto Luis García Santiago, que fue el primero que me metió en la cabeza que debía sacarme el doctorado y ser el responsable de que me guste profundamente el trabajo de investigar, en especial con todo lo que tenga que ver con la fabricación y puesta en obra de mezclas bituminosas. Querido Jacinto ya no eres mi jefe pero siempre serás mi amigo y ojalá que, con el tiempo, pueda llegar a ser tan buen profesional como tú.

A Carlos Blázquez en particular, y todo el equipo de PROETISA en general, por el magnífico trabajo que hicieron durante la fase de diseño y construcción de moldes para fabricar las probetas de ensayo y por la adaptación del equipo de pulimento acelerado de áridos y a Julián, del laboratorio de la Escuela, por su infinita paciencia y buen hacer en el conjunto de ensayos que se han tenido que desarrollar durante este trabajo.

A toda mi familia, a los que están arriba pendiente de lo que hago y a los que están aquí abajo, en especial a mis padres, que hicieron un gran esfuerzo porque sus hijos estudiaran y pudieran ir a la Universidad. Vosotros me habéis enseñado que con motivación y esfuerzo todo se puede conseguir. Quién te iba a decir madre que aquel niño de 5 años que no aprendía a leer iba a terminar escribiendo su tesis doctoral.

Gracias a vosotros chicos, mis príncipes Juan, María e Inés. Mi mundo es mucho mejor desde que vivís en él pero vosotros hacéis que quiera dejarlo mejor todavía. Espero que esta investigación aporte su granito de arena al respecto. Es lo que me ha motivado a hacer este esfuerzo.

Pero sobre todo, gracias a ti Hortensia. Sin tu ayuda no hubiera podido hacer este trabajo. Eres la persona que me da el equilibrio y la felicidad que necesito para hacer estas cosas y la que me da ánimos cuando me faltan las fuerzas. Cuando empecé con esto acababa de nacer Juan. Luego vinieron María e Inés y cada vez había menos tiempo, pero tú podías con todo y me diste el que necesitaba. 



\section{RESUMEN}

La resistencia al deslizamiento es una de las propiedades que tienen más influencia en lo que respecta a la seguridad ofrecida por el pavimento y tiene una gran repercusión en la reducción de los accidentes, especialmente en circunstancias de Iluvia o superficie mojada. La resistencia al deslizamiento en los pavimentos tiende a decrecer con el paso del tiempo, debido a la acción del tráfico y a otros factores, lo que repercute en una mayor inseguridad para los conductores. La medida de la resistencia al deslizamiento se ha convertido en una herramienta básica para la gestión de las redes de carreteras.

Si bien esta propiedad se mide en los pavimentos de carreteras en servicio, no hay apenas experiencias de su medida en laboratorio, siendo los equipos existentes en la actualidad de muy reciente desarrollo y/o de adquisición muy costosa. Debido a ello es difícil hacer extensivo su uso en el diseño de mezclas de una forma generalizada, quedando las pruebas que con ellos se hacen en un reducido grupo de laboratorios y sin posibilidad de comparar resultados entre diferentes centros de trabajo. Sería muy interesante el poder disponer de un nuevo procedimiento de ensayo, que permitiera predecir cuál va a ser la evolución de esta propiedad antes de proceder a la construcción de la capa de rodadura de una carretera, sin los inconvenientes asociados a los equipos actuales.

En el presente trabajo se resume la experiencia que se ha adquirido durante el desarrollo de un nuevo procedimiento de ensayo que ha tratado de predecir en el laboratorio cuál va a ser la evolución del valor de la resistencia al deslizamiento obtenido en mezclas bituminosas en caliente, mediante la adaptación del equipo con el que actualmente se determina el coeficiente de pulimento acelerado de los áridos de acuerdo a la norma UNE-EN 1097-8.

El estudio se ha estructurado en una serie de etapas o fases. La primera consistió en la realización del estado del arte, que ha permitido conocer qué es lo que se ha investigado hasta la fecha en esta materia. A continuación, se realizó el diseño de las modificaciones a introducir en la máquina de pulimento acelerado de áridos y de los moldes y útiles de compactación para construir las probetas de mezcla a ensayar, la construcción de los prototipos y la definición de las condiciones de ensayo. Por último, se procedió a realizar pruebas con distintos tipos de mezclas y a validar el nuevo método de ensayo.

Los resultado obtenidos ponen de manifiesto que el procedimiento de ensayo desarrollado en el presente trabajo para medir el coeficiente de pulimento acelerado de mezclas permite evaluar el comportamiento de éstas frente al 
fenómeno de resistencia al deslizamiento y que se podría emplear en el futuro, durante la fase de diseño en laboratorio de este tipo de materiales, para conocer cuál va ser la evolución de esta propiedad de las mezclas a lo largo de su vida útil.

Palabras clave: Resistencia al deslizamiento, pulimento, mezcla bituminosa en caliente, método de ensayo. 


\section{ABSTRACT}

The skid resistance is one of the most important properties with great influence as regards to the security offered by the pavement, which in turn, it has significant impact to favorably reduce the traffic accidents, especially, under circumstances of rain or wet surface. The pavement skid resistance tends to decrease over time due to traffic loads and many other factors, resulting in greater uncertainty and insecurity for drivers. The skid resistance measurement has become in a crucial tool for the management of highway network assets.

In spite of the fact of this property is readily measured on the service road pavements, there isn't enough experience with regards to their measuring in the laboratory, since current devices are still in development process or recent development, resulting in an expensive acquisition. Nowadays, it is increasingly difficult to promote its widespread use in the design of asphalt mixtures, there is evidence that are made in a small group of laboratories without possibility of comparing results between the different research centers. It would be interesting to develop a new testing method which allows predicting the evolution of the skid resistance of a bituminous mixture before its placing as a road pavement surface course, regardless the drawbacks associated to current equipment.

This research project summarizes the experience and knowledge gained during the development of a new testing equipment method which has tried to greatly predict the evolution of the skid resistance value of an asphalt in the laboratory through the latest modified version of an accelerated polishing machine, which is commonly used to determine the polished stone value of aggregates, according to UNE-EN 1097-8.

The research study has been divided in phases or stages. The first phase consisted of conducting the state of the art to know that has been done to date in this field. Subsequently, the development of this new testing device began by doing some amendments with the accelerated polishing machine, curved molds, and compacting tools that allow the construction of the curved prototypes asphalt mixture specimen, along with the definition of the testing conditions boundaries. Finally, the testing phase was conducted with different types of asphalt mixtures to validate the new testing method in the laboratory.

The main findings and results showed the development of this new test procedure enables to determine the accelerated polishing coefficient of new asphalt mixtures, as well as to evaluate the mixture performance compared to the skid resistance phenomenon, which can be applied during the initial approach of the mixture in the 
laboratory, and used as a source of valuable information to predict the evolution of the skid resistance of hot asphalt mixtures throughout its service life.

Keywords: Skid resistance, polishing, hot mix asphalt, testing method. 


\section{ÍNDICE GENERAL}

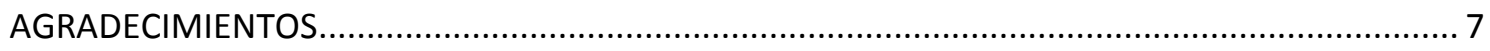

RESUMEN …

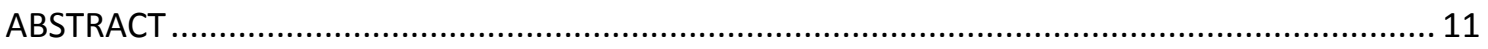

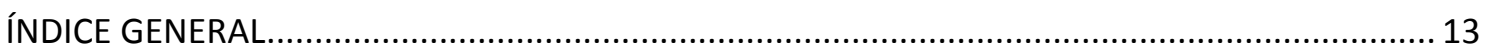

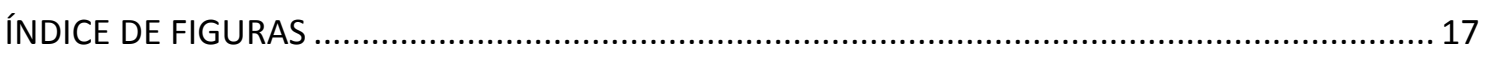

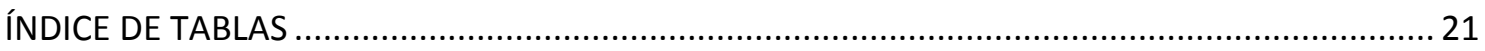

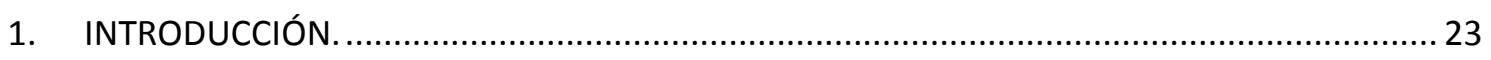

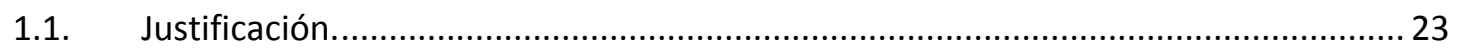

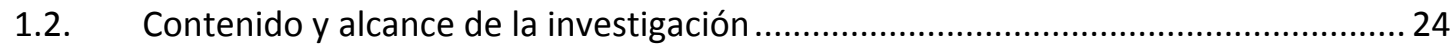

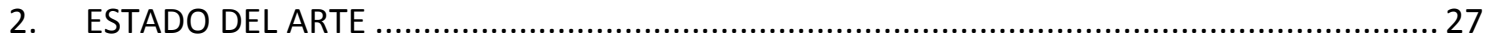

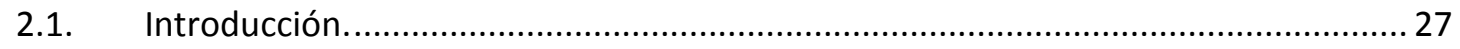

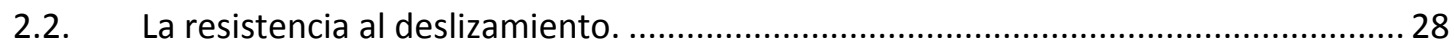

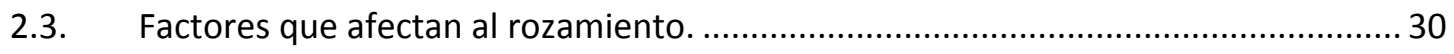

2.3.1. Factores debidos a la superficie del pavimento............................................... 31

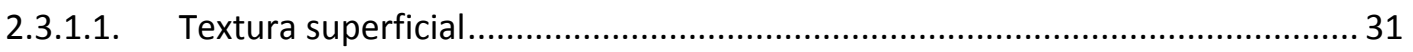

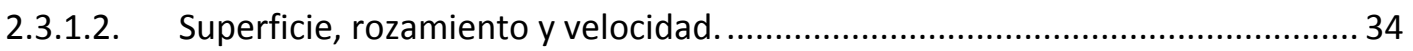

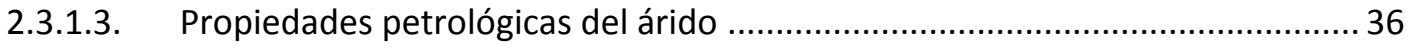

2.3.1.4. Tamaño y forma de los áridos y su distribución dentro de la mezcla.................37

2.3.2. Factores debidos a las cargas. Intensidad del tráfico y edad del pavimento......... 37

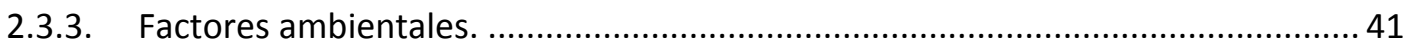

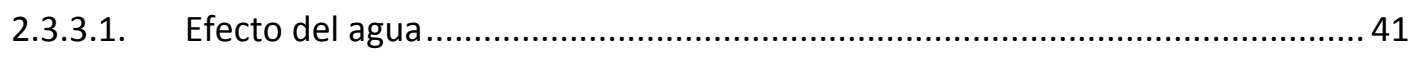

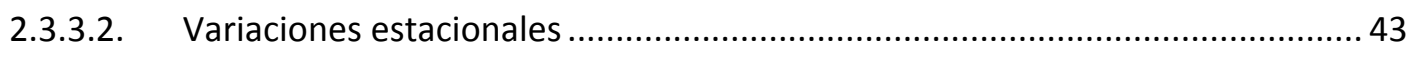

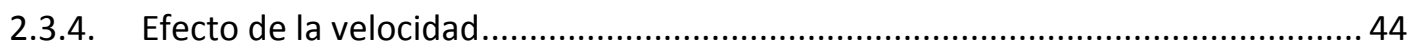

2.4. Equipos de medida de la resistencia al deslizamiento ............................................ 45

2.4.1. Equipos de medida del coeficiente de resistencia al deslizamiento in situ.......... 45

2.4.1.1. Método del péndulo británico …………...................................................... 46 


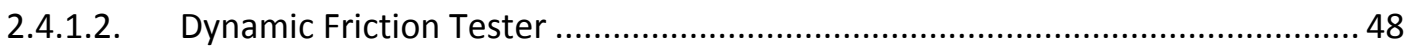

2.4.2. Método de medición continuos …........................................................................ 49

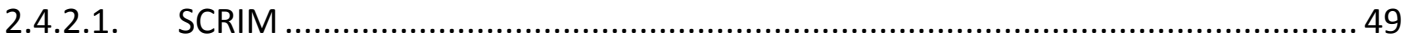

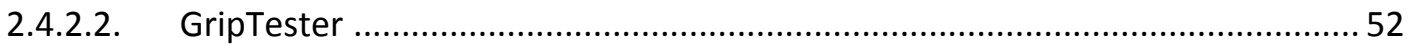

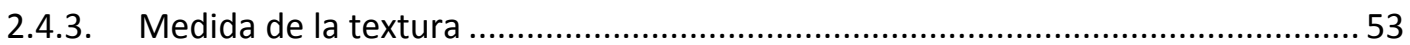

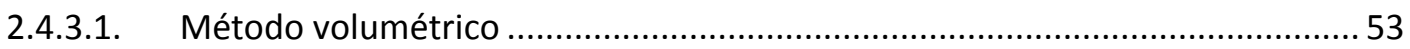

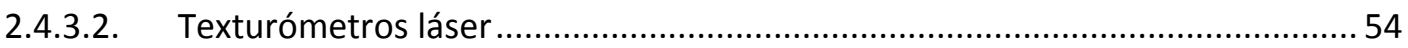

2.4.4. Equipos de medida de función múltiple ........................................................... 57

2.4.5. Equipos de laboratorio para la predicción del coeficiente de resistencia al

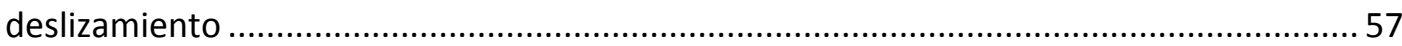

2.4.5.1. Equipo para medir el coeficiente de pulimento acelerado..............................57

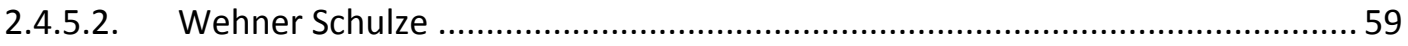

2.4.5.3. El equipo de pulimento del National Center of Asphalt Technology.................62

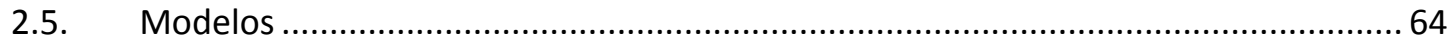

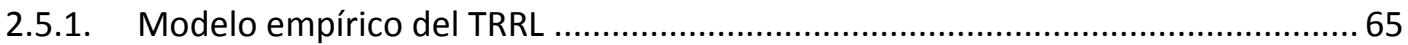

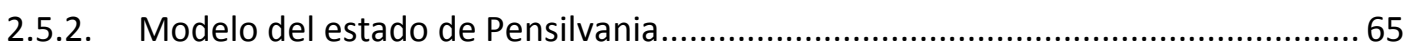

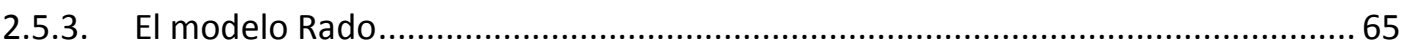

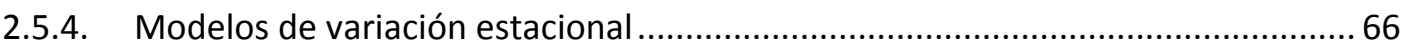

2.5.5. El modelo PIARC y el índice de rozamiento internacional ...................................67

2.6. Prescripciones españolas en relación con la resistencia al deslizamiento .................. 70

2.7. Conclusiones del estudio del estado del arte. Motivación de la tesis........................ 72

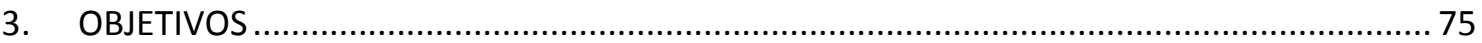

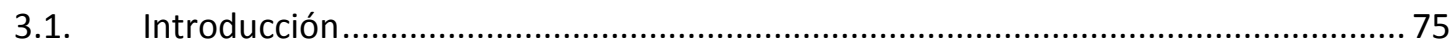

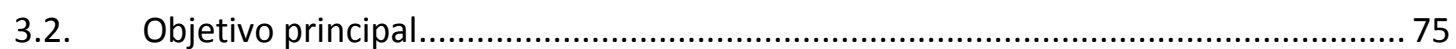

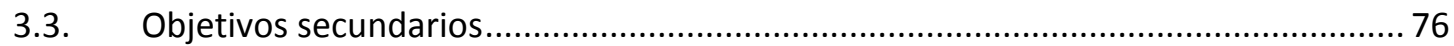

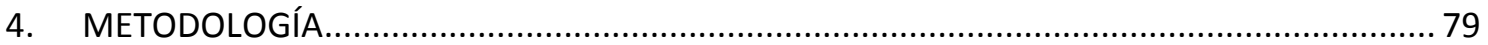

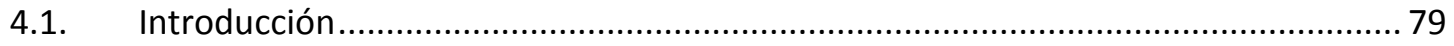

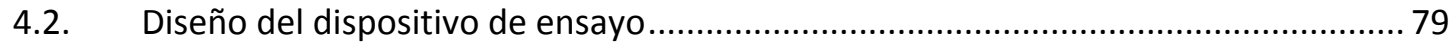


4.2.1. Condicionantes de diseño

4.2.2. Diseño del prototipo y geometría de las nuevas probetas ................................. 81

4.3. Definición de las características de ensayo ………............................................... 87

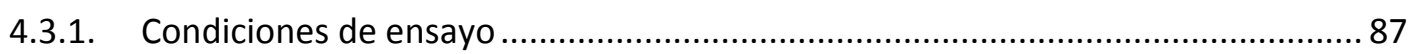

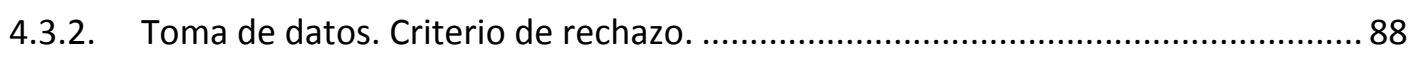

4.4. Medida del coeficiente de resistencia al deslizamiento sobre mezclas bituminosas. 90

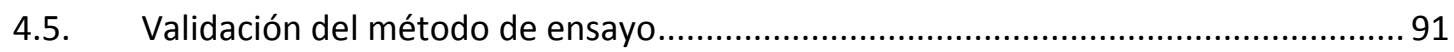

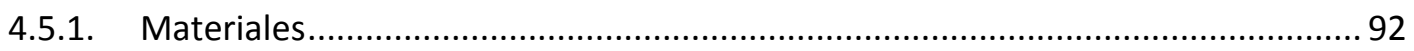

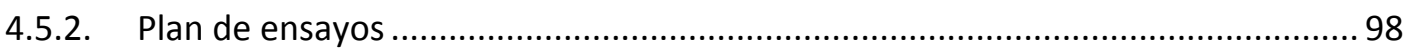

4.5.2.1. Coeficiente de pulimento acelerado de las mezclas. Duración del ensayo .......99

4.5.2.2. Análisis de la repetibilidad del método de ensayo ........................................... 99

4.5.2.3. Sensibilidad del ensayo CPM frente a las condiciones de ensayo .................... 104

4.5.2.4. Sensibilidad del ensayo CPM a los materiales evaluados .............................. 104

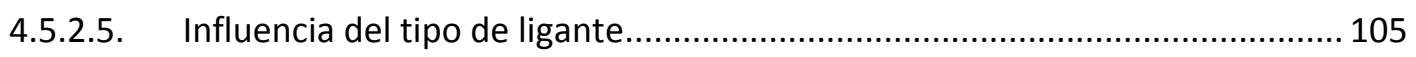

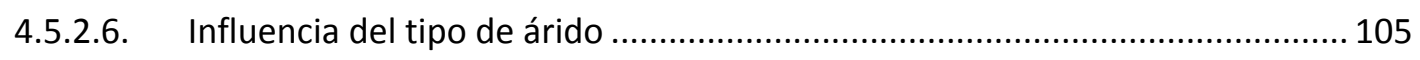

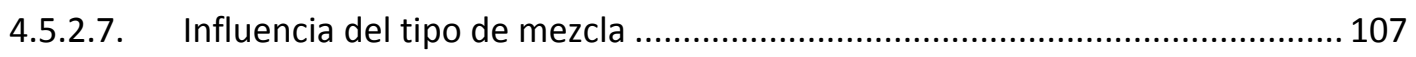

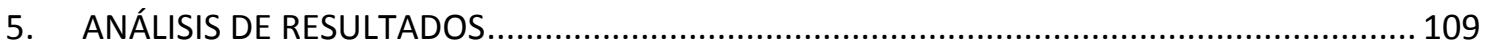

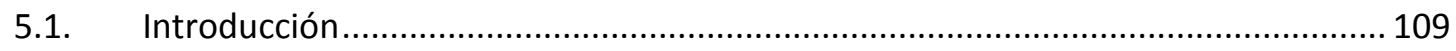

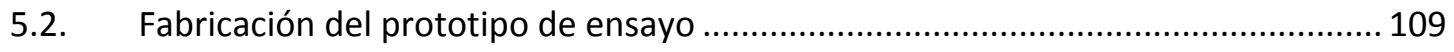

5.3. Validación del método de ensayo CPM .................................................................. 113

5.3.1. Características de las probetas de mezcla fabricadas ....................................... 113

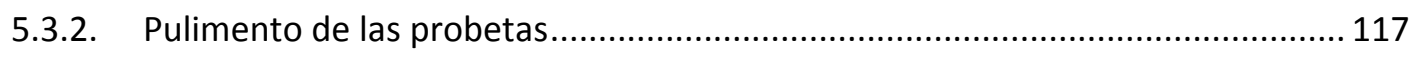

5.3.3. Cálculo del coeficiente de pulimento acelerado de las mezclas ......................... 120

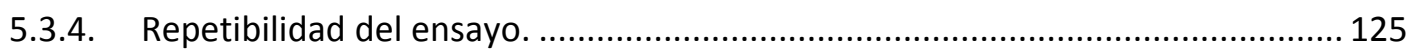

5.3.5. Análisis de la sensibilidad del ensayo a los materiales evaluados. ...................... 138

5.3.5.1. Sensibilidad del ensayo CPM frente al tipo de ligante.................................. 138

5.3.5.2. Sensibilidad del ensayo CPM frente al tipo de árido ...................................... 140 


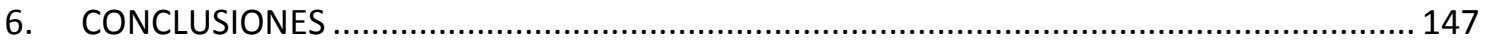

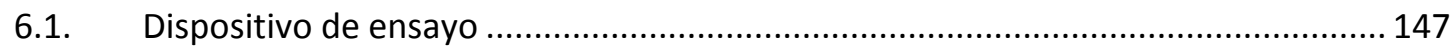

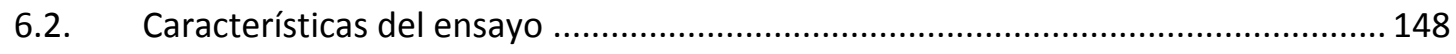

6.3. Medida del coeficiente de resistencia al deslizamiento sobre mezclas bituminosas. 149

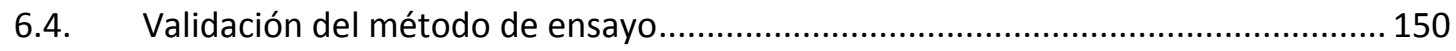

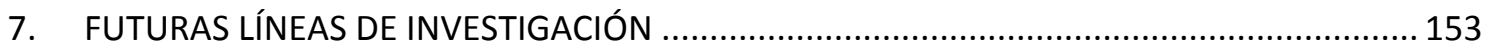

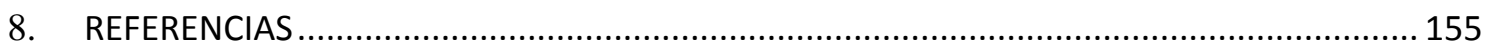

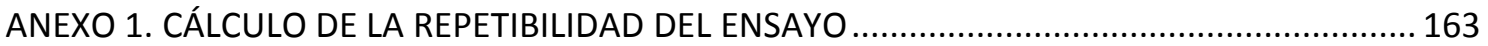




\section{ÍNDICE DE FIGURAS}

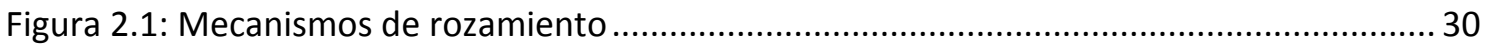

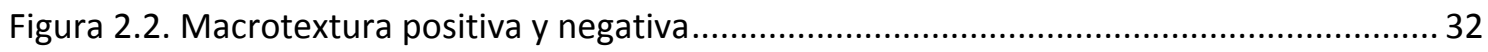

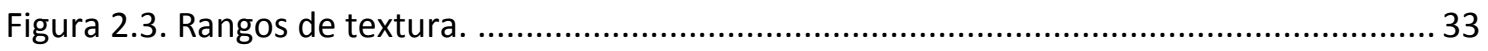

Figura 2.4. Espectro de las longitudes de onda en la superficie de una carretera ...................... 34

Figura 2.5: Relación entre microtextura, macrotextura, rozamiento y velocidad ....................... 35

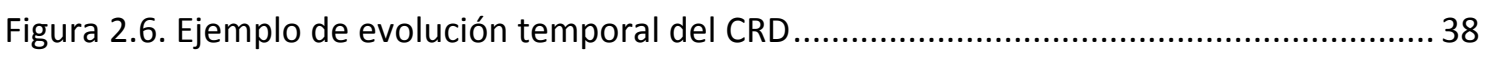

Figura 2.7. Ejemplo de distribución transversal del tráfico y del CRD ........................................ 38

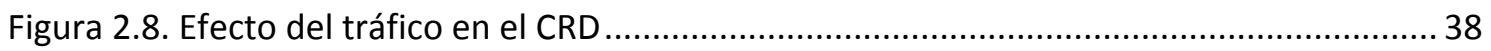

Figura 2.9: Modelo general simplificado de pulimento del pavimento ...................................... 40

Figura 2.10: Cambio en la resistencia al deslizamiento con el tiempo en una mezcla SMA rica en ligante modificado.

Figura 2.11. Reducciones en el coeficiente de resistencia al deslizamiento de húmedo a seco en función del tipo de superficie

Figura 2.12. Efecto del agua en un pavimento asfáltico

Figure 2.13: Coeficiente de resistencia al deslizamiento medido con el SCRIM en el Reino Unido

Figura 2.14. Diagrama simplificado de fuerzas actuando sobre una rueda .46

Figura 2.15: Péndulo de fricción TRRL .47

Figura 2.16. Principal unidad del equipo DF Tester. .............................................................. 48

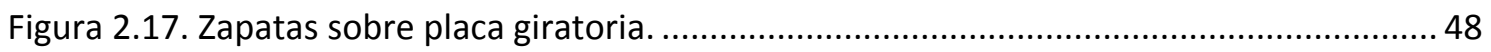

Figura 2.18. Gráfica típica de salida de resultados del DF Tester. .............................................. 48

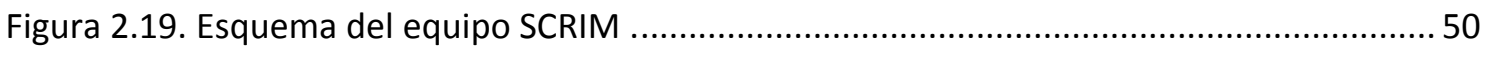

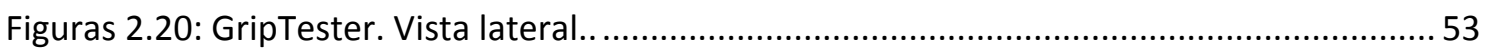

Figura 2.21. Vista de la rueda de medida y de la cadena de transmisión del GripTester............ 53

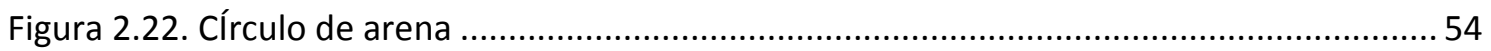

Figura 2.23: Método del círculo de arena para medida de la macrotextura .............................54

Figura 2.24: Sensores láser para medida de la textura ............................................................ 55

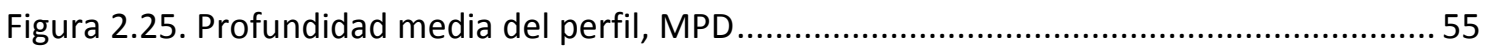




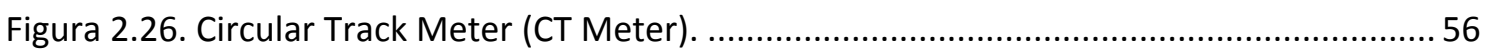

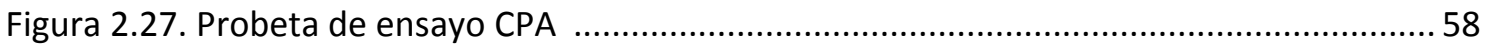

Figura 2.28. Máquina de pulimento según la UNE-EN 1097-8 …........................................... 58

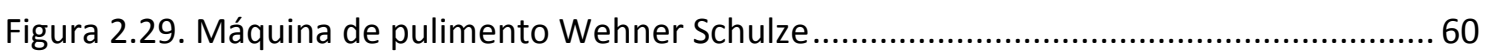

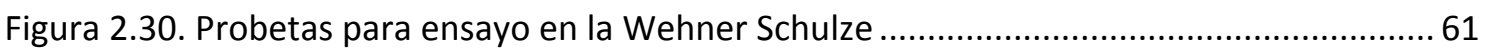

Figura 2.31. Esquema del dispositivo para el proceso de pulimento ........................................6 61

Figura 2.32. Módulo de medida de la resistencia al deslizamiento .........................................62

Figura 2.33: Compactador utilizado para fabricación de probetas ............................................ 62

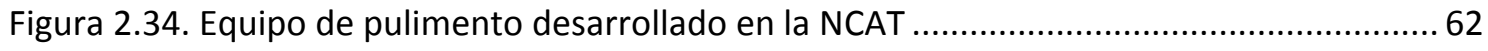

Figura 2.35. Curva fricción-velocidad de deslizamiento ............................................................. 68

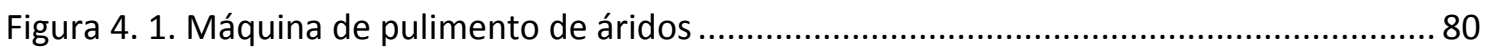

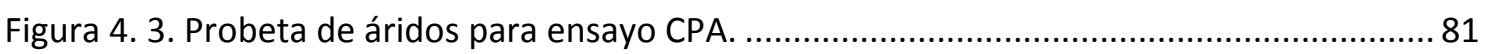

Figura 4. 4: Probeta de mezcla a pulimentar en el nuevo ensayo. ............................................ 83

Figura 4. 5 Esquema de la nueva rueda porta-muestras (izda.) y de la que se utiliza para el

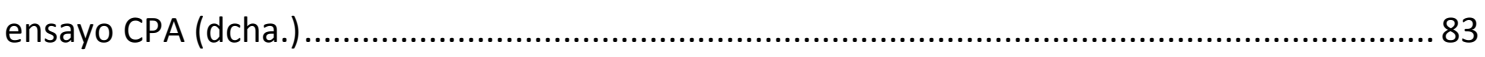

Figura 4. 6 Plano de planta de la nueva rueda porta-probetas. ............................................... 84

Figura 4. 7. Plano del molde, collarín y útil de compactación........................................................ 85

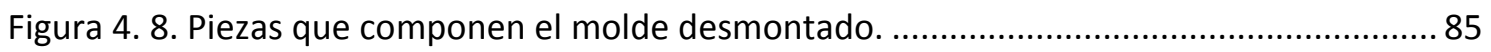

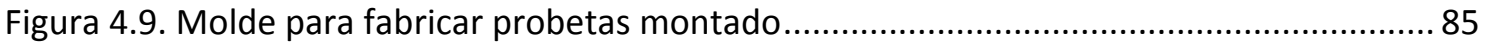

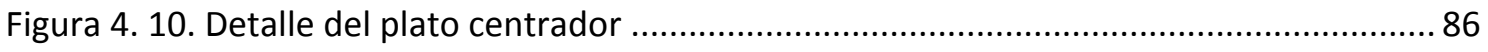

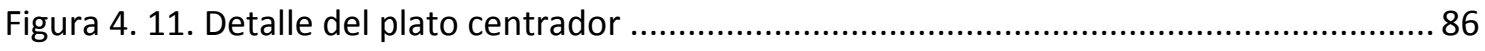

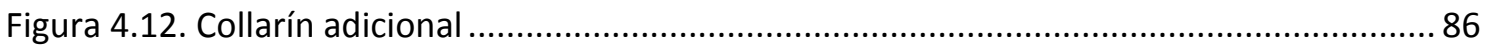

Figura 4.13. Detalle del molde para fabricación de probetas con collarín ................................. 86

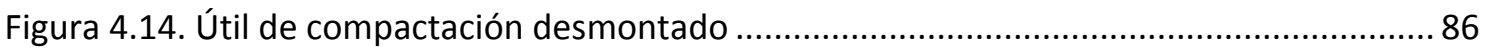

Figura 4.16. Plato centrador con molde, collarín y útil de compactación .................................. 87

Figura 4. 17. Husos granulométricos de una BBTM 11B y de una AC 16D............................... 93

Figura 4. 18. Curvas granulométricas de las BBTM 11B empleadas. ....................................... 97

Figura 4. 19. Curvas granulométricas de las AC 16 11D empleadas. .........................................97 
Figura 4. 20: Condiciones de repetibilidad 100

Figura 4. 21: Expresión gráfica del concepto de repetibilidad y reproducibilidad. 101

Figura 5. 1. Muelle utilizado para el pulimento de las probetas de mezcla 110

Figura 5. 2: Probeta de áridos.

Figura 5. 3: Probeta de mezcla.

Figura 5. 4. Probeta de mezcla junto a probeta fabricada sólo con el árido de referencia.

Figura 5. 5 Comparativa de la rueda porta-muestras de probetas de árido, (arriba), y de probetas de mezcla, (abajo).

Figura 5.6 Ruedas porta-muestras original de diámetro interno $385 \mathrm{~mm}$ (izquierda) y rueda modificada de diámetro interno $348 \mathrm{~mm}$, (derecha).

Figura 5.7. Nuevo eje sobre el que gira la rueda. 113

Figura 5.8. Detalle del sistema de anclaje. 113

Figura 5. 9. Macrotextura de 0,7 mm 117

Figura 5. 10. Macrotextura de $1 \mathrm{~mm}$ 117

Figura 5. 11. Rueda porta-muestras de mezcla bituminosa. 118

Figura 5. 12. Vista frontal lámina de caucho utilizada para corregir defectos de espesor. 118

Figura 5. 13 Vista superior lámina de caucho utilizada para corregir defectos de espesor. .... 118

Figura 5. 14. Inicio de rotura de probeta en junta y rotura de la misma 119

Figura 5. 15. Rotura de la probeta por la junta 119

Figura 5. 16. Mortero de resina en juntas. 119

Figura 5. 17. Preparación de la rueda para sellado juntas 119

Figura 5. 18. Péndulo TRRL preparado para medir la resistencia al deslizamiento en probeta de mezcla. 120

Figura 5. 19. Evolución en el tiempo del CRD de una BBTM 11B fabricada con pórfido. 122

Figura 5. 20. Evolución en el tiempo del CRD de una BBTM 11B fabricada con andesita y de probetas de árido fabricados con andesita.

Figura 5. 21. Rangos a 6 y 12 horas. Pulimento según UNE-EN 1097-8. 129

Figura 5.22. Coeficientes de variación a 6 y 12 horas. Pulimento según UNE-EN 1097-8. 130

Figura 5.23. Repetibilidad a 6 y 12 horas. Pulimento según UNE-EN 1097-8. 130 
Figura 5.24. CPM a 6 y 12 horas. Pulimento según UNE-EN 1097-8.

Figura 5.25. Probeta AC 16D caliza después de 5 horas de pulimento según UNE-EN 1097-8.132

Figura 5.26. Probeta BBTM 11B caliza después de 5 horas de pulimento según UNE-EN 1097-8

Figura 5. 27. Detalle del equipo de pulimento con muelle.

Figura 5. 28. Rango a 6 y 12 horas. Pulimento según UNE-EN 1097-8 más muelle.

Figura 5.29. Coeficientes de variación a 6 y 12 horas. Pulimento según UNE-EN 1097-8 más muelle.

Figura 5.30. Repetibilidad a 6 y 12 horas. Pulimento según UNE-EN 1097-8 más muelle 136

Figura 5.31. CPM a 6 y 12 horas. Pulimento según UNE-EN 1097-8 más muelle.

Figura 5.32. Sensibilidad del ensayo CPM frente al tipo de betún con que se fabrica la mezcla.

Pulimento según la UNE-EN 1097:8 más muelle. 139

Figura 5.33. Sensibilidad del ensayo CPM frente al tipo de árido con que se fabrica la mezcla.

Pulimento según UNE-EN 1097-8.

Figura 5.34. Sensibilidad del ensayo CPM frente al tipo de árido con que se fabrica la mezcla.

AC 16D caliza versus pórfido. Pulimento según UNE-EN 1097-8 más muelle.

Figura 5.35. Sensibilidad del ensayo CPM frente al tipo de árido con que se fabrica la mezcla.

BBTM 11B caliza versus pórfido. Pulimento según UNE-EN 1097-8 más muelle.

Figura 5.36. Probeta de AC 16D caliza tras 12 horas de pulimento con muelle.

Figura 5.37. Probeta BBTM 11B caliza tras 12 horas de pulimento con muelle

Figura 5. 38. Sensibilidad del ensayo CPM frente a la macrotextura. Pulimento según UNE-EN 1097-8.

Figura 5.39. Sensibilidad del ensayo CPM frente a la macrotextura. BBTM 11B caliza versus AC 16D caliza. Pulimento según UNE-EN 1097-8 más muelle

Figura 5.40. Sensibilidad del ensayo CPM frente a la macrotextura. BBTM 11B Pórfido versus AC 16D Pórfido. Pulimento según UNE-EN 1097-8 más muelle. 145 


\section{ÍNDICE DE TABLAS}

Tabla 2.1: Clasificación de las irregularidades de un pavimento

Tabla 2.2. Valor mínimo del CPA del árido grueso según la Orden FOM/2523/2014

Tabla 2.3. Prescripciones sobre fricción y textura de diferentes pavimentos según la Orden FOM/2523/2014.

Tabla 4. 1: Resultados de los ensayos de los áridos utilizados en la fabricación de las mezclas.94

Tabla 4. 2. Características de los betunes utilizados en la fabricación de las mezclas. .95

Tabla 4. 3 Dosificación óptima de los áridos de las fórmulas de trabajo. .95

Tabla 4. 4. Curva granulométrica de las BBTM 11B. 96

Tabla 4. 5. Curva granulométrica de las AC 16D. .96

Tabla 4. 6. Características de las mezclas empleadas en el estudio. .98

Tabla 4. 7. Plan de ensayos para definir la duración del ensayo 99

Tabla 4. 8. Plan de ensayos para el estudio de la repetibilidad ..... 102

Tabla 4. 9. Plan de ensayos para evaluar la influencia del ligante 105

Tabla 4. 10. Plan de ensayos para evaluar la influencia del árido 106

Tabla 4. 11. Plan de ensayos para evaluar la influencia del tipo de mezcla 108

Tabla 5. 1: Características de las probetas BBTM 11B fabricadas con árido pórfido. 115

Tabla 5. 2 Macrotextura de las probetas BBTM 11B fabricadas con pórfido. 116

Tabla 5. 3. Coeficiente de resistencia al deslizamiento de una BBTM 11B fabricada con pórfido.

Tabla 5. 4. Evolución en el tiempo del CRD de una BBTM 11B fabricada con andesita. 123

Tabla 5. 5. Evolución en el tiempo del CRD de una BBTM 11B fabricada con andesita. 124

Tabla 5. 6. Evolución del CRD de las mezclas fabricadas en rueda 1. Pulimento según UNE-EN 1097-8.

Tabla 5. 7. Evolución del CRD de las mezclas fabricadas en rueda 2. Pulimento según UNE-EN 1097-8

Tabla 5.8. Principales valores estadísticos a 6 y 12 horas. Pulimento según UNE-EN 1097-8.. 128

Tabla 5.9. Evolución del CRD de las mezclas fabricadas para la rueda 1. Pulimento según UNEEN 1097-8 con muelle 134 
Tabla 5. 10. Evolución del CRD de las mezclas fabricadas para la rueda 2. Pulimento según UNEEN 1097-8 con muelle

Tabla 5.11. Principales valores estadísticos a 6 y 12 horas. Pulimento según UNE-EN 1097-8 más muelle.

Tabla 5. 12. Criterio rechazo. Diferencias entre valores medios de cada rueda. Pulimento según UNE-EN 1097-8 más muelle.

Tabla 5. 13. Macrotextura de las mezclas fabricadas 144

Tabla A1. Repetibilidad BBTM 11B Caliza con PMB 45/80-65. Pulimento según UNE-EN 1097-8.

Tabla A2. Repetibilidad BBTM 11B Pórfido con PMB 45/80-65. Pulimento según UNE-EN 1097-

8.

Tabla A3. Repetibilidad AC 16D Caliza con B 45/80-65. Pulimento según UNE-EN 1097-8...... 164 Tabla A4. Repetibilidad AC 16D Pórfido con B 45/80-65. Pulimento según UNE-EN 1097-8. .. 164 Tabla A5. Repetibilidad BBTM 11B Pórfido con 50/70. Pulimento según UNE-EN 1097-8........ 165 Tabla A6. Repetibilidad árido de referencia. Pulimento según UNE-EN 1097-8. 165

Tabla A7. Repetibilidad BBTM 11B Caliza con PMB 45/80-65. Pulimento según UNE-EN 1097-8 más muelle 166

Tabla A8. Repetibilidad BBTM 11B Pórfido con PMB 45/80-65. Pulimento según UNE-EN 1097-8 más muelle. 166

Tabla A9. Repetibilidad AC 16D Caliza con PMB 45/80-65. Pulimento según UNE-EN 1097-8 más muelle.

Tabla A10. Repetibilidad AC 16D Pórfido con PMB 45/80-65. Pulimento según UNE-EN 1097-8 más muelle.

Tabla A11. Repetibilidad BBTM 11B Pórfido con 50/70. Pulimento según UNE-EN 1097-8 más muelle.

Tabla A12. Repetibilidad árido de referencia. Pulimento según UNE-EN 1097-8 más muelle. 168 


\section{INTRODUCCIÓN}

\subsection{Justificación.}

La resistencia al deslizamiento es el término usualmente dado al rozamiento generado entre los neumáticos de un vehículo y la superficie de rodadura de una carretera, (Austroads 2011a). Es una de las propiedades que tienen más influencia en lo que respecta a la seguridad ofrecida por el pavimento y tiene una gran repercusión en la reducción de los accidentes, especialmente en circunstancias de Iluvia o superficie mojada, (Henry 2000; Asi 2005; James 2006; Kane et al. 2013; Ech et al. 2012). Sin embargo, debido a la acción del tráfico y a otros factores, la resistencia al deslizamiento decrece a lo largo del tiempo, (Kane et al. 2010; Prowell et al. 2003; Do et al. 2009; Wang \& Wang 2013).

Debido a lo anterior, la medida de la resistencia al deslizamiento se ha convertido en una herramienta básica para la gestión de las redes de carreteras, (Vollor \& Hanson 2006). Se puede decir que, a día de hoy, todavía es necesario realizar muchos esfuerzos para poner a punto procedimientos normalizados que sirvan para cuantificar con precisión, durante la formulación de una mezcla bituminosa, la resistencia al deslizamiento que se puede obtener con ella, (Del Val 2010), y la evolución que tendrá a partir de su puesta en servicio. Actualmente, sólo se comprueba el valor de esta propiedad y el de la macrotextura sobre capas ya extendidas suponiendo a priori que deben dar valores adecuados, porque se han fabricado ajustándose a unos husos granulométricos concretos, con áridos poco pulimentables, y porque se han colocado de acuerdo a unas especificaciones recogidas en diferentes normas, (Mcdaniel \& Coree 2003).

En no pocos casos ocurre que, a pesar de haber cumplido todo lo que exige la normativa vigente, los resultados de resistencia al deslizamiento que finalmente se obtienen no son los esperados y no se alcanzan los umbrales especificados, debiendo el constructor que soportar, en el mejor de los casos, una penalización económica, cuando no la demolición y reposición de una nueva capa en la que, quizás, vuelva a tener el mismo problema.

Surge por tanto la necesidad de desarrollar algún procedimiento de ensayo que sea capaz de predecir en laboratorio cuáles son los valores de resistencia al deslizamiento que ofrecerá la mezcla que se vaya a fabricar y colocar finalmente en la obra, así como la evolución que puedan tener esta propiedad en el tiempo, (Vollor \& Hanson 2006; Del Val 2010; Do et al. 2007), lo cual constituye el objetivo principal de la presente tesis doctoral. 


\subsection{Contenido y alcance de la investigación}

El presente documento se ha estructurado en ocho capítulos.

En el capítulo 1 de introducción se justifica de forma resumida el interés por llevar a cabo la presente investigación y se describe el contenido de cada una de las partes que integran este documento.

En el capítulo 2 se hace un estudio del estado del arte con el objeto de conocer qué se ha investigado anteriormente sobre la temática en cuestión. En esta parte se describe en qué consiste el fenómeno de la resistencia al deslizamiento de un pavimento asfáltico, qué factores le afectan, con qué equipos se mide, qué modelos se han utilizado para predecir su valor en el tiempo, cuáles son los valores mínimos de resistencia al deslizamiento que exige la normativa actualmente en vigor para poder circular en condiciones de seguridad $y$, finalmente, se analizan las conclusiones del estudio realizado las cuales sirven de base para formular los objetivos de la tesis doctoral dentro del capítulo 3.

Como se ha comentado en el párrafo anterior, en el capítulo 3 se formulan los objetivos principales y secundarios de la tesis, a partir de las conclusiones que se obtienen del estudio del estado del arte realizado en el capítulo 2.

En el capítulo 4 se explica la metodología que se ha seguido durante la investigación, es decir, se hace una descripción de las fases en que se ha estructurado el proyecto para poder alcanzar los objetivos propuestos en el capítulo 3. Dichas fases han sido:

- El desarrollo de un dispositivo de ensayo nuevo, capaz de estudiar a nivel de mezclas y no sólo de áridos como ocurre actualmente, la evolución de la resistencia al deslizamiento de mezclas bituminosas colocadas en la capa de rodadura del firme de una carretera.

- Definición del procedimiento de ensayo, tanto durante la fase de preparación de las probetas de mezcla a pulir como durante la fase de pulimento de dichas probetas y de medición de los datos obtenidos, indicando la forma en que se debe hacer el ensayo, la frecuencia con la que se deben adquirir los datos y los criterios de fallo que se consideran.

- Validación del método de ensayo estudiando la repetibilidad del mismo y cómo varían los resultados en función de las condiciones en que éste se lleva a cabo y los materiales utilizados. 
En el capítulo 5 se hace un análisis de los resultados que se han obtenido en cada una de las fases en que se ha estructurado la investigación según el capítulo 4.

Las conclusiones más importantes que se obtienen en el capítulo 5 son recogidas en el capítulo 6 y a partir de ellas, ya dentro del capítulo 7, se indican posibles líneas de investigación a abordar en el futuro.

Para finalizar, dentro del capítulo 8, se incluyen las referencias bibliográficas que se han utilizado para la documentación de la presente tesis doctoral. 


\section{ESTADO DEL ARTE}

\subsection{Introducción.}

El segundo capítulo de esta tesis doctoral contiene el estado del arte que se tomará como base de partida para su desarrollo. Este capítulo puede dividirse en cinco partes en las que se profundiza en el fenómeno de la resistencia al deslizamiento en las capas de rodadura de los pavimentos asfálticos de las carreteras.

La primera parte de este capítulo está dedicada al fenómeno de la resistencia al deslizamiento, los mecanismos que lo producen y los factores que le afectan, tanto los debidos al propio vehículo, como los debidos a la superficie del pavimento, a las cargas que se aplican sobre dicho pavimento y la forma en que se aplican y al medioambiente.

La segunda parte de este capítulo se centra en los distintos equipos que se utilizan actualmente para medir esta propiedad. Dado que una de las variables que más afectan a la resistencia del deslizamiento de un pavimento es su macrotextura, también se describen los equipos y procedimientos que se utilizan para medirla. Así para la medida de la resistencia al deslizamiento se dedica un apartado a los equipos que miden in situ esta propiedad de manera puntual, como el péndulo británico o TRRL y el Dynamic Friction Tester y otro a los equipos que la miden en continuo, como el SCRIM y el GripTester. Entre los procedimientos para la medida de la macrotextura, se estudian el círculo de arena y el texturómetro láser. Dentro de esta segunda parte se dedica también un apartado a los equipos que miden de forma simultánea la resistencia al deslizamiento y la macrotextura de un pavimento $y$, finalmente, se estudian cuáles son los equipos y procedimientos que se utilizan actualmente para ayudar a predecir en laboratorio cuál va ser el comportamiento de las mezclas frente al deslizamiento, (máquina para medir el coeficiente de pulimento acelerado de los áridos o (PA) y cuáles son las investigaciones que se están llevando a cabo para tratar de mejorar la información que da el ensayo CPA y poder predecir con mayor grado de seguridad, en laboratorio, cuál va a ser el comportamiento de una mezcla frente a la resistencia al deslizamiento, (máquina Wehner Schulze y prototipo del NCAT).

La tercera parte de este capítulo se centra en el estudio de los modelos que se han desarrollado para tratar de predecir cuál va a ser la evolución de la resistencia al deslizamiento de un pavimento a lo largo del tiempo, desde los más sencillos, que daban un valor de la resistencia al deslizamiento en función únicamente del 
coeficiente de pulimento acelerado de los áridos, pasando por los que trataban de ajustar los valores dados en función a las posibles variaciones estacionales u otros factores que afectan a la medida de la resistencia al deslizamiento.

En la cuarta parte, se recogen cuáles son los valores mínimos de resistencia al deslizamiento y macrotextura que se exigen en España por el Pliego de Prescripciones Técnicas Generales para obras de carreteras y puentes, (PG-3), para garantizar una circulación segura, sobre pavimentos ejecutados de nueva construcción en función del tipo de pavimento y de la categoría del tráfico que por él circula. También se incluyen los valores mínimos de CPA que se exige a los áridos que se utilizan para fabricar las mezclas que formarán la capa de rodadura de dichos pavimentos, valores cada vez más exigentes y que obligan a tener que traer áridos de canteras más lejanas, con los consiguientes problemas económicos y medioambientales que ello lleva asociado.

Por último y como cierre a este capítulo, se establecen las principales conclusiones que se obtienen del estudio del estado del arte, las cuales sirven para motivar y poner de manifiesto los objetivos de la presente tesis doctoral.

\subsection{La resistencia al deslizamiento.}

Cada vez que un vehículo acelera, frena o cambia de dirección, aparecen unas fuerzas de rozamiento entre las ruedas y la superficie del pavimento. Para que no se produzca deslizamiento es necesario que la relación entre las fuerzas horizontales y las verticales en cada una de las ruedas no sobrepase el coeficiente de rozamiento entres los neumáticos y el pavimento. Como se verá más detenidamente en el siguiente apartado, el valor de este coeficiente de rozamiento es muy variable, pues depende de las características de los neumáticos, (dibujo de la rueda, composición del caucho, etc.), del estado de la superficie del pavimento, (presencia o no de humedad y/o suciedad) y del propio movimiento de las ruedas, (velocidad, grado de bloqueo, inclinación de las ruedas respecto a la trayectoria del vehículo, etc.). Además se ha comprobado que tiene una incidencia apreciable la temperatura ambiente. Por todo ello, en la práctica se suele considerar preferible hablar de resistencia al deslizamiento, (medida según procedimiento normalizados), antes que de un coeficiente de rozamiento que puede variar por tantas causas como las apuntadas y en términos de resistencia al deslizamiento es como suele valorarse la idoneidad de una superficie destinada a la circulación, (Del Val 2010).

La resistencia al deslizamiento es el término usualmente dado al rozamiento generado entre los neumáticos de un vehículo y la superficie de rodadura de una carretera, (Austroads 2011a). El rozamiento es definido por la World Road 
Association, como la resistencia al movimiento entre dos superficies en contacto, (PIARC 2003). Su magnitud se expresa por el coeficiente de rozamiento que es el cociente de dos fuerzas, una paralela a la superficie de contacto entre los dos cuerpos y con dirección opuesta al movimiento, (fuerza de rozamiento), y la otra perpendicular a dicha superficie de contacto, (fuerza normal).

Si el coeficiente de rozamiento se determina como el cociente entre la fuerza horizontal que aparece en el sentido de la marcha y la fuerza vertical que actúa sobre el punto de contacto se habla de coeficiente de rozamiento longitudinal. Por el contrario, si la fuerza horizontal considerada es la que aparece en una dirección distinta a la de la marcha se habla entonces de coeficiente de rozamiento transversal, (Del Val 2010).

En todo caso, el rozamiento entre el neumático de un vehículo y el pavimento de una carretera se produce por la combinación de dos mecanismos: rozamiento por adherencia y rozamiento por histéresis. Estos son definidos por la (Highways Agency 2001; Oliver 2003), y quedan representados en la figura 2.1.

La adherencia está generada por los enlaces intermoleculares entre el caucho de la rueda y el pavimento que surgen cuando las microasperezas de las dos superficies entran en contacto, creando unas fuerzas, llamadas de Van der Waals, que las atraen en áreas localizadas con altas presiones. La adherencia está relacionada con el área de contacto entre neumático y superficie. Al ser el caucho un material viscoelástico, las componentes del rozamiento pueden variar en gran medida con la temperatura de la superficie y la velocidad de deslizamiento. Está relacionada con la microtextura de pavimento.

La histéresis se debe a la pérdida de energía debida a la deformación de la rueda por las protuberancias y depresiones de la superficie de rodadura. Está relacionada con la macrotextura del pavimento.

Normalmente la contribución de la componente de rozamiento debido a la histéresis es pequeña, predominando la componente debida a la adhesión. Únicamente predomina aquella cuando la presencia de agua anula la adhesión, en cuyo caso el rozamiento es muy reducido, o en condiciones secas, cuando el deslizamiento se produce a velocidades elevadas. 


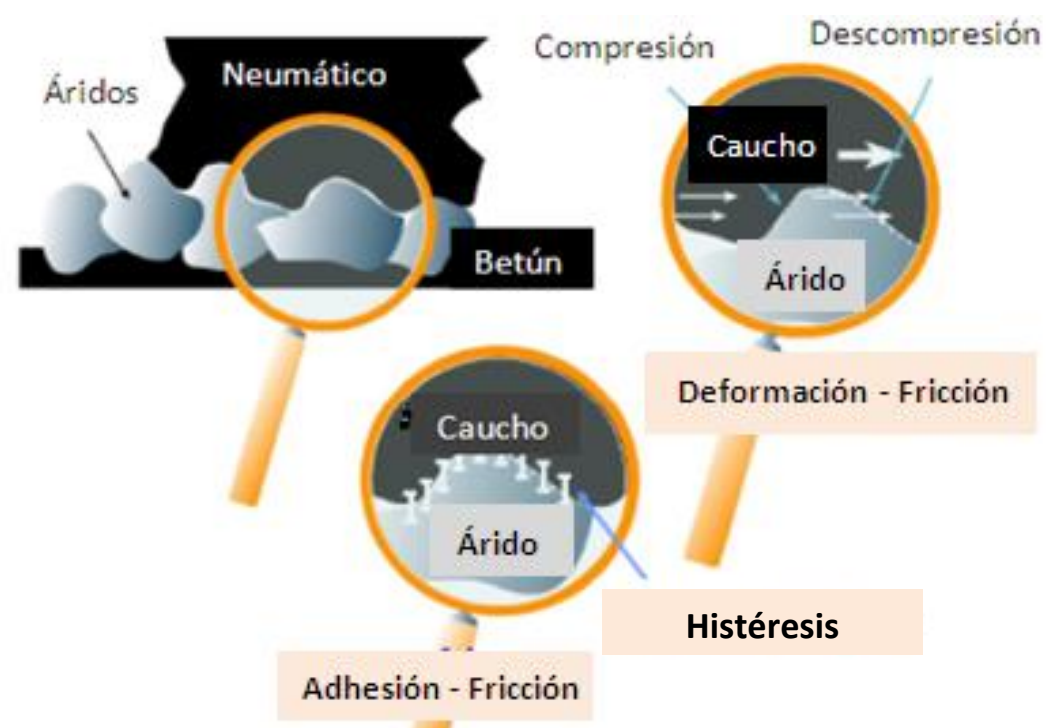

Figura 2.1: Mecanismos de rozamiento (Oliver 2003)

\subsection{Factores que afectan al rozamiento.}

En la resistencia al deslizamiento intervienen varios elementos, (Lamm et al. 1999): el vehículo, la superficie del pavimento, las cargas y los factores ambientales.

\section{Factores debidos al vehículo:}

- Velocidad del vehículo.

- Ángulo de la dirección de la rueda con respecto a la dirección del movimiento del vehículo.

- Carga por rueda

- Grado de deslizamiento de la rueda.

- Características del neumático (estructura, dureza y desgaste o profundidad de las ranuras).

\section{Factores debidos a la superficie el pavimento:}

- Propiedades petrológicas del árido.

- Textura superficial (microtextura y macrotextura).

- Tipo de superficie.

- Edad de la superficie.

\section{Factores debidos a las cargas y su forma de aplicación:}

- Intensidad media diaria de vehículos (IMD) y la intensidad media diaria de vehículos pesados (IMDP) desde la puesta en servicio de la carretera. 
- Geometría de la carretera.

- Condiciones de circulación.

\section{Factores ambientales:}

- Temperatura.

- Acumulación previa de agua de lluvia, intensidad y duración de las lluvias.

- Contaminación de la superficie.

Nos centraremos en estudiar más detenidamente aquellos factores que están más relacionados con el objeto del trabajo de la tesis doctoral.

\subsubsection{Factores debidos a la superficie del pavimento.}

\subsubsection{Textura superficial}

La textura del pavimento es la característica superficial de una carretera que más determina en último término la interacción entre el neumático de un coche y dicha carretera.

El Comité Técnico de Características Superficiales de la World Road Association, en el congresos mundial celebrado en Bruselas en 1987, (PIARC 1987), propuso una clasificación de las características geométricas superficiales de los pavimentos basada en las longitudes de onda y en las amplitudes de las irregularidades en el sentido de la marcha, dado que las características superficiales de los pavimentos que más interesan, entre ellas la resistencia al deslizamiento, están ligadas a las dimensiones de estas irregularidades, (tabla 2.1).

Tabla 2.1: Clasificación de las irregularidades de un pavimento (PIARC 1987).

\begin{tabular}{|c|c|c|c|}
\hline \multicolumn{2}{|c|}{ CLASE DE TEXTURA } & LONGITUD DE ONDA & AMPLITUD \\
\hline \multirow{3}{*}{ ONDAS } & Largas & $15-50 \mathrm{~m}$ & $10-200 \mathrm{~mm}$ \\
\cline { 2 - 4 } & Medias & $5-15 \mathrm{~m}$ & $5-50 \mathrm{~mm}$ \\
\cline { 2 - 4 } & Cortas & $0,5-5 \mathrm{~m}$ & $1-20 \mathrm{~mm}$ \\
\hline \multicolumn{2}{|c|}{ MEGATEXTURA } & $50-500 \mathrm{~mm}$ & $1-50 \mathrm{~mm}$ \\
\hline \multicolumn{2}{|r|}{ MACROTEXTURA } & $0,5-50 \mathrm{~mm}$ & $0,2-10 \mathrm{~mm}$ \\
\hline \multicolumn{2}{|r|}{ MICROTEXTURA } & $0-0,5 \mathrm{~mm}$ & $0-0,2 \mathrm{~mm}$ \\
\hline
\end{tabular}


Ondas. Corresponden a irregularidades del orden de centímetros a metros en lo que se refiere a la longitud de dicha onda y son las que reportan una descripción del perfil longitudinal de la carretera.

Megatextura: Corresponde a irregularidades del orden de centímetros tanto en lo que se refiere a la longitud de de onda como a la amplitud de la misma. Esas irregularidades suelen estar relacionadas con la puesta en obra y también con diversos tipos de fallos o de degradaciones y con sus reparaciones (bacheos, sellados de grietas), si no están bien realizadas. La megatextura aumenta la resistencia a la rodadura y el nivel de ruido a frecuencias bajas contribuyendo al desgaste de los vehículos, incluidos los neumáticos.

Macrotextura. Puede ser definida como la amplitud de las desviaciones, (irregularidades), de un plano con un rango de longitudes de onda entre 0,5 y 50 mm (PIARC 2003; Austroads 2011b). Está determinada por la granulometría y por el tamaño máximo de árido de la mezcla, riego o lechada asfáltica. La macrotextura influye en la pérdida de resistencia al deslizamiento cuando aumenta la velocidad. Es necesaria para una adecuada resistencia al deslizamiento a velocidades superiores a $60 \mathrm{~km} / \mathrm{h}$ con el pavimento mojado y controla, junto con el ranurado del neumático, la eliminación del agua en la superficie de contacto del neumático con el pavimento. Macrotexturas mayores de 0,8 mm son deseables (PIARC 2003), porque permiten canales de drenaje para la evacuación del agua cuando llueve sobre el pavimento, lo que permite una mayor deformación del neumático, permitiendo que se desarrolle el rozamiento por histéresis.

La macrotextura puede ser positiva o negativa como se muestra en la figura 2.2.

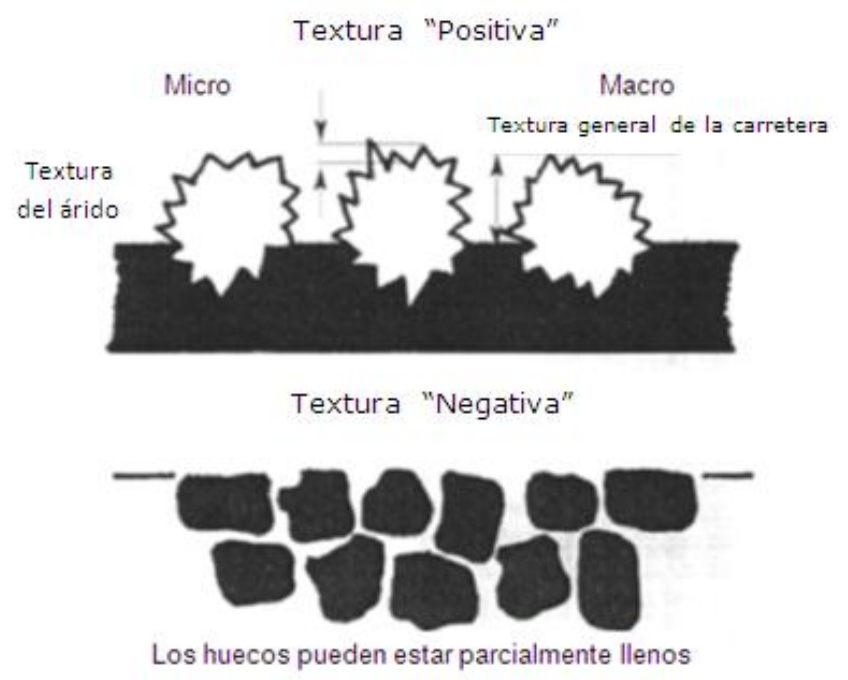

Figura 2.2. Macrotextura positiva y negativa (Walsh 2000) 
La macrotextura positiva es aquella que forman los áridos que sobresalen del plano de la superficie y es típica de tratamientos superficiales y de las mezclas asfálticas cerradas en capas impermeables. La macrotextura negativa está formada por los huecos que quedan entre los áridos que forman la superficie plana del pavimento. Se presenta en pavimentos porosos y en microaglomerados de granulometría discontinua.

Microtextura: La microtextura es la textura de pequeña escala (inferior a 0,5 $\mathrm{mm}$ en horizontal y a 0,2 $\mathrm{mm}$ en vertical), y está formada, en gran medida, por las irregularidades de la superficie de los áridos. Depende fundamentalmente de la mineralogía y textura del árido y, en mezclas asfálticas, de la del mortero. La (Highways Agency 2001), indica que la microtextura es la principal contribuidora a la resistencia al deslizamiento en todas las circunstancias, incluso aunque el pavimento esté seco, y es el factor dominante de la resistencia al deslizamiento en condiciones mojadas a bajas velocidades. La microtextura controla el contacto entre el neumático y la superficie del firme y en presencia de agua las crestas de la microtextura aseguran que se produzca ese contacto. La magnitud de la microtextura viene definida por la rugosidad inicial de las partículas de árido y de la rugosidad retenida tras el pulimento producido por el paso del tráfico y los factores ambientales.

En la figura 2.3 se representan los tipos de texturas mencionados anteriormente.

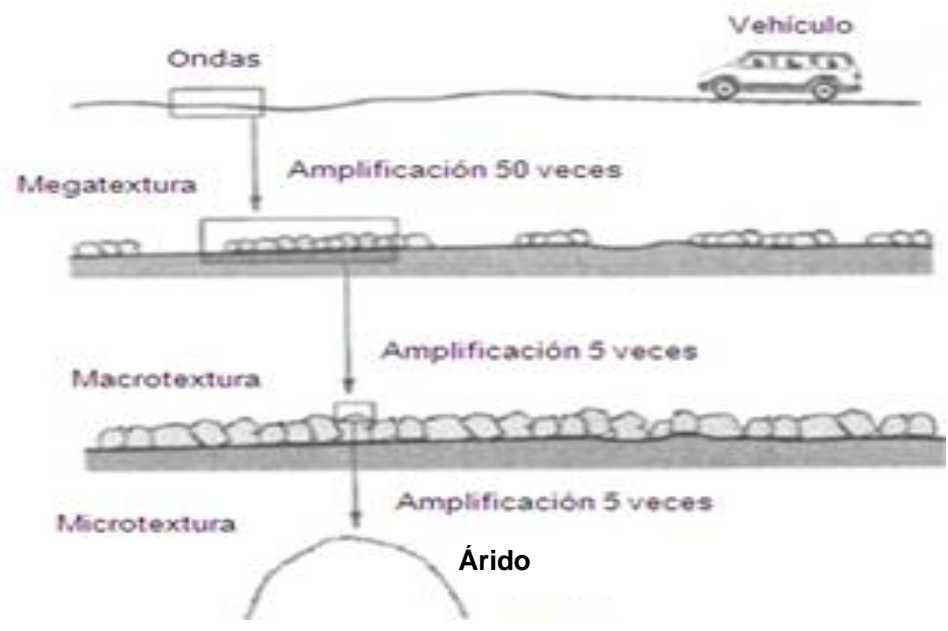

Figura 2.3. Rangos de textura (Sandberg 1999). 
La World Road Association (PIARC 2003), estableció también la relación entre los distintos tipos de textura y la regularidad superficial con las características superficiales que se veían afectadas por ellas, (figura 2.4).

Mientras que la microtextura afecta al desgaste de los neumáticos, la macrotextura tiene pequeña influencia en el consumo de combustible al aumentar la resistencia al deslizamiento, mejora la visibilidad al producir reflexión difusa de la luz de los faros y reducir las proyecciones de agua, permitiendo un mejor contraste de las marcas viales y tiene gran incidencia en el ruido de rodadura, (las negativas lo disminuyen y las positivas lo incrementan).

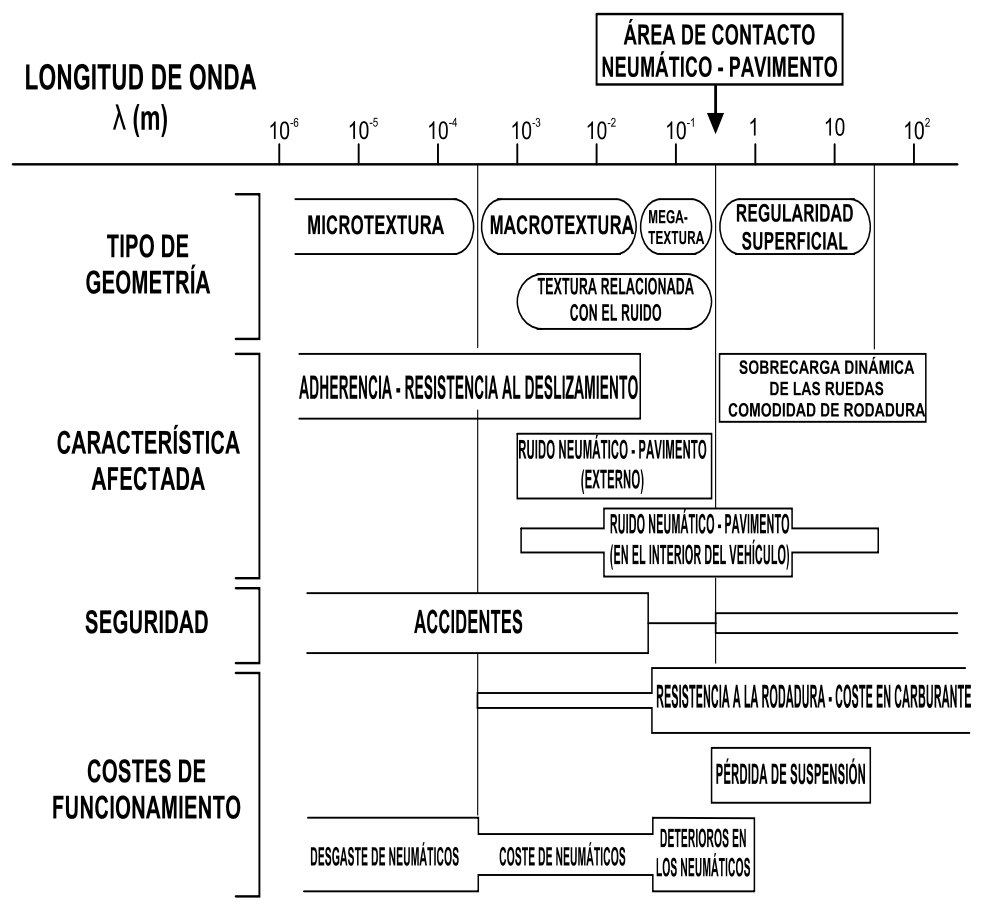

Figura 2.4. Espectro de las longitudes de onda en la superficie de una carretera

\subsubsection{Superficie, rozamiento y velocidad.}

Las características de la superficie de un pavimento que más contribuyen a la resistencia al deslizamiento son la macrotextura y la microtextura, (figura 2.4 y 2.5). Es importante conseguir que la macrotextura y la microtextura del pavimento sean adecuadas, lo que significa obtener superficies suficientemente rugosas.

Como se ha comentado anteriormente, la microtextura controla la resistencia máxima alcanzable al deslizamiento a baja velocidad. Sin embargo, afecta el nivel de resistencia al deslizamiento en todas las velocidades, como se muestra en la figura 2.5. Por su parte, la macrotextura determina la velocidad a la que se pierde 
la resistencia al deslizamiento a medida que aumenta la velocidad del vehículo, (PIARC 2003).

La figura 2.5 muestra la relación entre la microtextura, la macrotextura, la velocidad del vehículo y la resistencia al deslizamiento del pavimento de una carretera. El diagrama demuestra que mientras que una buena microtextura, puede ser suficiente para proporcionar una resistencia al deslizamiento adecuada a velocidades bajas, una buena micro y macrotextura es necesaria a velocidades más altas. Además puede observarse que mientras que los cuatro tipos de superficies disminuyen en la resistencia al deslizamiento a medida que aumenta la velocidad, la disminución no es tan rápida cuando la superficie del pavimento tiene una buena macrotextura.

En general se sabe que la resistencia al deslizamiento en condiciones húmedas se reduce conforme aumenta la velocidad del vehículo y que la macrotextura es la responsable de la importancia de dicha reducción. Como consecuencia de ello, la mayoría de los países exigen unos niveles mínimos de macrotextura. (Roe \& Hartshorne 1998) identificaron, a partir de medidas de resistencia al deslizamiento realizadas con vehículo SCRIM a velocidades entre 20 y $130 \mathrm{~km} / \mathrm{h}$, que la profundidad de la macrotextura tiene un impacto importante en la pérdida de resistencia al deslizamiento incluso a velocidades inferiores a $50 \mathrm{~km} / \mathrm{h}$, lo que queda reflejado en los casos B y D de la figura 2.5 .
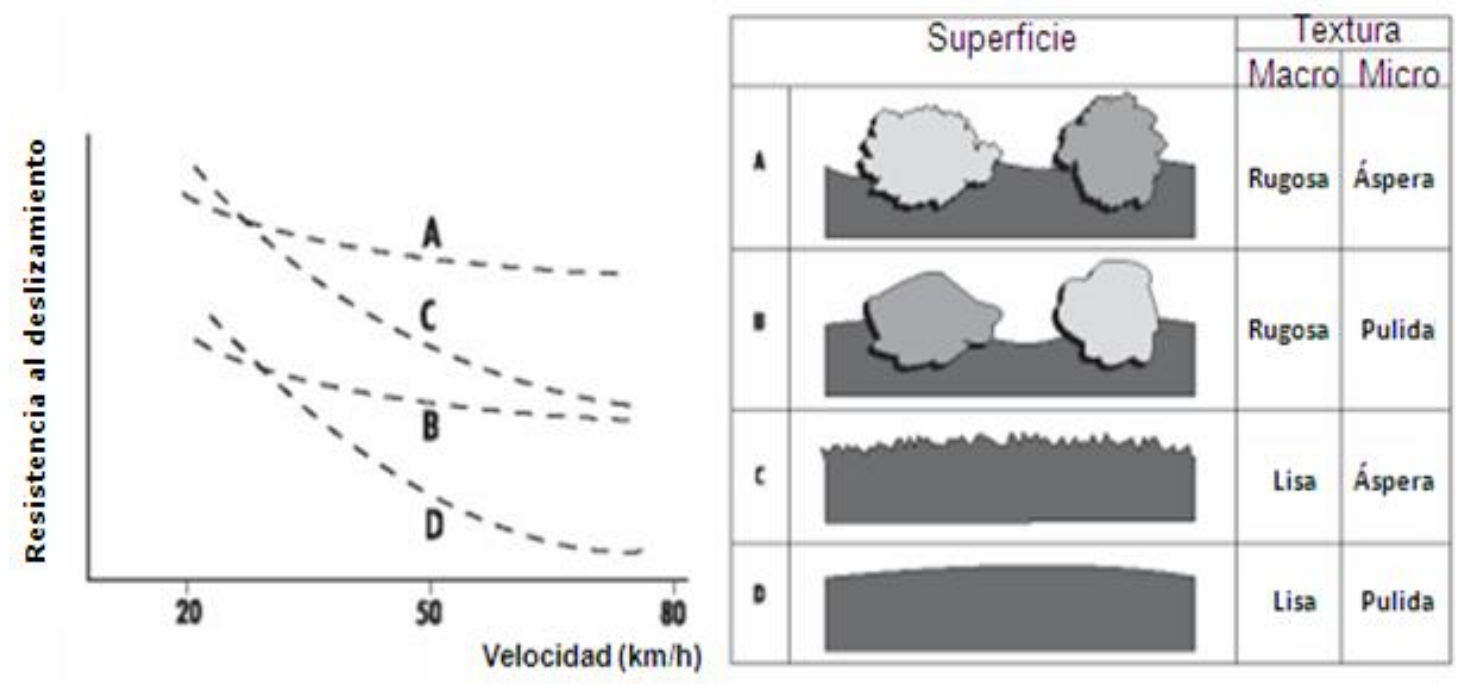

Figura 2.5: Relación entre microtextura, macrotextura, rozamiento y velocidad (PIARC 2003)

Este descubrimiento de que superficies con bajas macrotexturas pierden resistencia al deslizamiento con mayor velocidad que con altas macrotexturas, incluso a velocidades bajas, fue muy importante porque previamente a esto no se había 
tenido en cuenta esta propiedad en el diseño y en el mantenimiento de superficies de carreteras urbanas sometidas a tráficos con velocidad de desplazamiento bajas. Sin embargo, (Cenek et al. 2000) argumentaron que lo anterior representaba una situación poco probable y extrema, ya que el análisis se basó en los resultados obtenidos con neumáticos lisos. (Cenek et al. 2000) investigaron el comportamiento del frenado en seco y en mojado de neumáticos de coche comerciales, con sistema de frenado $A B S$, sobre superficies con la misma resistencia al deslizamiento, a una velocidad de $50 \mathrm{~km} / \mathrm{h}$, pero con distintas macrotexturas, para determinar si este efecto era significativo en condiciones de explotación habituales. Concluyeron de su investigación que la resistencia al deslizamiento en mojado se reduce al aumentar la velocidad pero no con el gradiente indicado por la investigación previa, atribuyendo las diferencias encontradas al hecho de haber utilizado neumáticos no lisos que proporcionaban profundidad de textura 'extra', además de la proporcionada por la superficie de la carretera.

\subsubsection{Propiedades petrológicas del árido}

Las propiedades más importantes que debe tener un árido que se utilice para la fabricación de mezclas bituminosas para carreteras son, según (Smith et al. 2001; Hosking 1970; Hartley 1974; Lees \& Kennedy 1975), las siguientes:

- Tenacidad o resistencia que ofrece el árido a ser roto o molido

- Resistente al desgaste y poco pulimentable frente a la acción del tráfico

- Con buena adhesión a los ligantes bituminosos que se utilicen en la fabricación de las mezclas asfálticas

- Resistente a las acciones medioambientales que debe soportar el pavimento una vez puesto en servicio

- Con una adecuada forma que ayude a contribuir a la rigidez intrínseca de la mezcla

(Neville 1974) afirma que los áridos utilizados en la superficie de una carretera se ven afectados por la abrasión, por el pulimento por el desgaste diferencial y por las condiciones meteorológicas y que la textura real en cualquier momento en el tiempo se determina por el equilibrio entre estos factores.

Las mejores rocas para fabricar áridos para capa de rodadura, son las que tienen minerales de diferente dureza y que son friables hasta cierto punto, (Austroads 
2011b). Los áridos procedentes de este tipo de rocas tienen un buen comportamiento frente al pulimento por lo que pueden mantener su microtextura durante más tiempo.

\subsubsection{Tamaño y forma de los áridos y su distribución dentro de la mezcla}

La macrotextura dependen en cierta grado del tamaño de las partículas del árido, de la forma de éstos y de los espacios que quedan entre los mismos en la mezcla que se coloca en la carretera (Highways Agency 2001).

Como ya hemos visto anteriormente, en mezclas porosas o drenantes y en mezclas delgadas discontinuas, la macrotextura es producida por los huecos que quedan entre los áridos y la forma en que dichos áridos quedan dispuestos dentro de este tipo de mezclas. Los áridos con forma cúbica contribuyen a hacer mezclas más densas y con menos huecos. Por su parte, áridos con forma de laja pueden ser rotos durante el proceso de compactación o por las cargas transmitidas por el tráfico, en aquellas mezclas con un alto número de puntos de contacto entre sus áridos.

En España la normativa en vigor, para mezclas discontinuas y drenantes, (Orden FOM/2523/2014), limita el índice de lajas a un máximo de 20 en tráficos T00 a T31 y de 25 en tráficos de menor intensidad y en arcenes, (DGC 2015).

\subsubsection{Factores debidos a las cargas. Intensidad del tráfico y edad del pavimento.}

La resistencia al deslizamiento de un pavimento asfáltico varía con la intensidad del tráfico que circula sobre el mismo.

Casi todas las nuevas rodaduras de carretera construidas con áridos triturados expuestos tienen una alta resistencia al deslizamiento debido a la buena microtextura y a la adecuada forma de los áridos con los que se fabrican dichos pavimentos. Sin embargo, bajo la acción de pulimento que producen los neumáticos de los vehículos, la microtextura se reduce, los bordes de los áridos se desgastan y la resistencia al deslizamiento disminuye.

Desde hace décadas, se han llevado a cabo estudios para analizar cómo evoluciona la resistencia al deslizamiento. En España los primeros estudios sobre este tema se remontan a la década de 1960, cuando se llevó a cabo el seguimiento del tramo de ensayo de la carretera N-II, actual autovía A-2, (figuras 2.6 y 2.7 ). 


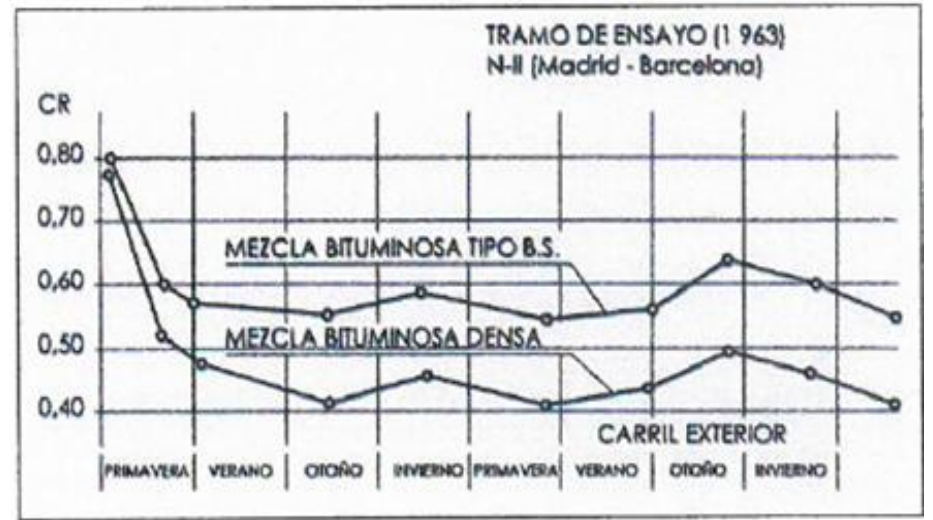

Figura 2.6. Ejemplo de evolución temporal del CRD, (Kraemer et al. 2009)

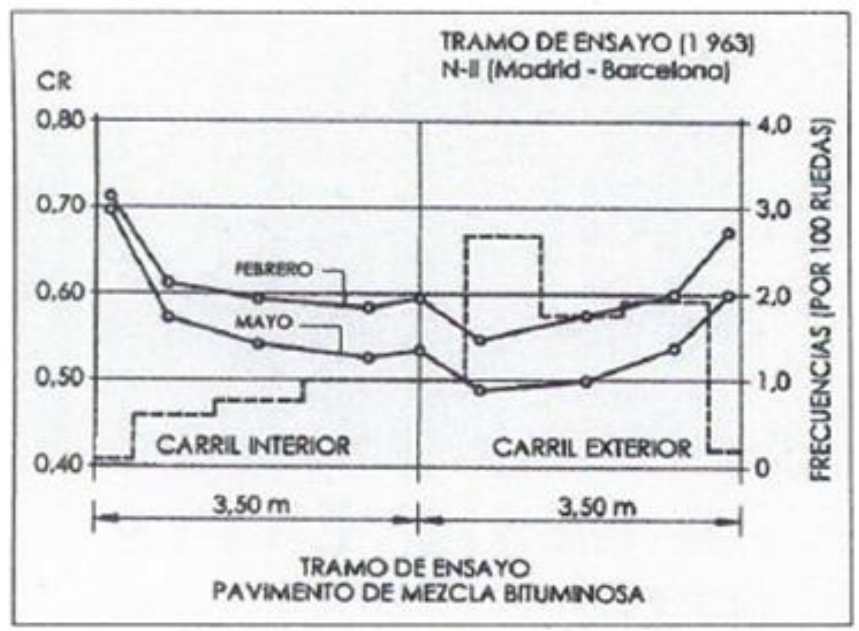

Figura 2.7. Ejemplo de distribución transversal del tráfico y del CRD, (Kraemer et al. 2009)

(Rogers \& Gargett 1991) establecen que el tráfico pesado tiende a pulimentar los áridos y que a medida que el tráfico se hace mayor, menor se hace la resistencia al deslizamiento en húmedo, (figura 2.8).

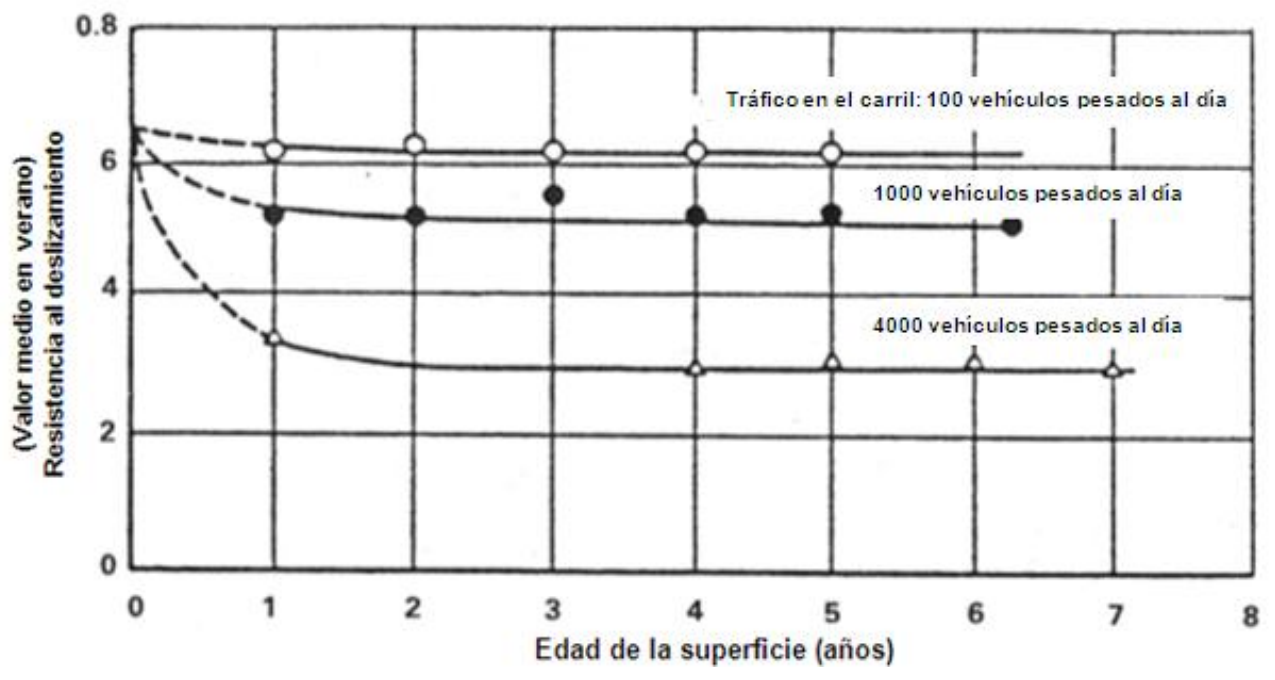

Figura 2.8. Efecto del tráfico en el CRD (Rogers \& Gargett 1991) 
La acción del tráfico en la superficie del pavimento causa su desgaste y pulimento $y$, por lo tanto, la resistencia al deslizamiento medido en cualquier momento, si se controlan las condiciones ambientales, es principalmente una función de las propiedades geológicas de los áridos y de las cargas del tráfico que circula sobre dicho pavimento.

La figura 2.9 es un modelo generalizado de cómo la resistencia al deslizamiento disminuye con el tiempo,(Prowell et al. 2003). Después de la construcción, puede haber un aumento inicial en dicha resistencia, hasta que la superficie de betún que envuelve el árido de la superficie desaparece y la microtextura del agregado es expuesta, hasta llegar a un máximo a partir del cual la resistencia al deslizamiento comienza a decrecer por la acción del tráfico. La figura 2.10, demuestra este efecto, mostrando cómo la resistencia al deslizamiento, medida durante el primer año, de una superficie asfáltica tipo SMA, aumentaba conforme se siguió eliminando la película de betún que envolvía a los áridos de dicha mezcla exponiendo así la superficie de los mismos. La importancia de este efecto, dependerá del tipo de mezcla que se coloca en la superficie de la carretera, (Jellie 2003). Por ejemplo, para tratamientos superficiales bien construidos, este efecto inicial no es muy evidente. Sin embargo, con mezclas tipo SMA, puede haber un mayor lapso de tiempo durante el cual la resistencia al deslizamiento aumenta, desde el momento en que se pone en servicio la carretera, debido al mayor espesor de la película de betún que recubre a los áridos. En este sentido, (Woodward et al. 2002; Woodward et al. 2005), demostraron la importancia de este efecto 'inicial' en una rodadura fabricada con una mezcla tipo SMA rica en ligante modificado. Después de cuatro años en servicio, la mezcla todavía no tenía el árido expuesto. La resistencia al deslizamiento medido se mantuvo baja durante todo ese tiempo, porque el tráfico y las condiciones climáticas a las que la mezcla estaba sometida, no eran lo suficientemente severas como para eliminar la película de betún de la superficie de los áridos, que resultó ser "demasiado bueno" en sus propiedades elásticas y cohesivas, lo que podía representar un riesgo significativo para la seguridad vial, (figura 2.10). 


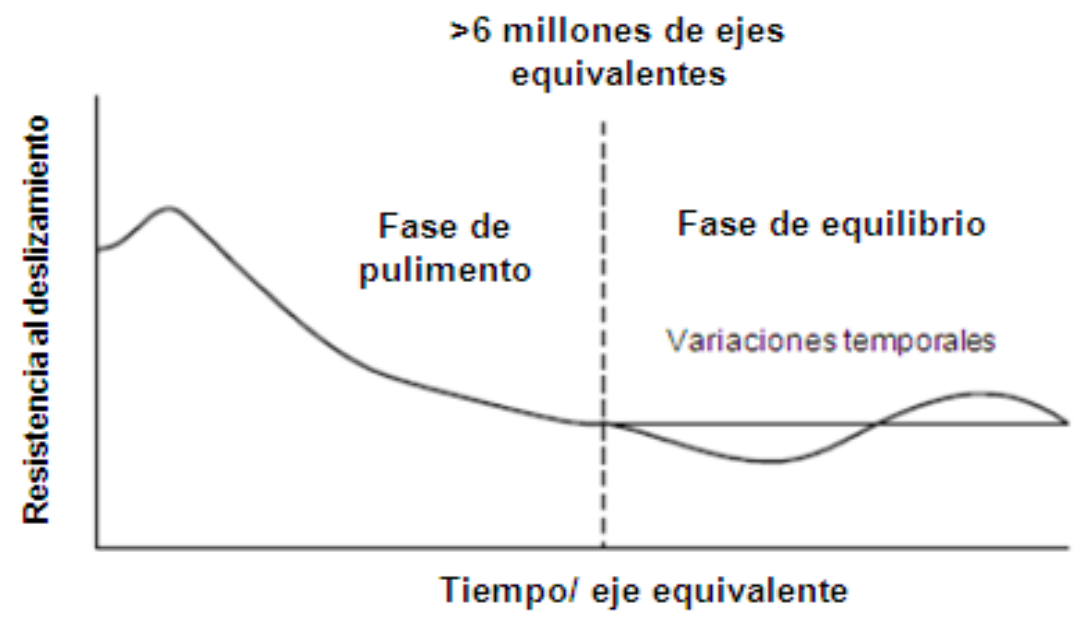

Figura 2.9: Modelo general simplificado de pulimento del pavimento (Prowell et al. 2003)

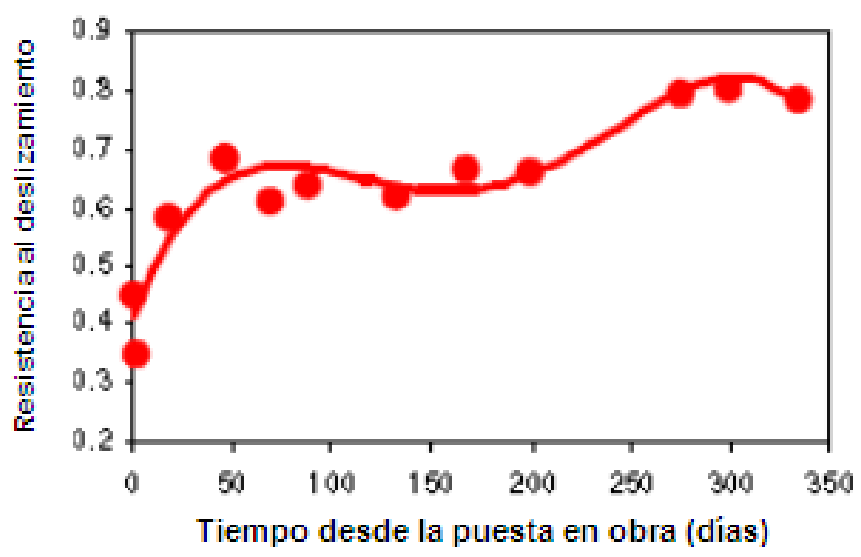

Figura 2.10: Cambio en la resistencia al deslizamiento con el tiempo en una mezcla SMA rica en ligante modificado (Woodward 2005)

Por su parte (Bullas 2005) afirmó que los pavimentos de carreteras con texturas negativas podían producir rozamientos en su superficie que desafiaban la creencia generalizada de que los pavimentos asfálticos no contaminados no podían dar lugar a problemas de resistencia de deslizamiento cuando estaban secos. Describió este fenómeno como 'bituplaning', que es la generación de niveles bajos de resistencia al deslizamiento como resultado de la presencia de una película gruesa de ligante bituminoso que envuelve a los áridos de la mezcla y que es el responsable de que se produzca deslizamiento en situación de frenado con bloqueo completo de la rueda. Este autor da ejemplos de accidentes ocurridos en el Reino Unido y en los Países Bajos sobre superficies con texturas negativas, en los que los investigadores de los incidentes producidos indicaron que este fenómeno era, en parte, responsable de que se produjeran dichos accidentes. Aunque los valores de 
resistencia al deslizamiento medidos no eran peores que los obtenidos en otro tipo de pavimentos en húmedo a velocidades intermedias, esta investigación constituyó un hallazgo significativo. Se concluyó que los conductores no están preparados, por lo general, a adecuar su conducción en condiciones secas en pavimentos recién construidos a como deberían hacerlo en mojado en carreteras en servicio, en las que suelen extremar las precauciones durante la conducción porque ya presuponen que los valores de resistencia al deslizamiento se hacen menores. Debido a esta razón, las autoridades responsables en Holanda ahora utilizan señalización específica para tramos recién construidos del tipo, "carretera con superficie nueva, aumentar la distancia de parada", diseñados especialmente para alertar al usuario de que hay riesgo específico de bituplaning y/o de baja resistencia al deslizamiento en seco y, sobre todo, en mojado.

\subsubsection{Factores ambientales.}

\subsubsection{Efecto del agua}

El rozamiento entre el neumático y el pavimento se analiza generalmente en la situación de pavimento mojado, aunque evidentemente, también preocupan las condiciones de nieve o hielo, pero estas se salen del objetivo marcado para este trabajo.

En general, se admite que con pavimento seco las condiciones de rozamiento que se dan en la mayoría de las carreteras son suficientes. Es en las condiciones de lluvia o pavimento mojado cuando el rozamiento disminuye de forma notable. Se debe tratar de conseguir que en esas condiciones el rozamiento sea lo más alto posible.

Investigaciones llevadas a cabo por (Fricke 1990) y recogidas por la (PIARC 2003), demostraron que dependiendo del estado de la superficie, el coeficiente de rozamiento varía de condiciones secas a húmedas de un $37,5 \%$ para velocidades por debajo de $50 \mathrm{~km} / \mathrm{h}$ a un $31 \%$ para velocidades mayores. En la figura 2.11 se muestra el grado de reducción para diferentes tipos de superficies asfálticas: de nueva construcción, rodadas, rodadas y pulimentas y con exceso de betún. 

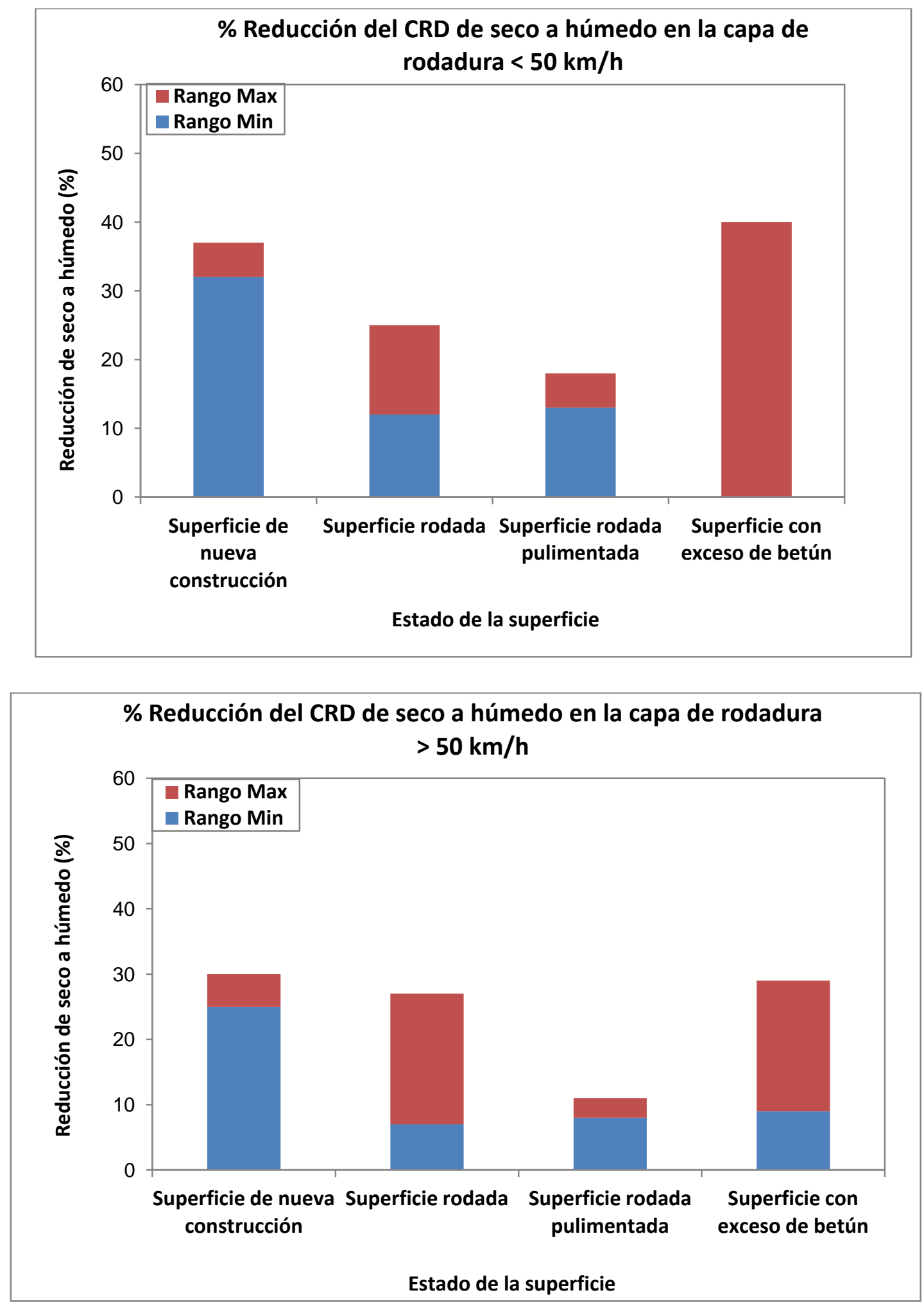

Figura 2.11. Reducciones en el coeficiente de resistencia al deslizamiento de húmedo a seco en función del tipo de superficie (PIARC 2003).

La presencia de agua sobre el pavimento actúa como una interfaz entre éste y el neumático. Esa película de agua se comporta como un lubricante, es decir, puede evitar el contacto directo entre el pavimento y el neumático, separándolos. 
(Harwood et al. 1989), demostraron que una película de agua de 0,025 mm sobre el pavimento puede reducir la resistencia al deslizamiento de éste en un $75 \%$.

En lo que se refiere a la carretera, el espesor de la película de agua que existe en el pavimento depende de su drenaje y de la capacidad de los materiales del firme de romper esa película de agua y mantener el contacto directo con el neumático.

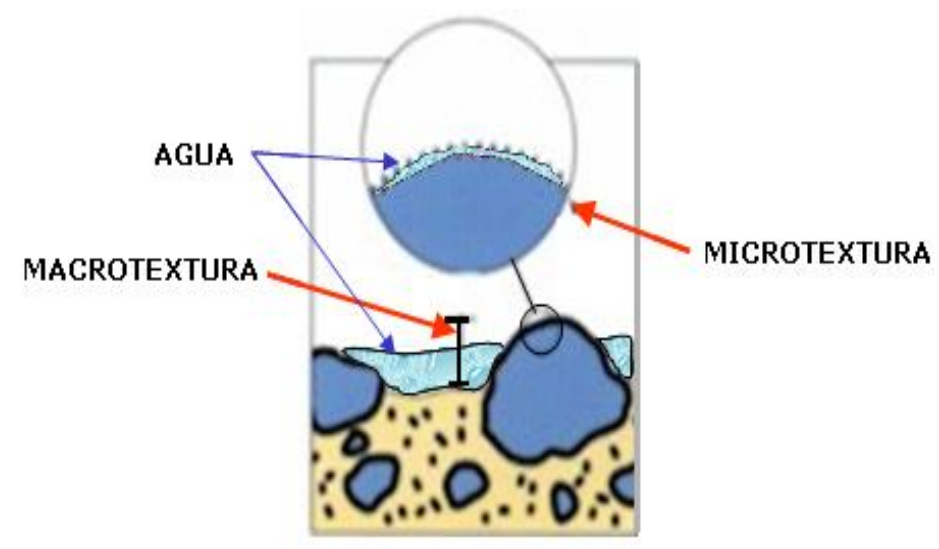

Figura 2.12. Efecto del agua en un pavimento asfáltico

Una buena macrotextura puede hacer que sobresalgan áridos por encima de dicha película de agua, permitiendo el contacto directo con el neumático. Esa cualidad evita que se forme un medio continuo de agua, que puede llegar a producir lo que se denomina "hidroplaneo", es decir, que la altura de la película de agua entre el neumático y el pavimento sea tal que el neumático no pueda eliminar el agua por sus ranuras y se produzca una presión hacia arriba que haga perder el control del vehículo.

\subsubsection{Variaciones estacionales}

El nivel medido de resistencia al deslizamiento de un carretera se ha demostrado que varía a lo largo del tiempo tal y como se ha visto en el apartado 2.3.2. Durante el invierno se suelen producir valores de resistencia al deslizamiento mayores que en verano. Este efecto se ha atribuido a un efecto combinado de las cargas del tráfico y a los factores ambientales que actúan sobre la superficie del árido. Periodos secos prolongados durante el verano permiten la acumulación de partículas finas en el pavimento que ayudan a pulir la superficie de los áridos. La combinación del pulimento producido por estas partículas, junto a la contaminación proveniente de los vehículos tales como pérdidas de aceite y grasa, contribuyen a una pérdida de macrotextura y microtextura de la mezcla durante los meses de verano. En invierno la superficie del árido vuelve a quedar expuesta gracias a la acción del agua de lluvia, que elimina las partículas responsables del pulimento de 
los áridos y otros restos, incrementándose la macrotextura de la mezcla. El árido limpio más áspero y la mayor macrotextura de la mezcla da lugar a un incremento de la resistencia al deslizamiento del pavimento, (Rogers and Gargett 1991).

La magnitud de los efectos estacionales depende en gran medida de la historia geológica y petrografía de los agregados. (Hosking 1976) informó sobre este efecto estacional en un estudio llevado a cabo en el que el coeficiente de resistencia al deslizamiento se midió con el SCRIM en una serie de carreteras del Reino Unido de forma mensual durante un período de 11 años, (1958-1968). Los resultados de este estudio se muestran en la figura 2.13 y muestran claramente una variación estacional cíclica en el valor de la resistencia al deslizamiento a lo largo del tiempo, con unos valores máximos que se suelen alcanzar en los meses de invierno mientras que los valores mínimos se corresponden con los meses de verano.

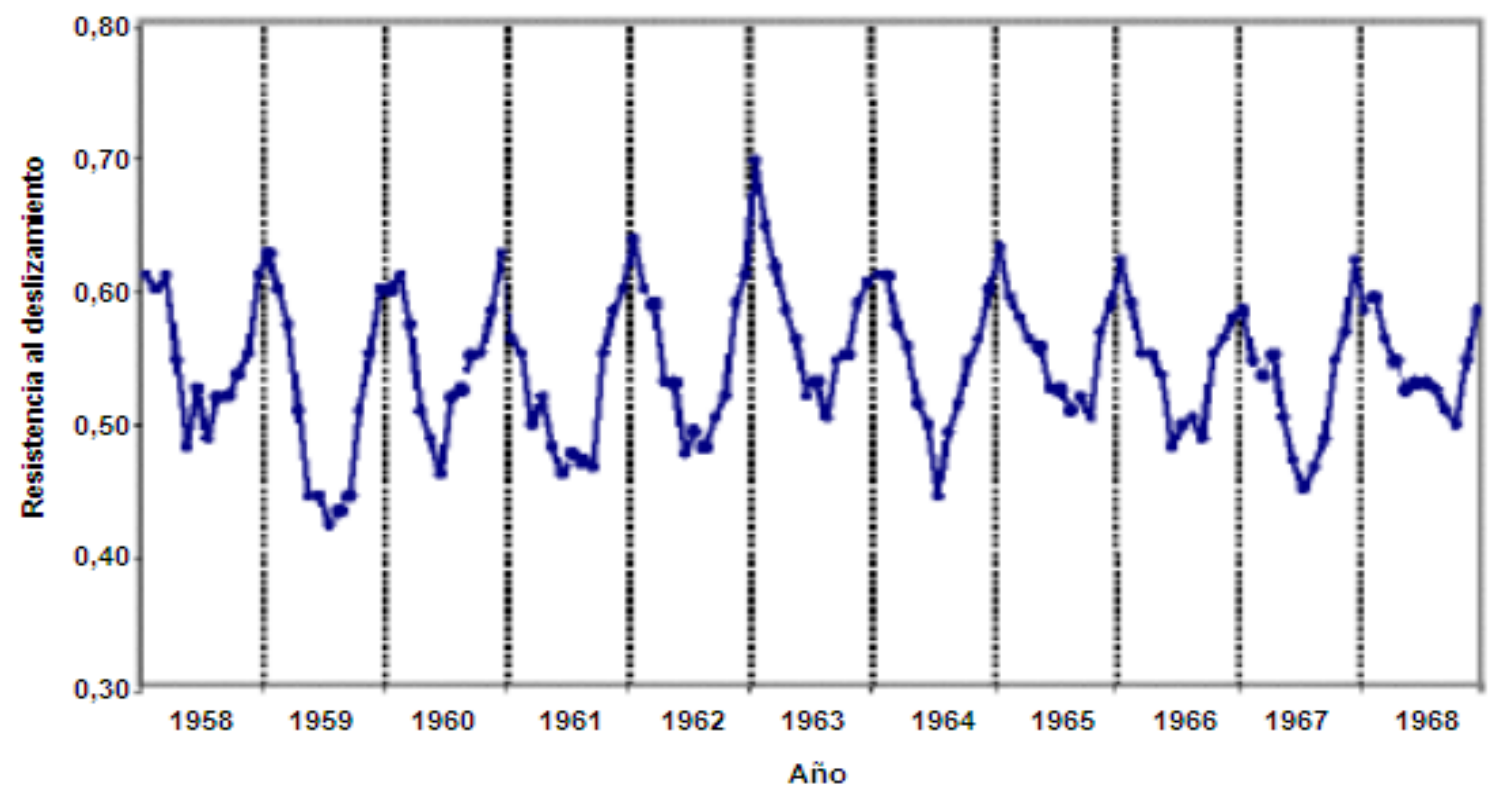

Figure 2.13: Coeficiente de resistencia al deslizamiento medido con el SCRIM en el Reino Unido (Hosking 1976)

\subsubsection{Efecto de la velocidad}

Se admite, de forma general, que la macrotextura juega un papel preponderante a altas velocidades, para que se pueda evacuar rápidamente el agua. A bajas velocidades la existencia de una película de agua no tiene gran influencia sobre la resistencia al deslizamiento ya que puede ser eliminada fácilmente por el dibujo de los neumáticos. Entre los $50 \circ 60 \mathrm{~km} / \mathrm{h}$, se podría establecer una línea de separación de protagonismos entre ambas texturas. Por debajo de 50-60 km/h la microtextura juega un papel dominante, mientras que por encima lo haría la macrotextura. Esto debe tomarse con las necesarias reservas, pues no es fácil delimitar cuándo deja de actuar cada una de ellas. Es necesario poner de manifiesto 
que la macrotextura empieza su función a altas velocidades, pero que al final es necesario detener el vehículo y en esta labor se pasa por las distintas velocidades hasta la parada.

\subsection{Equipos de medida de la resistencia al deslizamiento}

Para caracterizar la resistencia al deslizamiento del firme se utilizan generalmente dos medidas distintas:

- La del coeficiente de fricción o rozamiento entre el neumático y el pavimento mojado a una determinada velocidad.

- La de la macrotextura o capacidad de drenaje superficial, para estimar la reducción de la adherencia con el aumento de la velocidad.

Pasamos a estudiar los equipos que se utilizan para obtener estas medidas.

\subsubsection{Equipos de medida del coeficiente de resistencia al deslizamiento in situ.}

A fin de proporcionar una carretera segura es necesario poder medir y predecir la resistencia al deslizamiento en mojado de la superficie de la carretera (Woodward et al. 2002).

En general hay una variedad de equipos y métodos disponibles en el mercado para medir la resistencia al deslizamiento, que han sido desarrollados por diferentes países en los últimos 50 años, (PIARC 1995). Los dispositivos utilizados normalmente en Europa para medir la resistencia al deslizamiento in situ, fueron revisados por (Do \& Roe 2008) y se describirán en apartados posteriores.

Todas las máquinas de medición de la resistencia al deslizamiento disponibles utilizan esencialmente el mismo principio: el de una zapata de caucho o neumático que se ve obligada a deslizarse sobre una superficie mojada del pavimento bajo una carga aplicada. El rozamiento horizontal o la fuerza de resistencia al deslizamiento del neumático/caucho es medida y la carga vertical aplicada también se mide o bien se asume constante, (Austroads 2011b).

La resistencia al deslizamiento se expresa en términos de coeficiente de rozamiento o fricción, $(\mu)$, es decir como la relación entre la fuerza de tracción $(F)$ y la carga vertical (Fw), (figura 2.14).

$$
\mu=F / F W
$$

Un alto valor de $\mu$ significa alta resistencia al deslizamiento. El $\mu$ se conoce también como coeficiente de resistencia al deslizamiento. 


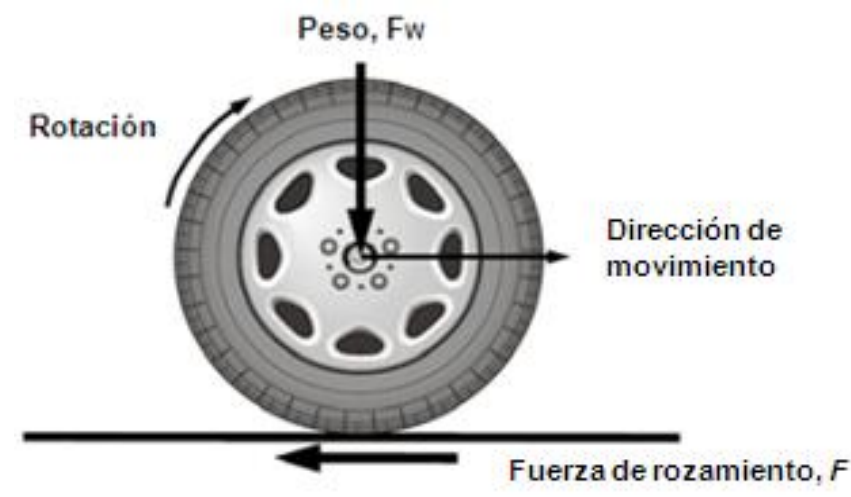

Figura 2.14. Diagrama simplificado de fuerzas actuando sobre una rueda (AASHTO 2008)

La mayoría de las máquinas de medición de la resistencia al deslizamiento, se configuran para que la velocidad angular del neumático de ensayo sea relativamente más lenta que la velocidad de desplazamiento del vehículo. La fuerza de tracción se registra y el coeficiente de rozamiento es calculado. Estos equipos requieren normalmente de un sistema de recogida de datos incorporado en el vehículo y permite medir grandes longitudes de carretera de forma continua. Para investigaciones más puntuales, existen una serie de modelos portátiles que son utilizados frente a los primeros por su menor coste de adquisición, de mantenimiento y por su más fácil manejo.

\subsubsection{Método del péndulo británico}

Entre los equipos para medir la resistencia al deslizamiento, el más utilizado es el del péndulo de fricción portátil TRRL que está recogido en la norma (NLT-175/98) para la determinación del coeficiente de resistencia al deslizamiento con el péndulo TRRL, (CEDEX 1998). Internacionalmente el péndulo de fricción está recogido en las normas British Standard BS 7976-1 (2002) y BS 7976-2 (2002) (BSI 2002a; BSI 2002b). Está normalizado en USA mediante la norma (ASTM. 2013) (Standard test method for measuring surface frictional properties using the British Pendulum Tester). Asimismo, la Asociación Española de Normalización y Certificación, (AENOR), ha regulado su empleo en España mediante la norma UNE-EN 130364:2012 (características superficiales de carreteras aeroportuarias y superficies. Parte 4: Método de ensayo para la medición de la resistencia al deslizamiento/derrape. Ensayo del péndulo (AENOR 2012b).

Es el método de ensayo más extendido en todo el mundo para medir la resistencia al deslizamiento y también el más sencillo y económico. 
El ensayo del péndulo consiste en esencia en medir la pérdida de energía de un péndulo de características conocidas, provisto en su extremo de una zapata de goma, cuando la arista de la zapata roza, con una presión determinada, sobre la superficie que se ensaya en una longitud fija. Esta pérdida de energía se relaciona con el coeficiente de fricción, o de resistencia al deslizamiento, mediante una escala en función del ángulo suplementario de la oscilación del péndulo.

Como la velocidad de deslizamiento es baja, ya que viene a ser de unos unos 10 $\mathrm{km} / \mathrm{h}$, el resultado viene influido sobre todo por la microtextura del pavimento y es una manera indirecta de caracterizarla, (Cairney 1997; Henry 2000).

El péndulo tiene la ventaja de ser de manejo muy sencillo, tanto en laboratorio como en campo.

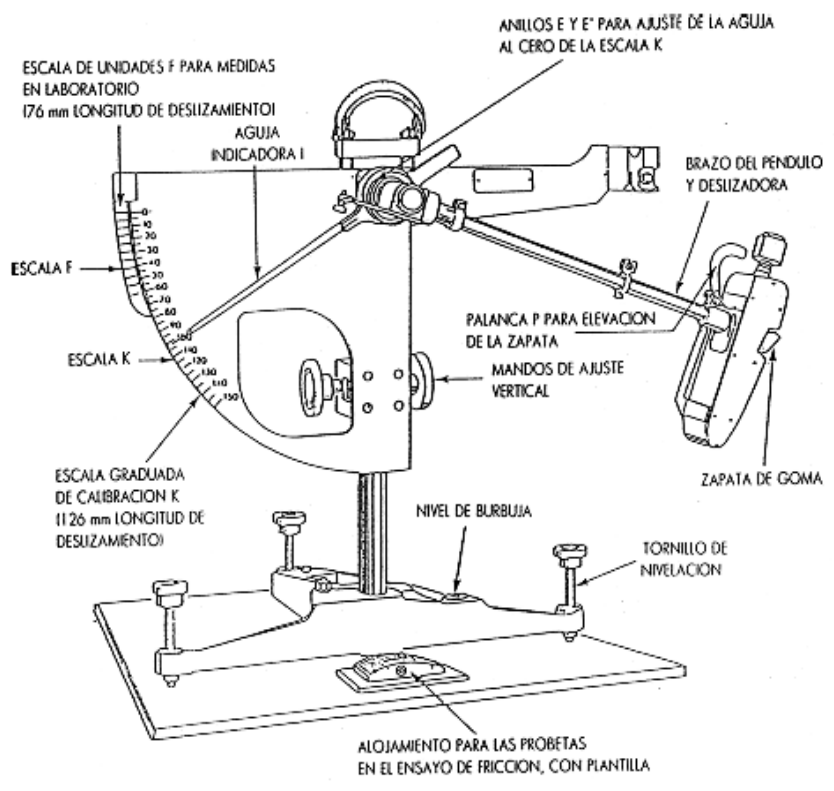

Figura 2.15: Péndulo de fricción TRRL, (CEDEX 1998).

El equipo tiene el inconveniente de que proporciona únicamente una medida de la resistencia al deslizamiento a baja velocidad. Aunque se acepta que este parámetro está muy relacionado con la microtextura, la experiencia indica que la macrotextura afecta también a la medida. Hay investigaciones que indican que el péndulo se ve afectado por la macrotextura pero estas investigaciones concluyen que el péndulo puede ser poco fiable en superficies de textura rugosa.

Otro inconveniente es que el tamaño de la zapata es pequeño y el desgaste de la superficie es muy irregular, por lo que se hace necesario llevar a cabo un número elevado de medidas para que el resultado sea fiable. Además, el péndulo es 
estacionario, por lo que el ensayo resulta lento y requiere cortar al tráfico el carril que se ensaya.

Otros equipos que se utilizan para medir la resistencia al deslizamiento son:

- El equipo de medida dinámica de la fricción o Dynamic Friction Tester (ASTM 2009a).

- El equipo de medida de la fricción a velocidad variable de North Carolina o North Carolina Variable Speed Friction Tester (ASTM 2002).

- El PTI Friction Tester.

De todos ellos el de más interés es el Dynamic Friction Tester, (DF Tester).

\subsubsection{Dynamic Friction Tester}

Este es un equipo desarrollado en Japón por la compañía Nippo Sangyo. Se trata de un equipo manual y estacionario para medir la fricción dinámica y se puede emplear en la carretera y en laboratorio. El equipo consiste en una placa rotatoria de $284 \mathrm{~mm}$ de diámetro, que mide el rozamiento entre la superficie de rodadura y tres zapatas de goma unidas a la mencionada placa, que gira a una velocidad comprendida entre 20 y $80 \mathrm{~km} / \mathrm{h}$ y está sometida a una carga constante de 150 $\mathrm{KPa}$. El equipo tiene la ventaja de que puede medir la resistencia al deslizamiento a cualquier velocidad dentro del rango señalado. Hay estudios que demuestran la relación entre las medidas de este equipo y el péndulo.

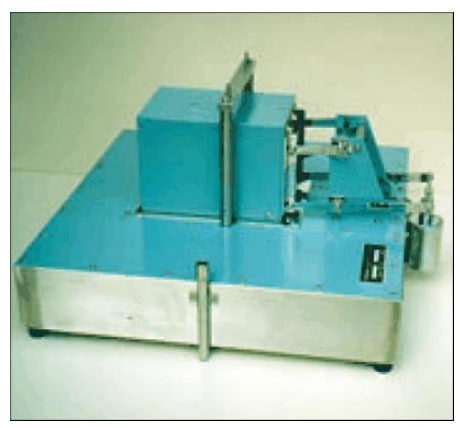

Figura 2.16. Principal unidad del equipo DF Tester.

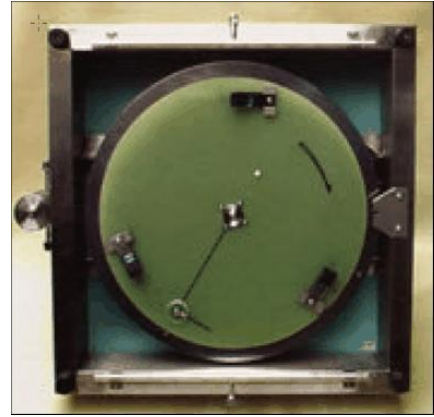

Figura 2.17. Zapatas sobre placa giratoria.

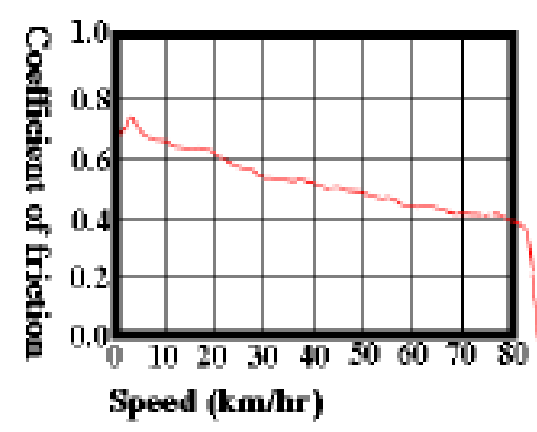

Figura 2.18. Gráfica típica de salida de resultados del DF Tester. 
Se trata de un equipo muy interesante por las siguientes razones:

- El DF Tester mide la resistencia al deslizamiento sobre mezclas bituminosas y no sobre áridos gruesos, como ocurre con el péndulo.

- Mide sobre una mayor superficie que el péndulo y sus resultados son más repetibles y reproducibles por verse menos afectados por partículas específicas de árido.

- Sus resultados se ven afectados por la micro y la macrotextura.

- Puede utilizase tanto en campo como en laboratorio, lo que facilita las calibraciones con modelos.

- Al medir sobre una zona repetidas veces reduce considerablemente el efecto estacional y las variaciones debidas a la presencia de detritus en la superficie.

- Cuando mide en campo, su medida circular recoge, junto a la zona de rodada, otras zonas menos rodadas, promediándolas.

Estos beneficios han hecho que este dispositivo se use para la calibración de otros de medición continua del rozamiento como el GripTester y el ROAR (Wambold \& Henry 1995).

\subsubsection{Método de medición continuos}

\subsubsection{SCRIM}

El Sideways force Coeficient Routine Investigation Machine, (SCRIM), se trata de un equipo desarrollado en el Reino Unido cuya versión moderna data de 1960. Actualmente se utiliza en Australia, Nueva Zelanda, en toda Europa, y en algunas partes de Asia, (Austroads 2011a).

El SCRIM, estaba normalizado en España con la NLT-336/92 (Determinación de la resistencia al deslizamiento con el equipo de medida del rozamiento transversal), (CEDEX 1992) la cual se basa en el TRRL Laboratory Report 737 (Measurement of skidding resistance. Part I. Guide to the use of SCRIM) del año 1976. En 2009, el TC 227/WC-5 (Características superficiales de los pavimentos) del Comité Europeo de Normalización publicó una especificación técnica relativa al empleo del SCRIM como paso previo a una eventual futura norma EN y en 2010, AENOR publicó el informe UNE 41201 IN, (Características superficiales de carreteras y aeropuertos. Procedimiento para determinar la resistencia al deslizamiento de la superficie de un pavimento a través de la medición del coeficiente de rozamiento transversal, (AENOR 2010c)), que sustituye a la NTL-336-92. 
El equipo va instalado en un camión rígido de dos ejes el cual lleva montado un tanque para el agua que va a ser vertida de manera controlada sobre el pavimento durante las mediciones, pues lo que se pretende es determinar la resistencia al deslizamiento del pavimento en unas condiciones de humedad determinadas, (la altura de la lámina de agua debe ser de 0,5 mm). Lo que se hace es medir la fuerza que se ejerce en la rueda que desliza parcialmente sobre el pavimento y que está inclinada $20^{\circ}$ en relación a la dirección de la marcha. Esta rueda está alojada en una caja situada en la parte inferior del camión (figura 2.19).

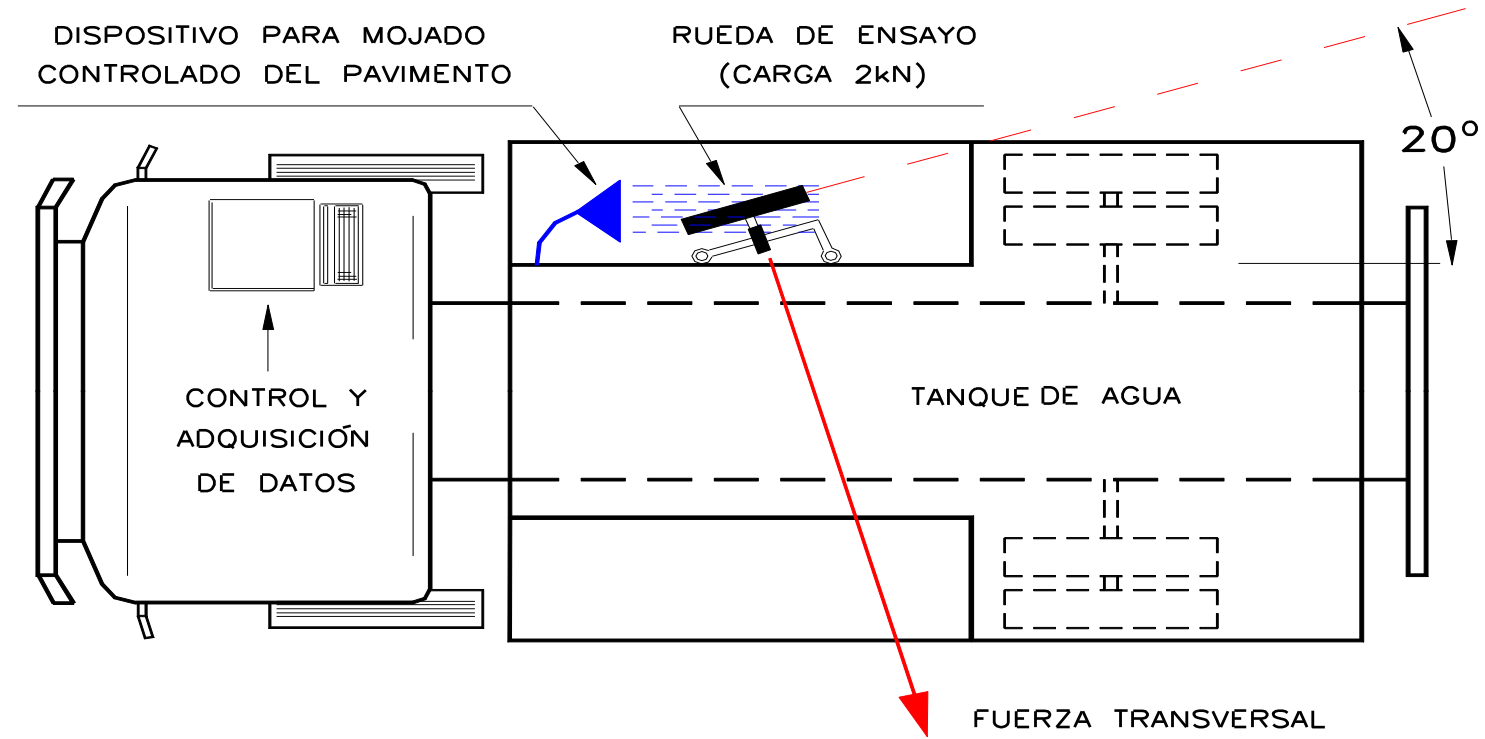

Figura 2.19. Esquema del equipo SCRIM (CEDEX 1992).

En la norma NLT se describe tanto el equipo de medición como algunos aspectos relacionados con la realización de los ensayos en carreteras. En concreto, se especifica que la velocidad de medición ha de ser de $50 \mathrm{~km} / \mathrm{h}$. Asimismo, se indica que la rueda de medida va alineada con la rodada derecha del carril ensayado, con un ángulo de esviaje de $20^{\circ}$ y cargada con $2 \mathrm{kN}$. Se establece que las medidas son validas en un intervalo de $\pm 10 \mathrm{~km} / \mathrm{h}$ sobre la velocidad de referencia, aunque se admite que "se pueden efectuar medidas a velocidades de hasta $70 \mathrm{~km} / \mathrm{h}$, o en el otro extremo, tan bajas como $30 \mathrm{~km} / \mathrm{h}$ ". El sistema electrónico digital debe registrar y guardar el valor de lectura del CRT cada 5, 10 o $20 \mathrm{~m}$ El neumático de la rueda de ensayo es liso, de $76 \times 508 \mathrm{~mm}^{2}$ e inflado a $350 \mathrm{kPa}$, con una resiliencia de $46 \% \pm 3 \%$ (a $20^{\circ} \mathrm{C}$ y medida con un resiliómetro Lüpke).

Durante el proceso el equipo registra una medida cada $100 \mathrm{~mm}$ Estos resultados son el cociente entre la fuerza lateral que se produce en un punto entre el pavimento y la rueda de medida y la fuerza vertical aplicada sobre ella ( $2 \mathrm{kN})$, es decir, son el coeficiente de rozamiento transversal en cada uno de esos puntos 
distanciados entre sí $100 \mathrm{~mm}$ Los resultados son automáticamente promediados cada 5, 10 o $20 \mathrm{~m}$, de acuerdo con la configuración indicada por el operador, dando lugar a lo que se denominan Scrim Readings (SR). A continuación, los SR se convierten en SC (Scrim Coefficients) tras aplicar factores de corrección por variaciones de carga, temperatura o velocidad.

Finalmente, el término Sideway Force Coefficient $\mathrm{SFC}_{m}$ aparece cuando el valor de SC se asocia a la velocidad $\mathrm{m}$ para la cual las lecturas SR fueron ajustadas (normalmente, $50 \mathrm{~km} / \mathrm{h}$ ). Este SFCm es el valor que en España se suele designar como CRT, aunque propiamente debería acompañarse también del subíndice indicativo de la velocidad (habitualmente CRT50).

La Dirección General de Carreteras del Ministerio de Fomento no contempla en su normativa ni en sus campañas auscultación la utilización de equipos diferentes del SCRIM para valorar la resistencia al deslizamiento de los pavimentos. Sin embargo, por diversas razones, la situación en otros países es distinta, (Del Val 2010).

Hay que empezar teniendo en cuenta que la medida del coeficiente de rozamiento transversal puede no ser la mejor forma de evaluar el riesgo real de deslizamiento, sobre todo desde que se generalizaron los sistemas de antibloqueo ABS, obligatorios desde julio de 2004 en todos los vehículos fabricados en la Unión Europea.

Por otro lado, la velocidad de ensayo de $50 \mathrm{~km} / \mathrm{h}$ es poco representativa de la velocidad real de los vehículos, siendo difícil medir a velocidades superiores con el SCRIM Al ser esta velocidad relativamente baja, su medición está más influenciada por la microtextura que por la macrotextura. Además, al ir montado el equipo en un camión convencional, el ensayo no es practicable en carreteras de montaña muy sinuosas, y resulta poco aplicable en zonas urbanas o suburbanas. Tampoco permite verificar la resistencia al deslizamiento en marcas viales. Al no estar reconocido por la Organización de Aviación Civil Internacional no cabe su empleo en superficies aeroportuarias. Finalmente, en otro orden de cosas, el SCRIM es un equipo muy caro, lo que inevitablemente repercute en el precio final de las medidas, y eso supone en última instancia que la evaluación de la resistencia al deslizamiento se acaba haciendo con menor frecuencia o sobre una menor extensión de lo que sería deseable. Sin embargo, es indudable que el uso del SCRIM también comporta ventajas, como las derivadas de ser un equipo muy robusto, y sobre cuyo empleo existe una gran experiencia acumulada, lo que redunda en el aprovechamiento que en la gestión viaria se puede hacer de las medidas obtenidas con él. 


\subsubsection{GripTester}

Este equipo mide el coeficiente de rozamiento longitudinal entre la carretera y un neumático normalizado con un bloqueo parcial del 15\%. En España está normalizado mediante la norma UNE-CEN/TS 15901-7:2010 IN, (Características superficiales de carreteras y aeropuertos. Parte 7: Procedimiento para determinar la resistencia al deslizamiento de la superficie de un pavimento utilizando un equipo con el ratio de deslizamiento longitudinal fijo (CRLG): GripTester®)(AENOR 2010a).

El Griptester es un equipo de medida de la resistencia al deslizamiento diseñado originalmente por la Findlay Irvine Limited de Escocia en 1987, para operaciones en pistas de aeropuertos. Ahora está en uso en más de 30 países de todo el mundo. Puede ser remolcado detrás de un vehículo con un sistema automático de suministro de agua o puede ser empujado a mano por un operador. El GripTester tiene una rueda de ensayo que está frenada y dos ruedas que se utilizan para desplazar el equipo tal y como se muestra en la figura 2.20. Su modo de funcionamiento es distinto al del SCRIM ya que la rueda de ensayo, normalizada y de $254 \mathrm{~mm}$ de diámetro, está orientada en el sentido de la circulación y parcialmente bloqueada, con un grado de bloqueo del $15 \%$, con respecto a la velocidad de deslizamiento del vehículo, por lo que se obtiene un coeficiente de rozamiento longitudinal denominado Grip Number (GN), que se define como la relación entre la fuerza de tracción y la carga vertical que se aplica sobre la rueda de ensayo.

El GripTester utiliza un sistema de suministro de agua automático o manual, que proporciona una profundidad película de agua de 0,25 $\mathrm{mm}$ por debajo de la cubierta de neumático de prueba. La profundidad de la película de agua se puede variar si es necesario. El Grip Number, se mide cada metro pero lo normal es aportar una medida cada 10 metros. El vehículo que remolca el GripTester puede circular a velocidades entre 5 y $130 \mathrm{~km} / \mathrm{h}$ sin entorpecer al resto de la circulación.

Junto al SCRIM es uno de los equipos más extendidos en Europa para la medida de la resistencia al deslizamiento. En el Ensayo Internacional de Resistencia al Deslizamiento realizado documentado por la PIARC en 1992, se demostró una buena correlación con otros equipos y una repetibilidad adecuada.

El GripTester es un equipo compacto, muy manejable y económico, con las ventajas e inconvenientes de otros equipos de gran rendimiento. Sus resultados pueden tener una cierta dispersión en carreteras irregulares debido a su peso reducido, ( 85 $\mathrm{kg}$ ). En carreteras de trazado sinuoso, trabaja mejor que el SCRIM y se 
correlaciona mejor con el péndulo y el DF Tester que este último equipo. Es más sensible que el SCRIM a los cambios de resistencia al deslizamiento.

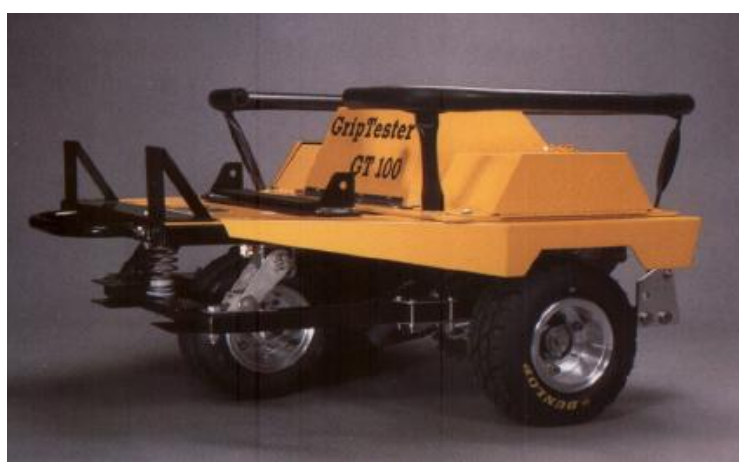

Figuras 2.20: GripTester. Vista lateral. Fuente (Irvine 2010).

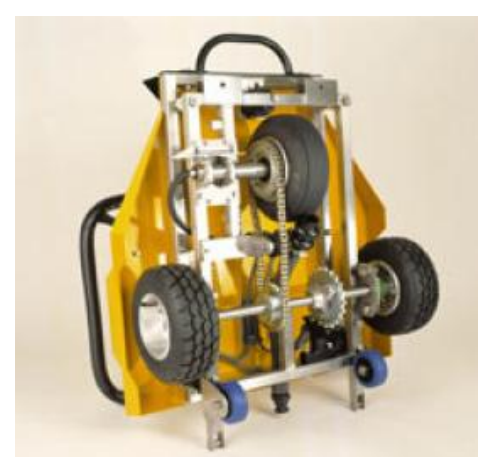

Figura 2.21. Vista de la rueda de medida y de la cadena de transmisión del GripTester. Fuente

(Do and Roe 2008).

\subsubsection{Medida de la textura}

Para caracterizar la macrotextura de un pavimento, se utilizan fundamentalmente dos procedimientos distintos, que pasamos a estudiar en los siguientes apartados.

\subsubsection{Método volumétrico}

Consiste en extender sobre el pavimento un volumen conocido de arena de tamaño uniforme formando un círculo. Dividiendo el volumen del material por el área del círculo, se obtiene la "Profundidad Media de Textura" o "Mean Texture Depth", MTD, que, expresada en milímetros, caracteriza la macrotextura. El ensayo se encuentra normalizado en la NLT-335, (CEDEX 1987) y más recientemente en la UNE EN 13036-1, (AENOR 2012a) y es el que habitualmente se ha venido utilizando en España para determinar la textura superficial del firme, (macrotextura).

La técnica, aunque simple, es vulnerable a inconsistencias del operador y puede ser distorsionada por los áridos de la superficie de la carretera. Por este motivo, se requieren mediciones repetidas a intervalos regulares para caracterizar un tramo de carretera. El método es lento en su ejecución y se requiere la gestión del tráfico, mediante cortes de carril en carreteras en servicio, para proteger al operador, por lo que no es adecuada para monitorizar la textura de la superficie de la carretera a gran escala, (Austroads 2011b).

En Japón, otra variación del método utiliza esferas de vidrio, pero los extiende en una pista lineal utilizando un esparcidor que se mantiene a una pequeña distancia fija por encima de la superficie en un accesorio de anchura constante, (Henry 2000). 


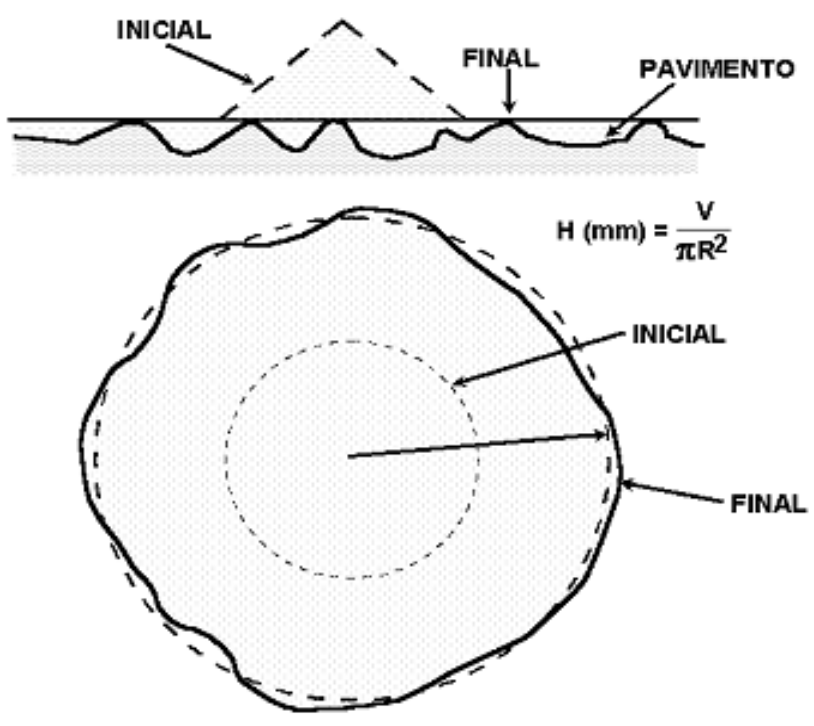

Figura 2.22. Círculo de arena

(i) Volumen conocido de arena extendida de tamaño uniforme de partícula puesta sobre la carretera

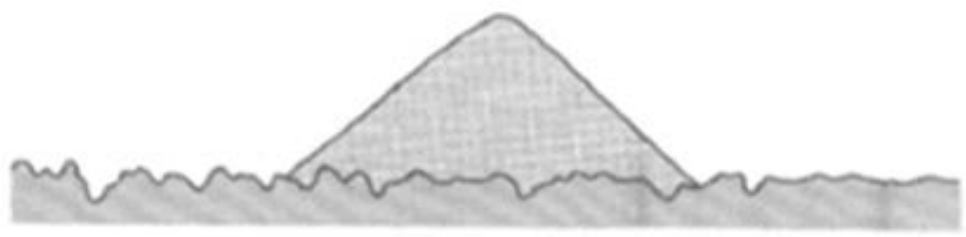

(ii) Volumen extendido para formar circulo de arena con "valles" llenos hasta el nivel de los "picos"

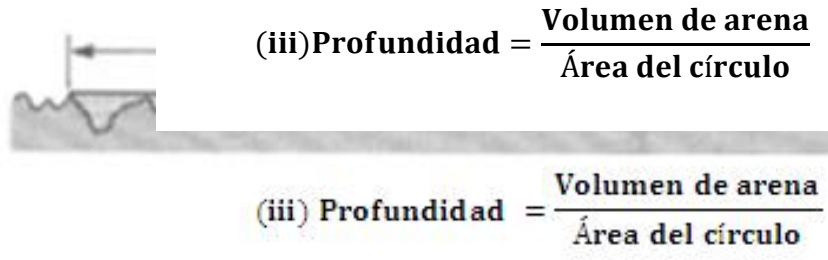

Figura 2.23: Método del círculo de arena para medida de la macrotextura (Woodward et al. 2002)

\subsubsection{Texturómetros láser}

Para un gestión eficiente y segura de las carreteras, se llegó a la conclusión que era importante el conseguir determinar el valor de la macrotextura de un pavimento a partir de procedimientos de mayor rendimiento que los conseguidos utilizando los métodos volumétricos. A partir de esta necesidad se han desarrollado varios métodos para la determinación de esta propiedad, basados en sensores de medición sin contacto, montados sobre equipos estacionarios o sobre vehículos en movimiento que se desplazan a velocidades de hasta $110 \mathrm{~km} / \mathrm{h}$, para la medida de la macrotextura en continuo. 
El principio en el que se basan este tipo de equipos, es el de emitir una luz láser sobre un punto del pavimento y determinar su altura mediante un receptor que forma un ángulo con el emisor.

Una vez medido el perfil, la mayoría de los equipos hallan la recta que, por regresión, mejor se ajusta a él y calculan la profundidad media del perfil, MPD (Mean Profile Depth), que sirve para estimar la textura.

La norma de ensayo que describe el procedimiento para el cálculo del MPD es la UNE EN ISO 13473-1:2006, parte 1 (Determinaación de la profundidad media del perfil), (AENOR 2006).

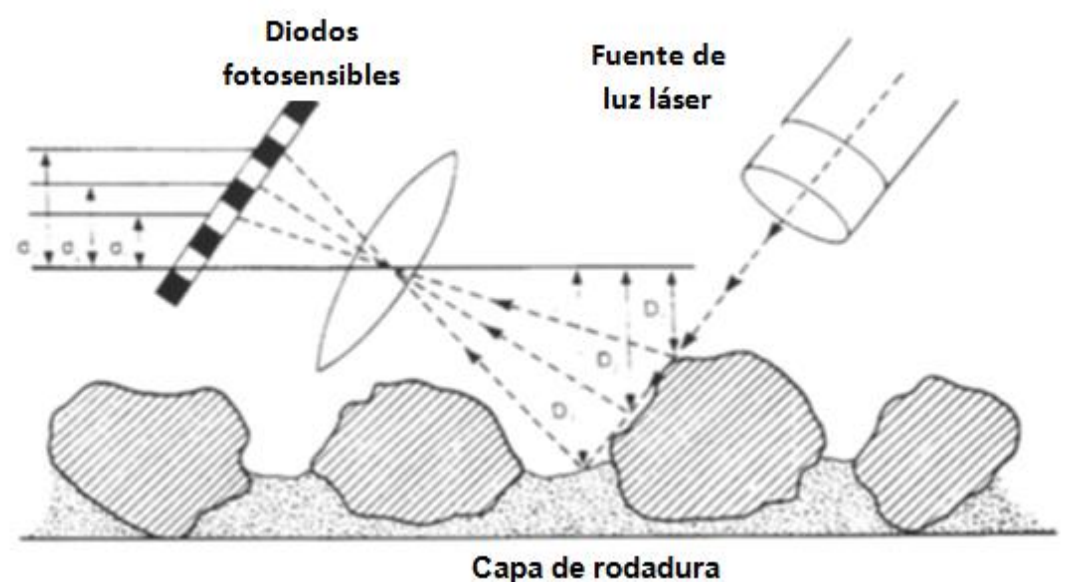

Figura 2.24: Sensores láser para medida de la textura (Millard 1993)

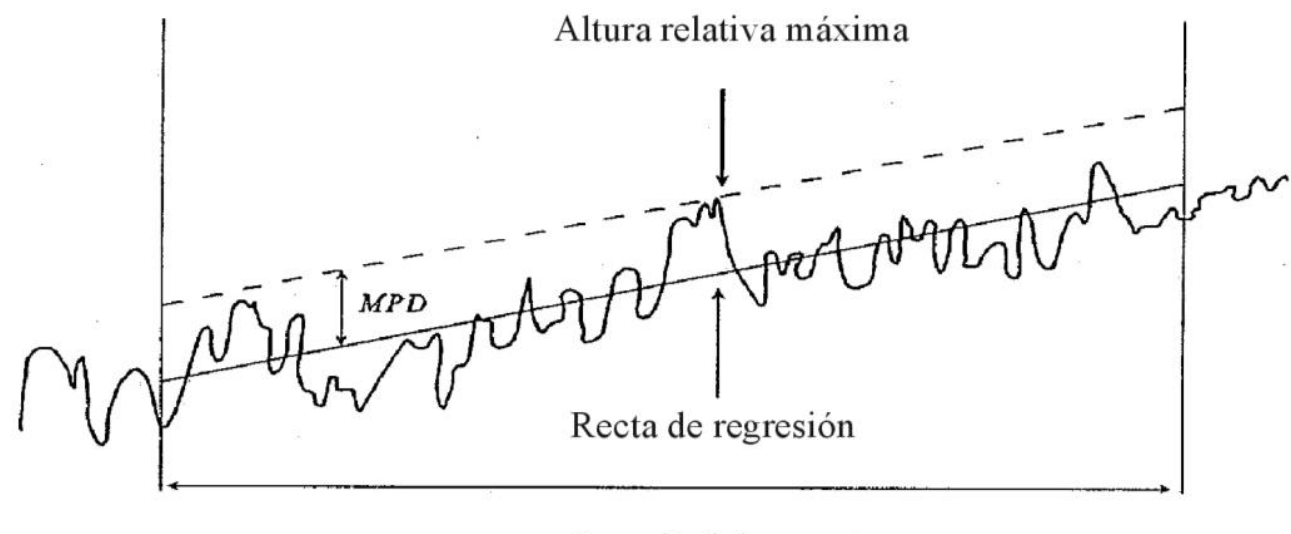

Longitud de muestra

Figura 2.25. Profundidad media del perfil, MPD, (Millard 1993) 
Otros equipos determinan otros valores estadísticos, como el RMS, (Root Mean Square)

Estos equipos han tenido un gran desarrollo en las últimas décadas debido al desarrollo de la tecnología láser y de los ordenadores que gestionan la información obtenida.

Ejemplos de esta tecnología son el mini-texturómetro láser portátil del TRRL, que se desplaza empujado por un operario, o los perfilómetros montados sobre vehículos de variadas marcas, como el Greenwood o el Dynatest.

Otros texturómetros de uso menos corriente utilizan agujas de contacto o métodos de fotoseccionamiento o estereofotografía para caracterizar la rugosidad o el perfil a la escala de la macrotextura.

Un equipo relativamente reciente es el Circular Track Meter, (CT Meter), que se basa en la tecnología láser para medir el MPD de una superficie en una posición estática. Se utiliza tanto en laboratorio como en campo. Emplea un láser para medir el perfil de un círculo de $284 \mathrm{~mm}$ de diámetro o de $892 \mathrm{~mm}$ de circunferencia, que a su vez se divide en ocho segmentos de $111,5 \mathrm{~mm}$ El aparato calcula la profundidad media de la textura de cada segmento. El valor de MPD que se aporta es la media de la obtenida en cada uno de ellos. Tiene más variación que el círculo de arena pero es de más sencillo manejo. Este procedimiento de ensayo se presenta en la norma ASTM E2157, (ASTM 2009b).

El CT Meter se puede utilizar para medir las características de MPD de muestras fabricadas en laboratorio de $450 \mathrm{~mm}$ por $450 \mathrm{~mm}$ que son las dimensiones mínimas que necesita el CT Meter para poder determinar la macrotextura de la mezcla.

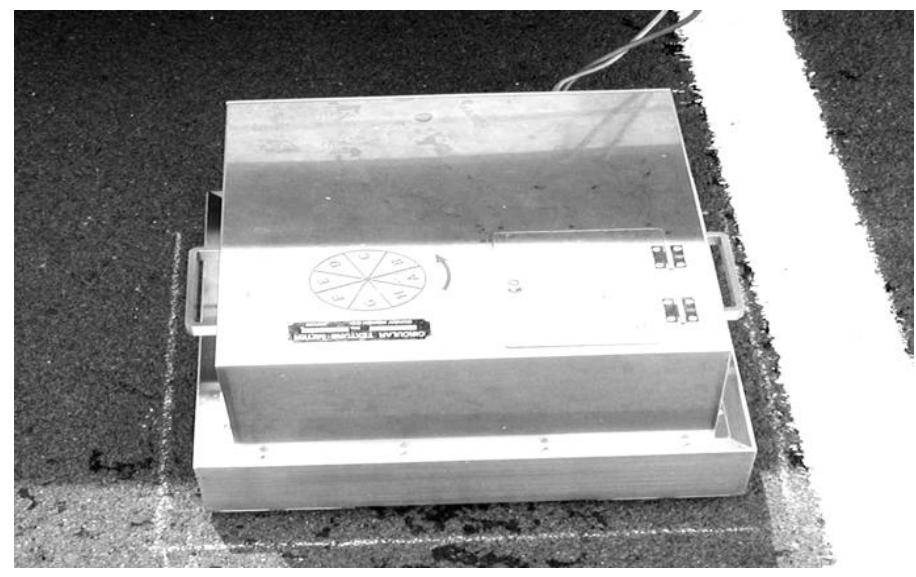

Figura 2.26. Circular Track Meter (CT Meter), (Vollor and Hanson 2006). 


\subsubsection{Equipos de medida de función múltiple}

Algunos equipos combinan la medida de la fricción con la de la textura con lo que están en las mejores condiciones de caracterizar la adherencia a cualquier velocidad de deslizamiento.

Entre ellos, destacan algunos modelos de SCRIM que llevan incorporado un equipo láser de medida de textura. Es de suponer que la adopción en el futuro del Índice de Fricción Internacional (IFI), por parte de los organismos de diversos países, haga que aumente la utilización de este tipo de equipos.

Otros equipos de función múltiple combinan la determinación de la textura con alguna otra característica del pavimento que no tiene que ver tan directamente con el coeficiente de resistencia al deslizamiento por ejemplo, la regularidad superficial, la pendiente transversal, etc. Estos equipos son los que, más frecuentemente, se conocen como de función múltiple o multifunción. Muy utilizados en España han sido o son, el láser RST sueco, el MRM británico y el perfilómetro danés Greenwood.

\subsubsection{Equipos de laboratorio para la predicción del coeficiente de resistencia al deslizamiento}

Desafortunadamente, a día de hoy, no existen todavía procedimientos normalizados que sirvan para cuantificar con precisión en la formulación de una mezcla bituminosa la resistencia al deslizamiento que se puede obtener con ella, (Del Val 2010). Se han llevado a cabo sin embargo diversos estudios sobre este particular centrados, por un lado, en la medición de la macrotextura superficial de probetas fabricadas con una cierta forma y, por otro, en el desgaste de dichas probetas para poder valorar cómo la resistencia al deslizamiento se mantendría o perdería a lo largo del tiempo. En este sentido, debe destacarse el equipo Wehner Shulze y los desarrollados llevados a cabo por la National Center of Asphalt Technology, (NCAT), de la Auburn University, que comentaremos en apartados posteriores.

\subsubsection{Equipo para medir el coeficiente de pulimento acelerado}

El equipo más utilizado para caracterizar la calidad de los áridos a utilizar en capas de rodadura en lo que se refiere a la resistencia al deslizamiento, es el ensayo de pulimento acelerado, según el método británico, que tiene dos fases, una de pulimento de probetas de árido dispuestas en una rueda y otra de medida mediante el péndulo TRRL. Hay un método ASTM basado en las normas ASTM D3319-11 y ASTM E303-93, que sigue también este procedimiento, (ASTM 2011 y ASTM 2013). En España se sigue el método de la norma UNE-EN 1097-8, (Ensayos para 
determinar las prestaciones mecánicas y físicas de los áridos. Parte 8: Determinación del coeficiente de pulimento acelerado, (AENOR 2010b).

Para la realización del ensayo se colocan los áridos en un molde con una cierta curvatura y se fijan mediante un mortero de resina. Las probetas se introducen en una rueda, junto con otras que tienen el árido de control y se someten a ciclos de pulido mediante la acción de una rueda cargada, agua y dos abrasivos que se utilizan secuencialmente. El ensayo se realiza durante tres horas con el abrasivo grueso y otras tres horas con el fino. Después del pulido se mide la resistencia al deslizamiento con el péndulo británico para obtener el PSV (Polish Stone Value) o valor del CPA, (coeficiente de pulimento acelerado).

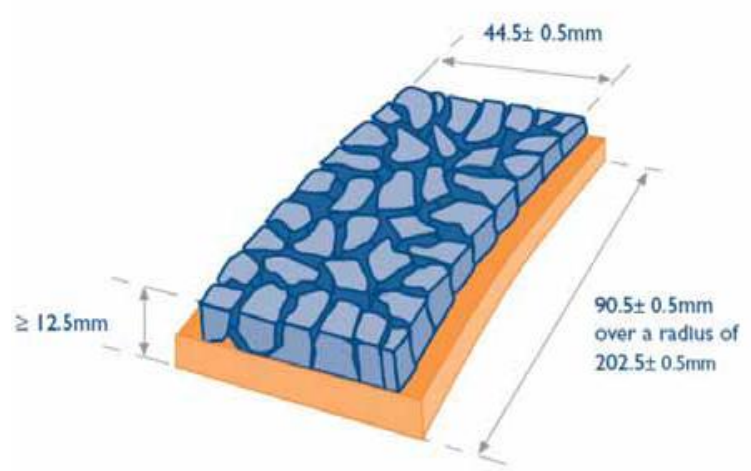

Figura 2.27. Probeta de ensayo CPA (AENOR 2010b)

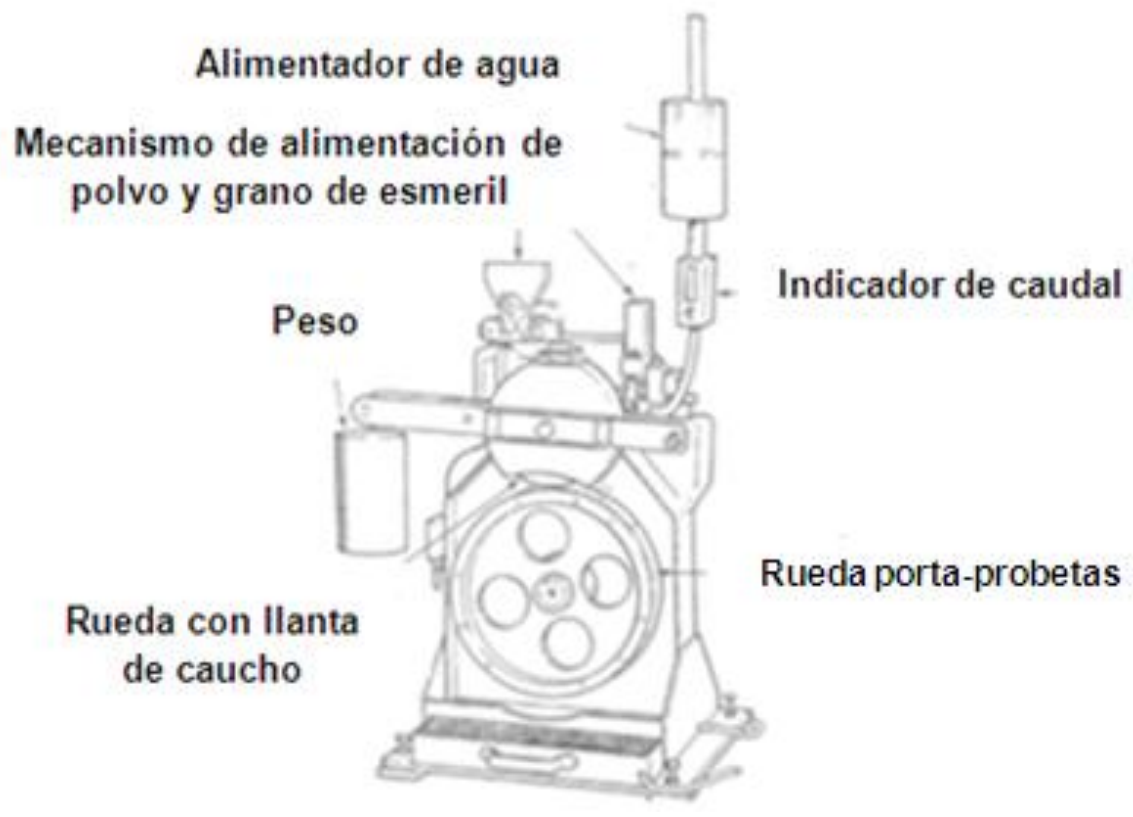

Figura 2.28. Máquina de pulimento según la UNE-EN 1097-8 (AENOR 2010b) 
Debemos destacar como principales características de este procedimiento:

- Es un ensayo lento, de calibración compleja y que requiere de operarios experimentados.

- Está muy afectado por la selección que se haga de los áridos a ensayar.

- No considera la mezcla bituminosa final por lo que no tiene en cuenta el efecto del betún, la granulometría o de la fracción arena, (Mcdaniel \& Coree 2003).

- Se discute mucho su efectividad para predecir la resistencia al deslizamiento en campo. Como el ensayo se realiza durante 6 horas, no se hace una determinación completa de la evaluación del comportamiento.

- La rueda de caucho rígido utilizada para efectuar el pulimento de las probetas, no simula de forma apropiada las condiciones que se producen realmente en el contacto entre las ruedas de los vehículos y la superficie de la carretera, (Wilson 2006).

- El CPA debe considerarse como una forma de comparar áridos no como un indicador del comportamiento de una mezcla bituminosa en cuanto a resistencia al deslizamiento.

\subsubsection{Wehner Schulze}

Como se ha explicado en apartados anteriores, son varios los equipos que actualmente existen en el mercado para la medida de la resistencia al deslizamiento, todos ellos utilizados sobre la mezcla bituminosa una vez colocada en obra.

Sin embargo, hasta hace unos años no se disponía de ningún método aceptable que pudiera correlacionar el comportamiento de una mezcla bituminosa frente a la adherencia neumático-pavimento en el laboratorio, es decir, antes de su puesta en obra.

Esta deficiencia parece que se ha resuelto después de varios años de estudio, con la aparición de un equipo que permite proporcionar información sobre la resistencia al deslizamiento que puede presentar una mezcla bituminosa. Esta máquina es conocida con el nombre Wehner Schulze.

Es un equipo desarrollado en Alemania en los años 60 que está compuesto de dos módulos, uno de pulimento y otro de medida del rozamiento. La probeta se introduce en el equipo donde se pule con unos rodillos giratorios. Luego se transfiere a la unidad de medida, donde un disco rotatorio con zapatas de goma 
toma la medida de la resistencia al deslizamiento. Se puede medir a distintas velocidades.

Este equipo es muy versátil, ya que permite por un lado la resistencia al pulimento de los áridos, semejante a la medida del CPA que se conoce hasta el momento, y por otro lado de la mezcla bituminosa bien fabricada o diseñada en laboratorio como a partir de testigos extraídos de obra pulidos por el propio tráfico. Es decir, te permite estudiar la evolución en el tiempo de la resistencia al pulimento y al deslizamiento.

En base a los estudios hechos en Alemania y Francia, recientemente se ha elaborado una norma, la UNE EN 12697-49, (AENOR 2014), donde se establece tanto la metodología del ensayo a seguir, como las características que debe tener la máquina de ensayo.

Para la determinación de la evolución del coeficiente de rozamiento sobre la mezcla bituminosa, se necesita una etapa de simulación del tráfico, mediante pulimento de la superficie, seguido de una etapa de medida de la resistencia al deslizamiento.

Las probetas son de forma circular de $250 \mathrm{~mm}$ de diámetro y pueden proceder de testigos tomados en la carretera o de probetas fabricadas en el laboratorio.

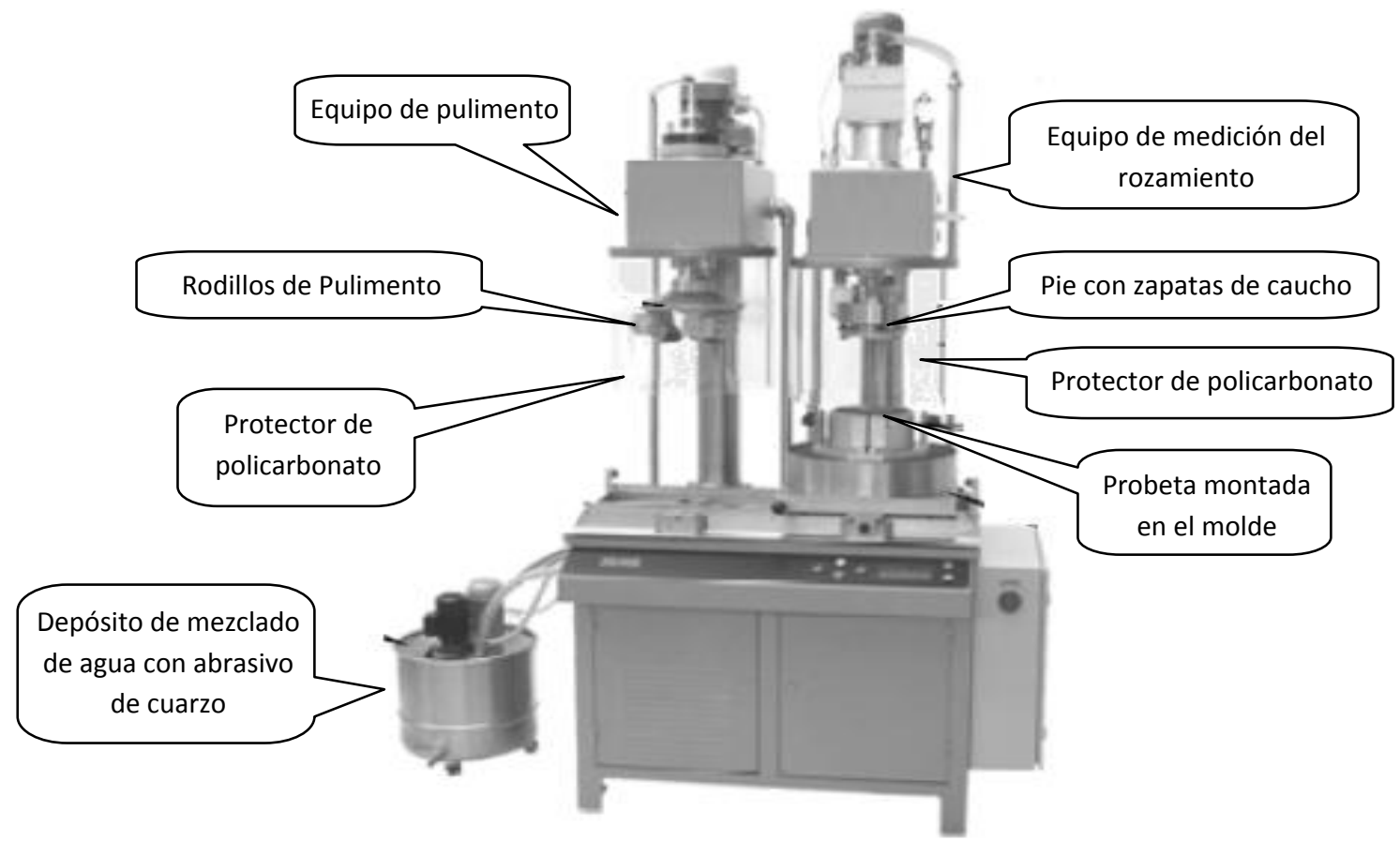

Figura 2.29. Máquina de pulimento Wehner Schulze, (Dunford 2008) 


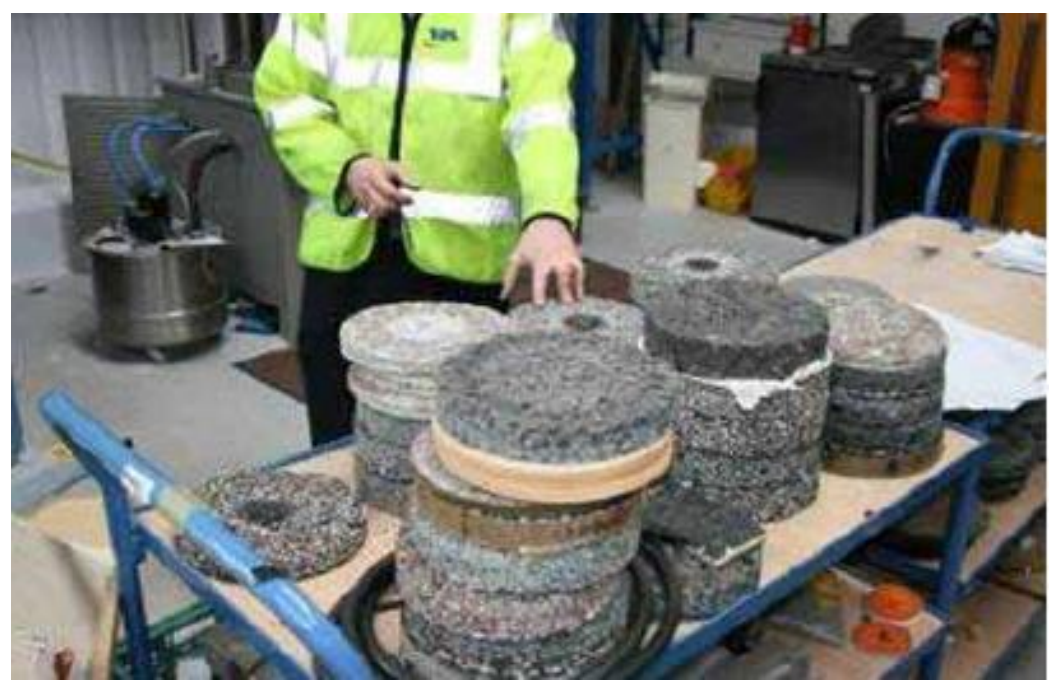

Figura 2.30. Probetas para ensayo en la Wehner Schulze, (Dunford 2008)

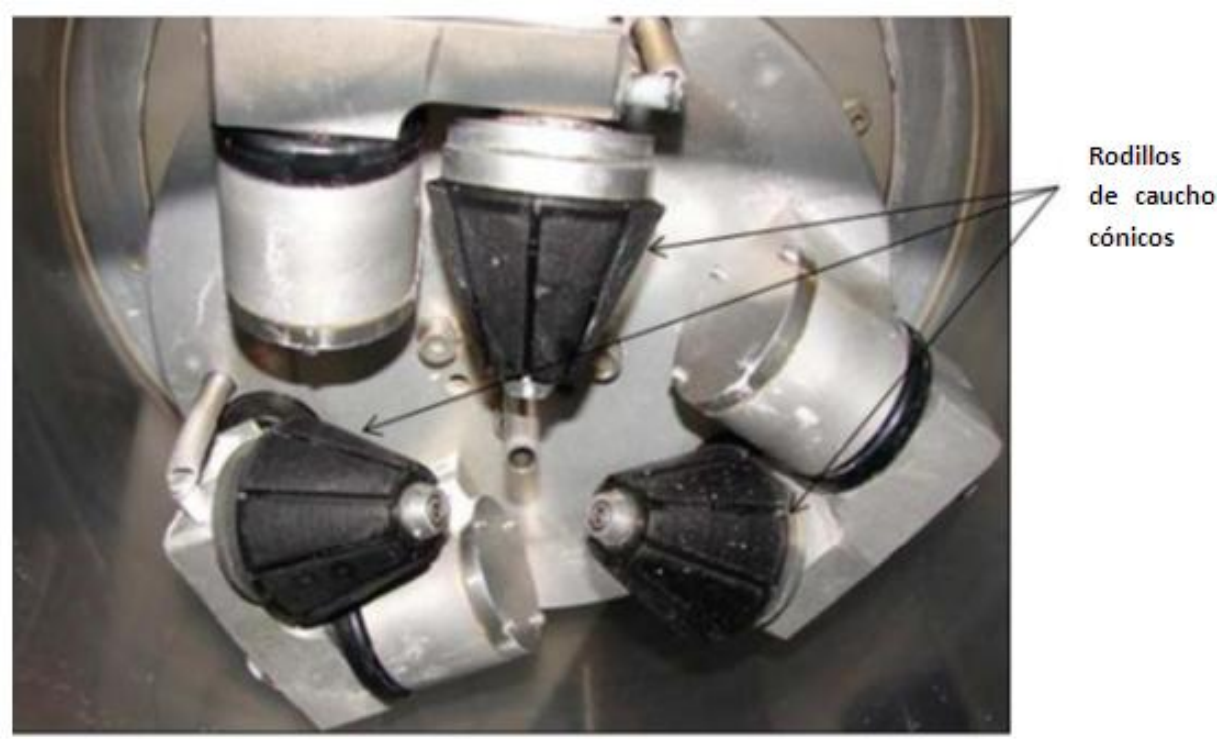

Figura 2.31. Esquema del dispositivo para el proceso de pulimento (Arampamoorthy \& Patrick 2011) 


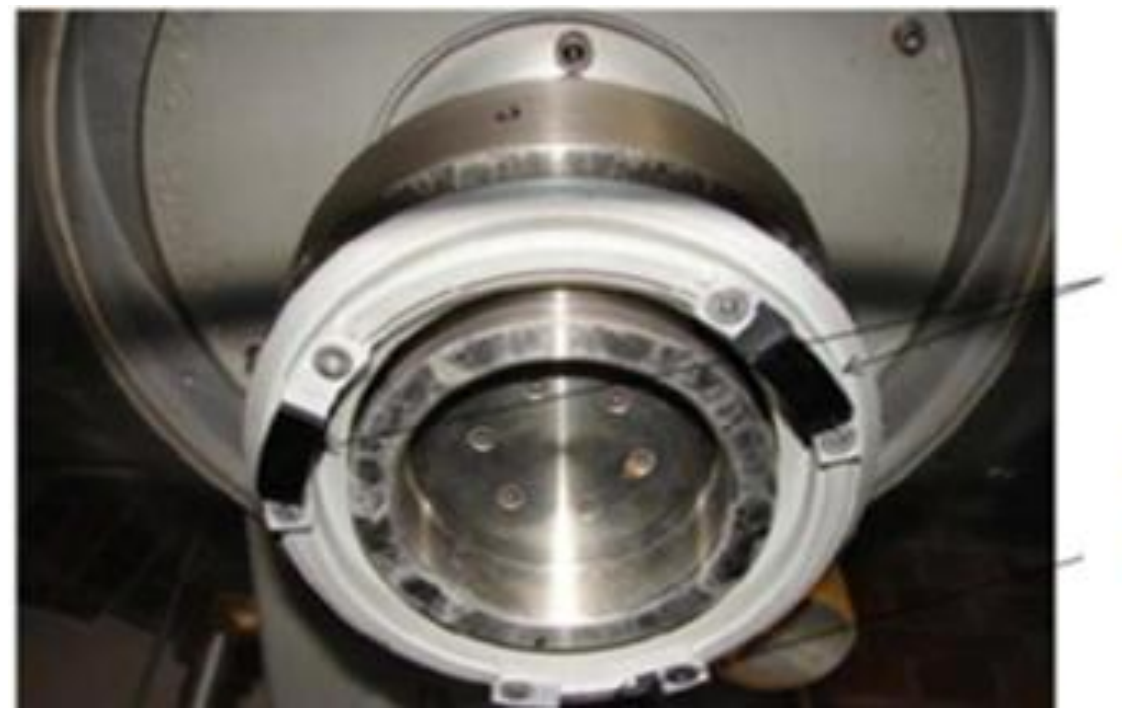

Dos zapatas

de caucho

Tercera zapata de caucho removida temporalmente

Figura 2.32. Módulo de medida de la resistencia al deslizamiento (Arampamoorthy \& Patrick 2011)

Este equipo ha mostrado buenas correlaciones con las medidas de campo. Su principal inconveniente viene derivado de los altos costes de adquisición y mantenimiento, (Austroads 2011b)

\subsubsection{El equipo de pulimento del National Center of Asphalt Technology}

EI NCAT ha desarrollado una versión un poco más pequeña de una máquina de pulimento circular que no está actualmente recogida en ninguna norma ASTM o AASHTO. Este dispositivo está dimensionado específicamente para posteriormente poder utilizar el DF Tester para que pueda determinar el coeficiente de resistencia al deslizamiento y el CT Meter para que pueda calcular la macrotextura, equipos que ya sí se encuentran cubiertos por normas ASTM, (Mcdaniel and Coree 2003)

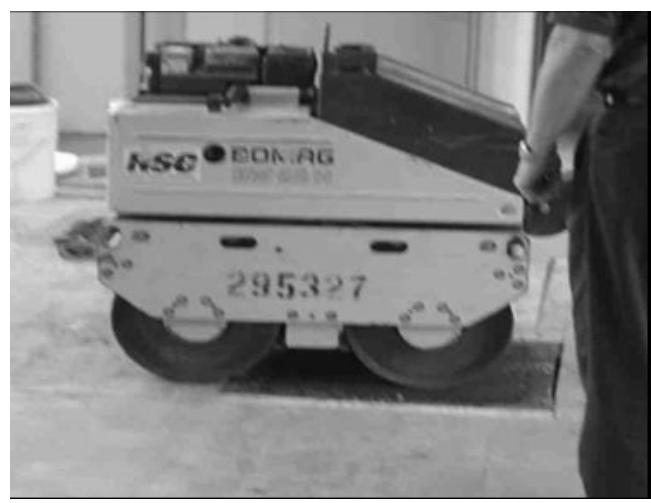

Figura 2.33: Compactador utilizado para fabricación de probetas, (Vollor and Hanson 2006)

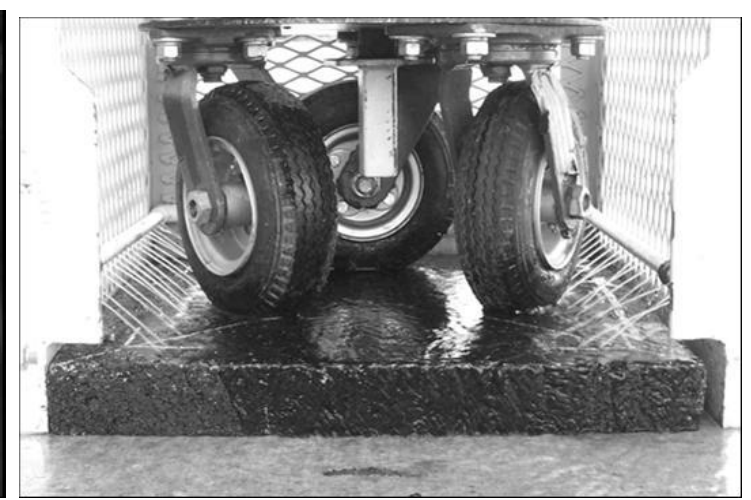

Figura 2.34. Equipo de pulimento desarrollado en la NCAT. (Vollor and Hanson 2006) 
La máquina pulidora NCAT utiliza tres ruedas neumáticas de $203 \mathrm{~mm}$ de diámetro para pulir una muestra cuadrada de $500 \mathrm{~mm}$ de lado. Se ha probado efectuar el pulimento con neumáticos de resina y macizos, aunque los resultados con los neumáticos hinchados parece que simulan mejor los resultados observados en el campo, (Vollor and Hanson 2006)

Con los neumáticos de caucho se utiliza agua para limpiar las partículas que se desprenden de las ruedas durante el proceso de pulido de la superficie. En el procedimiento desarrollado por NCAT, se aplica una carga máxima de $68 \mathrm{~kg}$ a través de las tres ruedas del equipo. Al igual que con otros dispositivos de pulimento, la máquina se puede detener periódicamente para permitir realizar medidas del coeficiente de resistencia al deslizamiento y/o de la macrotextura. Hasta 100.000 revoluciones a 40 rpm, se han llegado a aplicar con este equipo para conseguir terminar de pulir una muestra, pero rara vez se necesita llegar a tal número de ciclos.

El procedimiento NCAT utiliza un compactador lineal modificado, similares a los utilizados para compactar mezclas drenantes o porosas, para fabricar las muestras de laboratorio a ensayar.

El dispositivo NCAT es relativamente pequeño y, como hemos dicho anteriormente, requiere de agua para su funcionamiento.

Las experiencias llevadas a cabo por NCAT muestran que el dispositivo realmente es capaz de pulir muestras de pavimento hasta un valor final. En sus trabajos de desarrollo, experimentaron con diferentes velocidades, tipos de neumáticos y métodos de limpieza de la superficie. Encontraron que el método resumido aquí era suficientemente bueno debido a que los resultados obtenidos sobre determinado tipo de mezclas, dieron curvas de evolución de la resistencia al deslizamiento, con una forma similar a las obtenidas sobre mezclas colocadas en tramos de prueba que fueron auscultadas en el tiempo, lo que indicaba el potencial de este dispositivo para ser utilizado en la predicción de la resistencia al deslizamiento de mezclas a colocar en rodaduras de carreteras, durante su fase de diseño en laboratorio. El equipo pulidor tiene el potencial de ser utilizado además en el campo, sobre pavimentos ya construidos, si fuese necesario, (Vollor and Hanson 2006).

En base a los estudios llevados a cabo con este equipo se llega a las siguientes conclusiones:

- Se necesita investigar más para el desarrollo óptimo de este equipo de pulimento. Concretamente hace falta determinar la carga más idónea a 
aplicar sobre las ruedas de pulido y la velocidad de giro más adecuada de las mismas.

- Las muestras de laboratorio fabricadas por NCAT entre el 2003 y el 2006 para la construcción de distintos tramos de prueba, deberían ser probadas con este equipo para poder comparar los resultados de macrotextura y resistencia al deslizamiento que se obtengan en dichas muestras, con los obtenidos sobre las colocadas en los tramos de ensayo, que han estado sometidas a un tráfico real.

- Investigar con la instalación de instrumentación específica si el cambio en el esfuerzo de torsión que se desarrolla durante el pulimento de las muestras, puede ser relacionado con el valor de la resistencia al deslizamiento en cada momento, (Vollor and Hanson 2006).

\subsection{Modelos}

Hay varios modelos que han sido desarrollados para la determinación de la resistencia al deslizamiento de un pavimento. Los primeros modelos se basaron en los valores obtenidos a partir del SCRIM y el valor del coeficiente de pulimento acelerado. Estos modelos se desarrollaron por el Transport Research Laboratory del Reino Unido. A mediados de la década de los 70, se desarrolló en los EEUU el Modelo del Estado de Pensilvania, que fue luego ampliado por el modelo Rado en la década de 1990, (Henry 2000). Un modelo de la resistencia al deslizamiento que intentó ajustar las mediciones teniendo en cuenta las posibles variaciones estacionales, así como los valores anómalos que se suelen obtener en el corto plazo, fue el desarrollado por (Hill B.J and J.J 1981). La World Road Association, desarrolló el modelo PIARC, que utiliza la forma general del modelo del Estado de Pensilvania dentro de un experimento para armonizar las medidas de resistencia al deslizamiento de diferentes dispositivos mediante el uso de un Índice de Fricción Internacional (IFI), (Wambold and Henry 1995). Un modelo matemático más complejo fue desarrollado por (Golden 1981) para determinar la resistencia al deslizamiento teórica en el contacto rueda pavimento. Los avances en la modelización del coeficiente de la resistencia al deslizamiento hacen uso de redes neuronales (Owusu-Ababio 1995). Los modelos de uso más común, o los modelos que han investigado la relación entre los factores que afectan a la resistencia al deslizamiento, se describen en los siguientes apartados. 


\subsubsection{Modelo empírico del TRRL}

El modelo desarrollado por el Transport Research Laboratory del Reino Unido, (TRRL), permite predecir el coeficiente de resistencia al deslizamiento medido con el SCRIM a partir del valor del coeficiente de pulimento acelerado de los áridos de la mezcla, (CPA), y del tráfico que circula por la misma, según la siguiente ecuación:

$$
\mathrm{SFC}_{50}=0,024-0,0000663 \times \mathrm{CVD}+0,10 \times \mathrm{PSV}
$$

Donde:

$$
\begin{aligned}
& \circ \mathrm{SFC}_{50}=\text { Medida del SCRIM (Sideways Force Coefficient) a } 50 \mathrm{~km} / \mathrm{h} \\
& \circ \mathrm{CVD}=\text { Número de vehículos pesados por carril y día } \\
& \circ \mathrm{PSV}=\text { Polished Stone Value o valor del CPA }
\end{aligned}
$$

\subsubsection{Modelo del estado de Pensilvania}

El modelo del estado de Pensilvania, describe la relación entre el coeficiente de resistencia al deslizamiento $(\mu)$ a una velocidad de deslizamiento (S) por una función exponencial, (Leu and Henry 1978).

$$
\mu=\mu_{0} \cdot e^{-\frac{P N G}{100} S}
$$

Donde:

○ $\mu=$ coeficiente de rozamiento

- $\mu_{0}=$ el rozamiento para una velocidad de deslizamiento cero.

○ $\mathrm{S}=$ es la velocidad de deslizamiento en $\mathrm{km} / \mathrm{h}$

- $\quad$ PNG $=$ Porcentaje del gradiente de la velocidad normalizado, definido por:

$$
P N G=-\frac{100}{\mu} \cdot \frac{d \mu}{d s}
$$

\subsubsection{El modelo Rado}

El rozamiento varía durante todo el proceso de frenado y, por lo tanto, depende de la velocidad de deslizamiento del vehículo. De acuerdo al modelo Rado, conforme el neumático pasa de una rodadura libre a una condición de rueda bloqueada el 
rozamiento varía desde cero a un valor máximo que luego disminuye si la rueda sigue estando bloqueada, (Henry 2000). La parte ascendente de la curva, que relaciona la velocidad de deslizamiento con el rozamiento, depende de las propiedades del neumático, mientras que la parte de la curva que se encuentra después del pico depende de la macrotextura del pavimento. (Rado 1994) modela este comportamiento de la siguiente manera:

$$
\mu(S)=\mu_{\text {peak }} . e^{-\left(\frac{\ln \left(\frac{s}{s_{\text {peak }}}\right)}{C}\right)^{2}}
$$

Donde:

$\circ \mu(S)=$ coeficiente de rozamiento para una velocidad de deslizamiento determinada (S)

- $\quad \mu_{\text {peak }}=$ Nivel máximo de fricción

- $\mathrm{S}=$ velocidad de deslizamiento $(\mathrm{km} / \mathrm{h})$

- $\quad \mathrm{S}_{\text {peak }}=$ velocidad de deslizamiento máxima

- $\quad \mathrm{C}=$ factor de forma asociado a la dureza del árido

\subsubsection{Modelos de variación estacional}

(Hill B.J and J.J 1981) afirman que las variaciones estacionales en el rozamiento de la superficie de un pavimento dependen del régimen de lluvias y de las condiciones climáticas locales. Estos investigadores, dentro de un estudio que duró tres años, trataron de determinar los parámetros que se pueden utilizar para predecir la influencia de efectos estacionales y de corto plazo de las medidas de resistencia al deslizamiento con un equipo de rueda bloqueada. El modelo exponencial negativo del estado de Pensilvania fue utilizado como base para predecir la resistencia al deslizamiento. Se encontró que las variaciones a largo plazo, $\left(\mathrm{SN}_{\mathrm{OL}}\right)$, en la resistencia al deslizamiento en superficies asfálticas seguían una relación exponencial, mientras que los pavimentos de hormigón muestran un aumento lineal en la resistencia al deslizamiento con el tiempo. Por lo tanto, el valor de SNo en cualquier momento podría ser expresado como:

$$
\mathrm{SN}_{0}=\mathrm{SN}_{\mathrm{OR}}+\mathrm{SN}_{\mathrm{OL}}+\mathrm{SN}_{\mathrm{OF}}
$$

Donde: 
- $\mathrm{SN}_{0}=$ Resistencia al deslizamiento a velocidad de deslizamiento cero (función de la microtextura)

- $\quad \mathrm{SN}_{\mathrm{OR}}=$ Variación a corto plazo de la resistencia al deslizamiento

- $\mathrm{SN}_{\mathrm{OL}}=$ Variación a largo plazo de la resistencia al deslizamiento

- $\mathrm{SN}_{\mathrm{OF}}=$ Una medida del $\mathrm{SN}_{0}$ independiente de las variaciones a corto y a largo plazo

Para cada uno de esos términos hay distintos modelos, que no se recogen dentro de este documento por no alargarlo en exceso.

\subsubsection{El modelo PIARC y el índice de rozamiento internacional}

Hasta hace relativamente poco tiempo, la resistencia al deslizamiento se ha definido tomando como base un único parámetro que representaba el rozamiento disponible en el contacto rueda-pavimento, para unas condiciones definidas de la superficie y de la velocidad de la rueda en el ensayo. Sin embargo, la razón esencial para medir la resistencia al deslizamiento es estimar el rozamiento disponible para las distintas velocidades que se pueden dar en la práctica, es decir, la resistencia al deslizamiento que se puede esperar mientras el vehículo se mueve desde la rodadura libre a la situación de bloqueo de las ruedas.

En 1992 la World Road Association emprendió un experimento internacional para comparar y armonizar la textura y las mediciones de resistencia al deslizamiento, (Wambold and Henry 1995) el experimento se utilizaron 51 tipos de equipos, para la medida de la resistencia al deslizamiento y la macrotextura, de 14 países diferentes, en un total de 54 sitios localizados entre Bélgica y España. El modelo PIARC, partió del modelo del estado de Pensilvania ya que era menos complejo que el modelo Rado. El modelo desarrollado por la PIARC describe de una forma adecuada la relación entre la velocidad de deslizamiento y el coeficiente de rozamiento a dicha velocidad a través de una función exponencial simple como la que se demuestra a continuación:

$$
F R(S)=F R(60) \cdot e^{\frac{60-S}{S_{p}}}
$$

Donde:

- $\mathrm{FR}(\mathrm{S})$ es el coeficiente de rozamiento a una velocidad S.

- $\mathrm{FR}(60)$ es el valor armonizado del rozamiento en mojado a una velocidad de deslizamiento de $60 \mathrm{~km} / \mathrm{h}$, también conocido como número de fricción IFI. 
- S es la velocidad de deslizamiento

- El valor $S_{p}$ (speed number), define la relación entre el rozamiento medido en mojado y la velocidad de deslizamiento o de rotación libre del neumático. Se calcula mediante la macrotextura, medida por alguno de los procedimientos normalizados, y es una medida de la influencia de la parámetro en el rozamiento.

A una velocidad $S$ de deslizamiento baja, (próxima a cero), la fricción es tanto más elevada cuanto mayor es la microtextura. Por otra parte, $S_{p}$ es una constante del pavimento, tanto más grande cuanto más gruesa sea su macrotextura.

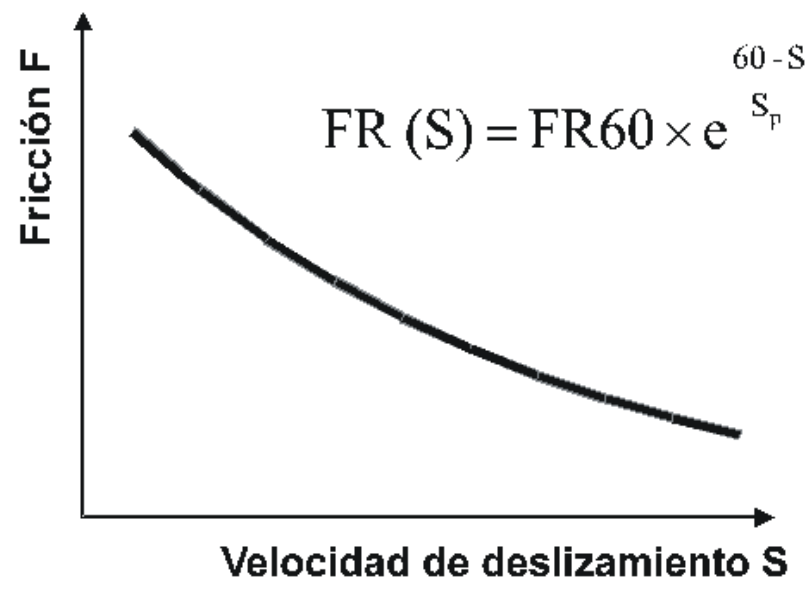

Figura 2.35. Curva fricción-velocidad de deslizamiento

Puede observarse como para un mismo firme el rozamiento o fricción va disminuyendo con la velocidad. Como se ha dicho anteriormente, la constante de velocidad Sp está relacionada linealmente con el resultado de la medición de la macrotextura, (TX), y unas constantes de transformación que se han determinado para cada tipo de dispositivo de medición de dicha macrotextura:

$$
S_{p}=a+b . T X
$$

Donde:

$\mathrm{Sp}=$ constante de velocidad

TX = medida de macrotextura con un dispositivo / método específico

a y $b=$ constantes que dependen del dispositivo de medición de la macrotextura utilizado

El valor de F60 se determina, a partir de un dispositivo de medición de fricción específico, por la siguiente ecuación: 


$$
F R(60)=A+B \cdot F R(S) \cdot e^{\frac{S-60}{S_{P}}}+C T X
$$

Donde:

A, B y C son constantes determinadas para cada dispositivo de medida en el experimento PIARC, que determinó que $C$ es siempre cero para dispositivos de medida del coeficiente de resistencia al deslizamiento que utilizan neumáticos con la banda de rodadura lisa.

Las constantes de transformación desarrolladas por la PIARC permiten la medición del IFI con todos los dispositivos de medición que se incluyeron en el experimento incluyendo el SCRIM, GripTester, ROAR y el DF Tester. La norma ASTM E-1960 (ASTM 2015), reporta los valores de a, b, A y B para los dispositivos participantes.

La medición del rozamiento, a cualquier velocidad de deslizamiento, cuando se combina con mediciones de macrotextura, permite el cálculo del IFI. Una ventaja del IFI es que el valor de $\mathrm{F}(60)$ para un pavimento será el mismo, independientemente de la velocidad a la que se realicen las mediciones con el vehículo de ensayo correspondiente. En cambio una desventaja la encontramos en el hecho de que si se desarrollan equipos de medición nuevos, y distintos a los que se utilizaron en el experimento, sólo se podrán comparar con los que se utilizaron en su día para realizar el experimento.

Mediante el IFI se puede por tanto:

- Considerar la textura en la evaluación de la resistencia al deslizamiento.

- Comparar resultados de distintos equipos.

- Definir valores límite en función de la textura de los pavimentos e incluso de la velocidad esperada en la zona.

El IFI no ha llegado a alcanzar un grado de utilización comparable al IRI por diversas razones (Del Val 2010):

- Sólo es aplicable por puntos, no a un tramo determinado.

- No hay correlaciones con los tramos de concentración de accidentes.

- No es una función matemáticamente estable.

- No ha permitido establecer criterios de clasificación de pavimentos.

EI IFI está siendo discutido en algunos países por la poca validez de los resultados con mezclas drenantes y porque en la comparación entre equipos, se obtienen intervalos de confianza de gran magnitud. Actualmente se está estudiando un 
nuevo índice, el EFI, y se están llevando a cabo nuevos estudios de correlación intentando mejorar el concepto del IFI.

\subsection{Prescripciones españolas en relación con la resistencia al deslizamiento}

El Pliego de Prescripciones Técnicas Generales, en su versión de 1975 (PG-3/75), basaba el control de la resistencia al deslizamiento exclusivamente en los ensayos previos de los áridos de la capa de rodadura, exigiéndole superar un límite del valor del coeficiente de pulimento acelerado mayor o igual que 0,45, en el caso de mezclas en frío o en caliente con tráfico pesado, o de 0,40 , para mezclas con otro tipo de tráfico o para lechadas bituminosas.

La versión actual del Pliego, Orden FOM/2523/2014 (DGC 2015), incluye, además de una exigencia sobre el pulimento acelerado de los áridos, un control basado en la auscultación de la obra terminada.

En la tabla siguiente se indican los valores mínimos del coeficiente de pulimento acelerado que deben tener los áridos que se empleen en pavimentos de lechada bituminosa, mezclas bituminosas en caliente, discontinuas o no, y hormigón vibrado.

Tabla 2.2. Valor mínimo del CPA del árido grueso según la Orden FOM/2523/2014

\begin{tabular}{|c|c|c|c|c|c|c|}
\hline \multirow[b]{2}{*}{ TIPO DE PAVIMENTO } & \multirow{2}{*}{$\begin{array}{l}\text { ART. } \\
\text { PG-3 }\end{array}$} & \multicolumn{5}{|c|}{ CATEGORÍA DE TRÁFICO PESADO } \\
\hline & & TOO & TO & T1 & T2 Y T31 & $\begin{array}{l}\text { T32, T4 Y } \\
\text { ARCENES }\end{array}$ \\
\hline MICROAGLOMERADOS EN FRIO & 540 & - & 56 & 50 & 50 & 44 \\
\hline $\begin{array}{l}\text { MEZCLAS BITUMINOSAS TIPO } \\
\text { HORMIGÓN BITUMINOSO }\end{array}$ & 542 & 56 & 56 & 50 & 50 & 44 \\
\hline $\begin{array}{l}\text { MEZCLAS BITUMINOSAS EN CALIENTE } \\
\text { DISCONTINUAS Y DRENANTES }\end{array}$ & 543 & 56 & 56 & 50 & 50 & 44 \\
\hline PAVIMENTOS DE HORMIGON & 550 & & & 50 & & - \\
\hline
\end{tabular}

En la siguiente tabla se resumen las exigencias de resistencia al deslizamiento, caracterizada por el CRT mínimo medido con el SCRIM según la UNE 412101 IN, (AENOR 2010c), y de macrotextura, medida con el ensayo del círculo de arena según la UNE EN 13036-1, (AENOR 2012a), con independencia de ciertas tolerancias en algunas medidas. Los valores de CRT se refieren a ensayos realizados una vez transcurrido un mes de haber soportado la circulación, para que se haya eliminado al menos parte de la película de ligante que envuelve el árido. 
Los valores prescritos dependen de las características del material utilizado en el pavimento. En el caso del pavimento de hormigón, la adherencia se confía a la textura que proporciona el estriado.

Tabla 2.3. Prescripciones sobre fricción y textura de diferentes pavimentos según la Orden $\mathrm{FOM} / 2523 / 2014$

\begin{tabular}{|c|c|c|c|}
\hline \multicolumn{2}{|c|}{ TIPO DE PAVIMENTO } & $\begin{array}{c}\text { MACROTEXTURA } \\
\text { SUPERFICIAL (mm) }\end{array}$ & $\begin{array}{c}\text { RESISTENCIA AL } \\
\text { DESLIZAMIENTO CRT } \\
\text { MÍNIMO (\%) }\end{array}$ \\
\hline $\begin{array}{c}\text { MEZCLAS BITUMINOSAS TIPO } \\
\text { HORMIGÓN BITUMINOSO }\end{array}$ & AC S Y D & $\geq 0,7$ & 65 \\
\hline $\begin{array}{c}\text { MEZCLAS BITUMINOSAS EN } \\
\text { CALIENTE DISCONTINUAS Y } \\
\text { DRENANTES }\end{array}$ & BBTM B Y PA & $\geq 1,5$ & 60 \\
\cline { 2 - 4 } & BBTM A & $\geq 1,1$ & 65 \\
\hline \multirow{2}{*}{\begin{tabular}{c} 
MICROAGLOMERADOS EN FRÍO \\
\cline { 2 - 4 }
\end{tabular}} & MICROF 11 & $\geq 1,2$ & 65 \\
\cline { 2 - 4 } & MICROF 5 & $\geq 1,0$ & 60 \\
\hline PAVIMENTOS DE HORMIGÓN & & $\geq 0,7$ & 75 \\
\hline
\end{tabular}

Para las mezclas de rodadura contempladas en el artículo 542 de la Orden FOM/2523/2014, el resultado medio del ensayo de macrotextura no deberá resultar inferior a $0,7 \mathrm{~mm}$ y no más de un individuo de la muestra podrá presentar un resultado inferior a dicho valor, en más de un $25 \%$. Si el resultado medio del ensayo de macrotextura resulta inferior al $90 \%$ de dicho valor, se demolerá la capa y se repondrá por una que cumpla o se extenderá una nueva capa por cuenta del contratista si no hubiera problemas de gálibo o sobrecargas. Si está entre el 90 y el $100 \%$, se le aplicará una penalización económica del 10\%.

De la misma forma, el resultado medio de determinación de CRT, no deberá ser inferior a 65 . No más del $5 \%$ de la longitud total medida en cada lote, podrá presentar un resultado individual inferior a dicho valor en más de 5 unidades. Si el resultado medio de CRT resulta inferior, se procederá de la siguiente forma: Si es inferior al $90 \%$, se demolerá la capa y se repondrá por una que cumpla o se extenderá una nueva capa por cuenta del contratista si no hubiera problemas de gálibo o sobrecargas. Si fuera superior al $90 \%$ de dicho valor, se aplicará una penalización económica del 10\%.

Para las mezclas de rodadura contempladas en el artículo 543, (mezclas porosas o discontínuas), el resultado medio del ensayo de macrotextura no deberá resultar inferior a 1,5 mm, (BBTM B o PA) y 1,1 mm, (BBTM A). No más de un individuo de la muestra podrá presentar un resultado inferior a dicho valor, en más de un $25 \%$. 
Si el resultado medio del ensayo de macrotextura resulta inferior al $90 \%$ de dicho valor, se extenderá una nueva capa por cuenta del contratista, en caso de mezclas discontinuas, o se demolerá la capa de rodadura y se extenderá una nueva, en el caso de mezclas drenantes. Si está entre el 90 y el 100\%, se le aplicará una penalización económica del 10\%.

De la misma forma, el resultado medio de determinación de CRT, no deberá ser inferior a 60, (BBTM B y PA), y 65, (BBTM A). No más del 5\% de la longitud total medida en cada lote, podrá presentar un resultado individual inferior a dicho valor en más de 5 unidades. Si el resultado medio de CRT resulta inferior a los valores anteriores, se procederá de la siguiente forma: si es inferior al 95\%, se extenderá una nueva capa por cuenta del contratista, en el caso de mezclas discontinuas, o se demolerá y se extenderá una nueva capa en el caso de mezclas drenantes, y si está entre el 95 y el $100 \%$ de dicho valor, se aplicará una penalización económica del $10 \%$.

Para la gestión de la conservación, en la red estatal española, se hacen campañas periódicas de medida del coeficiente de rozamiento transversal de sus firmes, con lo que pueden detectarse los tramos con valores bajos de resistencia al deslizamiento. Aunque la interpretación de los resultados a veces resulta compleja, por las variaciones de los valores de CRT con las condiciones ambientales (temperatura $\mathrm{y}$, sobre todo, períodos de humedad-sequedad), los tramos con índices CRT inferiores a 35 se corrigen normalmente con la aplicación de lechadas bituminosas antideslizantes o microaglomerados en caliente.

\subsection{Conclusiones del estudio del estado del arte. Motivación de la tesis.}

Con la realización del presente estado del arte, se ha pretendido profundizar en los aspectos que tienen influencia en una de las propiedades superficiales de los pavimentos asfálticos que tienen más influencia en la seguridad de los conductores: la resistencia al deslizamiento.

También se han investigado los distintos procedimientos de ensayo que existen para medir esta propiedad, los modelos que se han desarrollado para predecir cómo puede evolucionar en el tiempo y cuáles son las exigencias que debe cumplir el constructor que coloca las mezclas que van en la capa de rodadura de un firme asfáltico. En el caso concreto de España, pasan por cumplir unos valores concretos de resistencia al pulimento de los áridos gruesos y de macrotextura y de resistencia al rozamiento transversal del pavimento ya colocado. Sin embargo, no se consideran otros aspectos igualmente importantes como son el contenido de ligante de la mezcla, el tipo de árido fino o de ligante utilizados en la fabricación de la 
misma, la climatología o la composición del tráfico, (proporción de vehículos pesados y ligeros).

Por todo lo anterior, el objetivo de la presente investigación va a ser el desarrollo de un nuevo procedimiento de ensayo, basado en el utilizado actualmente para determinar el coeficiente de pulimento acelerado de áridos, que permita integrar en una única prueba las variables más importantes que influyen en el valor del coeficiente de resistencia al deslizamiento del pavimento: granulometría y coeficiente de pulimento de los áridos, macrotextura de la mezcla y características del ligante empleado en su fabricación. De esta manera se podrá predecir en laboratorio, durante la etapa de diseño de la mezcla, cuál va ser la evolución de su resistencia al deslizamiento y se podrá elegir, entre varias opciones posibles, qué mezcla bituminosa es la que mejor se comporta frente a deslizamiento a un coste adecuado. 


\section{OBJETIVOS}

\subsection{Introducción}

En el capítulo anterior se ha puesto de manifiesto los problemas que existen actualmente para garantizar con seguridad el cumplimiento de los valores mínimos de resistencia al deslizamiento exigidos por la normativa técnica en vigor de capa país sobre mezclas colocadas en los pavimentos de las carreteras, aunque dichas mezclas se hayan fabricado y puesto en obra siguiendo de forma escrupulosa lo que dicha normativa exige.

Las administraciones de carreteras confían en que utilizando áridos poco pulimentables en la fabricación de unas mezclas de granulometría concreta, con los procedimientos de ejecución actualmente empleados, dichos valores mínimos se cumplen. La experiencia ha demostrado en muchas ocasiones que esto no siempre es así dado que, en la resistencia al deslizamiento, intervienen otros muchos factores.

Debido a ello, se están probando a nivel internacional diversos prototipos de ensayo entre los que destacan la máquina Wehner Schulze, de muy elevado coste, y el prototipo NCAT, en fase de desarrollo y todavía no normalizado, que lo que buscan es conseguir eliminar la incertidumbre que existe actualmente en este sentido.

Resulta pues necesario desarrollar algún procedimiento de ensayo, de no muy alto coste y de sencilla ejecución, basado en la utilización de equipos de uso común, que sea capaz de predecir en laboratorio, qué valores de resistencia al deslizamiento se van a conseguir cuando las mezclas se colocan en la capa de rodadura de una carretera y qué evolución va a tener esta propiedad en el tiempo. Este procedimiento debe ser capaz de tener en cuenta la mayoría de los factores que influyen en la resistencia al deslizamiento de una carretera y su sencillez de ejecución debe permitir que el personal de laboratorio no requiera de una formación muy diferente a la que tienen en estos momentos, lo que también facilitará su rápida normalización e introducción en el mercado.

\subsection{Objetivo principal}

En base a todo lo expuesto anteriormente, el objetivo principal de la presente investigación va a ser el desarrollar un nuevo procedimiento de ensayo de bajo coste y fácil estandarización, que sea capaz de predecir en laboratorio cuál va a ser la evolución del valor de la resistencia al deslizamiento obtenido en mezclas bituminosas. 
El desarrollo de un ensayo de este tipo podría ser utilizado, en la etapa de diseño de mezclas para capas de rodadura de carretera, como una importante ayuda para terminar de eliminar las incertidumbres que actualmente existen sobre el cumplimiento de esta propiedad. También, para poder elegir entre varias soluciones cuál es la que se va a tener en el tiempo un mejor comportamiento frente al deslizamiento.

La consecución de este objetivo principal se concreta en el logro de una serie de objetivos secundarios que marcarán el desarrollo y la metodología a seguir durante la investigación.

\subsection{Objetivos secundarios}

El objetivo principal de la presente tesis se concreta en los siguientes objetivos secundarios:

- Diseño del dispositivo de ensayo con el que poder pulir probetas de mezcla.

Definición del conjunto de adaptaciones que se van a realizar en la máquina utilizada para determinación del coeficiente de pulimento de los áridos, (CPA), descrita en la UNE-EN 1097-8, (Ensayos para determinar las propiedades mecánicas y físicas de los áridos. Parte 8: Determinación del coeficiente de pulimento acelerado), con el objeto de que pueda pulir probetas de mezcla bituminosa.

- Definición de las características del método de ensayo.

Definición del procedimiento de fabricación elegido para conseguir reproducir en las probetas de mezcla las mismas características mecánicas, volumétricas y de textura que se consiguen en las mezclas que se colocan en una carretera, de manera que el pulimento que se produce en el dispositivo de ensayo se realice sobre mezclas que sean representativas de lo que luego se va a pulimentar en la carretera por la acción del tráfico rodado. Dicho procedimiento de fabricación debe permitir el conseguir probetas lo más homogéneas posibles de forma que se pueda conseguir una correcta repetibilidad en el ensayo.

Definición de las características geométricas de dichas probetas, de manera que se facilite su manipulación y fabricación, sin necesidad de sobreconsumos de material que aumentarían el coste del ensayo.

Definición de las condiciones en que se debe realizar el pulimento de las probetas de forma que se consiga reproducir en un periodo de tiempo lo 
suficientemente corto, el proceso de pulimento que posteriormente van a tener las mezclas cuando se someten a la acción del tráfico rodado.

Por último, definición del proceso de toma de datos durante el ensayo, para una correcta evaluación de la evolución de la resistencia al deslizamiento en mezclas bituminosas.

- Validación del método de ensayo desarrollado.

Evaluación de la repetibilidad del ensayo y de la variación de los resultados del mismo en función de los materiales empleados y de las condiciones en que el ensayo se lleva a cabo, de manera que se pueda garantizar su empleo como método de ensayo durante la fase de diseño de una mezcla bituminosa.

La evaluación de la reproducibilidad del ensayo, siendo necesaria, no puede ser objeto de la presente investigación dado que, para ello, se necesitaría otro equipo similar al desarrollado en la presente tesis que fuese utilizado por otro operador y en otro laboratorio distinto. 


\section{METODOLOGÍA}

\subsection{Introducción}

En este capítulo se expone la metodología que se ha seguido durante la investigación realizada con la finalidad de alcanzar los objetivos expuestos en el capítulo anterior.

En la primera fase del estudio llevado a cabo, se describen las modificaciones realizadas sobre la máquina que actualmente se emplea para el pulimento de probetas de árido con el objeto de que pueda pulir probetas de mezcla. En la segunda se define el procedimiento de fabricación de las probetas y la forma en que estas se deben pulimentar y se indica el procedimiento a seguir para la toma de datos a lo largo del ensayo y los criterios de rechazo que se consideran en el mismo. En la última parte se evalúa el método de ensayo desarrollado, valorando si cumple con los objetivos que se propusieron en el capítulo 3 de la tesis. Por este motivo se comprobará la repetibilidad del ensayo desarrollado, así como la variación que se obtiene en los resultados conseguidos en función de los materiales y condiciones de ensayo que se empleen.

\subsection{Diseño del dispositivo de ensayo}

\subsubsection{Condicionantes de diseño}

En este apartado se definen las condiciones que debe ofrecer el prototipo que se construya para pulir probetas curvas de mezclas.

Como se ha comentado anteriormente, desde un primer momento se ha planteado el desarrollo de un procedimiento de ensayo que fuese lo más sencillo y económico posible, en el que el personal de laboratorio no requiriese de una formación muy diferente de la que ya tuviera, porque se basase en equipos de uso común y así facilitar la normalización y la generalización de su utilización por otros laboratorios de control de calidad, universidades y centro tecnológicos especializados en el diseño y control de calidad de mezclas bituminosas.

El proceso de pulimento debe reproducir con fiabilidad, de forma controlada y en un razonable periodo de tiempo, el desgaste por abrasión que sufren las mezclas bituminosas en capa de rodadura cuando son sometidas a la acción del tráfico rodado.

El dispositivo debe poder pulir probetas de las mezclas habitualmente empleadas en la construcción de capas de rodadura de carreteras y autovías, ya sean éstas del tipo hormigón asfáltico, discontinuas o drenantes, que son los tipos de 
mezclas más habitualmente empleados en la rodadura de carreteras con alta intensidad de tráfico.

Por estos motivos se ha partido de una máquina ampliamente conocida como la utilizada para la determinación del coeficiente de pulimento acelerado de los áridos, (CPA), descrita en la UNE-EN 1097-8, (Ensayos para determinar las propiedades mecánicas y físicas de los áridos. Parte 8: Determinación del coeficiente de pulimento acelerado), (figura 4.1).

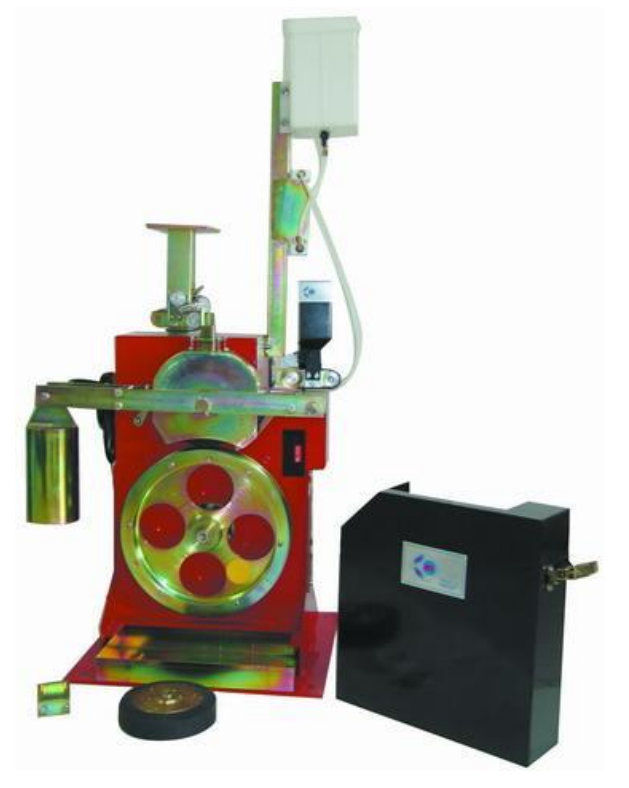

Figura 4. 1. Máquina de pulimento de áridos

Definido el procedimiento para pulir probetas de mezcla, el sistema para medir el pulimento de las mismas será el mismo que el utilizado en la mencionada norma para medir el pulimento de los áridos, esto es, mediante el péndulo TRRL (figura 4.2).

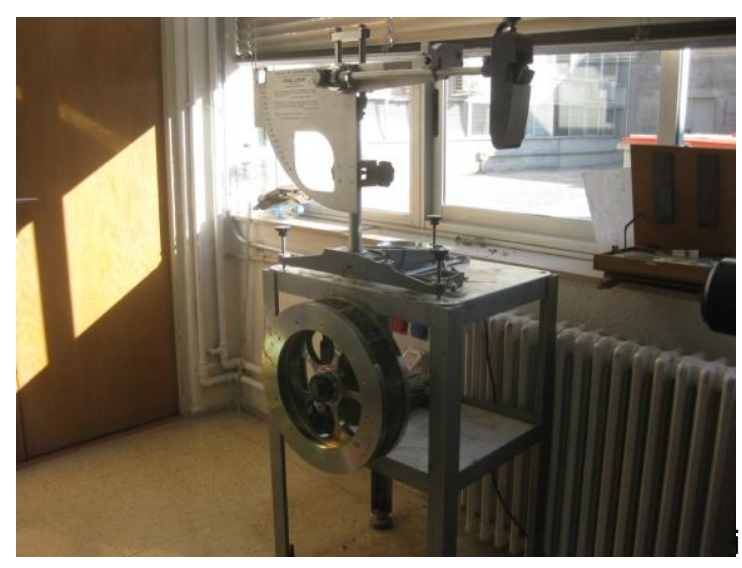

Figura 4. 2. Péndulo de fricción TRRL dispuesto para medir la resistencia al deslizamiento de probetas de mezcla 


\subsubsection{Diseño del prototipo y geometría de las nuevas probetas}

En base a las consideraciones establecidas en el apartado anterior, se llevó a cabo el diseño del dispositivo de ensayo desarrollado en esta investigación, tomando como base la máquina para pulimentar áridos de acuerdo a la UNE-EN 1097-8.

Para la determinación del coeficiente de pulimento acelerado de los áridos, (CPA), se colocan éstos encajados en un molde con una cierta curvatura y se cementan mediante un mortero de resina, (figura 4.3).

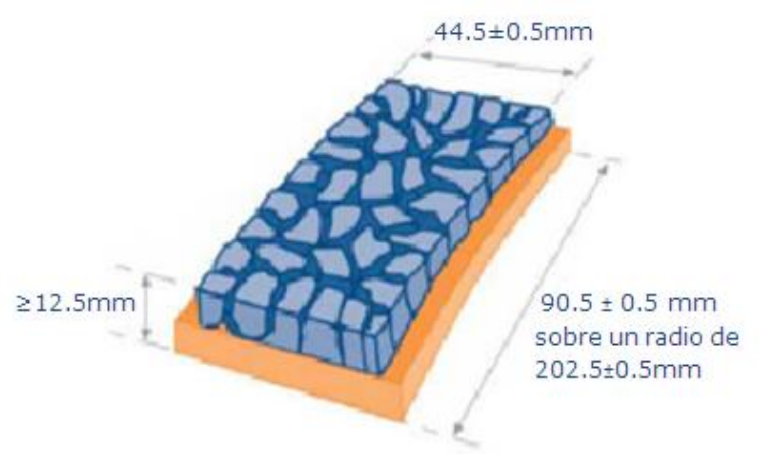

Figura 4. 3. Probeta de áridos para ensayo CPA.

Catorce probetas de $90,5 \mathrm{~mm}$ de largo, por $44,5 \mathrm{~mm}$ de ancho y un espesor de $12,5 \mathrm{~mm}$, dos de un árido patrón o de referencia y otras 12 correspondientes a 6 tipos de árido distintos se colocan en una rueda porta-muestras y se someten a ciclos de pulimento mediante la acción de una rueda cargada, agua y dos abrasivos que se utilizan secuencialmente durante tres horas cada uno. Después se mide la resistencia al deslizamiento con el péndulo británico TRRL para obtener el valor del CPA. Este ensayo consiste en esencia en medir la pérdida de energía de un péndulo de características conocidas, provisto en su extremo de una zapata de goma, cuando la arista de la zapata roza, con una presión determinada, sobre la superficie que se ensaya en una longitud fija. Esta pérdida de energía se relaciona con el coeficiente de fricción, o de resistencia al deslizamiento, mediante una escala en función del ángulo suplementario de la oscilación del péndulo.

Como la velocidad de deslizamiento es baja, ya que viene a ser de unos $10 \mathrm{~km} / \mathrm{h}$, el resultado viene influido, sobre todo, por la microtextura del pavimento y es una manera indirecta de caracterizarla. En la figura 4.2 se puede ver una imagen del péndulo TRRL utilizado en el presente trabajo para medir el coeficiente de pulimento acelerado de las mezclas estudiadas. 
Con el fin de poder determinar el coeficiente de pulimento acelerado de mezclas bituminosas, en lugar del de áridos, y dado que no es posible fabricar probetas de mezcla bituminosa con estas dimensiones, será preciso reconfigurar el equipo de ensayo original. Habrá que realizar modificaciones a la rueda porta-muestras, a sus placas laterales de sujeción y al eje que la soporta y dotar de mayor potencia al motor. El resto de las partes del equipo de ensayo CPA no será necesario modificarlas.

La forma y dimensiones de las probetas de mezcla a ensayar no deben presentar dificultades en su fabricación, para no tener que emplear excesivo tiempo en su elaboración y se tengan garantías de que se pueden repetir con características homogéneas.

Las dimensiones de las probetas deben permitir una buena trabajabilidad sin incurrir en tamaños demasiado grandes que incrementen el consumo de material a utilizar, lo que daría lugar a un incremento del precio del ensayo. Su tamaño debe ser tal que obligue a tener que realizar modificaciones mínimas en el equipo empleado actualmente para pulir áridos.

Las probetas de mezcla se deberán fabricar con forma de dovela y con la misma curvatura externa que la conseguida en las de los áridos, para que el pulimento se produzca de una forma similar. Estas probetas tendrán un ancho suficiente para poder medir en todo momento la resistencia al deslizamiento con el péndulo TRRL. Teniendo en cuenta que el ancho de las probetas de árido en el ensayo CPA es de $44,5 \mathrm{~mm}$, diseñaremos probetas de mezcla con un ancho real de 80 $\mathrm{mm}$ que se quedarán en $44 \mathrm{~mm}$ efectivos al quedar sujetas a ambos lados por un sistema de sujeción continuo, tipo uña, de $18 \mathrm{~mm}$ de ancho que evitará que las probetas de muevan durante el pulimento de las mismas.

En cuanto al espesor de las probetas será el suficiente como para se pueda asegurar densidades y porcentajes de huecos similares a los que se deben alcanzar en obra.

Las mezclas que se quieren ensayar con el dispositivo de ensayo a desarrollar en la presente investigación son fundamentalmente las empleadas en capa de rodadura de carreteras con tráficos elevados, es decir, mezclas de tipo discontinuo y drenantes con tamaño máximo de árido de 8, 11,2 y $16 \mathrm{~mm}$. Con un espesor de probeta de $30 \mathrm{~mm}$ se podrán conseguir sin problemas densidades y huecos con los dos tamaños más bajos y, con gran probabilidad, en las de 
tamaño máximo de $16 \mathrm{~mm}$, motivo por el que éste será el espesor de probeta elegido, (figura 4.4).

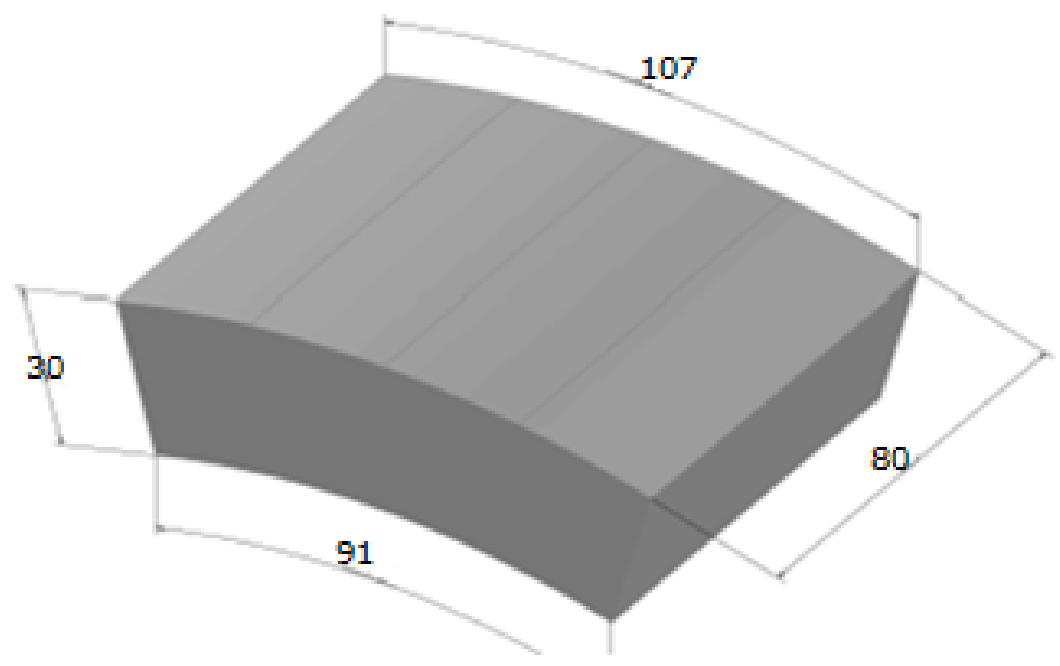

Figura 4. 4: Probeta de mezcla a pulimentar en el nuevo ensayo.

La nueva rueda porta-muestras, (figuras 4.5 y 4.6), pasa a tener un diámetro interior de $348 \mathrm{~mm}$ de forma que el diámetro externo, rueda más probeta de mezcla, sea el mismo que en la máquina original. Con esta configuración se pueden colocar 12 probetas de mezcla de las dimensiones mencionadas en cada rueda.
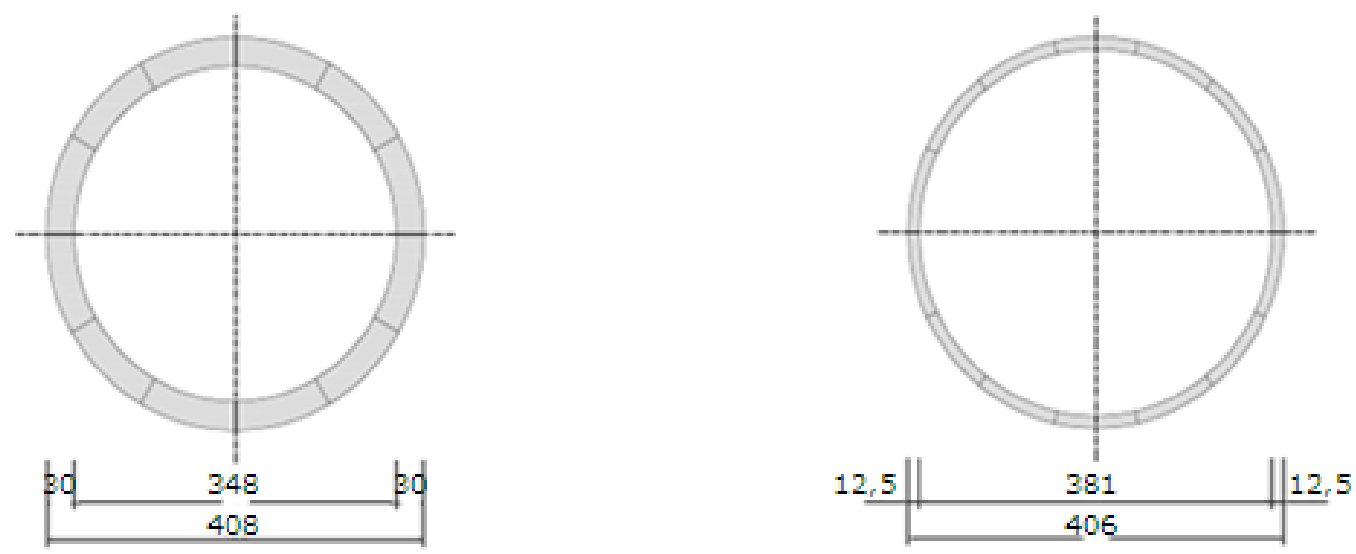

Figura 4. 5 Esquema de la nueva rueda porta-muestras (izda.) y de la que se utiliza para el ensayo CPA (dcha.) 


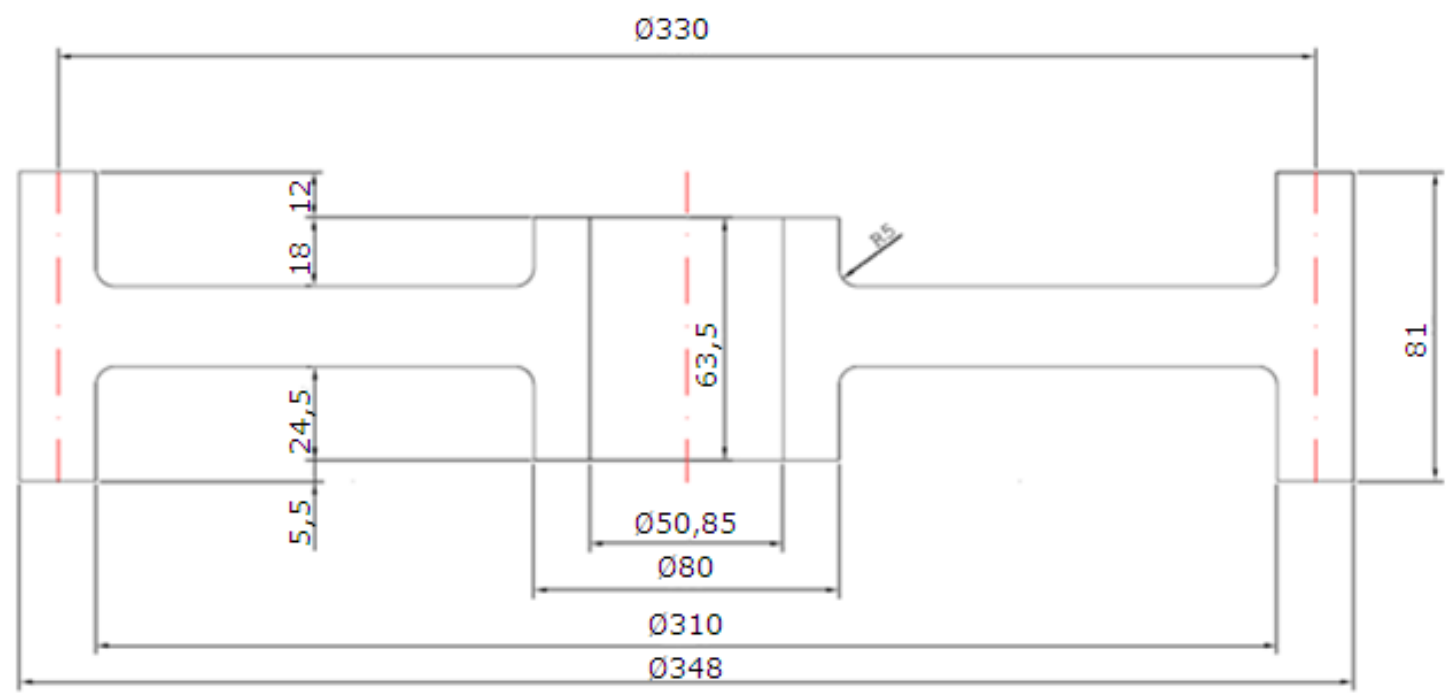

Figura 4. 6 Plano de planta de la nueva rueda porta-probetas.

Los elementos empleados para la fabricación de las probetas han de ser equipos de uso común en laboratorios de carreteras, de manera que no haya que incurrir en ningún tipo de inversión específica.

Los moldes en los que se fabricarán las probetas serán lo suficientemente robustos como para no sufrir deformaciones durante el proceso de fabricación de las probetas, lo suficientemente gruesos, para poder conservar el calor durante más tiempo y desmontables de forma que permitan extraer la muestra sin dañarla. En la figura 4.7 se incluyen los planos del molde y de los útiles de compactación que se han elaborado para la construcción de los mismos. 

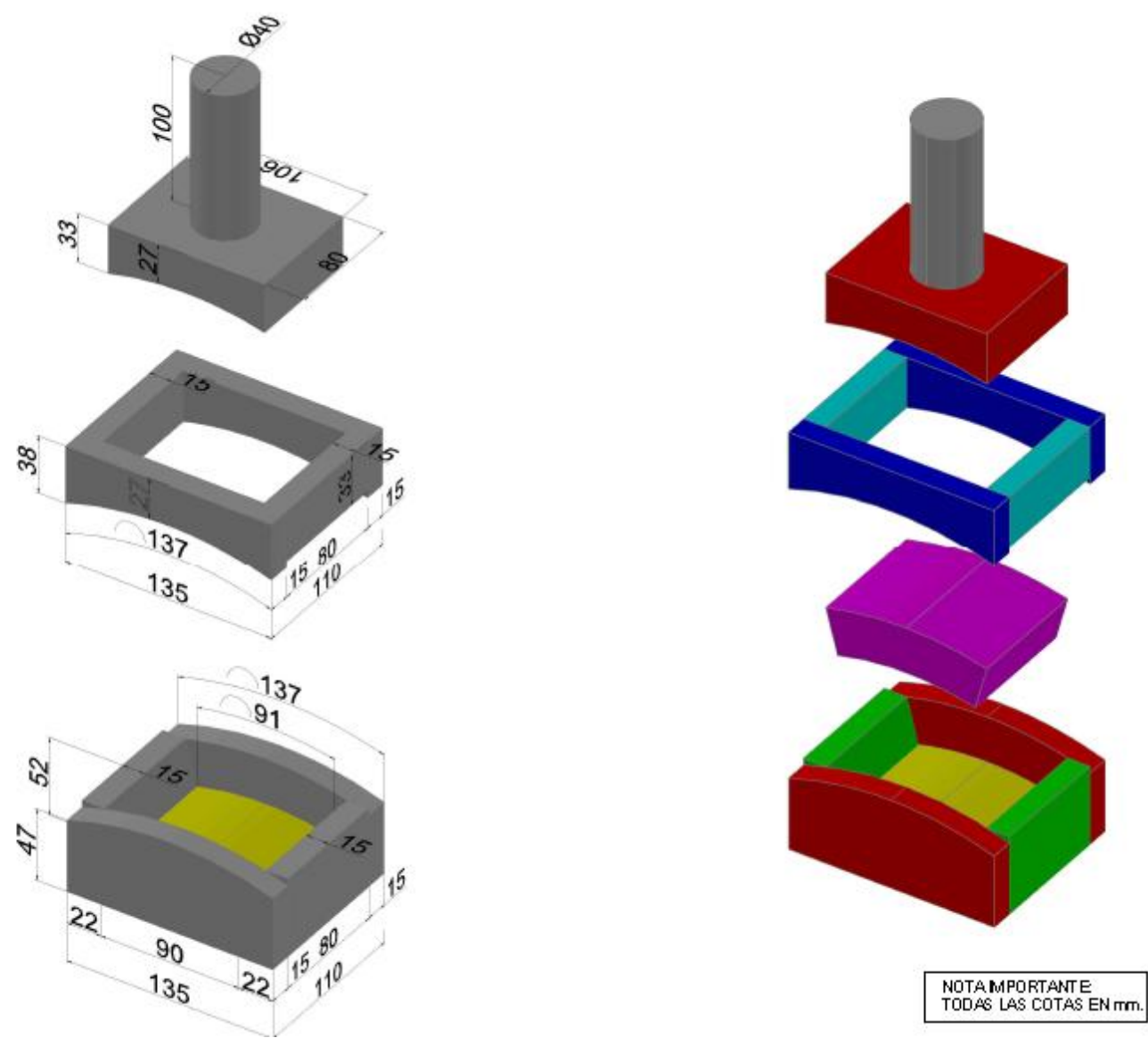

Figura 4. 7. Plano del molde, collarín y útil de compactación.

En la figura 4.8 se muestran las piezas que integran el molde fabricado para construir las probetas de mezcla y en la figura 4.9 puede verse cómo queda el molde una vez montado.

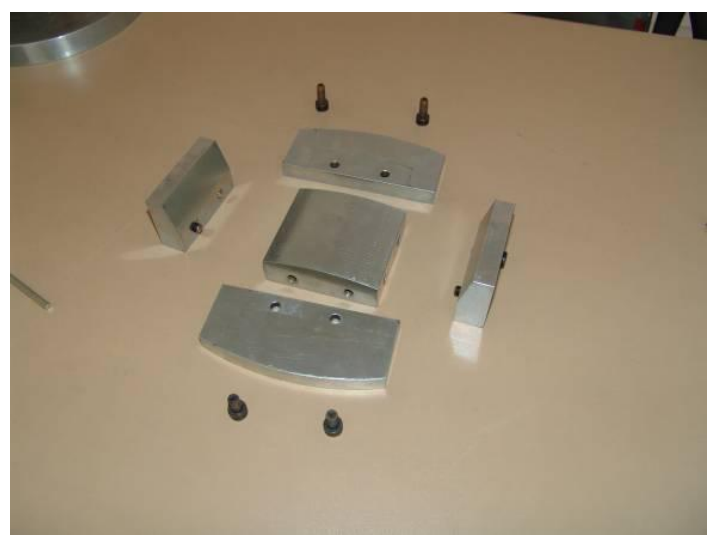

Figura 4. 8. Piezas que componen el molde desmontado.

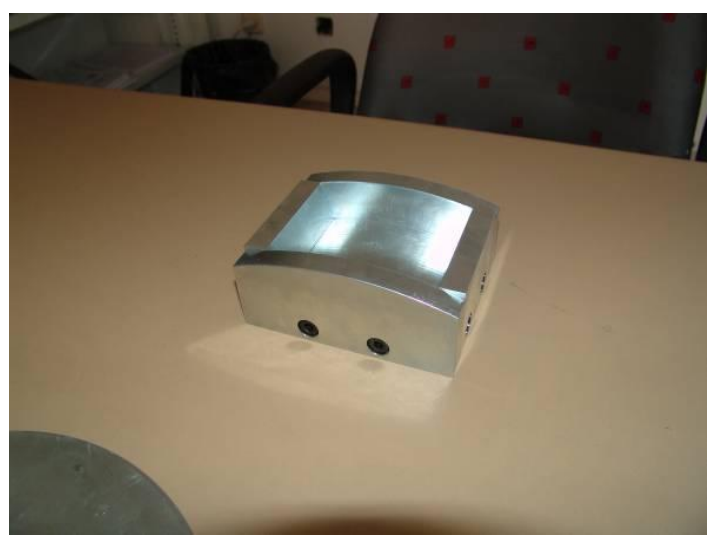

Figura 4.9. Molde para fabricar probetas montado

Se ha diseñado y construido un plato centrador que se utiliza para el correcto posicionamiento del molde en la prensa durante el proceso de compactación (figuras 4.10 y 4.11 ) 


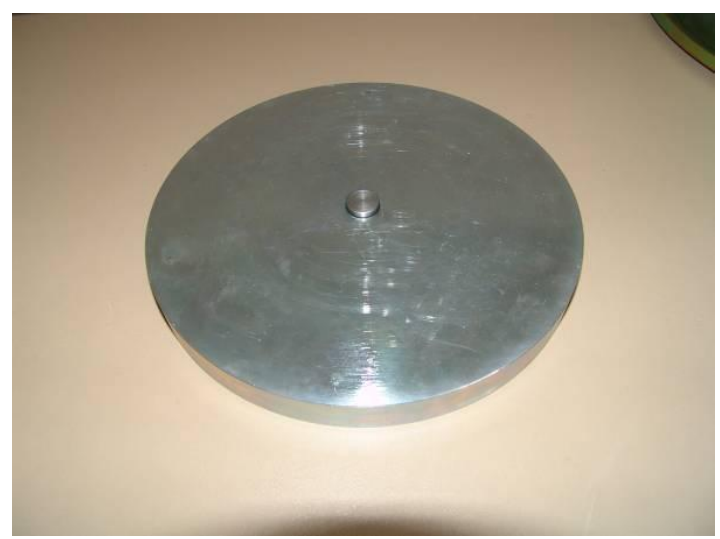

Figura 4. 10. Detalle del plato centrador

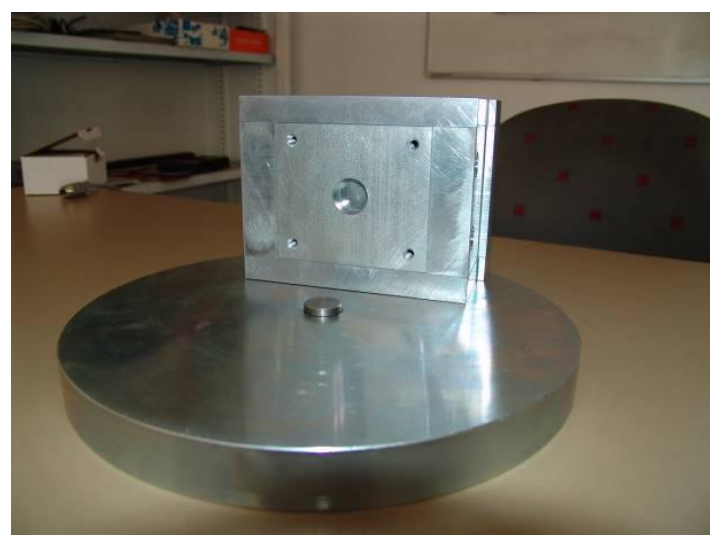

Figura 4. 11. Detalle del plato centrador

Además se ha diseñado y construido un collarín que permite añadir el material a compactar y después aplicar las cargas sin que hubiese pérdida de material por desplazamiento de la mezcla fuera del molde, (figuras 4.12 y 4.13 ).

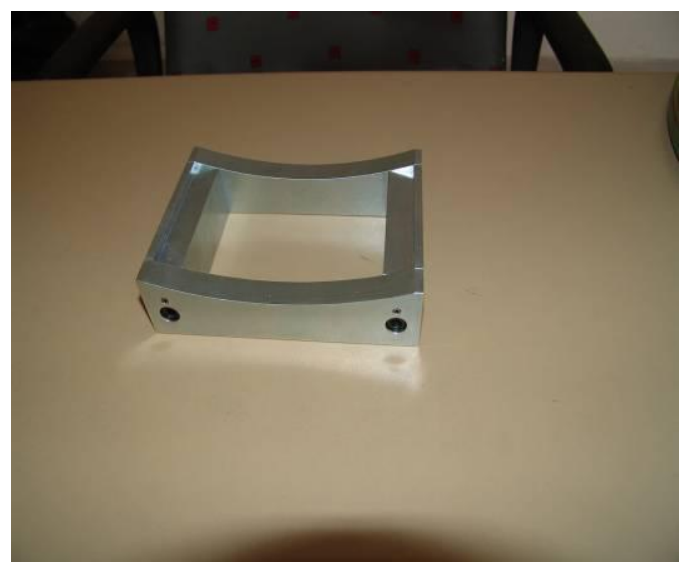

Figura 4.12. Collarín adicional

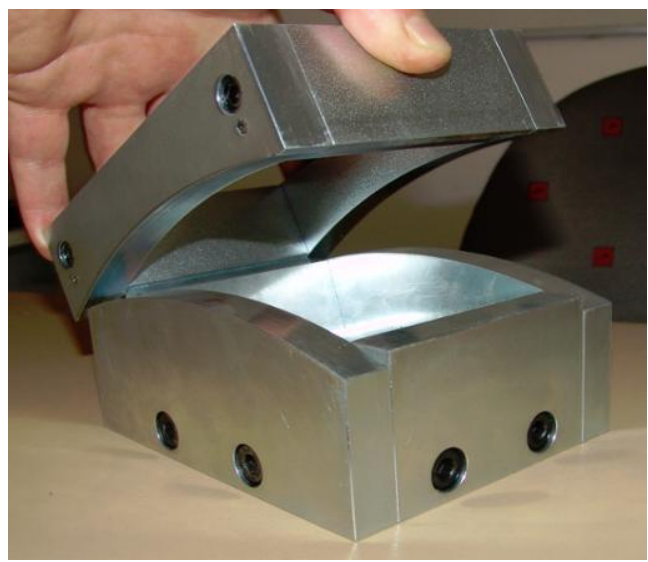

Figura 4.13. Detalle del molde para fabricación de probetas con collarín

Por último en las figuras $4.14,4.15$ y 4.16 se muestra el útil de compactación montado y desmontado que se ha utilizado para compactar las probetas de mezcla.

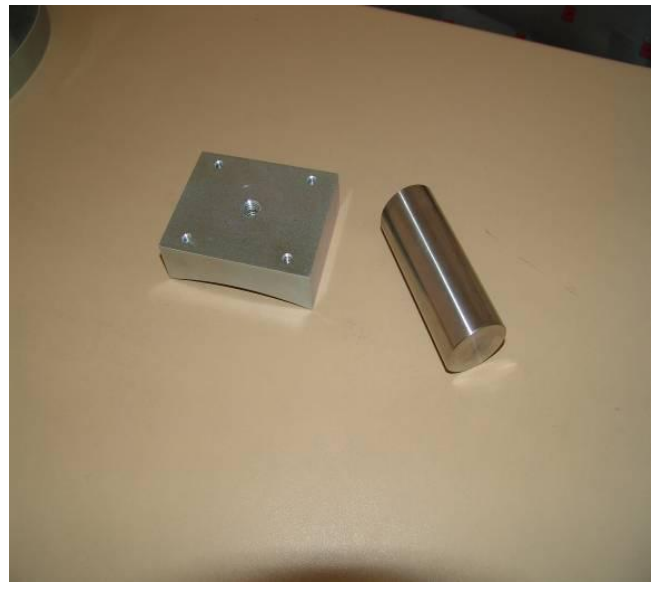

Figura 4.14. Útil de compactación desmontado

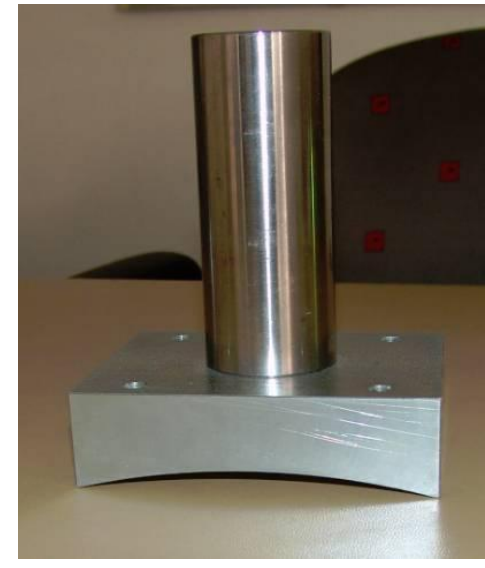

Figura 4.15. Útil de compactación montado 


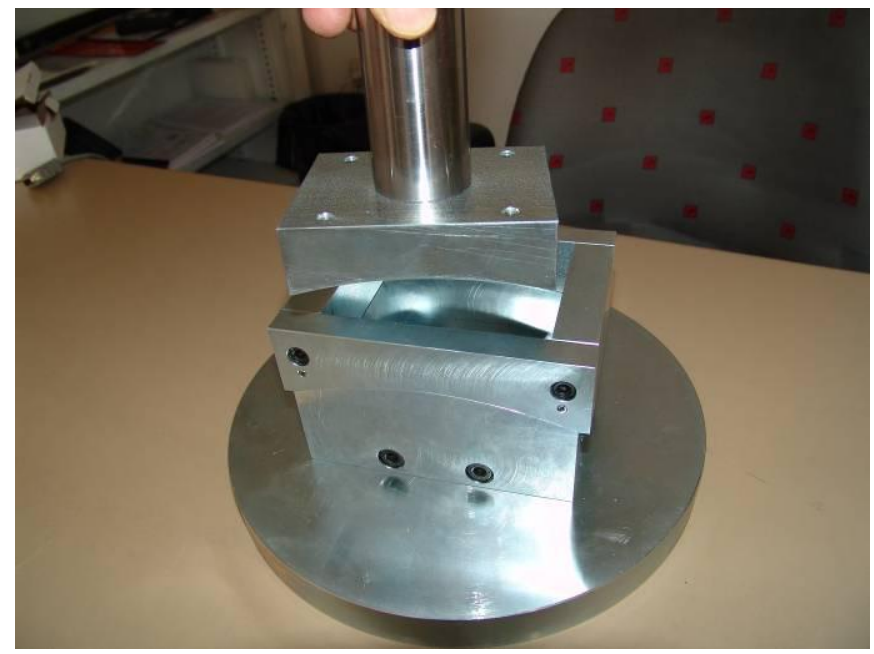

Figura 4.16. Plato centrador con molde, collarín y útil de compactación

\subsection{Definición de las características de ensayo}

\subsubsection{Condiciones de ensayo}

Los materiales a emplear durante el ensayo deben de cumplir unas condiciones de homogeneidad que permitan garantizar una evaluación fiable de su comportamiento frente al fenómeno de la resistencia al deslizamiento. Es conveniente que el conjunto de probetas fabricadas para la ejecución de un mismo ensayo provengan del mismo acopio de áridos y en su fabricación se emplee una misma partida de ligante.

Las condiciones del ensayo son las mismas que las que se describen en la norma para la determinación del coeficiente de pulimento acelerado de los áridos, (UNE-EN 1097-8).

La dureza y resiliencia del patín de caucho del péndulo TRRL varía con la temperatura por lo que los equipos y patines del ensayo de fricción se mantendrán en una sala de temperatura controlada a $20 \pm 2{ }^{\circ} \mathrm{C}$ durante al menos 120 min antes de comenzar el ensayo.

También varían las propiedades del caucho de las ruedas que se usan para producir el pulimento de las probetas de mezcla, por lo que el ensayo de pulimento se llevará a cabo a una temperatura ambiente de $20 \pm 5{ }^{\circ} \mathrm{C}$.

Las probetas de mezcla se disponen sobre la rueda porta-muestras formando un banda continua con un diámetro de $406 \pm 3 \mathrm{~mm}$, para que la rueda de caucho que produce el pulimento pueda rodar libremente sin chocar ni patinar sobre las probetas de mezcla. Si fuese necesario, los huecos que pudieran quedar entre probetas de mezcla consecutivas, o entre las probetas de mezcla y la rueda porta- 
muestras, se rellenarán con materiales adecuados de forma que se eviten escalones entre una probeta de mezcla y otra que pudieran dar lugar a un pulimento no uniforme o a un posible punto por donde la probetas pudieran deteriorarse, sin que el ensayo pudiera darse por válido.

Al igual que en la UNE-EN 1097-8, la rueda porta-probetas o porta-muestras girará a un velocidad de $320 \pm 5$ r.p.m y sobre la misma apoyará una rueda de caucho de $200 \pm 3 \mathrm{~mm}$ de diámetro, con un ancho de $38 \pm 2 \mathrm{~mm}$ y con una dureza inicial de $69 \pm 3$ IRHD. Esta rueda aplicará sobre las probetas de mezcla una fuerza normal de $725 \pm 10 \mathrm{~N}$ debido a la acción de un peso situado en el extremo de una palanca, que actúa empujando la rueda de caucho sobre las probetas de mezcla. Se empleará un mecanismo de alimentación para asegurar un caudal de esmeril grueso igual al utilizado para pulir áridos de $27 \pm 7 \mathrm{~g} / \mathrm{min}$ con agua durante $180 \pm 1 \mathrm{~min}$. El caudal de agua deberá ser suficiente para hacer llegar el esmeril a la rueda, siendo en condiciones normales, el mismo que el caudal del grano de esmeril.

A diferencia que en la UNE-EN 1097-8, donde el ensayo se interrumpe a las 3 horas para limpiar la rueda porta-muestras y el equipo de pulimento y eliminar cualquier resto de grano de esmeril, en el ensayo de pulimento de probetas de mezcla se interrumpirá la prueba cada $60 \pm 5 \mathrm{~min}$, momento en el que se desmonta la rueda porta-muestras para limpiar el exceso de grano de esmeril que se haya acumulado en las probetas o en la máquina y para tomar medidas con el péndulo TRRL. La razón de tomar medidas con una frecuencia horaria es la de poder monitorizar la evolución de todo el proceso de pulimento de la mezcla desde un principio.

Al igual que en la UNE-EN 1097-8, a los 180 minutos, se inicia el pulimento utilizando otra rueda de caucho distinta a la anterior, pero de las mismas características, y sustituyendo el grano de esmeril, por polvo de esmeril de granulometría más fina, (el mismo que se utiliza para pulir áridos en la UNE-EN 1097-8). El caudal de alimentación del polvo será de $3 \pm 1 \mathrm{~g} / \mathrm{min}$, acompañado de agua a un caudal del doble del ritmo de alimentación del grano de esmeril.

Nuevamente la rueda porta-muestras se desmonta cada $60 \pm 5$ min, para tomar medidas con el péndulo TRRL y para limpiar los excesos de polvo de esmeril que se hayan podido acumular en las probetas de mezcla o en la máquina.

\subsubsection{Toma de datos. Criterio de rechazo.}

Cuanta más información se tenga de cada ensayo, más completo podrá ser el análisis sobre el comportamiento de la mezcla frente al fenómeno de resistencia al deslizamiento. Así, será necesario llevar a cabo una correcta toma de datos que 
permita poder representar de una forma adecuada el comportamiento de una mezcla frente a la resistencia al deslizamiento.

Para que la adquisición de datos sea efectiva, es necesario tomar un número mínimo de datos en cada ciclo de pulimento, tanto durante la fase de pulimento con esmeril grueso como en la fase de pulimento con polvo de esmeril. Como se ha comentado, un buen rango de medidas sería tomar un valor del coeficiente de pulimento medido con el péndulo TRRL cada 60 minutos. Intervalos de tiempo menores alargarían en exceso la duración del ensayo y no aportarían gran valor añadido para la determinación de la evolución de la resistencia al deslizamiento en el tiempo.

La toma de datos con el péndulo TRRL se hará según lo descrito en la UNE-EN 1097-8. El patín del péndulo TRRL se coloca de modo que recorra las probetas de mezcla en un sentido opuesto al que tenían durante la rotación en la rueda portaprobetas.

En cada toma de datos con el péndulo se ajusta el brazo de éste de modo que cuando recorra la probeta de mezcla el patín en todo en su ancho esté en contacto una longitud de $76 \pm 1 \mathrm{~mm}$.

Se humedecerán las superficies de la probeta y del patín de caucho con abundante agua limpia en cada medida.

Para la determinación del coeficiente de resistencia al deslizamiento de cada probeta cada hora, se tomarán cinco datos con el péndulo TRRL, humedeciendo el patín cada vez. Se anota la media de las tres últimas lecturas redondeada a la décima, repitiendo el procedimiento con cada probeta de mezcla tras cada ciclo de pulimento.

Es necesario establecer un criterio de fin de ensayo a partir del cual se determine el final del proceso de pulimento de una mezcla. En nuestro caso, el ensayo se dará por finalizado después de haber sido pulidas las probetas de mezcla el tiempo necesario como para que no se aprecien cambios en la resistencia al deslizamiento, ( 3 horas con el grano de esmeril y el tiempo hasta fin de pulimento con el polvo de esmeril).

Una vez finalizado el pulimento de una rueda de 10 probetas de 5 mezclas distintas, más dos probetas de árido de referencia de las mismas dimensiones que las probetas de mezcla, se volverá repetir el proceso con otra rueda formada por 
las 5 mismas mezclas y árido de referencia, que se pulirán con el mismo procedimiento descrito.

Finalmente es necesario establecer un criterio de rechazo que nos indique que el ensayo se ha realizado de forma incorrecta. Como criterio de rechazo seguiremos el que marca la UNE-EN 1097-8, según el cual, el ensayo no se dará por bueno si los resultados medios de resistencia al deslizamiento de dos probetas de mezcla de una rueda a 6 horas difieren en más de 5 puntos de los obtenidos en la otra rueda para la misma mezcla. Tampoco si uno de los valores medios de resistencia al deslizamiento a 6 horas de las probetas del árido de referencia difieren en más de 3 unidades del valor de CPA calculado para dicho árido de referencia.

\subsection{Medida del coeficiente de resistencia al deslizamiento sobre mezclas bituminosas.}

Una vez definidas las modificaciones a introducir en el equipo para pulir probetas de mezcla, la forma de éstas probetas y su procedimiento de compactación, la forma en que deben pulirse las mismas y la manera en que debe medirse dicho pulimento, hay que definir el tratamiento que se va a dar a los datos obtenidos para poder caracterizar el comportamiento de una mezcla frente al deslizamiento.

Como hemos comentado anteriormente mediante el péndulo TRRL se medirá con una frecuencia horaria el pulimento al que se van a ver sometidas las mezclas a ensayar. Los valores obtenidos se representarán en una gráfica, donde la ordenada corresponderá a los valores de resistencia al deslizamiento medidos con el péndulo TRRL, (media de los tres últimos valores de 5 mediciones que se hagan en cada intervalo temporal y por tipo de mezcla), y la abcisa al tiempo en que se efectúa cada medición. El primer valor corresponderá al de la resistencia al deslizamiento antes de empezar a pulir las probetas de mezcla, (tiempo $\mathrm{t}=0$ ). El último valor, será el que indique el final del ensayo.

La norma UNE-EN 1097-8 calcula el CPA de un árido con la ecuación:

$$
\mathrm{CPA}=\mathrm{S}+52,5-\mathrm{C}:
$$

Donde:

$S$ es el valor medio de la resistencia al deslizamiento, medido con el péndulo TRRL a las 6 horas de pulimento, tres con grano de esmeril y tres más con polvo de esmeril, de las cuatro probetas de árido ensayadas.

52,5 es el valor medio de las mediciones realizadas con el péndulo TRRL del árido de referencia utilizado para el ensayo CPA. 
C es el valor medio de resistencia al deslizamiento, medido con el péndulo TRRL a las 6 horas, de las cuatro probetas de árido de referencia pulimentadas en el ensayo.

De la misma manera que se hace en el ensayo UNE-EN 1097-8 se caracterizará el comportamiento de una mezcla frente al deslizamiento con un parámetro al que denominaremos coeficiente de pulimento acelerado de la mezcla en el tiempo $t$, $\left(\mathrm{CPM}_{\mathrm{t}}\right)$, que se calculará de acuerdo a la siguiente ecuación:

$$
\mathrm{CPM}_{\mathrm{t}}=\mathrm{S}_{\mathrm{t}}+\mathrm{CPA}_{\mathrm{t}}-\mathrm{C}_{\mathrm{t}}
$$

Donde:

$\mathrm{CPM}_{\mathrm{t}}$ es el coeficiente de pulimento acelerado de la mezcla estudiada en el tiempo $\mathrm{t}$.

$\mathrm{S}_{\mathrm{t}}$ es el valor medio en el tiempo $\mathrm{t}$ de resistencia al deslizamiento, medido con el péndulo TRRL, de las cuatro probetas de mezcla pulimentadas, (dos en cada una de las dos ruedas porta-probetas ensayadas).

$\mathrm{CPA}_{\mathrm{t}}$ es valor estimado del coeficiente de pulimento acelerado del árido de referencia utilizado en el tiempo t. El árido de referencia utilizado en el presente trabajo ha sido una andesita que ha dado un valor medio medido con el péndulo TRRL de 57 a 6 horas y de 56 a las 12 horas de pulimento ( 3 con grano de esmeril y 9 con polvo de esmeril).

$\mathrm{C}_{\mathrm{t}}$ es el valor medio obtenido en el tiempo $t$ de resistencia al deslizamiento, medido con el péndulo TRRL, de las cuatro probetas de árido pulimentadas, (dos en cada una de las dos ruedas porta-probetas ensayadas).

Como puede verse, el valor CPM se podrá calcular para el intervalo de tiempo t que se desee aunque interesará, sobre todo, el valor de CPM correspondiente al final del ensayo, siendo las mezclas con mayor CPM las que presentarán un mejor comportamiento frente a la resistencia al deslizamiento.

\subsection{Validación del método de ensayo}

Finalmente, la última etapa de la metodología propuesta define el procedimiento de validación del método de ensayo desarrollado.

Para ello, será necesario seleccionar los materiales adecuados y definir un plan de ensayos que permita validar el método de ensayo propuesto que pasamos a describir a continuación. 


\subsubsection{Materiales}

Durante el estudio de validación del método de ensayo desarrollado en esta tesis se utilizarán diferentes tipos de mezclas bituminosas compuestas por varios tipos de materiales. Los tipos de mezclas seleccionadas para el estudio serán dos: mezclas tipo AC 16D y tipo BBTM 11B, cuyo empleo se encuentra muy extendido en las carreteras españolas como capa de rodadura.

Las mezclas AC 16D, son del tipo hormigón bituminoso, (Asphalt Concrete, UNE-EN 13108-1, con granulometría cerrada y un esqueleto mineral continuo, sin ausencia de ningún tamaño intermedio. El porcentaje de huecos suele ser bajo, pues las partículas más finas tienden a rellenar los huecos que dejan las más gruesas. El espesor de extensión de este tipo de materiales suele estar comprendido entre los 4-5 cm, ofreciendo buena capacidad estructural para disipar las cargas transmitidas por el tráfico, buena resistencia mecánica a compresión, debida al gran rozamiento interno de sus partículas minerales, así como ante esfuerzos tangenciales y a tracción.

Por su parte, las mezclas BBTM, (Bétons Bitumineux Très Minces, UNE-EN 131082 ), son microaglomerados con curva granulométrica discontinua, utilizadas en capa de rodadura, con un esqueleto mineral principalmente compuesto por árido grueso, careciendo de tamaños intermedios, y una fuerte cohesión, ya que suelen fabricarse con un betún modificado. Suelen extenderse en espesores reducidos, (2$3,5 \mathrm{~cm}$ ), tanto en rehabilitaciones superficiales de firmes deteriorados, como en carreteras de nueva construcción, presentando una buena macrotextura superficial gracias a la discontinuidad en su granulometría. La normativa española recoge dos variantes con dos tamaños máximos de árido: las BBTM 8 y 11A y BBTM 8 y 11B. Las BBTM 11B, están formadas por un $75-85 \%$ de árido grueso, mayor de 2,0 mm, un $15-25 \%$ de árido fino y un $5-8 \%$ filler, con un porcentaje de betún en torno al $5 \%$, presentando un superior contenido de huecos a las tipo $A$, debido a su menor contenido de finos.

En la figura 4.17 puede apreciarse las diferencias entre el huso granulométrico de una mezcla AC 16D y una BBTM 11B. 


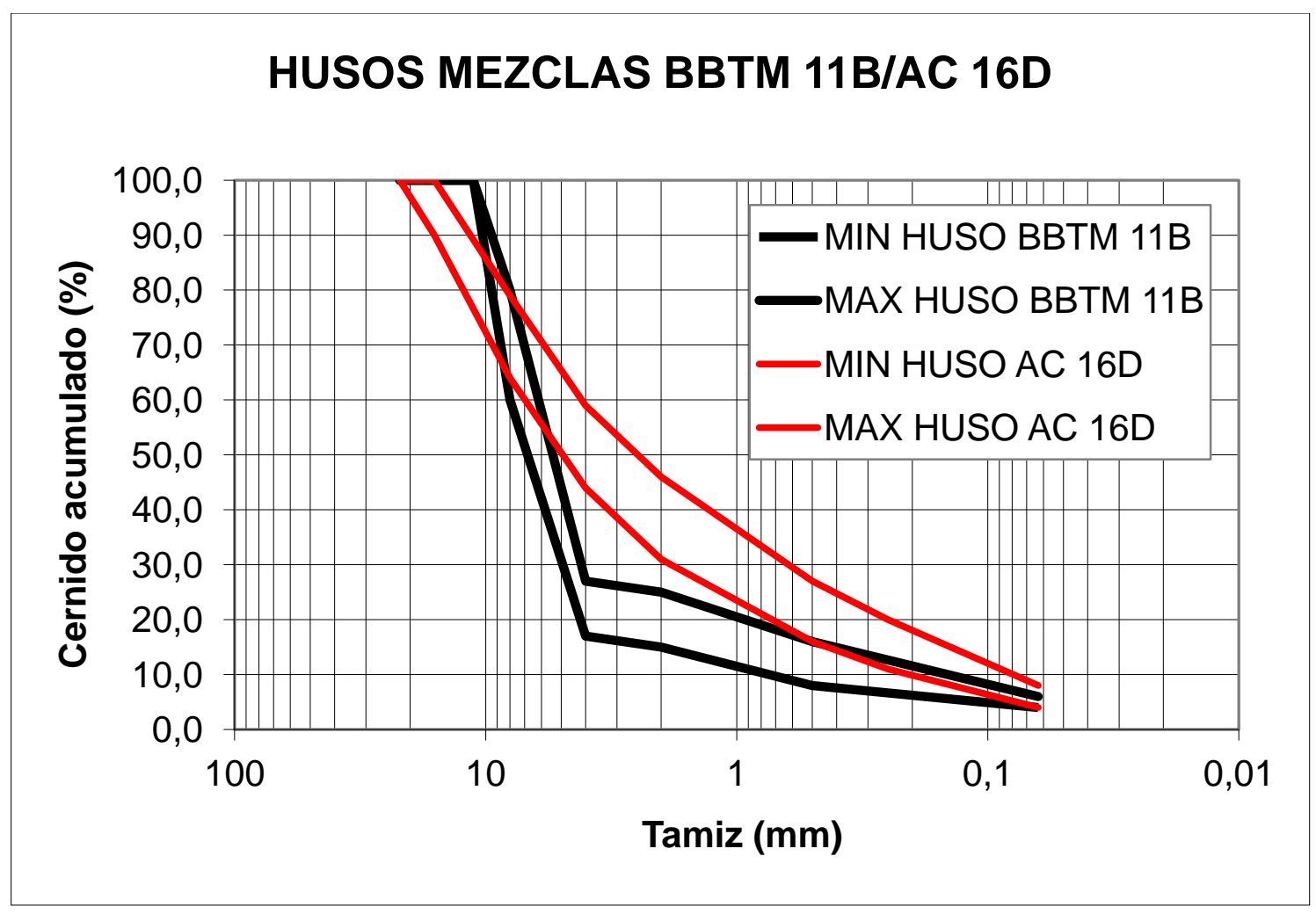

Figura 4. 17. Husos granulométricos de una BBTM 11B y de una AC 16D.

Los dos tipos de mezclas anteriores se fabricarán con áridos calizos, gruesos y finos, con coeficientes de pulimento acelerado más bajos, y con áridos gruesos de tipo pórfido y andesitas, de coeficiente de pulimento acelerado mucho más alto, con el objeto de poder observar, con el método de ensayo desarrollado, la influencia de esta propiedad en la resistencia al deslizamiento de las mezclas fabricadas. En todos los casos, el filler seleccionado para la fabricación de las mezclas será de aportación, del tipo carbonato cálcico y el árido fino utilizado para las mezclas fabricadas con pórfidos o andesitas será de tipo silíceo.

Como ya se ha explicado en otros apartados, cada rueda de ensayo incluye dos probetas fabricadas sólo con el árido de referencia, con coeficiente de pulimento conocido, con el objeto de comprobar si las mediciones efectuadas son correctas. El árido de referencia utilizado será el que utiliza la UPM para el ensayo CPA, una andesita con coeficiente de pulimento acelerado, según la UNE-EN 1097-8, de 57.

Para caracterizar tanto los materiales, como las mezclas en sí, se utilizarán las normas EN, European Committee for Standarization, así como, en algún caso, las normas NLT, para ensayos de carreteras del Centro de Estudio y Experimentación de Obras Públicas, (CEDEX). 
En la tabla 4.1, se muestran las principales características de los áridos a utilizar en este trabajo.

Tabla 4. 1: Resultados de los ensayos de los áridos utilizados en la fabricación de las mezclas.

\begin{tabular}{|c|c|c|c|c|c|c|c|c|}
\hline \multirow[b]{2}{*}{ ENSAYO } & \multicolumn{8}{|c|}{ RESULTADO } \\
\hline & $\begin{array}{l}\text { CALIZA } \\
(8 / 11) \\
\end{array}$ & $\begin{array}{c}\text { CALIZA } \\
(4 / 8)\end{array}$ & $\begin{array}{c}\text { CALIZA } \\
(2 / 4)\end{array}$ & $\begin{array}{c}\text { CALIZA } \\
(0 / 2)\end{array}$ & $\begin{array}{l}\text { PÓRFIDO } \\
(6 / 12)\end{array}$ & $\begin{array}{l}\text { ANDESITA } \\
(6 / 12) \\
\end{array}$ & $\begin{array}{l}\text { SILÍCEA } \\
(0 / 6)\end{array}$ & $\begin{array}{c}\text { SILÍCEA } \\
(0 / 3)\end{array}$ \\
\hline $\begin{array}{c}\text { EQUIVALENTE DE } \\
\text { ARENA } \\
\text { (UNE-EN 933-8) }\end{array}$ & - & - & - & 67 & - & - & 47 & 47 \\
\hline $\begin{array}{c}\text { PROPORCIÓN DE } \\
\text { PARTÍCULAS } \\
\text { TRITURADAS } \\
\text { (UNE-EN 933-5) }\end{array}$ & 100 & 100 & 100 & - & 100 & 100 & - & - \\
\hline $\begin{array}{r}\text { ÍNDICE DE LAJAS } \\
(\text { UNE-EN 933-3) } \\
\end{array}$ & 15 & 15 & 15 & - & 6,7 & 7,8 & - & - \\
\hline $\begin{array}{l}\text { COEFICIENTE LOS } \\
\text { ÁNGELES, CDLA } \\
\text { (UNE-EN1097-2) }\end{array}$ & 25 & 25 & - & - & 10,5 & 17 & - & - \\
\hline $\begin{array}{c}\text { CPA } \\
\text { (UNE-EN 1097-8) }\end{array}$ & 43 & 43 & - & - & $47-50$ & 57 & - & - \\
\hline
\end{tabular}

Como ya se ha dicho, el filler utilizado en la fabricación de las mezclas será, en su totalidad, de aportación y del tipo $\mathrm{CaCO}_{3}$, con una densidad aparente, según el anexo A de la norma UNE-EN 1097-3, (AENOR 1999), de 0,68 g/ $\mathrm{cm}^{3}$ pasando el $100 \%$ por el tamiz $0,063 \mathrm{~mm}$.

El betún utilizado en la fabricación de las mezclas será un PMB 45/80-65, modificado con polímeros, que cumple con todas las prescripciones marcadas en el artículo 212 del Pliego de Prescripciones Técnicas Generales para Obras de Carreteras y Puentes, (PG3), del Ministerio de Fomento, excepto para una mezcla BBTM 11B que se fabricará con un betún convencional 50/70, con el objeto de comprobar la influencia del betún en la resistencia al deslizamiento de las mezclas. En la tabla 4.2 se incluyen las principales propiedades de los betunes utilizados: 
Tabla 4. 2. Características de los betunes utilizados en la fabricación de las mezclas.

\begin{tabular}{|c|c|c|c|}
\hline & UNIDAD & $\mathbf{5 0 / 7 0}$ & PMB 45/80-65 \\
\hline Penetración 25ac (UNE-EN 1426) & $0,1 \mathrm{~mm}$ & $50-70$ & $45-80$ \\
\hline Punto de reblandecimiento (UNE-EN 1427) & ${ }^{\circ} \mathrm{C}$ & $46-54$ & $\geq 65$ \\
\hline Punto de fragilidad Fraass (UNE-EN 12593) & ${ }^{\circ} \mathrm{C}$ & $\leq-8$ & $\leq-15$ \\
\hline Recuperación elástica a 250C (UNE-EN 13398) & $\%$ & & $\geq 70$ \\
\hline
\end{tabular}

A partir de las granulometrías de cada uno de los áridos a utilizar en la mezcla, se ha procedido a realizar los tanteos para encajar la granulometría del conjunto de los áridos en el huso granulométrico que marca el PG3 para las mezclas BBTM 11B, y AC $16 \mathrm{D}$ del proyecto. En la tabla 4.3 se incluyen las dosificaciones empleadas.

Tabla 4. 3 Dosificación óptima de los áridos de las fórmulas de trabajo.

\begin{tabular}{|c|c|c|c|c|c|c|}
\hline & $\begin{array}{c}\text { AC 16D } \\
\text { PMB } \\
45 / 80-65\end{array}$ & $\begin{array}{l}\text { BBTM 11B } \\
\text { PMB } \\
45 / 80-65\end{array}$ & $\begin{array}{c}\text { BBTM 11B } \\
\text { PMB } \\
45 / 80-65\end{array}$ & $\begin{array}{l}\text { BBTM 11B } \\
\text { PMB } \\
45 / 80-65\end{array}$ & $\begin{array}{l}\text { BBTM } \\
50 / 70\end{array}$ & $\begin{array}{c}\text { AC 16D } \\
\text { PMB } \\
45 / 80-65\end{array}$ \\
\hline $\begin{array}{c}8 / 11 \\
\text { calizo }\end{array}$ & $30,0 \%$ & $80,0 \%$ & & & & \\
\hline $\begin{array}{c}4 / 8 \\
\text { calizo }\end{array}$ & $19,0 \%$ & $5,0 \%$ & & & & \\
\hline $\begin{array}{l}2 / 4 \\
\text { calizo }\end{array}$ & $13,0 \%$ & & & & & \\
\hline $\begin{array}{c}0 / 2 \\
\text { calizo }\end{array}$ & $32,5 \%$ & $10,5 \%$ & & & & \\
\hline $\begin{array}{l}\text { Filler } \\
\mathrm{CaCO}_{3} \\
\end{array}$ & $5,5 \%$ & $4,5 \%$ & $5,0 \%$ & $4,7 \%$ & $4,7 \%$ & $4,0 \%$ \\
\hline $\begin{array}{c}6 / 12 \\
\text { andesita }\end{array}$ & & & $77,1 \%$ & & & \\
\hline $\begin{array}{c}6 / 12 \\
\text { pórfido }\end{array}$ & & & & $78,0 \%$ & $78,0 \%$ & $51,0 \%$ \\
\hline $\begin{array}{l}\text { 0/4 } \\
\text { sílice }\end{array}$ & & & $17,9 \%$ & $17,3 \%$ & $17,3 \%$ & $45,0 \%$ \\
\hline
\end{tabular}


A partir de estas dosificaciones se obtiene la curva granulométrica del árido combinado de cada mezcla que, como puede verse, encaja en el huso correspondiente, (tablas 4.4 y 4.5 ).

Tabla 4. 4. Curva granulométrica de las BBTM 11B.

\begin{tabular}{|c|c|c|c|c|c|c|}
\hline \multicolumn{6}{|c|}{ GRANULOMETRÍAS DE LAS FÓRMULAS DE TRABAJO BBTM 11B } \\
\hline TAMICES & $\begin{array}{c}\text { MAX } \\
\text { BBTM 11B }\end{array}$ & $\begin{array}{c}\text { MIN } \\
\text { BBTM 11B }\end{array}$ & $\begin{array}{c}\text { BBTM 11B } \\
\text { CALIZA PMB } \\
\mathbf{4 5 / 8 0 - 6 5}\end{array}$ & $\begin{array}{c}\text { BBTM } \\
\text { ANDESITA } \\
\text { PMB } \\
\mathbf{4 5 / 8 0 - 6 5}\end{array}$ & $\begin{array}{c}\text { BBTM 11B } \\
\text { PÓRFIDO } \\
\text { PMB } \\
\mathbf{4 5 / 8 0 - 6 5}\end{array}$ & $\begin{array}{c}\text { BBTM 11B } \\
\text { PÓRFIDO } \\
\mathbf{5 0 / 7 0}\end{array}$ \\
\hline 22 & 100,0 & 100,0 & 100,0 & 0,0 & 0,0 & 0,0 \\
\hline 16 & 100,0 & 100,0 & 100,0 & 100,0 & 100,0 & 100,0 \\
\hline 11,2 & 100,0 & 100,0 & 100,0 & 96,5 & 100,0 & 100,0 \\
\hline 8 & 80,0 & 60,0 & 60,8 & 60,7 & 73,7 & 73,7 \\
\hline 4 & 27,0 & 17,0 & 15,0 & 23,5 & 23,2 & 23,2 \\
\hline 2 & 25,0 & 15,0 & 15,0 & 17,6 & 17,6 & 17,6 \\
\hline 0,5 & 16,0 & 8,0 & 11,0 & 10,5 & 10,7 & 10,7 \\
\hline 0,063 & 6,0 & 4,0 & 4,8 & 5,8 & 5,7 & 5,7 \\
\hline
\end{tabular}

Tabla 4. 5. Curva granulométrica de las AC 16D.

\begin{tabular}{|c|c|c|c|c|}
\hline \multicolumn{6}{|c|}{ GRANULOMETRÍAS DE LAS FÓRMULAS DE TRABAJO AC16D } \\
\hline TAMICES & $\begin{array}{c}\text { MÁX. } \\
\text { AC 16D }\end{array}$ & $\begin{array}{c}\text { MÍN. } \\
\text { AC 16D }\end{array}$ & $\begin{array}{c}\text { AC 16D CALIZA } \\
\text { PMB 45/80-65 }\end{array}$ & $\begin{array}{c}\text { AC 16D PÓRFIDO } \\
\text { PMB 45/80-65 }\end{array}$ \\
\hline 22 & 100,0 & 100,0 & 100,0 & 100,0 \\
\hline 16 & 100,0 & 90,0 & 100,0 & 100,0 \\
\hline 8 & 79,0 & 64,0 & 70,0 & 75,1 \\
\hline 4 & 59,0 & 44,0 & 51,0 & 49,0 \\
\hline 2 & 46,0 & 31,0 & 38,0 & 38,2 \\
\hline 0,5 & 27,0 & 16,0 & 22,2 & 20,5 \\
\hline 0,25 & 20,0 & 11,0 & 13,9 & 14,0 \\
\hline 0,063 & 8,0 & 4,0 & 6,3 & 8,0 \\
\hline
\end{tabular}

En las siguientes figuras puede verse representada la curva granulométrica de cada fórmula de trabajo estudiada. 


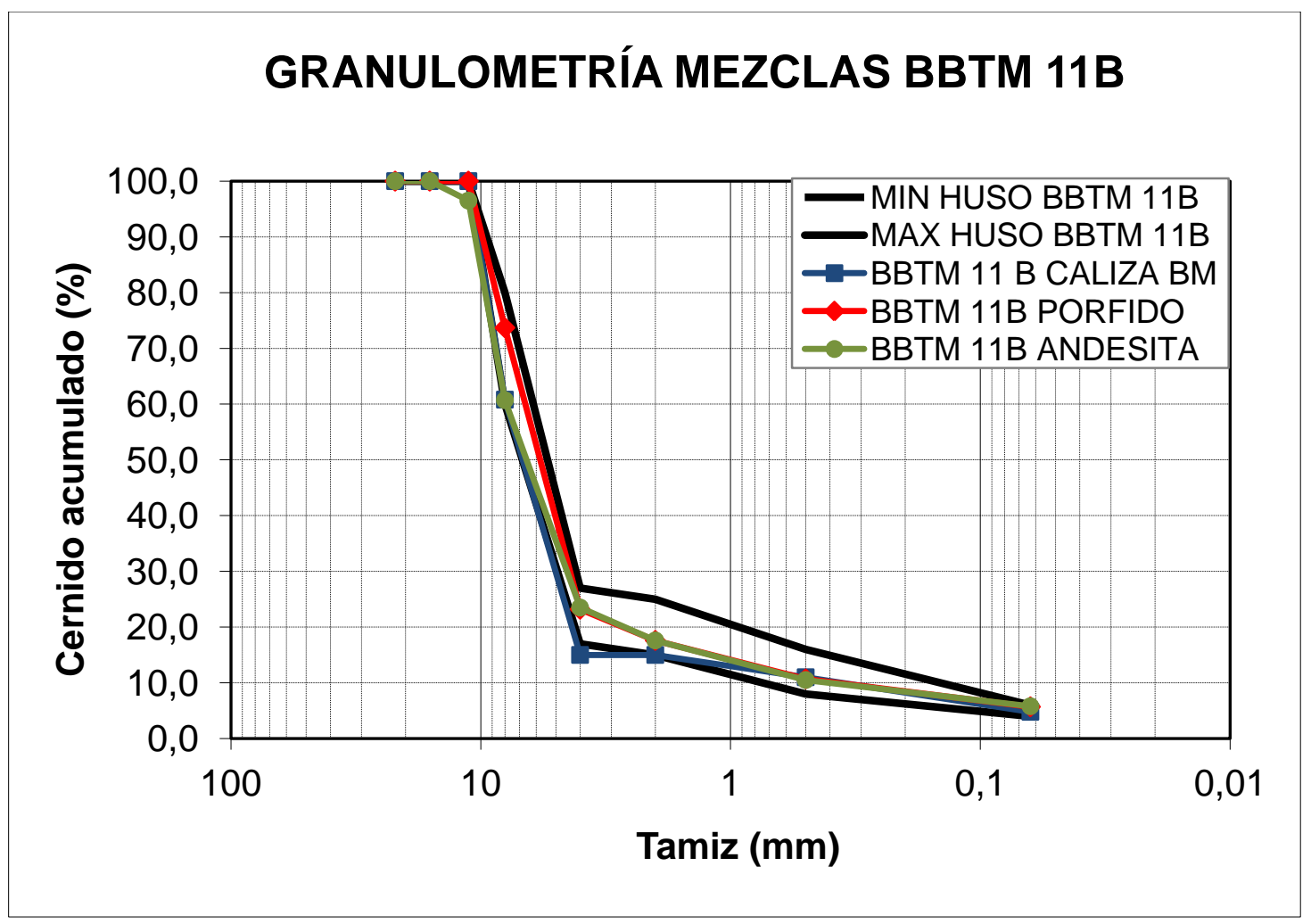

Figura 4. 18. Curvas granulométricas de las BBTM 11B empleadas.

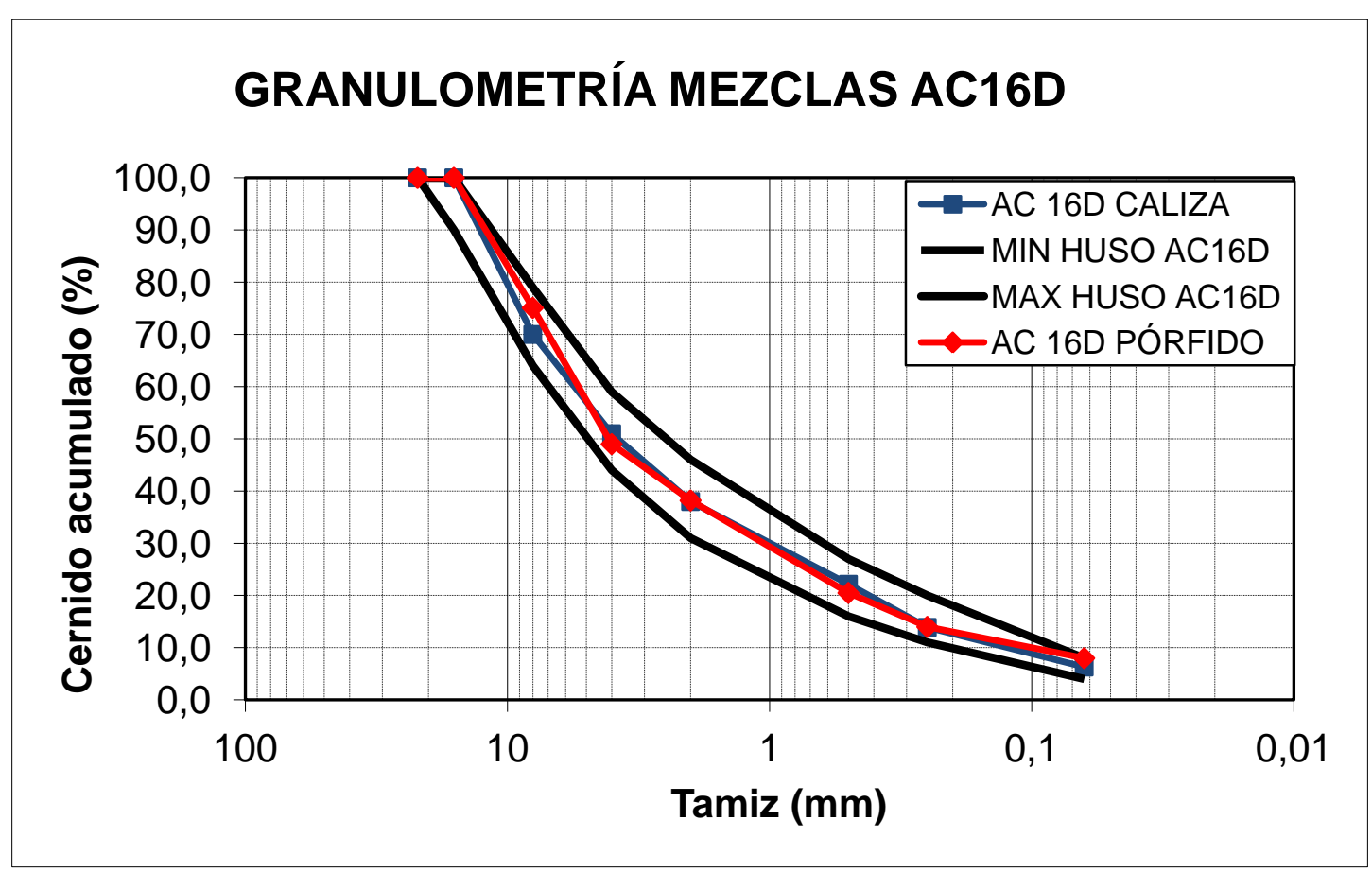

Figura 4. 19. Curvas granulométricas de las AC 16D empleadas.

Para la determinación del contenido de betún óptimo de cada mezcla se utilizó el ensayo Marshall, (UNE-EN 12697-34), dando los \% óptimos de betún sobre árido, densidades aparentes y máximas y porcentaje de huecos en mezcla que se indican en la tabla 4.6. 
Tabla 4. 6. Características de las mezclas empleadas en el estudio.

\begin{tabular}{|c|c|c|c|c|c|c|}
\hline & $\begin{array}{c}\text { AC 16D } \\
\text { CALIZA } \\
\text { PMB } \\
\mathbf{4 5 / 8 0 - 6 5}\end{array}$ & $\begin{array}{c}\text { BBTM 11B } \\
\text { CALIZA } \\
\text { PMB } \\
\mathbf{4 5 / 8 0 - 6 5}\end{array}$ & $\begin{array}{c}\text { BBTM 11B } \\
\text { ANDESITA } \\
\text { PMB } \\
\mathbf{4 5 / 8 0 - 6 5}\end{array}$ & $\begin{array}{c}\text { BBTM 11B } \\
\text { PÓRFIDO } \\
\text { PMB } \\
\mathbf{4 5 / 8 0 - 6 5}\end{array}$ & $\begin{array}{c}\text { BBTM 11B } \\
\text { PÓRFIDO } \\
\mathbf{5 0 / 7 0}\end{array}$ & $\begin{array}{c}\text { AC 16D } \\
\text { PÓRFIDO } \\
\text { PMB } \\
\mathbf{4 5 / 8 0 - 6 5}\end{array}$ \\
\hline $\begin{array}{c}\text { BETÚN ÁRIDO } \\
(\%)\end{array}$ & 5 & 5,35 & 5,35 & 5,35 & 5,35 & 5 \\
\hline $\begin{array}{c}\text { DENSIDAD } \\
\text { MÁXIMA } \\
(\mathrm{g} / \mathrm{cm} 3)\end{array}$ & 2,428 & 2,381 & 2,42 & 2,489 & 2,489 & 2,518 \\
\hline $\begin{array}{c}\text { DENSIDAD } \\
\text { APARENTE } \\
\left(\mathrm{g} / \mathrm{cm}^{3}\right)\end{array}$ & 2,311 & 2,044 & 1,96 & 2,02 & 2,02 & 2,393 \\
\hline $\mathrm{Vm}(\%)$ & 4,82 & 14,2 & 19 & 18,9 & 18,9 & 4,96 \\
\hline
\end{tabular}

Con los porcentajes óptimos de betún de cada fórmula, se hizo el ensayo de sensibilidad al agua, según la UNE-EN 12697-12, en la BBTM 11B pórfido PMB 45/80-65 y en la BBTM 11B andesita PMB 45/80-65, obteniendo valores de resistencia conservada superiores al $90 \%$. No se hizo sensibilidad al agua del resto de mezclas por no ser un ensayo de cumplimento estrictamente necesario para los objetivos del presente trabajo. Por último, se hizo el ensayo en pista de laboratorio, según la UNE-EN 12697-22, de las dos mezclas BBTM 11B anteriores, obteniéndose una pendiente media de deformación en el intervalo de 5.000 a 10.000 ciclos inferior en ambos casos a 0,07 ( $\mathrm{mm} / 1000$ ciclos de carga). Por los mismos motivos mencionados, no se hizo el ensayo en pista del resto de mezclas.

\subsubsection{Plan de ensayos}

El plan de ensayos que se describe a continuación tiene por objeto validar el método de ensayo propuesto.

Durante esta fase se pretende:

- Demostrar que el procedimiento de ensayo es válido y da resultados coherentes con la bibliografía consultada. En esta fase se determinará cuál debe ser la duración del ensayo y si los criterios de rechazo del ensayo propuestos son coherentes. Finalmente permitirá definir el valor de coeficiente de pulimento acelerado de las mezclas estudiadas.

- Estudiar cuál es la repetibilidad del método de ensayo dado que el ensayo debe ser lo suficientemente preciso como para que se pueda garantizar una evaluación fiable del comportamiento a deslizamiento de las mezclas estudiadas.

- Estudiar cómo varían los resultados de los ensayos en función de los materiales empleados, (áridos y ligante), las condiciones de ensayo y las 
curvas granulométricas empleadas, (macrotextura). El procedimiento de ensayo desarrollado debe poder apreciar diferentes comportamientos frente al deslizamiento en función del tipo de materiales empleados en la fabricación de las mezclas y el tipo de granulometría y, por tanto, macrotextura de cada mezcla ensayada, para que pueda ser un procedimiento de ensayo a incorporar durante la fase de diseño de estos materiales.

\subsubsection{Coeficiente de pulimento acelerado de las mezclas. Duración del ensayo}

Una vez definida la forma en que deben fabricarse las probetas de mezcla, fabricado el prototipo de ensayo con el que pulir dichas probetas y la forma en que se debe medir el pulimento de éstas, durante esta fase se procederá a validar el procedimiento de ensayo desarrollado y a calcular el coeficiente de pulimento acelerado de varias mezclas. A la terminación de esta fase, se deberá saber cuál debe ser la duración que debe tener el ensayo, si los criterios de rechazo que hemos propuesto son adecuados, si el proceso de pulimento de las mezclas difiere del pulimento que tienen los áridos, si dicho proceso de pulimento es coherente con lo descrito en la bibliografía consultada y si es necesario introducir alguna modificación que corrija algún posible error del método propuesto.

En la tabla 4.7, se incluye el plan de ensayos que se va a llevar a cabo para conseguir esto.

Tabla 4. 7. Plan de ensayos para definir la duración del ensayo

\begin{tabular}{|c|c|c|c|c|}
\hline $\begin{array}{c}\text { TIPO DE } \\
\text { MEZCLA }\end{array}$ & $\begin{array}{c}\text { ÁRIDO } \\
\text { GRUESO }\end{array}$ & LIGANTE & $\begin{array}{c}\text { CONDICIONES } \\
\text { ENSAYO }\end{array}$ & $\begin{array}{c}\text { NÚMERO DE } \\
\text { PROBETAS }\end{array}$ \\
\hline BBTMV11B & PÓRFIDO & $\begin{array}{c}\text { PMB } \\
45 / 80-65\end{array}$ & UNE-EN 1097-8 & 12 \\
\hline BBTM 11B & ANDESITA & $\begin{array}{c}\text { PMB } \\
45 / 80-66\end{array}$ & UNE-EN 1097-8 & 12 \\
\hline
\end{tabular}

\subsubsection{Análisis de la repetibilidad del método de ensayo}

A la hora de evaluar el comportamiento de un material mediante cualquier método de ensayo, puede ocurrir que los resultados obtenidos en varias pruebas realizadas bajo las mismas condiciones no coincidan. Este hecho es debido a errores que se cometen durante la preparación de los materiales o en la toma de las medidas y determinan la precisión del método de ensayo. 
Así pues, cuando se evalúa una determinada característica de algún material en laboratorio, el valor que se obtiene en el ensayo es en realidad un valor que se encuentra dentro de un intervalo en el cual es probable que estén los valores de la característica que estamos evaluando. En función de la precisión del método de ensayo utilizado, dicho intervalo será más o menos amplio y, por tanto, la forma de evaluar la característica del material será más o menos adecuada.

Los conceptos empleados habitualmente para medir la precisión de un método de ensayo son el de repetibilidad y reproducibilidad, que quedan recogidos en la UNEEN 932-6:1999 (AENOR 2000). La repetibilidad indica el grado de acuerdo entre resultados mutuamente independientes de un ensayo, obtenidos utilizando el mismo método, con muestras idénticas, en el mismo laboratorio, por el mismo operador, usando el mismo equipo y en un corto intervalo de tiempo. La siguiente figura, reproduce el esquema para que se den condiciones de repetibilidad.

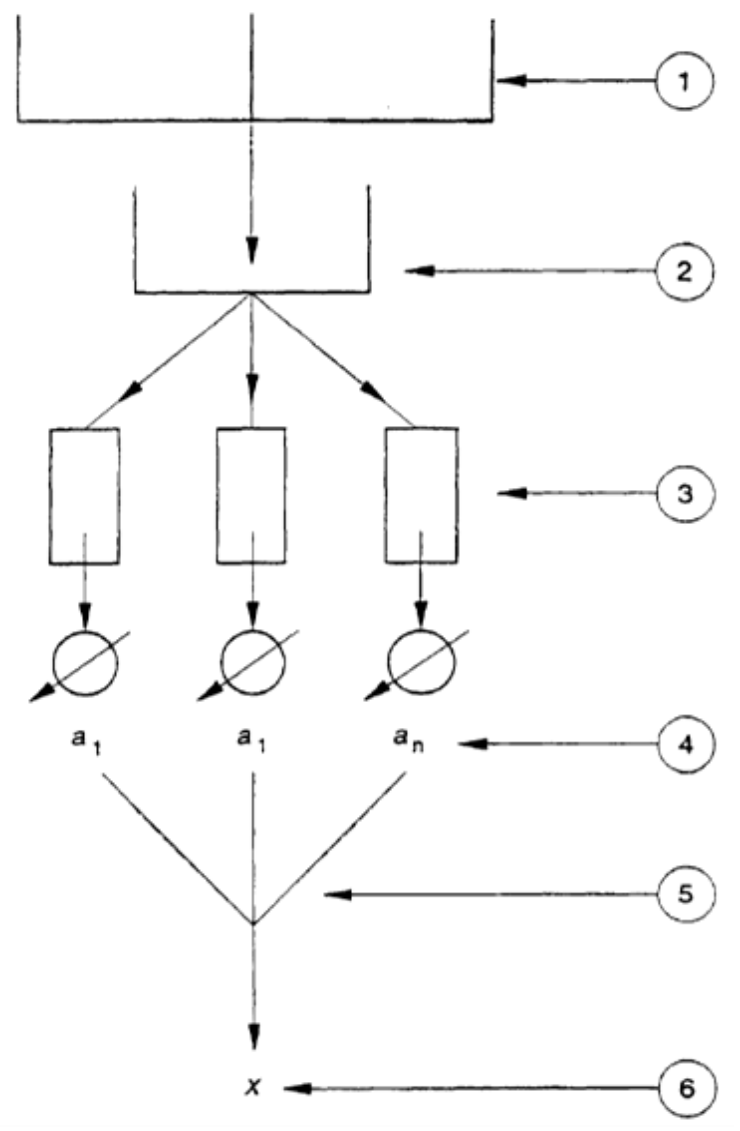

Figura 4. 20: Condiciones de repetibilidad

Donde 1 representa la muestra de laboratorio, 2 la muestra de ensayo y 3 el resultado del ensayo, debiéndose cumplir que $|x 1-x 2| \leq r$, siendo $r$ la repetibilidad del ensayo, que se define como el máximo valor del intervalo de variación dentro del cual se encontrarán las diferencias absolutas entre dos resultados de ensayos, 
(efectuados en condiciones de repetibilidad), con una probabilidad del 95\%. En este sentido, cuanto mayor es la precisión de un ensayo, más pequeño es el valor de repetibilidad " $r$ ".

Por otra parte, la reproducibilidad indica el grado de acuerdo entre resultados mutuamente independientes de un ensayo obtenidos con el mismo método, en idénticos materiales, en diferentes laboratorios, con diferentes operadores $y$ utilizando distintos equipos.

La repetibilidad y reprodubilidad se pueden expresar cuantitativamente en términos de dispersión característica de los resultados. En la siguiente figura se representan gráficamente los conceptos de repetibilidad y reproducibilidad.

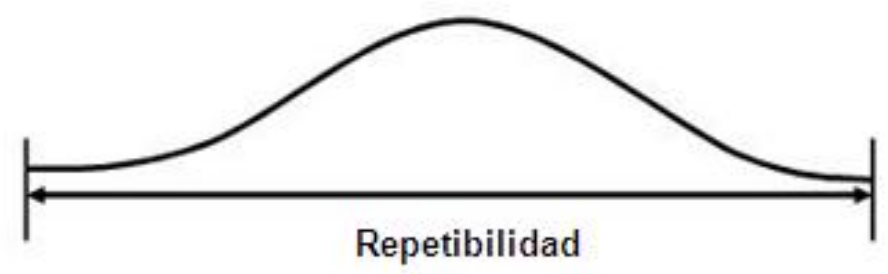

Gráfico de repetibilidad

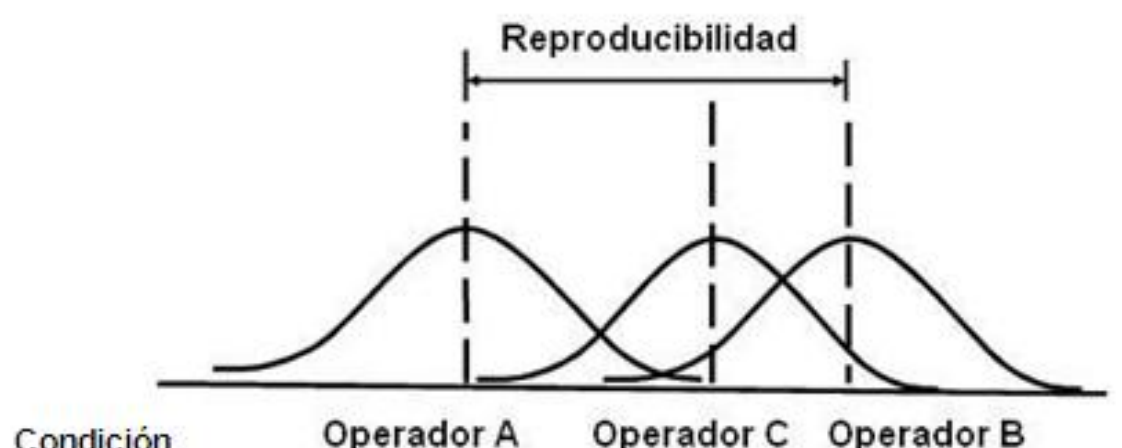

Gráfico de reproducibilidad

Figura 4. 21: Expresión gráfica del concepto de repetibilidad y reproducibilidad.

La obtención valores adecuados de repetibilidad y reproducibilidad resultan fundamentales para poder garantizar que los resultados obtenidos con el procedimiento de ensayo desarrollado son fiables a la hora de evaluar el comportamiento a deslizamiento de mezclas bituminosas. Dado que la máquina con la que se consiguen pulimentar probetas de mezcla es un prototipo, no se ha podido realizar la evaluación de la reproducibilidad del método de ensayo propuesto pues para la misma sería necesaria la colaboración de varios laboratorios que 
tuvieran esta misma máquina en la que probetas de mezcla similares se pudiesen pulimentar por distintos laborantes. Por este motivo en este trabajo solo se llevará a cabo el estudio de la repetibilidad del ensayo.

El estudio de la repetibilidad debe iniciarse realizando un experimento diseñado estadísticamente, en el que se proceda a estudiar la variabilidad de los datos de coeficiente de resistencia al deslizamiento medidos en condiciones de repetibilidad. Para este trabajo el plan de ensayos que se ha propuesto para estudiar la repetibilidad del método de ensayo desarrollado, se basa en 6 tipos de mezclas distintas, compuestas por áridos y ligantes diferentes, con distintas curvas granulométricas, ensayadas en distintas condiciones, de acuerdo al plan de ensayos incluido en la tabla 4.8.

Tabla 4. 8. Plan de ensayos para el estudio de la repetibilidad

\begin{tabular}{|c|c|c|c|c|}
\hline $\begin{array}{l}\text { TIPO DE } \\
\text { MEZCLA }\end{array}$ & $\begin{array}{l}\text { ÁRIDO } \\
\text { GRUESO }\end{array}$ & LIGANTE & $\begin{array}{c}\text { CONDICIONES } \\
\text { ENSAYO }\end{array}$ & $\begin{array}{l}\text { NÚMERO DE } \\
\text { PROBETAS }\end{array}$ \\
\hline BBTM 11B & CALIZO & $\begin{array}{c}\text { PMB } \\
45 / 80-65\end{array}$ & UNE-EN 1097-8 & 4 \\
\hline BBTM 11B & CALIZO & $\begin{array}{c}\text { PMB } \\
45 / 80-65\end{array}$ & $\begin{array}{c}\text { UNE-EN 1097-8 } \\
\text { MODIFICADO }\end{array}$ & 4 \\
\hline BBTM 11B & PÓRFIDO & $\begin{array}{c}\text { PMB } \\
45 / 80-65\end{array}$ & UNE-EN 1097-8 & 4 \\
\hline BBTM 11B & PÓRFIDO & $\begin{array}{c}\text { PMB } \\
45 / 80-65\end{array}$ & $\begin{array}{l}\text { UNE-EN 1097-8 } \\
\text { MODIFICADO }\end{array}$ & 4 \\
\hline AC 16D & CALIZA & $\begin{array}{c}\text { PMB } \\
45 / 80-65\end{array}$ & UNE-EN 1097-8 & 4 \\
\hline AC 16D & CALIZA & $\begin{array}{c}\text { PMB } \\
45 / 80-65\end{array}$ & $\begin{array}{l}\text { UNE-EN 1097-8 } \\
\text { MODIFICADO }\end{array}$ & 4 \\
\hline AC 16D & PÓRFIDO & $\begin{array}{c}\text { PMB } \\
45 / 80-65\end{array}$ & UNE-EN 1097-8 & 4 \\
\hline AC 16D & PÓRFIDO & $\begin{array}{c}\text { PMB } \\
45 / 80-65\end{array}$ & $\begin{array}{c}\text { UNE-EN 1097-8 } \\
\text { MODIFICADO }\end{array}$ & 4 \\
\hline BBTM 11B & PÓRFIDO & $50 / 70$ & UNE-EN 1097-8 & 4 \\
\hline BBTM 11B & PÓRFIDO & $50 / 70$ & $\begin{array}{c}\text { UNE-EN 1097-8 } \\
\text { MODIFICADO }\end{array}$ & 4 \\
\hline ARI REF & ANDESITA & RESINA & UNE-EN 1097-8 & 4 \\
\hline ARI REF & ANDESITA & RESINA & $\begin{array}{c}\text { UNE-EN 1097-8 } \\
\text { MODIFICADO }\end{array}$ & 4 \\
\hline
\end{tabular}

Para cada tipo de mezcla se han propuesto dos condiciones de ensayo. Por un lado se seguirán de forma escrupulosa las que marca la UNE-EN 1097-8 para pulimento de áridos. Por otro lado, las mismas mezclas se volverán a ensayar bajo unas condiciones de pulimento basadas en la UNE-EN 1097-8 pero modificadas para hacer menos agresivo el pulimento de las mezclas tal y como se explica en el apartado 4.5.2.3 de la tesis. 
La ejecución de los ensayos no se realizará de forma consecutiva, para evitar que los datos observados sean contaminados por el efecto de otras variables no conocidas y que no pueden ser controladas, por ejemplo, el desgaste de alguna pieza del equipo de pulimento o la descalibración del dispositivo de medida utilizado.

Una vez realizado el experimento y obtenidos los resultados del ensayo, se procede a calcular para cada intervalo temporal en que se mide el coeficiente de resistencia al deslizamiento, el recorrido o rango de cada medición, o diferencia entre el valor máximo y mínimo de cada medida, la media aritmética, la desviación típica, el coeficiente de variación y, por último, la repetibilidad del ensayo.

Para el cálculo de la repetibilidad del ensayo se construye el intervalo de confianza al $95 \%$ en torno al valor medio de cada muestra basado en la distribución $t$ de Student que es la más adecuada cuando el tamaño de la muestra es pequeño. Este intervalo de confianza de define por la ecuación:

$$
r=2 * k^{*} \sigma / \sqrt{ } n
$$

Donde:

$r$ es la repetilidad del ensayo.

$\mathrm{k}$ es el estadístico de la $\mathrm{t}$ de Student para $\mathrm{n}-1$ grados de libertad y el $95 \%$ de probabilidad.

$\sigma$ es la desviación típica de la muestra.

$\mathrm{n}$ es el tamaño de la muestra.

En nuestro caso, el tamaño de la muestra es de 4 para cada una de las mezclas estudiadas, lo que quiere decir que son 3 los grados de libertad de cara a calcular el coeficiente a utilizar de la t de Student, por lo que el valor de $K=3,182$.

En base a los resultados obtenidos para estos parámetros en cada uno de los ensayos, se determinará la variabilidad de los resultados obtenidos en las diferentes pruebas y se podrá valorar y comparar la precisión del método de ensayo desarrollado con respecto a la que se consigue para medir el coeficiente de pulimento acelerado de los áridos según la UNE-EN 1097-8. 


\subsubsection{Sensibilidad del ensayo CPM frente a las condiciones de ensayo}

Para poder validar la eficacia de este método de ensayo se ha procedido a analizar cuáles son los factores que más influyen en los resultados obtenidos sobre los materiales ensayados de forma que se puedan definir unas condiciones óptimas para la realización del mismo.

La norma UNE-EN 1097-8, para la determinación del coeficiente de pulimento acelerado de áridos, establece las condiciones en las que debe realizarse este ensayo, que son las que a priori se utilizarán para realizar el ensayo de coeficiente de pulimento acelerado sobre mezclas.

Sin embargo, durante las primeras pruebas efectuadas, se ha podido comprobar que el pulimento que producen las ruedas de caucho rígidas en las probetas de mezcla ha sido demasiado agresivo y ha dado lugar a roturas de las mismas antes de que el ensayo se pudiese dar por concluido. Por este motivo se ha pensado hacer una modificación adicional al equipo de pulimento de la UNE-EN 1097-8. La modificación va a consistir en suspender de un muelle el peso que produce, a través del brazo de palanca del equipo, la fuerza con la que las ruedas de caucho entran en contacto con las probetas de mezcla que deben pulir. Este muelle tiene una longitud $86 \mathrm{~mm}$ y una constante "k" de Young de $17.500 \mathrm{~N} / \mathrm{m}$. De esta manera, se pueden disminuir de forma notoria los impactos que el proceso de pulimento del ensayo CPA introduce en las probetas de mezcla y evitar que éstas se rompan antes de tiempo. En el plan de ensayos definido para conocer la repetibilidad del procedimiento de ensayo desarrollado se ha propuesto cómo y en qué medida afectan a los resultados y precisión del ensayo la presencia o no de este muelle.

\subsubsection{Sensibilidad del ensayo CPM a los materiales evaluados}

Cualquier ensayo de laboratorio que pretende ser utilizado en el diseño de mezclas asfálticas debe ser sensible a los cambios en la composición de los materiales con los que se fabrican dichas mezclas. Por este motivo, en la presente investigación se decidió evaluar la sensibilidad del método de ensayo para determinar el coeficiente de pulimento acelerado de mezclas fabricadas con curvas granulométricas y macrotexturas distintas y con distintos áridos y tipos de betún. 


\subsubsection{Influencia del tipo de ligante}

La bibliografía consultada pone de manifiesto que determinados tipos de ligantes asfálticos tardan más tiempo en desprenderse del árido por la acción del tráfico lo que ocasiona que el valor del coeficiente de resistencia al deslizamiento dé valores bajos durante más tiempo que cuando se utilizan otros ligantes. Por este motivo se quiere comprobar si este fenómeno se puede observar durante la realización del ensayo.

Para definir la influencia del tipo de ligante en el comportamiento a deslizamiento de mezclas bituminosas es necesario que el ensayo se haga sobre probetas del mismo tipo de mezcla, con el mismo tipo de árido, pero con ligantes distintos.

Para ello se empleará una mezcla tipo BBTM 11B con la misma curva granulométrica y, por tanto, con la misma macrotextura en la que únicamente se modifica el tipo de ligante.

Los ligantes a utilizar serán un betún modificado con polímeros, el PMB 45/80-65, habitualmente empleado en la fabricación de este tipo de mezclas discontinuas, y un betún convencional tipo 50/70.

La tabla 4.9 muestra el plan de ensayos a seguir para evaluar la influencia del ligante en el comportamiento a deslizamiento de las mezclas asfálticas.

Tabla 4. 9. Plan de ensayos para evaluar la influencia del ligante

\begin{tabular}{|c|c|c|c|c|c|c|}
\hline $\begin{array}{c}\text { TIPO DE } \\
\text { MEZCLA }\end{array}$ & $\begin{array}{c}\text { ÁRIDO } \\
\text { GRUESO }\end{array}$ & CPA & $\begin{array}{c}\text { ÁRIDO } \\
\text { FINO }\end{array}$ & LIGANTE & $\begin{array}{c}\text { CONDICIONES } \\
\text { ENSAYO }\end{array}$ & $\begin{array}{c}\text { NÚMERO } \\
\text { DE } \\
\text { PROBETAS }\end{array}$ \\
\hline $\begin{array}{c}\text { BBTM } \\
11 B\end{array}$ & PÓRFIDO & 47 & SÍLICE & $\begin{array}{c}\text { PMB } \\
45 / 80-65\end{array}$ & $\begin{array}{c}\text { UNE-EN 1097-8 } \\
\text { MODIFICADO }\end{array}$ & 4 \\
\hline $\begin{array}{c}\text { BBTM } \\
11 B\end{array}$ & PÓRFIDO & 47 & SÍLICE & $50 / 70$ & $\begin{array}{c}\text { UNE-EN 1097-8 } \\
\text { MODIFICADO }\end{array}$ & 4 \\
\hline
\end{tabular}

\subsubsection{Influencia del tipo de árido}

El estado del arte realizado pone de manifiesto que las mezclas fabricadas con áridos más resistentes al pulimento dan lugar a mezclas que se comportan mejor frente al deslizamiento. Por este motivo es fundamental comprobar si dependiendo del tipo de árido empleado, en mezclas fabricadas con la misma curva 
granulométrica y betún, el comportamiento frente al deslizamiento de las mismas varía con este método de ensayo.

Para definir la influencia del tipo de árido en el comportamiento a deslizamiento de mezclas bituminosas es necesario que el ensayo se haga sobre probetas del mismo tipo de mezcla, con el mismo tipo de ligante, pero con áridos de distinta naturaleza.

En un primera fase, con el proceso de pulimento que marca la UNE-EN 1097-8, se ensayarán 12 probetas de dos mezclas BBTM 11B distintas, con similares macrotexturas pero fabricadas con dos áridos gruesos distintos. Uno de ellos será de tipo andesítico, con CPA de 57. El otro será un pórfido, con un CPA de 47. En ambos casos, el árido fino será el mismo, de tipo silíceo y el betún también, un PMB 45/80-65.

En una segunda fase, con el equipo de pulimento modificado con el muelle, se empleará mezclas tipo BBTM 11B, con la misma macrotextura y con el mismo ligante, en la que únicamente se modifica el tipo de árido. En una de las mezclas BBTM 11B se utilizará pórfido como árido grueso y árido fino silíceo. En la otra árido calizo tanto grueso como fino. Lo mismo se hará con mezclas tipo AC 16D. El ligante a utilizar será en todos los casos un betún modificado con polímeros, el PMB 45/80-65.

La tabla 4.10 muestra el plan de ensayos para evaluar la influencia del árido en el comportamiento a deslizamiento de las mezclas asfálticas.

Tabla 4. 10. Plan de ensayos para evaluar la influencia del árido

\begin{tabular}{|c|c|c|c|c|c|c|}
\hline \multirow{2}{*}{$\begin{array}{l}\text { TIPO DE } \\
\text { MEZCLA }\end{array}$} & \multicolumn{2}{|c|}{ ÁRIDO GRUESO } & \multirow{2}{*}{$\begin{array}{l}\text { ÁRIDO } \\
\text { FINO }\end{array}$} & \multirow{2}{*}{ LIGANTE } & \multirow{2}{*}{$\begin{array}{l}\text { CONDICIONES } \\
\text { ENSAYO }\end{array}$} & \multirow{2}{*}{$\begin{array}{l}\text { NÚMERO } \\
\text { DE } \\
\text { PROBETAS }\end{array}$} \\
\hline & TIPO & CPA & & & & \\
\hline $\begin{array}{c}\text { BBTM } \\
11 \mathrm{~B}\end{array}$ & ANDESITA & 57 & SILÍCEO & $\begin{array}{c}\text { PMB } \\
45 / 80-63\end{array}$ & UNE-EN 1097-8 & 12 \\
\hline $\begin{array}{c}\text { BBTM } \\
11 \mathrm{~B}\end{array}$ & PÓRFIDO & 47 & SILÍCEO & $\begin{array}{c}\text { PMB } \\
45 / 80-64\end{array}$ & UNE-EN 1097-8 & 12 \\
\hline $\begin{array}{c}\text { BBTM } \\
11 \mathrm{~B}\end{array}$ & PÓRFIDO & 47 & SILÍCEO & $\begin{array}{c}\text { PMB } \\
45 / 80-65\end{array}$ & $\begin{array}{l}\text { UNE-EN 1097-8 } \\
\text { MODIFICADO }\end{array}$ & 4 \\
\hline $\begin{array}{c}\text { BBTM } \\
11 \mathrm{~B}\end{array}$ & CALIZO & 43 & CALIZO & $50 / 70$ & $\begin{array}{l}\text { UNE-EN } 1097-8 \\
\text { MODIFICADO }\end{array}$ & 4 \\
\hline$A C 16 D$ & PÓRFIDO & 47 & SILÍCEO & $\begin{array}{c}\text { PMB } \\
45 / 80-65\end{array}$ & $\begin{array}{l}\text { UNE-EN 1097-8 } \\
\text { MODIFICADO }\end{array}$ & 4 \\
\hline$A C$ 16D & CALIZO & 43 & CALIZO & $50 / 70$ & $\begin{array}{l}\text { UNE-EN 1097-8 } \\
\text { MODIFICADO }\end{array}$ & 4 \\
\hline
\end{tabular}




\subsubsection{Influencia del tipo de mezcla}

Como se vio al hacer el estudio del estado del arte, uno de los factores que afectan a la resistencia al deslizamiento de una mezcla bituminosa, a velocidades superiores a $60 \mathrm{~km} / \mathrm{h}$, es su macrotextura, la cual está relacionada con su curva granulométrica y el tamaño máximo de su árido. De acuerdo a la normativa en vigor, para mezclas discontinuas y drenantes, (artículo 543 de la Orden FOM/2523/2014), las mezclas discontinuas tipo B, deben tener macrotexturas superiores a 1,5 mm, medidas con el ensayo del círculo de arena, (UNE-EN 130361), y la resistencia al deslizamiento medida con el SCRIM, según la UNE 41201 IN, debe ser superior al 60\%, una vez transcurridos dos meses de la puesta en servicio de la carretera. Para una mezcla tipo AC, los valores de macrotextura y coeficiente de resistencia al deslizamiento, medidos en las mismas condiciones, son 0,7 $\mathrm{mm}$ y 65\% respectivamente, (artículo 542 de la Orden FOM/2523/2014), (DGC 2015).

Dentro de la presente investigación se quiere evaluar la influencia de la macrotextura de la mezcla en los valores de resistencia al deslizamiento medidos con el péndulo TRRL y comprobar si esta propiedad influye en los resultados del ensayo.

Para definir la influencia de la macrotextura en el comportamiento a deslizamiento de mezclas bituminosas con el método de ensayo desarrollado, es necesario que el ensayo se haga sobre probetas fabricadas con los mismos áridos y betún pero con distintas macrotexturas.

En una primera fase, con el equipo de pulimento de mezclas sin muelle, se empleará una mezcla tipo BBTM 11B fabricada con los mismos áridos y ligante, pero con probetas con distintas macrotexturas. En este tipo de mezcla se empleará un pórfido con CPA de 47 y con arena de tipo silíceo. El betún será un PMB 45/8065.

En una segunda fase, con el equipo de pulimento de mezclas modificado con el muelle, se estudiará la evolución del coeficiente de resistencia al deslizamiento de mezclas fabricadas con los mismos áridos y ligante pero con husos granulométricos muy diferentes. En concreto se compararán los resultados obtenidos en mezclas tipo BBTM 11B, de mayor macrotextura, con los conseguidos en mezclas tipo AC $16 \mathrm{D}$.

La tabla 4.11 muestra el plan de ensayos que se llevará a cabo, para evaluar la influencia de la macrotextura en el comportamiento a deslizamiento de las mezclas asfálticas con el método de ensayo desarrollado. 
Tabla 4. 11. Plan de ensayos para evaluar la influencia del tipo de mezcla

\begin{tabular}{|c|c|c|c|c|c|c|c|}
\hline MEZCLA & $\begin{array}{l}\text { ÁRIDO } \\
\text { GRUESO }\end{array}$ & CPA & $\begin{array}{l}\text { ÁRIDO } \\
\text { FINO }\end{array}$ & $\begin{array}{c}\text { MACRO } \\
(\mathbf{m m})\end{array}$ & LIGANTE & $\begin{array}{l}\text { COND. } \\
\text { ENSAYO }\end{array}$ & $\begin{array}{c}\text { No } \\
\text { PROBETAS }\end{array}$ \\
\hline \multirow{2}{*}{$\begin{array}{c}\text { BBTM } \\
11 B\end{array}$} & \multirow{2}{*}{ PÓRFIDO } & \multirow{2}{*}{47} & \multirow{2}{*}{ SÍLICE } & MENOR & $\begin{array}{c}\text { PMB } \\
45 / 80-65\end{array}$ & \multirow{2}{*}{$\begin{array}{l}\text { UNE-EN } \\
1097-8\end{array}$} & 6 \\
\hline & & & & MAYOR & $\begin{array}{c}\text { PMB } \\
45 / 80-65\end{array}$ & & 6 \\
\hline $\begin{array}{c}\text { BBTM } \\
11 \mathrm{~B}\end{array}$ & PÓRFIDO & 50 & SÍLICE & $>1,5$ & $\begin{array}{c}\text { PMB } \\
45 / 80-65\end{array}$ & $\begin{array}{l}\text { UNE-EN } \\
1097-8 \\
\text { MUELLE }\end{array}$ & 4 \\
\hline AC 16D & PÓRFIDO & 50 & SÍLICE & $<1,5$ & $\begin{array}{c}\text { PMB } \\
45 / 80-65\end{array}$ & $\begin{array}{l}\text { UNE-EN } \\
1097-8 \\
\text { MUELLE }\end{array}$ & 4 \\
\hline $\begin{array}{c}\text { BBTM } \\
11 \mathrm{~B} \\
\end{array}$ & CALIZA & 43 & CALIZA & $>1,5$ & $\begin{array}{c}\text { PMB } \\
45 / 80-65\end{array}$ & $\begin{array}{l}\text { UNE-EN } \\
1097-8 \\
\text { MUELLE }\end{array}$ & 4 \\
\hline$A C 16 D$ & CALIZA & 43 & CALIZA & $<1,5$ & $\begin{array}{c}\text { PMB } \\
45 / 80-65\end{array}$ & $\begin{array}{l}\text { UNE-EN } \\
1097-8 \\
\text { MUELLE }\end{array}$ & 4 \\
\hline
\end{tabular}




\section{ANÁLISIS DE RESULTADOS}

\subsection{Introducción}

Durante el desarrollo de este capítulo se expone y analiza el conjunto de resultados obtenidos en cada una de las fases de la investigación llevada a cabo para el desarrollo del método de ensayo CPM. Siguiendo el mismo orden establecido en la metodología, en primer lugar se presentan los resultados relativos a la fabricación del prototipo de ensayo diseñado en el capítulo anterior. En esta sección se describirán las principales características del dispositivo de ensayo fabricado.

En segundo lugar, se definen las condiciones durante la realización del ensayo CPM, las características de las probetas de mezcla fabricadas, el procedimiento para pulir dichas probetas, la toma de datos durante la realización del ensayo y los criterios de rechazo más apropiados para optimizar la evaluación del comportamiento de las mezclas bituminosas frente a la resistencia al deslizamiento.

Finalmente, se mostrarán los resultados concernientes al plan de ensayos ejecutado durante esta investigación para validar el método de ensayo CPM, los valores de repetibilidad conseguidos y los resultados del estudio de sensibilidad llevado a cabo respecto a las condiciones de ensayo y a los materiales evaluados.

\subsection{Fabricación del prototipo de ensayo}

Tal y como se definió en la fase de diseño, el dispositivo fabricado ha consistido en una modificación del equipo que actualmente se usa para pulir probetas de árido, según la UNE-EN 1097-8, para la determinación del coeficiente de pulimento acelerado de los áridos.

Con el fin de poder determinar el coeficiente de pulimento de mezclas bituminosas en lugar de en áridos, ha sido necesario realizar modificaciones a la rueda porta-muestras del equipo originalmente empleado para pulir áridos, a sus placas laterales, al eje que la debía soportar y dotar de mayor potencia al motor. En una fase posterior, como consecuencia de las roturas que se producían en algunas probetas de mezcla durante su pulimento, se añadió una última modificación al equipo para pulir probetas de árido, consistente en colgar el peso, que en el equipo original está unido a un brazo palanca, de un muelle de longitud $86 \mathrm{~mm}$ y una constante "k" de Young de $17.500 \mathrm{~N} / \mathrm{m}$. Este peso es el 
responsable de la fuerza de $725 \pm 10 \mathrm{~N}$ que ejerce la rueda de caucho rígido contra las probetas de árido en el ensayo CPA. Durante el proceso de pulimento la rueda porta-muestras gira a 320 r.p.m. Las pequeñas irregularidades que existen en la superficie de las probetas dan lugar a que se produzcan pequeños saltos o impactos de la rueda de caucho rígido contra las probetas. Si son probetas de árido, su integridad no se ve afectada. Por el contrario, si son probetas de mezcla, estos golpes terminan degradando o rompiendo las mismas antes de que el ensayo se pudiera dar por finalizado.

Aunque se probó con distintos tipos de muelle se decidió elegir el de $17.500 \mathrm{~N} / \mathrm{m}$ por ser el que mejor conseguía amortiguar los golpes de la rueda de caucho contra las probetas de mezcla y el que daba lugar a un pulimento más homogéneo, (figura 5.1).

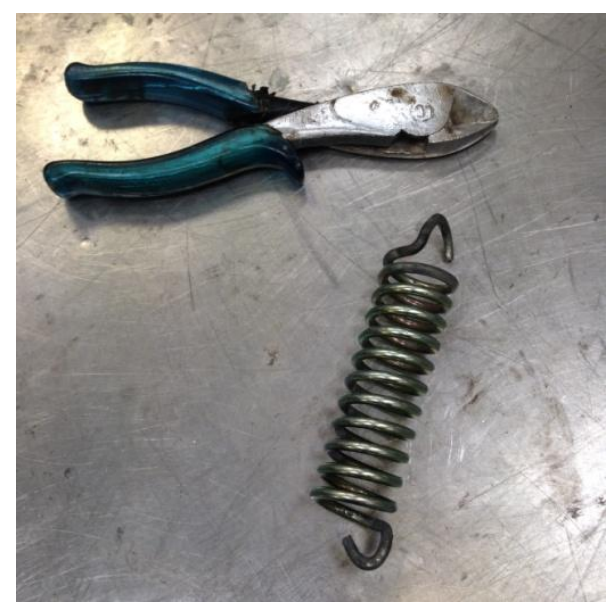

Figura 5. 1. Muelle utilizado para el pulimento de las probetas de mezcla

Como ya se explicó en el capítulo anterior, las probetas de mezcla se fabricaron con la misma curvatura que la conseguida en las de los áridos, para que el pulimento se produjese de una forma similar. Estas probetas, con forma de dovela, en su cara externa tienen una longitud de $107 \mathrm{~mm}$ y en la interna de 91 $\mathrm{mm}$. Su anchura es de $80 \mathrm{~mm}$ y su espesor de $30 \mathrm{~mm}$, (figura 5.3), con el objeto de poder garantizar una compactación adecuada en el molde, que asegure una densidad y porcentaje de huecos lo más parecida posible a la que se debe alcanzar en obra. 


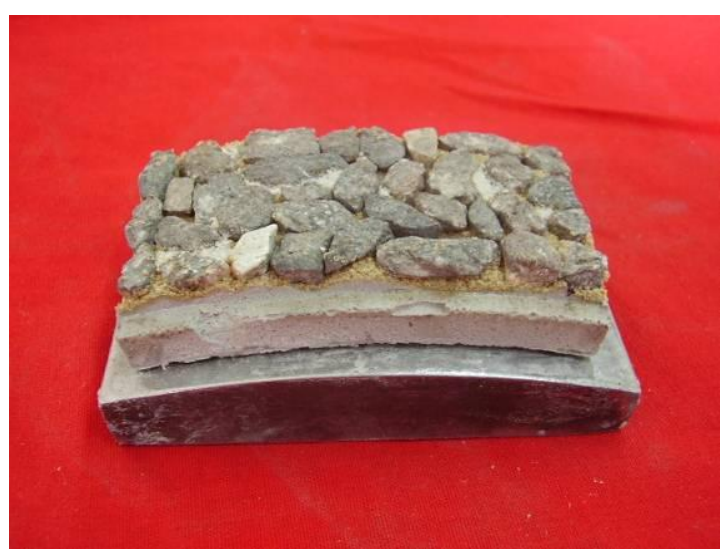

Figura 5. 2: Probeta de áridos.

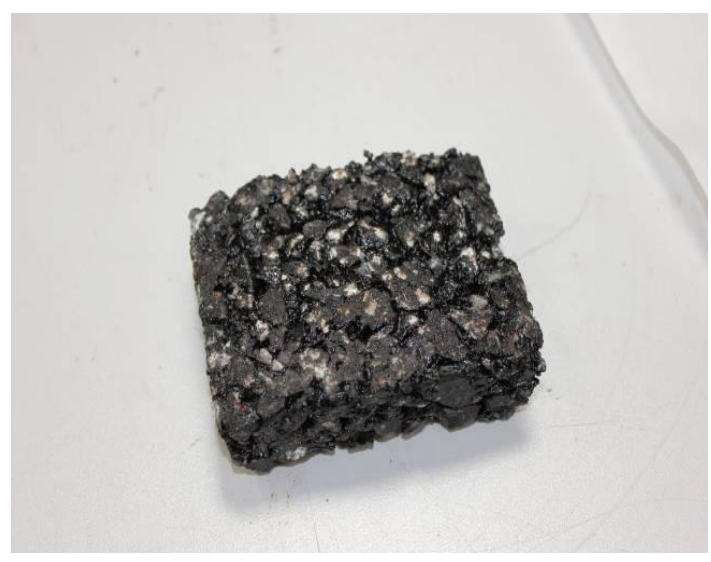

Figura 5. 3: Probeta de mezcla.

La nueva rueda porta-muestras pasó a tener un diámetro interior de $348 \mathrm{~mm}$, de forma que el diámetro externo, rueda más probeta de mezcla, fuese el mismo que en la máquina original. Con esta configuración, se pueden colocar 10 probetas de 5 tipos de mezclas distintos más 2 probetas fabricadas sólo con el árido de referencia de CPA conocido, que al igual que en el ensayo de la UNE-EN 1097-8, se colocan en cada rueda, con el objeto de poder comprobar en cada ensayo que el pulimento y la medición de datos con el péndulo TRRL se hacen de forma adecuada, (figura 5.4).

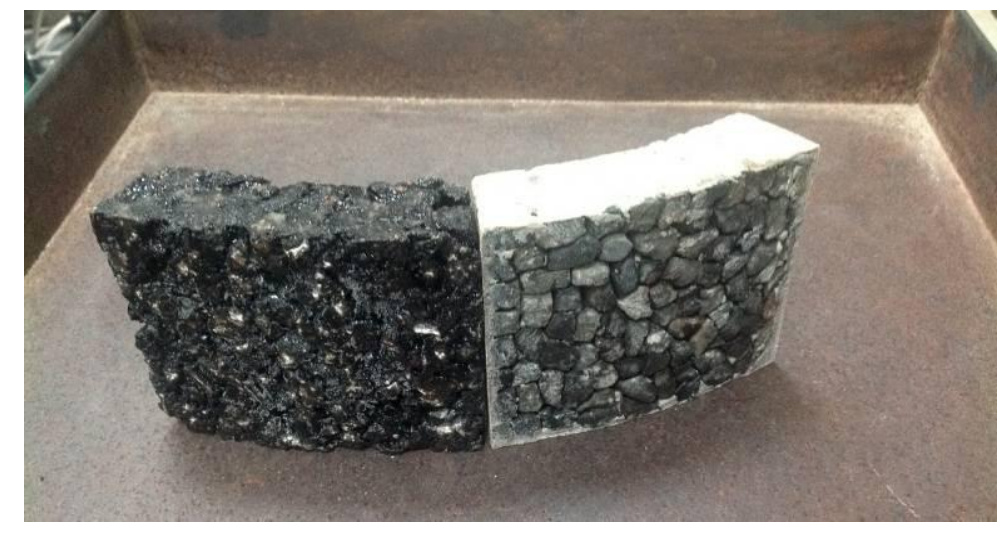

Figura 5. 4. Probeta de mezcla junto a probeta fabricada sólo con el árido de referencia.

Las dos probetas con el árido de referencia se fabrican sobre una dovela de mortero de cemento, de las mismas dimensiones que las probetas de mezcla, pero de un espesor igual a $17,5 \mathrm{~mm}$, que sumados a los $12,5 \mathrm{~mm}$ de la probeta de árido, que se fabrica según dicha norma, da lugar a una probeta de espesor final $30 \mathrm{~mm}$ igual al del resto de las probetas de mezcla a ensayar en la misma rueda.

La rueda porta-muestras desarrollada posee un sistema de uña continuo para soportar y sujetar las probetas de mezcla durante la fase de pulimento. La uña sobre la muestra tiene un ancho de $18 \mathrm{~mm}$ dejando una zona para el pulimento de de $44 \mathrm{~mm}$, (figura 5.5 y 5.6). 


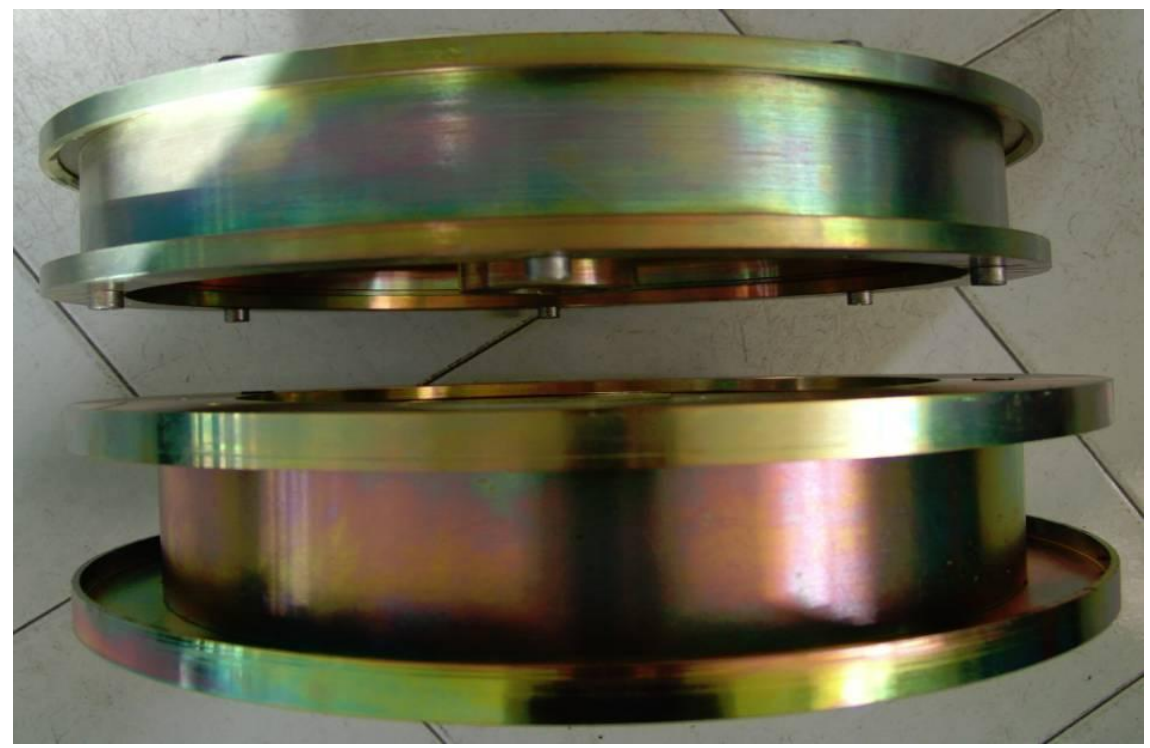

Figura 5. 5 Comparativa de la rueda porta-muestras de probetas de árido, (arriba), y de probetas de mezcla, (abajo).

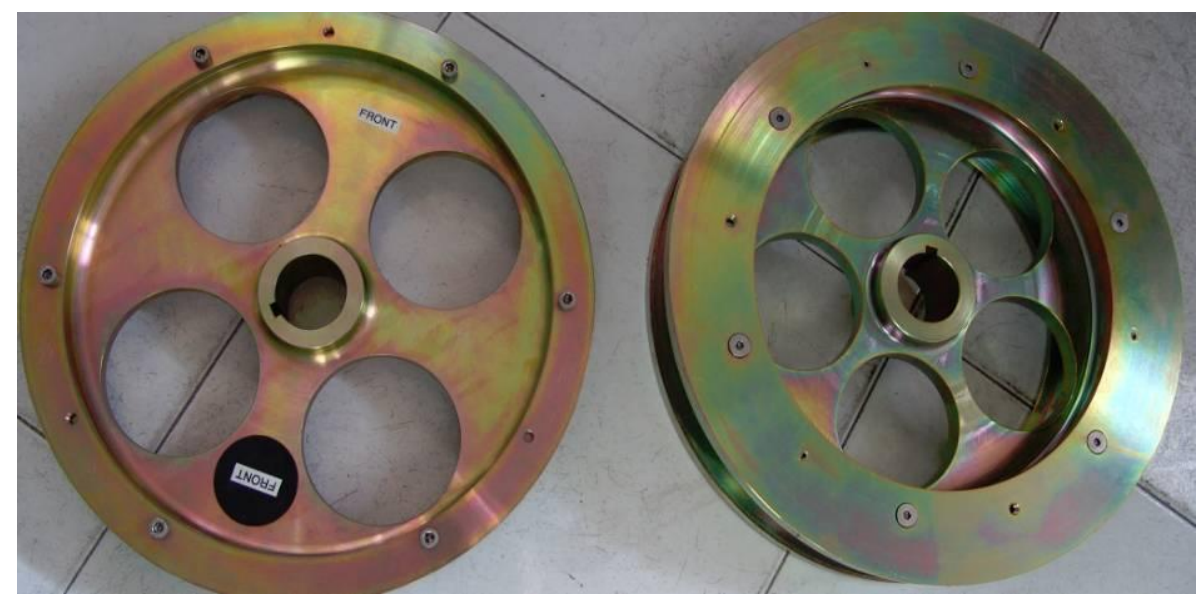

Figura 5.6 Ruedas porta-muestras original de diámetro interno $385 \mathrm{~mm}$ (izquierda) y rueda modificada de diámetro interno $348 \mathrm{~mm}$, (derecha).

La nueva rueda, más pesada que la anterior y de mayor ancho, obligó a fabricar un nuevo eje capaz de soportar el mayor peso, (figura 5.7.), y un nuevo sistema de anclaje para el nuevo eje, (figura 5.8).

A causa del mayor peso del conjunto rueda porta-muestras probetas, hubo que sustituir el motor del equipo por otro de más potencia, $(0,37 \mathrm{~kW})$. 


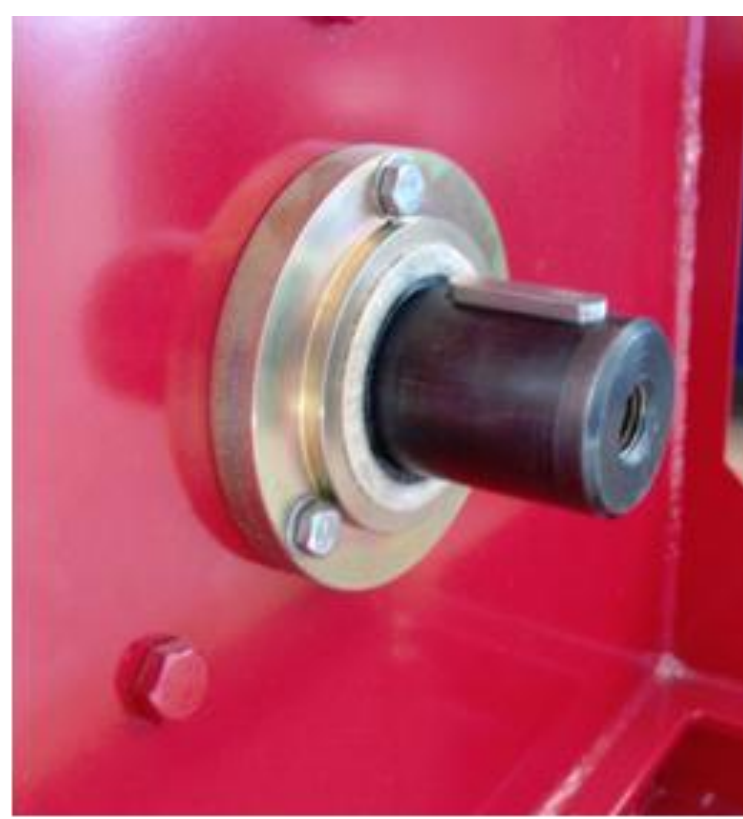

Figura 5.7. Nuevo eje sobre el que gira la rueda.

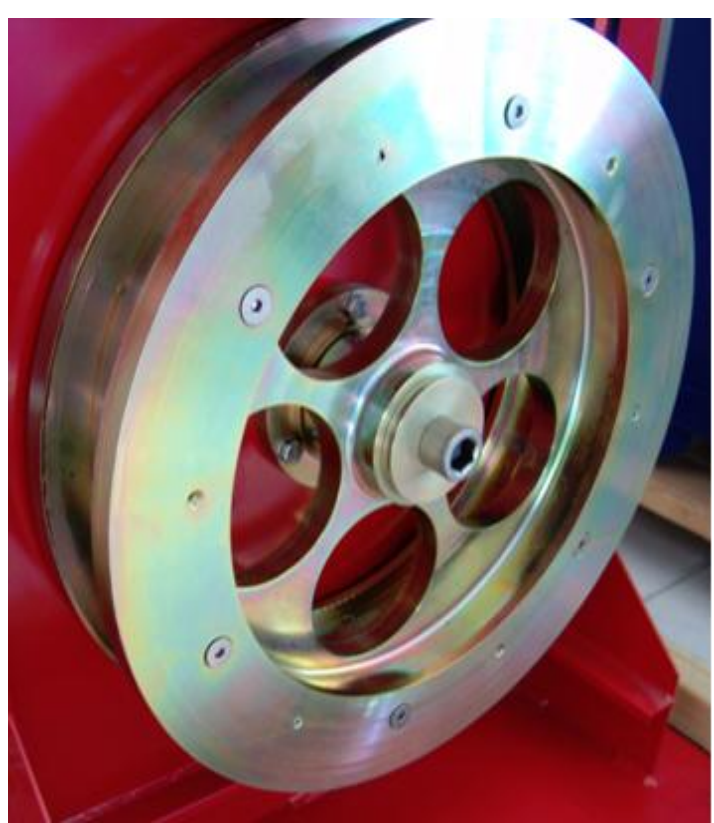

Figura 5.8. Detalle del sistema de anclaje

\subsection{Validación del método de ensayo CPM}

Una vez adaptados tanto el equipo de pulimento como la rueda porta-muestras, para que la máquina que sirve para pulir áridos según la UNE-EN 1097-8 pueda pulir también probetas de mezcla bituminosa, en el presente apartado se procederá a validar el método de ensayo definido en el capítulo 4.

\subsubsection{Características de las probetas de mezcla fabricadas}

El procedimiento de compactación que se ha seguido para fabricar las probetas de mezcla ha tratado de garantizar una densidad, porcentaje de huecos y macrotextura en las muestras fabricadas en laboratorio que fuesen representativas de las que se tendrían sobre la misma mezcla colocada en el pavimento de una carretera.

En un primer momento el procedimiento de compactación elegido fue el de aplicar, con los útiles de compactación descritos en el apartado 4.2.2 de la tesis, una compresión simple sobre la mezcla colocada dentro del molde mediante la aplicación de una fuerza con una cadencia de $800 \mathrm{~N} / \mathrm{s}$ hasta que el espesor de la muestra alcanzase el valor de $30 \mathrm{~mm} \pm 1,5 \mathrm{~mm}$ y no superándose, en ningún caso, los $200 \mathrm{kN}$ durante todo el proceso.

Antes de iniciar el proceso de compactación se precalentaron en estufas los útiles a emplear hasta la temperatura óptima, con el objeto de no enfriar la mezcla durante la compactación y evitar problemas de falta de densidad. La temperatura de 
compactación de las mezclas que se fabricaron para el desarrollo de este trabajo fue de $165^{\circ} \mathrm{C}$.

En la tabla 5.1 se incluyen los datos que se tomaron para la fabricación de las 12 primeras probetas de mezcla BBTM 11B, fabricados con áridos gruesos tipo pórfido, árido fino síliceo y betún tipo PMB 45/80-65.

Con el objeto de comprobar si el grado de compactación alcanzado era el adecuado, se calculó la densidad y el porcentaje de huecos en mezcla de cada una de las probetas fabricadas. De acuerdo al artículo 543 del Pliego de Prescripciones Técnicas Generales para Obras de Carreteras y Puentes del Ministerio de Fomento, (PG3), en mezclas BBTM 11B con espesores iguales o superiores a $2,5 \mathrm{~cm}$, el porcentaje de huecos en mezcla de la mezcla fabricada y colocada en obra no puede diferir en $\pm 2 \%$ del obtenido de la fórmula de trabajo.

El porcentaje de huecos en mezcla, (UNE-EN 12697-8), que varió ligeramente en cada probeta, se obtuvo a partir de la densidad máxima de la mezcla, (UNE-EN 12697-5) y de la densidad aparente, procedimiento geométrico, (UNE-EN 12697-6). Al tratarse de probetas con forma de dovela, su volumen geométrico se calculó utilizando la fórmula de la corona circular y las medidas realizadas con calibre en diferentes puntos de la probeta para calcular su espesor, anchura y longitud. Como se puede observar, el valor del porcentaje de huecos obtenido con este procedimiento fue prácticamente idéntico al de la fórmula de trabajo. Todas las probetas dieron valores dentro del intervalo $\pm 2 \%$ por lo que se dio por bueno el procedimiento de compactación definido a falta de conocer la macrotextura conseguida en cada probeta.

Como se ha comentado anteriormente, el procedimiento de compactación debía además conseguir reproducir en laboratorio la macrotextura que se alcanza en las mezclas que se colocan en obra. Por este motivo se procedió en cada ensayo a determinar la macrotextura obtenida de cada probeta después de su compactación, mediante una adaptación del ensayo del círculo de arena, (UNE-EN 13036-1), en el que se ha utilizado un volumen menor de arena, $\left(5.000 \mathrm{~mm}^{3}\right)$. Esta arena se extendía sobre la superficie de la probeta con la herramienta esparcidora definida en la mencionada norma, procurando rellenar los huecos de la superficie de la probeta a ras con los picos de las partículas de árido. A partir de la medida de superficie de la mancha obtenida digitalmente se ha calculado la profundidad media del círculo de arena dividiendo el volumen de arena empleado por dicha superficie. 
Tabla 5. 1: Características de las probetas BBTM 11B fabricadas con árido pórfido.

\begin{tabular}{|c|c|c|c|c|c|c|c|}
\hline PROBETA & $\begin{array}{c}\text { ESPESOR } \\
(\mathrm{cm})\end{array}$ & $\begin{array}{c}\text { ANCHURA } \\
(\mathrm{cm})\end{array}$ & $\begin{array}{c}\text { VOLUMEN } \\
\left(\mathrm{cm}^{3}\right)\end{array}$ & $\begin{array}{c}\text { MASA } \\
(\mathrm{g})\end{array}$ & $\begin{array}{c}\text { DENSIDAD } \\
\text { GEOMÉTRICA } \\
\left(\mathbf{g} / \mathbf{c m}^{3}\right)\end{array}$ & $\begin{array}{c}\text { HUECOS } \\
\text { MEZCLA } \\
(\%)\end{array}$ & $\begin{array}{c}\text { SUP. } \\
\text { PROBETA } \\
\left(\mathbf{m m}^{2}\right)\end{array}$ \\
\hline 1 & 2,9 & 8,11 & 238 & 489 & 2,092 & 18,9 & 8702 \\
\hline 2 & 2,9 & 8,16 & 238 & 483 & 2,061 & 19,7 & 8755 \\
\hline 3 & 2,9 & 8,25 & 239 & 489 & 2,052 & 19,1 & 8853 \\
\hline 4 & 2,9 & 8,10 & 242 & 484 & 2,039 & 20,9 & 8694 \\
\hline 5 & 3,0 & 8,12 & 244 & 485 & 2,013 & 21,5 & 8721 \\
\hline 6 & 3,0 & 8,11 & 242 & 487 & 2,045 & 20,5 & 8704 \\
\hline 7 & 2,9 & 8,09 & 239 & 481 & 2,052 & 20,6 & 8688 \\
\hline 8 & 2,9 & 8,34 & 236 & 492 & 2,071 & 17,6 & 8950 \\
\hline 9 & 2,9 & 8,22 & 238 & 482 & 2,033 & 20,1 & 8824 \\
\hline 10 & 2,9 & 8,24 & 236 & 483 & 2,056 & 19,1 & 8849 \\
\hline 11 & 2,9 & 8,23 & 239 & 483 & 2,028 & 20,2 & 8837 \\
\hline 12 & 2,9 & 8,11 & 239 & 484 & 2,061 & 20,1 & 8700 \\
\hline MÁXIMO & 2,98 & 8,34 & 244 & 492 & 2,092 & 21,52 & 8950 \\
\hline MÍNIMO & 2,87 & 8,09 & 236 & 481 & 2,013 & 17,61 & 8688 \\
\hline MÁX-MÍN & 0,11 & 0,25 & 8,23 & 11,00 & 0,08 & 3,91 & 262,26 \\
\hline MEDIA & 2,92 & 8,17 & 239 & 485 & 2,050 & 19,87 & 8773,21 \\
\hline $\begin{array}{l}\text { DESV. } \\
\text { TÍPICA }\end{array}$ & 0,032 & 0,08 & 2,426 & 3,353 & 0,021 & 1,048 & 86,308 \\
\hline
\end{tabular}


En la tabla 5.2 se incluyen los resultados de la macrotextura obtenidos para las primeras probetas de mezcla fabricadas que presentan una cierta dispersión. Pero el principal problema es que la macrotextura que debía conseguirse, superior a 1,5 $\mathrm{mm}$, no se logra obteniendo valores entre 0,74 y $1 \mathrm{~mm}$, lo que parece poner de manifiesto que no sólo no se estaban consiguiendo probetas con una macrotextura homogénea sino que ésta, que podía tener influencia en la determinación del coeficiente de resistencia al deslizamiento, difería sustancialmente de los valores que se consiguen con los medios de compactación que se emplean habitualmente en obra para una mezcla tipo BBTM 11B.

Tabla 5. 2 Macrotextura de las probetas BBTM 11B fabricadas con pórfido.

\begin{tabular}{|c|c|c|c|c|c|c|c|}
\hline PROBETA & $\begin{array}{c}\text { VOLUMEN } \\
(\mathrm{cm} 3)\end{array}$ & $\begin{array}{c}\text { MASA } \\
(\mathrm{g})\end{array}$ & $\begin{array}{c}\text { DENSIDAD } \\
\text { GEOM. } \\
\left(\mathrm{g} / \mathrm{cm}^{3}\right)\end{array}$ & $\begin{array}{c}\text { HUECOS } \\
\text { MEZCLA } \\
(\%)\end{array}$ & $\begin{array}{c}\text { SUP. } \\
\text { PROBETA } \\
\left(\mathrm{mm}^{2}\right)\end{array}$ & $\begin{array}{c}\text { SUP. } \\
\text { MANCHA } \\
\text { ARENA } \\
\left(\mathbf{m m}^{2}\right)\end{array}$ & $\begin{array}{c}\text { MACRO. } \\
(\mathrm{mm})\end{array}$ \\
\hline 1 & 238 & 489 & 2,092 & 18,9 & 8702 & 5061 & 0,99 \\
\hline 2 & 238 & 483 & 2,061 & 19,7 & 8755 & 5941 & 0,84 \\
\hline 3 & 239 & 489 & 2,052 & 19,1 & 8853 & 6073 & 0,82 \\
\hline 4 & 242 & 484 & 2,039 & 20,9 & 8694 & 5498 & 0,91 \\
\hline 5 & 244 & 485 & 2,013 & 21,5 & 8721 & 5539 & 0,90 \\
\hline 6 & 242 & 487 & 2,045 & 20,5 & 8704 & 5885 & 0,85 \\
\hline 7 & 239 & 481 & 2,052 & 20,6 & 8688 & 5953 & 0,84 \\
\hline 8 & 236 & 492 & 2,071 & 17,6 & 8950 & 6204 & 0,81 \\
\hline 9 & 238 & 482 & 2,033 & 20,1 & 8824 & 5443 & 0,92 \\
\hline 10 & 236 & 483 & 2,056 & 19,1 & 8849 & 6723 & 0,74 \\
\hline 11 & 239 & 483 & 2,028 & 20,2 & 8837 & 6279 & 0,80 \\
\hline 12 & 239 & 484 & 2,061 & 20,1 & 8700 & 4995 & 1,00 \\
\hline MÁXIMO & 244 & 492 & 2,092 & 21,5 & 8950 & 6723 & 1,00 \\
\hline MÍNIMO & 236 & 481 & 2,013 & 17,6 & 8688 & 4995 & 0,74 \\
\hline MÁX-MÍN & 8 & 11 & 0,08 & 3,9 & 262 & 1728 & 0,26 \\
\hline MEDIA & 239 & 485 & 2,050 & 19,9 & 8773 & 5799 & 0,87 \\
\hline $\begin{array}{l}\text { DESV. } \\
\text { TÍPICA }\end{array}$ & 2,426 & 3,35 & 0,021 & 1,048 & 86,308 & 509,087 & 0,077 \\
\hline
\end{tabular}


Por este motivo hubo que cambiar el sistema de compactación utilizado, disminuyendo la carga de 200 a 170 kN y el tiempo de aplicación de la carga a 6 segundos lo que ayudó a conseguir valores de macrotextura más representativos del tipo de mezcla a ensayar, como se podrá ver en apartados posteriores.

Las figuras 5.9 y 5.10 corresponden a las dos probetas de mezcla fabricadas en las que se consiguieron los valores máximo y mínimo de macrotextura. En ellas puede apreciarse a simple vista que la superficie de la mancha de arena es menor en la probeta de mezcla con mayor macrotextura.

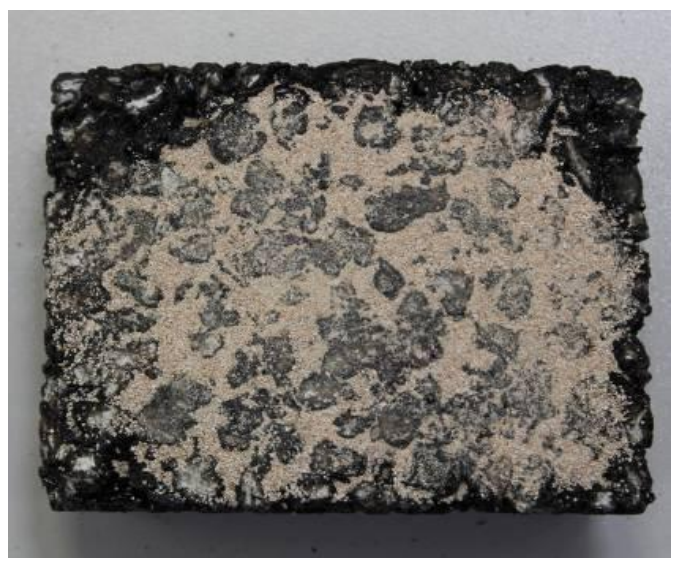

Figura 5. 9. Macrotextura de $0,7 \mathrm{~mm}$

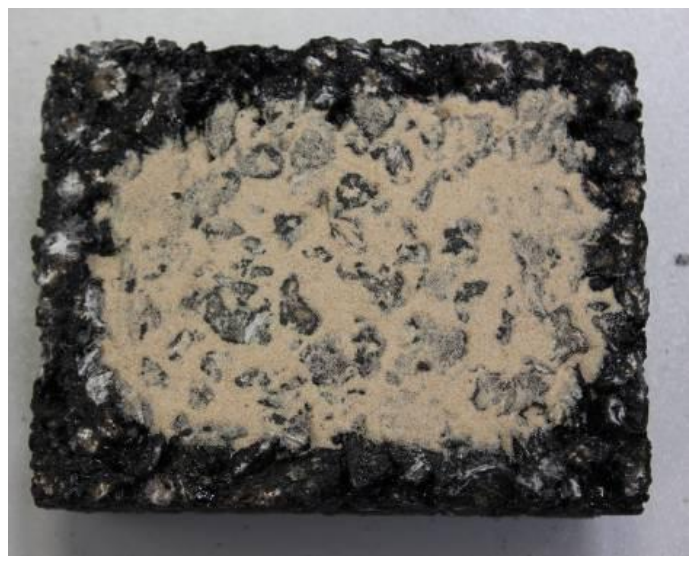

Figura 5. 10. Macrotextura de $1 \mathrm{~mm}$

\subsubsection{Pulimento de las probetas}

La temperatura de acondicionamiento del ensayo deberá estar en consonancia con las que va a soportar la mezcla durante su vida de servicio. Aunque no es una variable que tenga una especial importancia en la determinación de la resistencia al deslizamiento, por defecto se realizará el ensayo de pulimento de mezclas a una temperatura ambiente de $20^{\circ} \mathrm{C} \pm 5{ }^{\circ} \mathrm{C}$, por analogía con la temperatura que se emplea en la norma UNE-EN 1097-8 sobre pulimento de áridos. Además es una temperatura cercana a las medias anuales de muchas provincias españolas.

En cada rueda porta-probetas se colocarán 10 probetas de las 5 mezclas a ensayar y 2 probetas fabricadas sólo con el árido de referencia, según el procedimiento descrito en la UNE-EN 1097-8. Estas probetas de referencia se fabricarán con un árido de valor CPA conocido. Al finalizar el ensayo el valor medio de resistencia al deslizamiento de las dos probetas de árido, obtenido con el péndulo TRRL, después de un pulimento de 3 horas utilizando un abrasivo de grano fino y otras tres horas con un abrasivo de grano más grueso, debe estar en el intervalo del árido de referencia utilizado en este trabajo definido como su media \pm 3 unidades. 
Las probetas de mezcla se disponen sobre la rueda porta-muestras desarrollada formando una banda continua con un diámetro exterior de $408 \pm 3 \mathrm{~mm}$ para que la rueda de caucho rígido que produce el pulimento pueda rodar libremente sin chocar ni patinar sobre las probetas de mezcla.

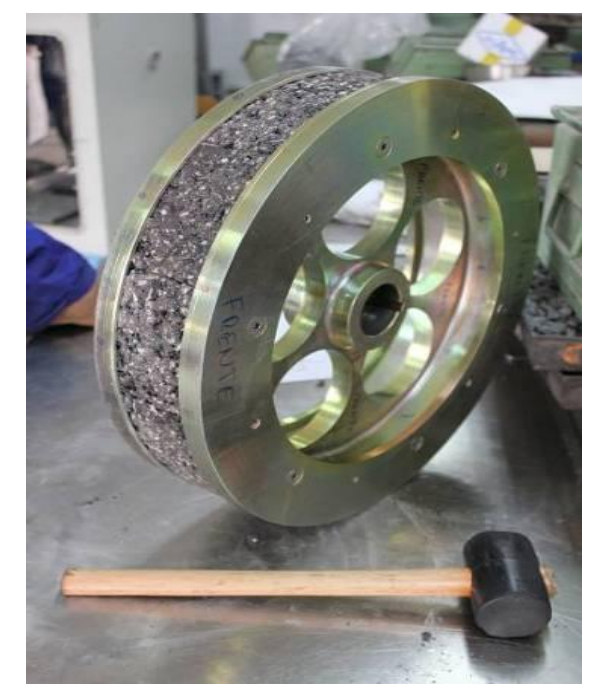

Figura 5. 11. Rueda porta-muestras de mezcla bituminosa.

Si fuese necesario los huecos que pudieran quedar entre probetas de mezcla consecutivas, o entre las probetas de mezcla y la rueda porta-muestras, se rellenarán con materiales adecuados para evitar escalones entre una probeta de mezcla y otra que pudieran dar lugar a un pulimento no uniforme, o a un posible punto por donde la probetas pudieran deteriorarse sin que el ensayo pudiera darse por válido, (figuras 5.12 y 5.13 ).

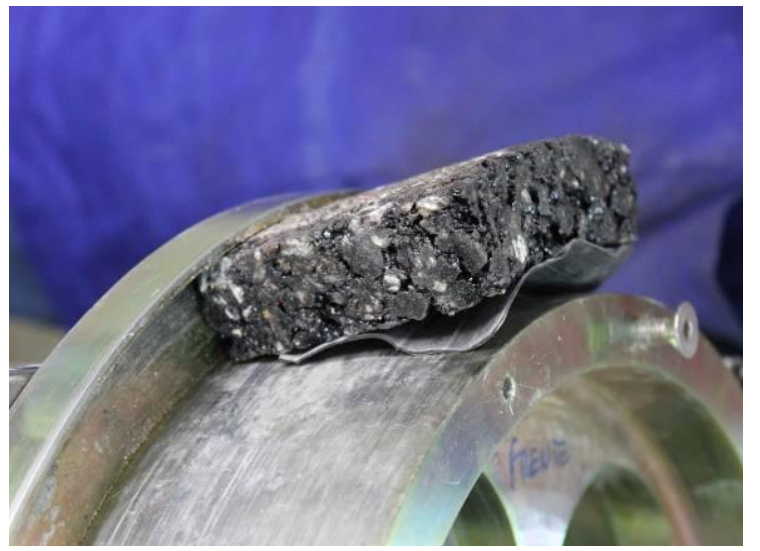

Figura 5. 12. Vista frontal lámina de caucho utilizada para corregir defectos de espesor.

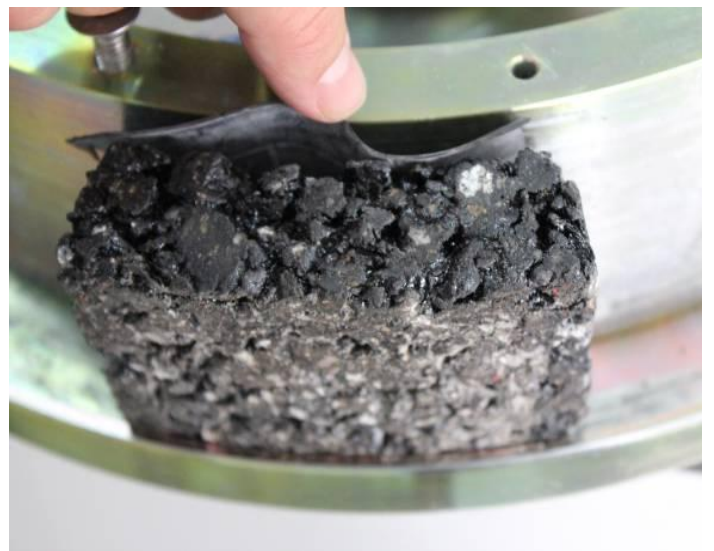

Figura 5. 13 Vista superior lámina de caucho utilizada para corregir defectos de espesor.

A medida que la investigación fue avanzando, la precisión alcanzada a la hora de determinar el espesor de las probetas evitó, en las últimas ruedas ensayadas, el 
que se tuviese que hacer uso de estos artificios. A pesar de ello, comprobamos en las primeras ruedas de mezcla ensayadas, la necesidad de reforzar las juntas entre dovelas de probetas consecutivas mediante un sellado hecho a base de un árido fino y una resina epoxi de baja viscosidad, con cuidado de no afectar a la zona de medida del rozamiento. Aunque los escalones entre probetas consecutivas prácticamente no eran apreciables, el rozamiento provocado por la rueda de caucho rígido generaba en las juntas de las dovelas de mezcla un efecto dinámico capaz de romper las probetas en poco tiempo, (figuras 5.14 a 5.17), lo que pudo evitarse con el empleo del mortero de resina.

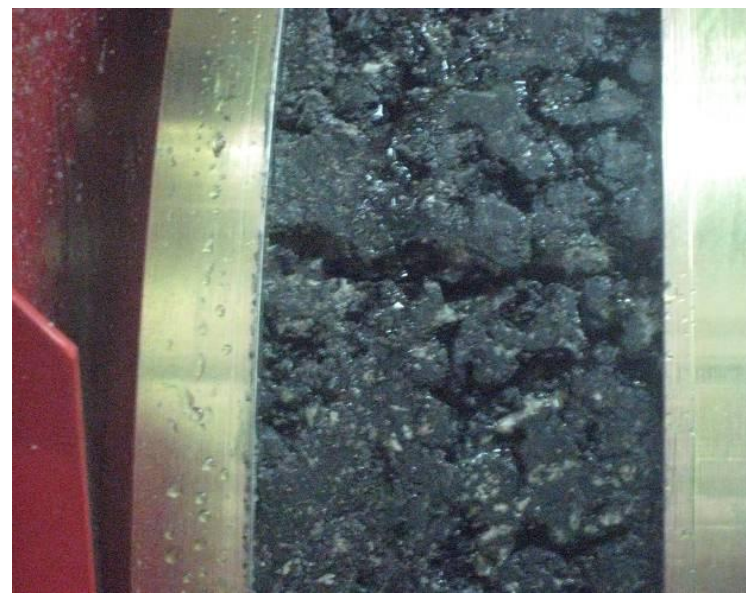

Figura 5. 14. Inicio de rotura de probeta en junta y rotura de la misma

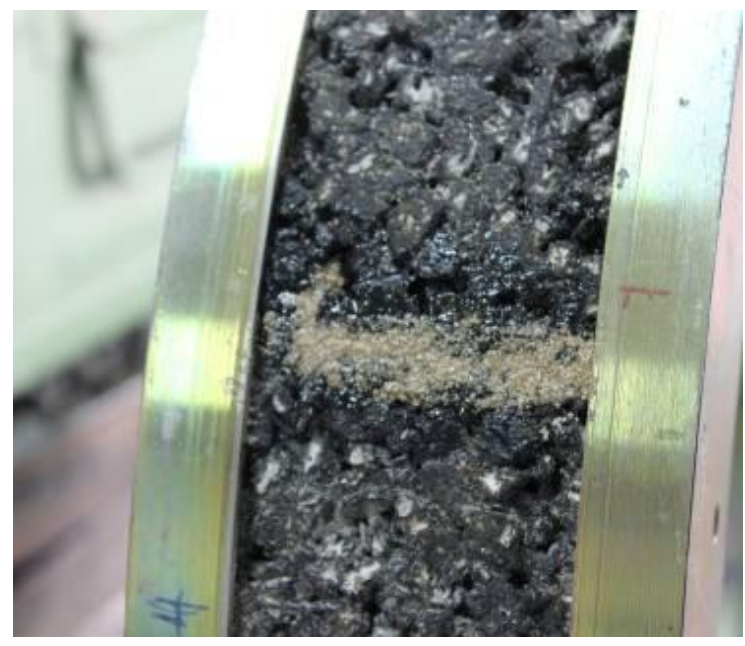

Figura 5. 16. Mortero de resina en juntas.

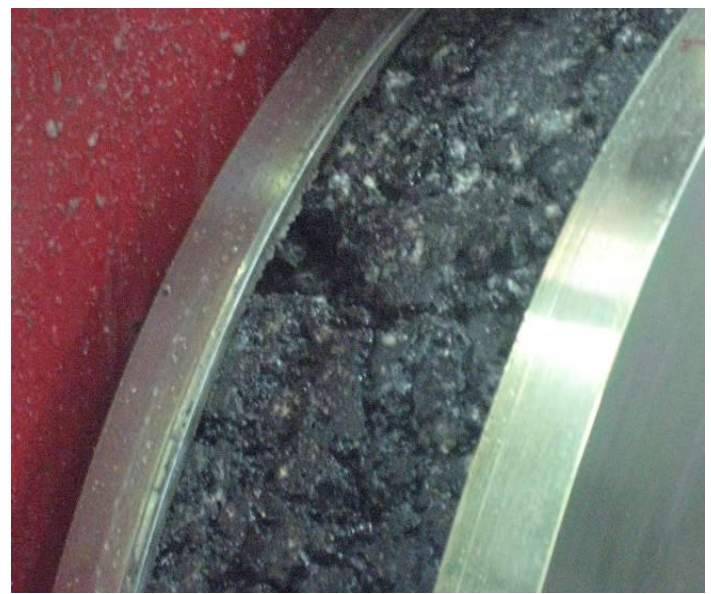

Figura 5. 15. Rotura de la probeta por la junta

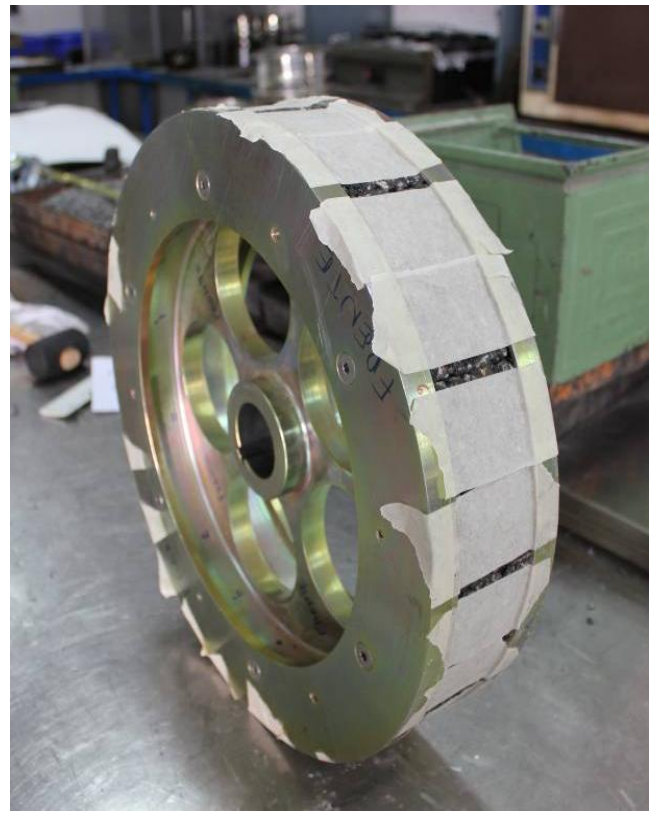

Figura 5. 17. Preparación de la rueda para sellado juntas 
El proceso de pulimento de las probetas de mezcla se hizo de acuerdo a lo indicado en la UNE-EN 1097-8, tal y como se explicó en el capítulo 4 del presente trabajo, con las siguientes modificaciones:

- Las medidas con el péndulo TRRL se hicieron cada hora, con el objeto de caracterizar mejor el proceso de pulimento de las mezclas.

- Las últimas ruedas fabricadas se pulieron con el equipo modificado con muelle, con el objeto de limitar los golpes que se producían entre la rueda de caucho rígida y las probetas de mezcla

- La duración del ensayo se prolongó hasta las 12 horas, 3 horas puliendo con el grano de esmeril y 9 horas con el polvo de esmeril, dado que se comprobó que para esa duración de ensayo prácticamente no había variación en los valores de resistencia al deslizamiento medidos con el péndulo TRRL, para la mayoría de mezclas ensayadas.

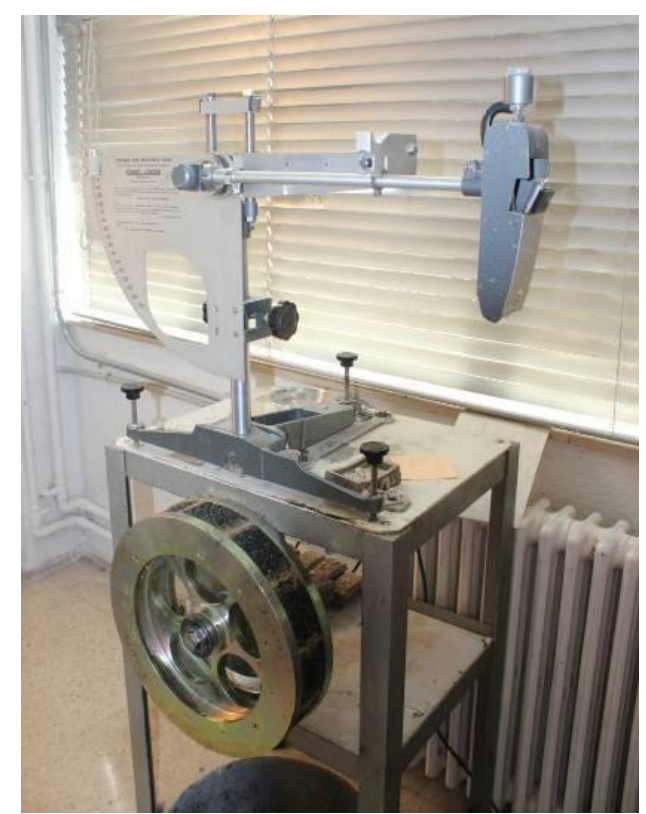

Figura 5. 18. Péndulo TRRL preparado para medir la resistencia al deslizamiento en probeta de mezcla.

\subsubsection{Cálculo del coeficiente de pulimento acelerado de las mezclas}

Como ya se ha comentado anteriormente, la primera mezcla que se fabricó para la presente investigación consistió en una BBTM 11B fabricada con pórfido como árido grueso, con un árido fino silíceo, con $\mathrm{CaCO}_{3}$ con filler de aportación y un betún modificado tipo PMB 45/80-65. En la tabla 5.3 se muestran los valores de resistencia al deslizamiento obtenidos con el péndulo TRRL a lo largo del tiempo, (6 horas). 
Tabla 5. 3. Coeficiente de resistencia al deslizamiento de una BBTM 11B fabricada con pórfido.

\begin{tabular}{|c|c|c|c|c|c|c|c|}
\hline \multicolumn{7}{|c|}{ COEFICIENTE DE RESISTENCIA AL DESLIZAMIENTO } \\
\hline PROBETA & $\mathbf{0}$ & $\mathbf{1}$ & $\mathbf{2}$ & $\mathbf{3}$ & $\mathbf{4}$ & $\mathbf{5}$ & $\mathbf{6}$ \\
\hline 1 & 64 & 71 & 67 & 74 & 60 & 65 & 59 \\
\hline 2 & 74 & 75 & 73 & 70 & 60 & 65 & 57 \\
\hline 3 & 75 & 77 & 75 & 74 & 70 & 65 & 59 \\
\hline 4 & 75 & 75 & 75 & 74 & 70 & 58 & 60 \\
\hline 5 & 77 & 74 & 73 & 72 & 70 & 55 & 59 \\
\hline 6 & 80 & 74 & 67 & 65 & 62 & 65 & 61 \\
\hline 7 & 75 & 74 & 70 & 65 & 65 & 67 & 59 \\
\hline 8 & 67 & 72 & 74 & 69 & 65 & 60 & 60 \\
\hline 9 & 77 & 77 & 75 & 70 & 65 & 65 & 62 \\
\hline 10 & 67 & 75 & 74 & 67 & 65 & 60 & 61 \\
\hline 11 & 77 & 75 & 70 & 70 & 60 & 65 & 61 \\
\hline 12 & 77 & 77 & 73 & 71 & 65 & 65 & 63 \\
\hline MÁX. & 80 & 77 & 75 & 74 & 70 & 67 & 63 \\
\hline MÍN. & 64 & 71 & 67 & 65 & 60 & 55 & 57 \\
\hline MÁX-MÍN & 16 & 6 & 8 & 9 & 10 & 12 & 6 \\
\hline MEDIA & 74 & 75 & 72 & 70 & 65 & 63 & 60 \\
\hline DESV. TÍPICA & 5,0 & 1,9 & 2,9 & 3,2 & 3,8 & 3,7 & 1,6 \\
\hline CV & $6,7 \%$ & $2,5 \%$ & $4,1 \%$ & $4,6 \%$ & $5,9 \%$ & $5,9 \%$ & $2,7 \%$ \\
\hline \multicolumn{7}{|c|}{}
\end{tabular}

Como puede observarse, los resultados del coeficiente de resistencia al deslizamiento a las 6 horas no presentan gran dispersión, variando entre un máximo de 63 y un mínimo de 57, con una media de 60 y una desviación típica de 1,6 .

En la figura 5.19 se muestra cómo ha evolucionado el valor medio del CRD medido a lo largo del tiempo.

Esta evolución está en consonancia con investigaciones realizas previamente sobre la evolución de la resistencia al deslizamiento de un pavimento en el tiempo. Después de la construcción de la rodadura de una carretera puede haber un incremento en el valor de la resistencia al deslizamiento hasta que la película de betún, que envuelve la superficie del árido en contacto con las ruedas de los vehículos, desaparece y la microtextura del agregado es expuesta. Posteriormente el CRD va disminuyendo a lo largo del tiempo conforme el pulimento de los áridos se produce por la acción del tráfico.

Este primer ensayo terminó a las 6 horas porque empezaron a percibirse síntomas de deterioro en las probetas de mezcla, que se habían pulimentando de acuerdo con el procedimiento de ensayo que se describe en la UNE-EN 1097-8, quedando pendiente de determinar la duración del ensayo más adecuada. 


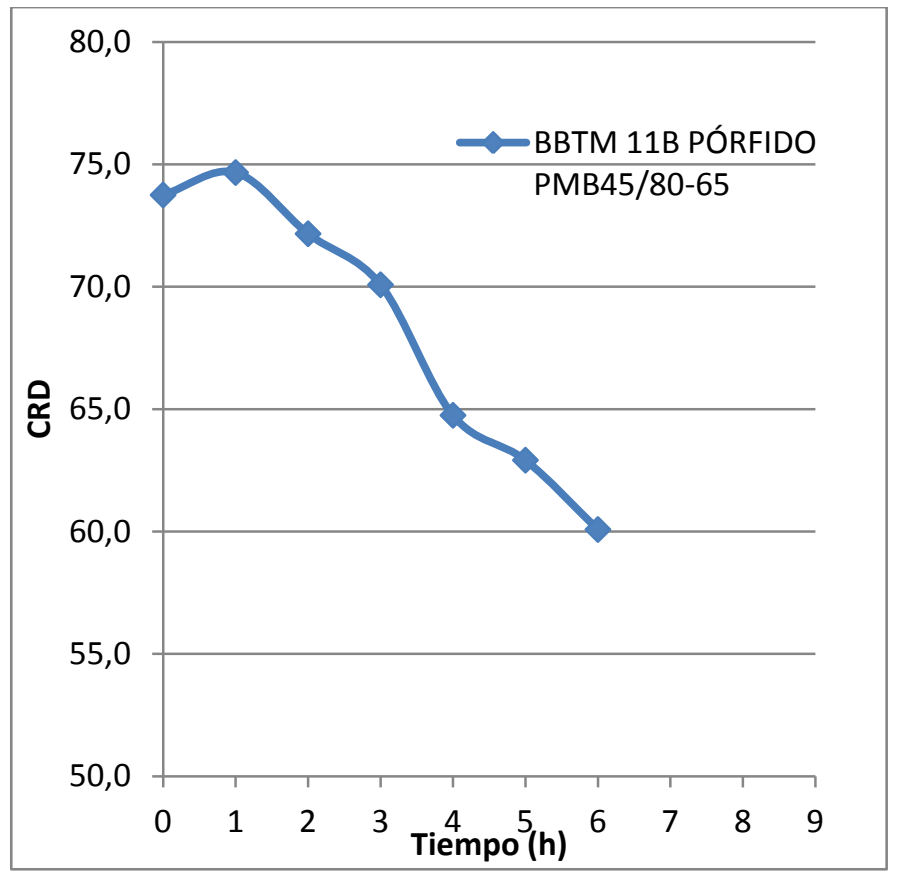

Figura 5. 19. Evolución en el tiempo del CRD de una BBTM 11B fabricada con pórfido.

A continuación se fabricó una segunda rueda con 12 probetas de mezcla BBTM 11B cambiando el árido grueso tipo pórfido de CPA 50 por uno tipo andesita de CPA 57, alargando el tiempo de ensayo, (tabla 5.4). Los resultados de una de las probetas no se incluyen porque se produjo desprendimiento de parte del árido grueso.

La representación gráfica de la evolución de la resistencia al deslizamiento de esta mezcla se incluye en la figura 5.20 en la que se han representado los valores medios obtenidos de las probetas de mezcla pulidas. En la misma gráfica de forma intencionada se ha querido incluir también la evolución del CRD, medido con péndulo TRRL, de probetas de árido andesita fabricadas y pulidas de acuerdo a la UNE-EN 1097-8 con el objeto de comprobar diferencias en el pulimento de probetas de mezcla y de árido. 
Tabla 5. 4. Evolución en el tiempo del CRD de una BBTM 11B fabricada con andesita.

\begin{tabular}{|c|c|c|c|c|c|c|c|c|c|c|c|c|c|c|}
\hline \multirow{2}{*}{$\begin{array}{c}\text { No } \\
\text { PROBETA }\end{array}$} & \multicolumn{4}{|c|}{$\begin{array}{l}\text { ESMERIL } \\
\text { GRUESO }\end{array}$} & \multicolumn{10}{|c|}{ ESMERIL FINO } \\
\hline & 0 & 1 & 2 & 3 & 4 & 5 & 6 & 7 & 8 & 9 & 10 & 12 & 14 & 16 \\
\hline 10 & 75 & 75 & 75 & 76 & 66 & 64 & 64 & 65 & 65 & 68 & 63 & 61 & 64 & 60 \\
\hline 11 & 75 & 75 & 70 & 77 & 69 & 65 & 65 & 66 & 66 & 70 & 70 & & & \\
\hline 1 & 77 & 79 & 75 & 75 & 65 & 60 & 67 & 65 & 65 & 66 & 65 & 61 & 61 & 61 \\
\hline 3 & 75 & 70 & 71 & 76 & 64 & 60 & 65 & 62 & 65 & 69 & 65 & 61 & 61 & 61 \\
\hline 6 & 70 & 75 & 72 & 75 & 71 & 68 & 66 & 64 & 67 & 70 & 67 & 62 & 65 & 65 \\
\hline 12 & 70 & 76 & 78 & 76 & 70 & 68 & 67 & 69 & 69 & 69 & 65 & 64 & 66 & 61 \\
\hline 8 & 74 & 76 & 76 & 75 & 65 & 65 & 66 & 63 & 60 & 63 & 61 & 60 & 60 & 57 \\
\hline 2 & 75 & 77 & 75 & 75 & 65 & 60 & 67 & 65 & 65 & 66 & 65 & 62 & 62 & \\
\hline 5 & 77 & 79 & 76 & 79 & 65 & 65 & 69 & 67 & 66 & 70 & 69 & 63 & 65 & 65 \\
\hline 7 & 75 & 80 & 78 & 76 & 70 & 65 & 66 & 64 & 65 & 66 & 60 & 65 & 65 & \\
\hline 9 & 75 & 80 & 80 & 80 & 75 & 65 & 68 & 69 & 70 & 70 & 68 & 65 & 63 & 56 \\
\hline MÁX. & 77 & 80 & 80 & 80 & 75 & 68 & 69 & 69 & 70 & 70 & 70 & 65 & 66 & 65 \\
\hline MÍN. & 70 & 70 & 70 & 75 & 64 & 60 & 64 & 62 & 60 & 63 & 60 & 60 & 60 & 56 \\
\hline MÁX-MÍN & 7 & 10 & 10 & 5 & 11 & 8 & 5 & 7 & 10 & 7 & 10 & 5 & 6 & 9 \\
\hline MEDIA & 74 & 77 & 75 & 76 & 68 & 64 & 66 & 65 & 66 & 68 & 65 & 62 & 63 & 61 \\
\hline $\begin{array}{c}\text { DESV. } \\
\text { TÍPICA }\end{array}$ & 2,3 & 2,9 & 3,1 & 1,7 & 3,5 & 2,9 & 1,4 & 2,2 & 2,6 & 2,3 & 3,1 & 1,8 & 2,1 & 3,2 \\
\hline
\end{tabular}

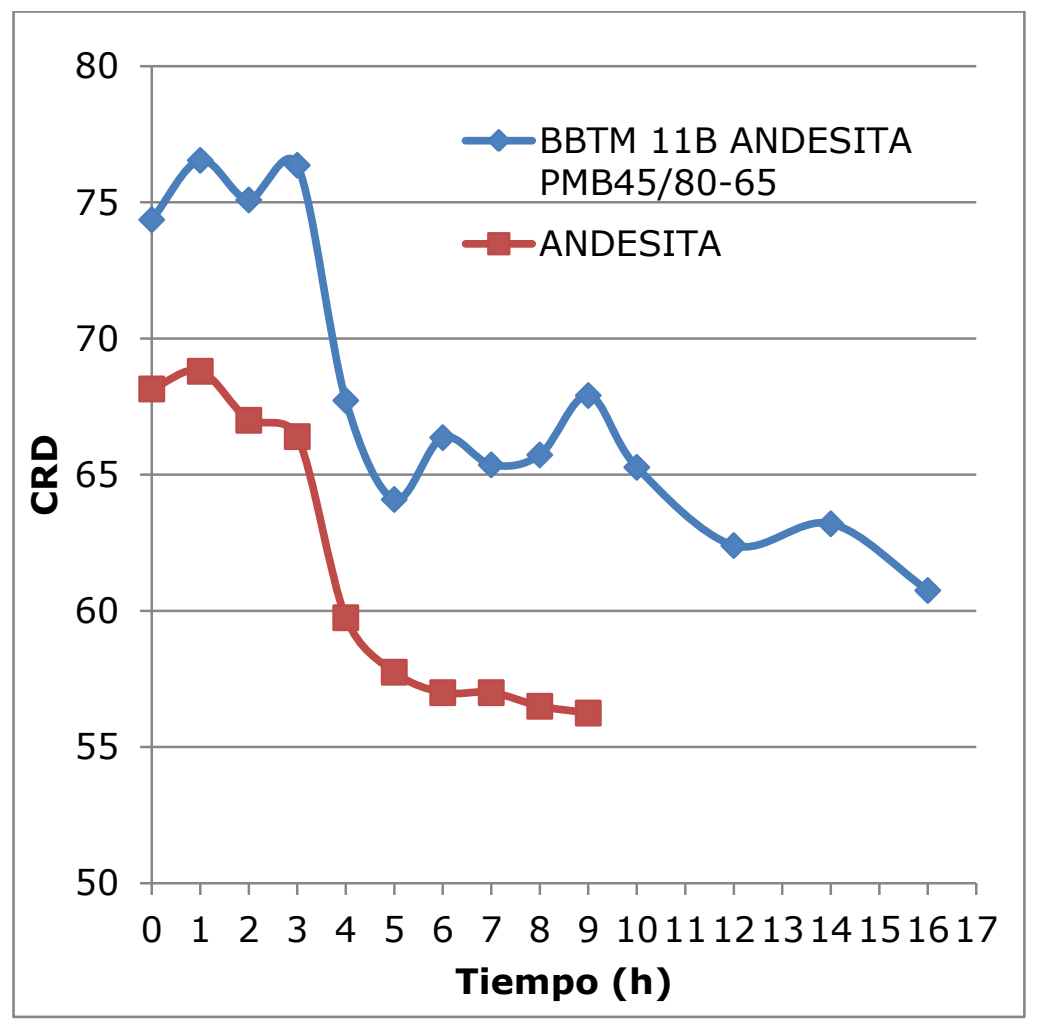

Figura 5. 20. Evolución en el tiempo del CRD de una BBTM 11B fabricada con andesita y de probetas de árido fabricados con andesita. 
La macrotextura obtenida en esto caso fue la indicada en la tabla 5.5.

Tabla 5. 5. Evolución en el tiempo del CRD de una BBTM 11B fabricada con andesita.

\begin{tabular}{|c|c|c|c|c|c|c|}
\hline PROBETA & $\begin{array}{c}\text { VOLUMEN } \\
\left(\mathrm{cm}^{3}\right)\end{array}$ & $\begin{array}{c}\text { MASA } \\
(\mathrm{g})\end{array}$ & $\begin{array}{c}\text { DENSIDAD } \\
\text { GEOMÉTRICA } \\
\left(\mathrm{g} / \mathrm{cm}^{3}\right)\end{array}$ & $\begin{array}{c}\text { HUECOS } \\
\text { MEZCLA } \\
(\%)\end{array}$ & $\begin{array}{c}\text { SUPERFICIE } \\
\text { MANCHA } \\
\text { ARENA } \\
\left(\mathrm{mm}^{2}\right)\end{array}$ & $\begin{array}{c}\text { MACRO. } \\
(\mathrm{mm})\end{array}$ \\
\hline 1 & 248 & 468 & 1,889 & 22,89 & 4644 & 1,1 \\
\hline 2 & 264 & 504 & 1,912 & 21,96 & 3560 & 1,4 \\
\hline 3 & 256 & 464 & 1,812 & 26,04 & 4081 & 1,2 \\
\hline 4 & 261 & 502 & 1,926 & 21,37 & 4115 & 1,2 \\
\hline 5 & 260 & 497 & 1,913 & 21,93 & 4252 & 1,2 \\
\hline 6 & 239 & 437 & 1,832 & 25,23 & 4070 & 1,2 \\
\hline 7 & 245 & 454 & 1,856 & 24,26 & 4358 & 1,1 \\
\hline 8 & 263 & 509 & 1,937 & 20,96 & 3614 & 1,4 \\
\hline 9 & 261 & 485 & 1,861 & 24,03 & 4559 & 1,1 \\
\hline 10 & 270 & 518 & 1,916 & 21,79 & 4769 & 1,0 \\
\hline 11 & 250 & 458 & 1,832 & 25,22 & 4667 & 1,1 \\
\hline 12 & 247 & 441 & 1,786 & 27,11 & 3822 & 1,3 \\
\hline MÁXIMO & 270 & 518 & 1,937 & 27,11 & 4769 & 1,4 \\
\hline MÍNIMO & 239 & 437 & 1,786 & 20,96 & 3560 & 1,0 \\
\hline MÁX.-MÍN. & 31 & 81 & 0,151 & 6,15 & 1209 & 0,4 \\
\hline MEDIA & 255,3 & 478,1 & 1,9 & 23,6 & 4209,3 & 1,2 \\
\hline $\begin{array}{l}\text { DESV. } \\
\text { TÍPICA }\end{array}$ & 9,3 & 27,9 & 0,0 & 2,0 & 407,7 & 0,1 \\
\hline
\end{tabular}

A la vista de los resultados conseguidos se podía concluir que se había conseguido desarrollar un nuevo procedimiento de ensayo que permitía medir en laboratorio cuál es la evolución que sufre la resistencia al deslizamiento de una mezcla bituminosa cuando dicha mezcla es sometida a un proceso de pulimento similar al que sufren los áridos cuando se quiere determinar su coeficiente de pulimento acelerado.

El proceso de pulimento de una mezcla es distinto al proceso de pulimento del árido grueso con la que se fabrica como se puede observar por las diferencias obtenidas en las dos curvas representadas en la figura 5.22.

Después de 6 horas de pulimento las probetas de mezcla no han terminado de pulimentarse al contrario de lo que ocurre con las probetas de árido en las que a partir de la hora 5 apenas hay variaciones en los valores medidos con el péndulo. Es necesario alargar el proceso de pulimento de las probetas de mezcla hasta las 12 horas. Más allá de este tiempo, los cambios en el valor de resistencia al deslizamiento se deben más a defectos ocasionados en las probetas, 
(desprendimientos de árido principalmente), que al propio pulimento de las mismas.

Se ha conseguido desarrollar un procedimiento de compactación que consigue reproducir, en las probetas de mezcla fabricadas en laboratorio, la densidad y el porcentaje de huecos que se obtienen cuando se colocan en la carretera. En cambio no se ha conseguido reproducir la macrotextura que debía tener la mezcla discontinua que se fabricó para el ensayo obteniendo valores de macrotextura por debajo de $1,5 \mathrm{~mm}$ en mezclas del tipo BBTM 11B.

Los aumentos en el valor de resistencia al deslizamiento observado a partir de la quinta hora se deben a defectos introducidos en las probetas de mezcla durante el pulimento de éstas. Es fundamental que las probetas se fabriquen con espesores que estén dentro de las tolerancias definidas, $(28,5-31,5 \mathrm{~mm})$. Más concretamente se ha estudiado que el espesor idóneo, medido con calibre en 6 puntos de la probeta de mezcla, debe ser de $29,3 \mathrm{~mm}$. Con este espesor se ha comprobado que las 12 probetas de mezcla encajan de forma precisa en la rueda porta-muestras, sin necesidad de tener que acudir a suplementos de espesor con láminas de caucho, ni a tener que rebajar de forma artificiosa el espesor de la probeta de mezcla por ningún lado.

El proceso de pulimento según la UNE-EN 1097-8 induce una serie de efectos dinámicos sobre las probetas que pueden terminar afectando a la regularidad de éstas, lo que es especialmente evidente al cabo de 5-6 horas. Habría que introducir algún tipo de elemento tipo muelle que sirviese para amortiguar la carga aplicada por el peso a la rueda de caucho que pule las probetas de mezcla, de forma que el proceso de pulimento fuese lo más homogéneo posible. Esto quedó confirmado por las bajas repetibilidades que se consiguieron en el ensayo antes de colocar este muelle como veremos en el siguiente apartado.

\subsubsection{Repetibilidad del ensayo.}

Se ha calculado la repetibilidad de los resultados obtenidos cada hora hasta la finalización del ensayo que se ha estimado en 12 horas de pulimento, 3 con abrasivo de grano grueso y 9 con abrasivo de grano más fino.

Para el estudio de repetibilidad se construyeron dos ruedas formadas por 10 probetas de 5 mezclas distintas, más dos probetas del árido de referencia elegido, de acuerdo al plan de ensayos descrito en el capítulo 4 de este trabajo. Estas dos ruedas se pulieron siguiendo los criterios de la UNE-EN 1097-8 para pulimento de 
los áridos. En las tablas 5.6 y 5.7 se incluyen las mezclas fabricadas y los valores de CRD medidos a lo largo del tiempo con el péndulo TRRL.

Tabla 5. 6. Evolución del CRD de las mezclas fabricadas en rueda 1. Pulimento según UNE-EN 1097-8.

\begin{tabular}{|c|c|c|c|c|c|c|c|c|c|c|}
\hline \multicolumn{11}{|c|}{ RUEDA 1} \\
\hline \multirow[t]{2}{*}{ MEZCLA } & \multirow[t]{2}{*}{ PROBETA } & & \multicolumn{3}{|c|}{$\begin{array}{l}\text { Esmeril } \\
\text { Grueso }\end{array}$} & \multicolumn{5}{|c|}{$\begin{array}{l}\text { Esmeril } \\
\text { Fino }\end{array}$} \\
\hline & & 0 & 1 & 2 & 3 & 4 & 5 & 6 & 9 & 12 \\
\hline \multirow{2}{*}{$\begin{array}{l}\text { BBTM 11B CALIZO } \\
\text { PMB 45/80-65 }\end{array}$} & $\begin{array}{c}11 \mathrm{~B} \mathrm{C} \mathrm{BM} \\
\mathrm{R} 1,1\end{array}$ & 65 & 67 & 70 & 60 & 53 & 45 & 46 & 45 & \\
\hline & $\begin{array}{c}11 \mathrm{~B} \text { C BM } \\
\mathrm{R} 1,2\end{array}$ & 71 & 69 & 70 & 67 & 57 & 45 & 51 & & \\
\hline \multirow{2}{*}{$\begin{array}{l}\text { BBTM 11B PÓRFIDO } \\
\text { PMB 45/80-65 }\end{array}$} & $\begin{array}{c}\text { 11B P BM } \\
\text { R1,1 }\end{array}$ & 60 & 70 & 74 & 65 & 64 & 60 & 60 & 60 & 64 \\
\hline & $\begin{array}{c}\text { 11B P BM } \\
\text { R1,2 }\end{array}$ & 60 & 71 & 70 & 62 & 64 & 55 & 57 & 57 & 60 \\
\hline \multirow{2}{*}{$\begin{array}{l}\text { AC 16D CALIZA } \\
\text { PMB 45/80-65 }\end{array}$} & $\begin{array}{c}\text { 16D C BM } \\
\text { R } 1,1\end{array}$ & 65 & 67 & 70 & 60 & 53 & 45 & 46 & 45 & \\
\hline & $\begin{array}{c}\text { 16D C BM } \\
\text { R1,2 }\end{array}$ & 71 & 69 & 70 & 67 & 57 & 45 & 51 & & \\
\hline \multirow{2}{*}{$\begin{array}{l}\text { AC 16D PÓRFIDO } \\
\text { PMB 45/80-65 }\end{array}$} & $\begin{array}{c}\text { 16D P BM } \\
\text { R1,1 }\end{array}$ & 69 & 65 & 64 & 65 & 61 & 57 & 60 & 55 & 59 \\
\hline & $\begin{array}{c}\text { 16D P BM } \\
\text { R1,2 }\end{array}$ & 65 & 66 & 70 & 65 & 65 & 59 & 59 & 57 & 60 \\
\hline \multirow{2}{*}{$\begin{array}{c}\text { BBTM 11B PÓRFIDO } \\
50 / 70\end{array}$} & $\begin{array}{c}11 \mathrm{~B} \mathrm{P} \mathrm{BC} \\
\mathrm{R} 1,1\end{array}$ & 73 & 74 & 71 & 67 & 65 & 61 & 60 & 60 & 66 \\
\hline & $\begin{array}{c}\text { 11B P BC } \\
\text { R1,2 }\end{array}$ & 72 & 65 & 69 & 66 & 64 & 55 & 62 & 57 & 60 \\
\hline \multirow{2}{*}{ ARI REF } & ARI R1,1 & 54 & 60 & 55 & 55 & 60 & 55 & 55 & 50 & 49 \\
\hline & ARI $\mathrm{R} 1,2$ & 63 & 63 & 60 & 59 & 60 & 57 & 56 & 55 & 55 \\
\hline
\end{tabular}

Como ya se indicó en el capítulo 4, los 5 tipos de mezcla correspondieron a una BBTM 11B fabricada con árido grueso y fino calizo, dos BBTM 11B fabricadas con árido grueso pórfido y árido fino silíceo, una AC 16D fabricada sólo con árido calizo, tanto el grueso como el fino, y una AC 16D, fabricada con árido grueso pórfido y árido fino silíceo. El betún ha sido un modificado tipo PMB 45/80-65 excepto en una de las BBTM 11B fabricada con pórfido donde se empleó un betún 50/70. El filler en todos los casos fue de aportación y del tipo $\mathrm{CaCO}_{3}$. 
Tabla 5. 7. Evolución del CRD de las mezclas fabricadas en rueda 2. Pulimento según UNE-EN 1097-8

\begin{tabular}{|c|c|c|c|c|c|c|c|c|c|c|}
\hline \multicolumn{11}{|c|}{ RUEDA 2} \\
\hline \multirow[t]{2}{*}{ MEZCLA } & \multirow{2}{*}{ PROBETA } & & \multicolumn{3}{|c|}{$\begin{array}{l}\text { Esmeril } \\
\text { Grueso }\end{array}$} & \multicolumn{5}{|c|}{$\begin{array}{l}\text { Esmeril } \\
\text { Fino }\end{array}$} \\
\hline & & 0 & 1 & 2 & 3 & 4 & 5 & 6 & 9 & 12 \\
\hline \multirow{2}{*}{$\begin{array}{l}\text { BBTM 11B CALIZO } \\
\text { PMB 45/80-65 }\end{array}$} & $\begin{array}{c}\text { 11B C BM } \\
\text { R1,1 }\end{array}$ & 62 & 66 & 70 & 70 & 64 & 55 & 53 & 50 & 49 \\
\hline & $\begin{array}{c}11 \mathrm{~B} \mathrm{C} \mathrm{BM} \\
\mathrm{R} 1,2\end{array}$ & 65 & 63 & 64 & 64 & 69 & 67 & 64 & 64 & 64 \\
\hline \multirow{2}{*}{$\begin{array}{c}\text { BBTM 11B } \\
\text { PÓRFIDO } \\
\text { PMB 45/80-65 }\end{array}$} & $\begin{array}{c}\text { 11B P BM } \\
\text { R1, } 1\end{array}$ & 57 & 64 & 66 & 66 & 65 & 60 & 60 & 60 & \\
\hline & $\begin{array}{c}\text { 11B P BM } \\
\text { R1,2 }\end{array}$ & 60 & 64 & 65 & 65 & 64 & 61 & 61 & 61 & 61 \\
\hline \multirow{2}{*}{$\begin{array}{l}\text { AC 16D CALIZA } \\
\text { PMB 45/80-65 }\end{array}$} & $\begin{array}{c}\text { 16D C BM } \\
\text { R } 1,1\end{array}$ & 74 & 65 & 66 & 66 & 66 & 58 & & & \\
\hline & $\begin{array}{c}\text { 16D C BM } \\
\text { R1,2 }\end{array}$ & 73 & 65 & 65 & 65 & 70 & 56 & & & \\
\hline \multirow{2}{*}{$\begin{array}{l}\text { AC 16D PÓRFIDO } \\
\text { PMB 45/80-65 }\end{array}$} & $\begin{array}{c}\text { 16D P BM } \\
\text { R1,1 }\end{array}$ & 68 & 65 & 65 & 65 & 65 & 62 & 63 & 63 & 62 \\
\hline & $\begin{array}{c}\text { 16D P BM } \\
\text { R1,2 }\end{array}$ & 67 & 65 & 69 & 69 & 69 & 65 & 62 & 61 & 60 \\
\hline \multirow{2}{*}{$\begin{array}{c}\text { BBTM 11B } \\
\text { PÓRFIDO 50/70 }\end{array}$} & $\begin{array}{c}\text { 11B P BC } \\
\text { R } 1,1\end{array}$ & 72 & 61 & 61 & 61 & 65 & 64 & 64 & 62 & 61 \\
\hline & $\begin{array}{c}\text { 11B P BC } \\
\text { R1,2 }\end{array}$ & 73 & 65 & 69 & 69 & 74 & 68 & 65 & 63 & 70 \\
\hline \multirow{2}{*}{ ARI REF } & ARI R1,1 & 63 & 65 & 60 & 60 & 60 & 60 & 58 & 57 & 56 \\
\hline & ARI $R 1,2$ & 67 & 65 & 62 & 62 & 61 & 61 & 59 & 60 & 59 \\
\hline
\end{tabular}

La precisión del ensayo se determinó en función de su rango o recorrido, desviación típica, coeficiente de variación y repetibilidad.

Los resultados de rango, media, desviación típica, coeficiente de variación y repetibilidad para cada hora, obtenidos con este procedimiento de ensayo, son los indicados en las tablas A1 a A6 incluidas en el anexo 1. Los valores en blanco corresponden a probetas de mezcla que durante el ensayo han presentado algún tipo de defecto siendo estos más frecuentes, como era de esperar, en las mezclas fabricadas con áridos más blandos.

En la tabla 5.8 se resumen los valores estadísticos analizados para 6 y 12 horas y los CPM en esos intervalos temporales. 
Tabla 5.8. Principales valores estadísticos a 6 y 12 horas. Pulimento según UNE-EN 1097-8.

\begin{tabular}{|c|c|c|c|c|c|c|c|c|c|c|c|c|}
\hline \multicolumn{13}{|c|}{ CONDICIONES ENSAYOS EN 1097-8 } \\
\hline \multirow{2}{*}{$\begin{array}{l}\text { TIPO DE } \\
\text { MEZCLA }\end{array}$} & \multicolumn{6}{|c|}{6 HORAS } & \multicolumn{6}{|c|}{12 HORAS } \\
\hline & $\begin{array}{l}\text { MÁX.- } \\
\text { MÍN. }\end{array}$ & MEDIA & $\begin{array}{c}\text { DESV } \\
\text { TÍPICA }\end{array}$ & CV & $\mathbf{r}$ & CPM & $\begin{array}{l}\text { MÁX.- } \\
\text { MÍN. }\end{array}$ & MEDIA & $\begin{array}{c}\text { DESV } \\
\text { TÍPICA }\end{array}$ & CV & $\mathbf{r}$ & CPM \\
\hline $\begin{array}{c}\text { BBTM } \\
11 \mathrm{~B} \mathrm{C} \\
\text { PMB } \\
45 / 80-65\end{array}$ & 18 & 53,5 & 7,6 & $14,2 \%$ & 24,2 & 53,5 & 15 & 56,5 & 10,6 & $18,8 \%$ & 33,8 & 57,8 \\
\hline $\begin{array}{c}\text { BBTM } \\
11 B \text { P } \\
\text { PMB } \\
45 / 80-65\end{array}$ & 4 & 59,5 & 1,7 & $2,9 \%$ & 5,5 & 59,5 & 4 & 61,7 & 2,1 & $3,4 \%$ & 6,6 & 62,9 \\
\hline $\begin{array}{l}\text { BBTM } \\
11 B \text { P } \\
50 / 70\end{array}$ & 5 & 62,8 & 2,2 & $3,5 \%$ & 7,1 & 62,8 & 10 & 64,3 & 4,6 & $7,2 \%$ & 14,8 & 65,5 \\
\hline $\begin{array}{c}\text { AC 16D } \\
\text { CALIZA } \\
\text { PMB } \\
45 / 80-65\end{array}$ & 5 & 48,5 & 3,5 & $7,3 \%$ & 11,3 & 48,5 & & & & & & \\
\hline $\begin{array}{c}\text { AC 16D P } \\
\text { PMB } \\
45 / 80-65\end{array}$ & 4 & 61,0 & 1,8 & $3,0 \%$ & 5,8 & 61,0 & 3 & 60,3 & 1,3 & $2,1 \%$ & 4,0 & 61,5 \\
\hline ARI REF & 4 & 57,0 & 1,8 & $3,2 \%$ & 5,8 & 57,0 & 10 & 54,8 & 4,2 & $7,7 \%$ & 13,3 & 56,0 \\
\hline
\end{tabular}

El recorrido o rango es la medida de dispersión más sencilla de calcular aunque es algo burda porque sólo toma en consideración un par de observaciones. La UNE-EN 1097-8 descarta todos aquellos ensayos en los que los valores medios de resistencia al deslizamiento a 6 horas de cada pareja de áridos ensayados en una rueda difieren en más de 5 unidades de los valores medios obtenidos en la segunda para los mismos áridos. También descarta los ensayos en los que en el árido de referencia utilizado se mide una resistencia al deslizamiento que salga fuera de su intervalo de confianza, definido como su valor de CRD medido con el péndulo TRRL conocido \pm 3 unidades. Por este motivo, los rangos o recorridos menores de 6 se han considerado como adecuados lo que en el ensayo de pulimento de mezclas, pulidas de acuerdo a la UNE-EN 1097-8, se conseguía a 6 horas en prácticamente todas las mezclas estudiadas menos en la BBTM 11B fabricada con árido calizo. En cambio a 12 horas la mitad de las mezclas estudiadas tuvieron rangos mayores de 6 , sin contar la AC 16D caliza de la que no se tuvieron datos porque las probetas presentaron problemas de desprendimiento de áridos antes de la terminación del ensayo, (figura 5.21). 


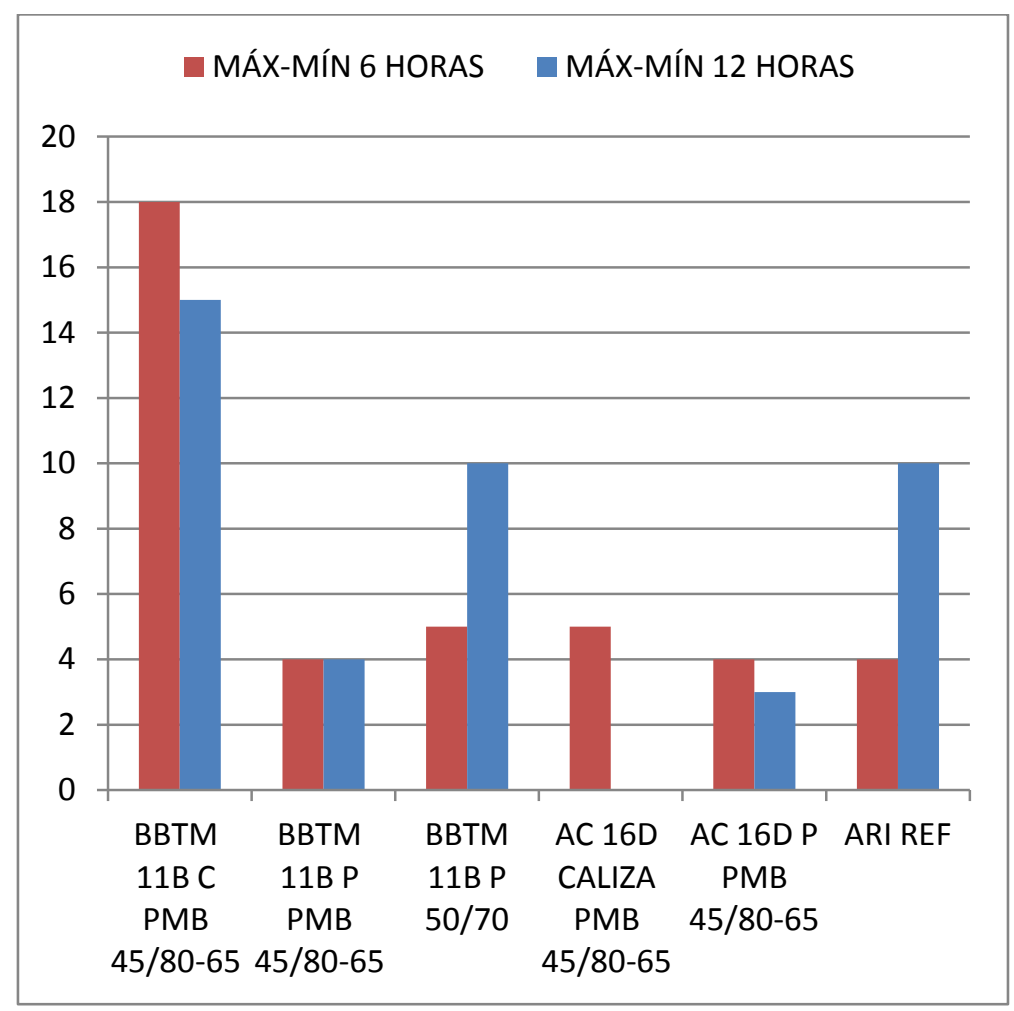

Figura 5. 21. Rangos a 6 y 12 horas. Pulimento según UNE-EN 1097-8.

Los mayores coeficientes de variación se obtuvieron para las mezclas fabricadas con áridos calizos siendo los valores obtenidos mayores a 12 horas que a 6 horas.

De acuerdo a (Miró 1994; Moreno-Navarro 2013), valores del coeficiente de variación por debajo del 15\% pueden considerarse adecuados. Por ejemplo en el estudio realizado sobre el ensayo cántabro se consiguieron repetibilidades basadas en el CV entre 12,3 y $15,9 \%$ y con el ensayo Fénix se consiguieron valores del CV del $15 \%$ para el parámetro energía disipada y del $8.5 \%$ para la carga máxima tracción, (Valdés 2011). Sólo la mezcla BBTM 11B fabricada con árido calizo presenta coeficientes de variación por encima del $10 \%$ en el ensayo realizado para pulir probetas de mezcla, (figura 5.22).

En la UNE-EN 1097-8 se indica que de un trabajo realizado con tres tipos de árido diferentes y 11 laboratorios distintos se llegó a la conclusión que la repetibilidad del ensayo CPA a 6 horas es de 3, por lo que se tomó este valor como el objetivo a conseguir. En la figura 5.23, se incluyen los valores de repetibilidad conseguidos a 6 y 12 horas en el ensayo de pulimento de mezclas. Estos valores ponen de manifiesto que el valor de resistencia a pulimento de mezclas dista mucho de conseguir esos valores de precisión, sobre todo a 12 horas. 


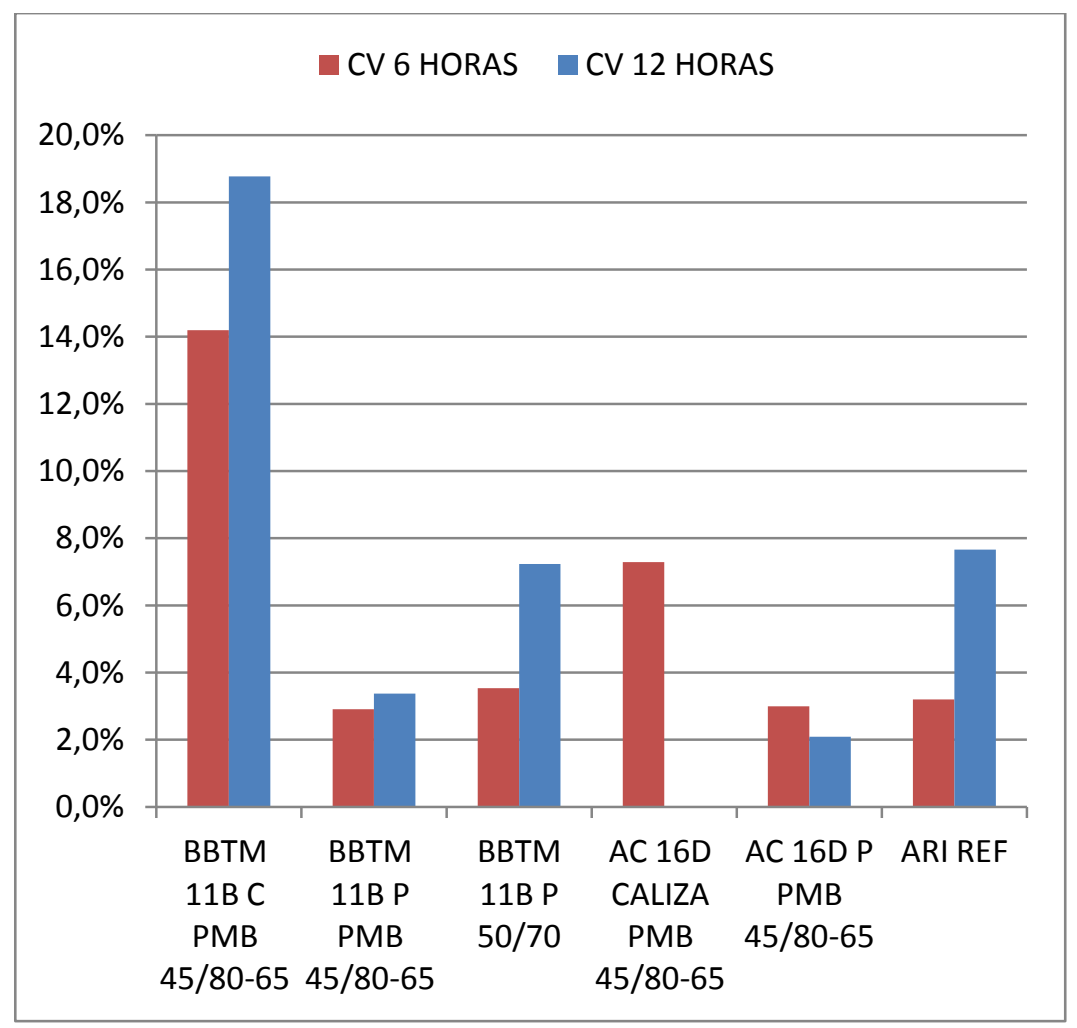

Figura 5.22. Coeficientes de variación a 6 y 12 horas. Pulimento según UNE-EN 1097-8.

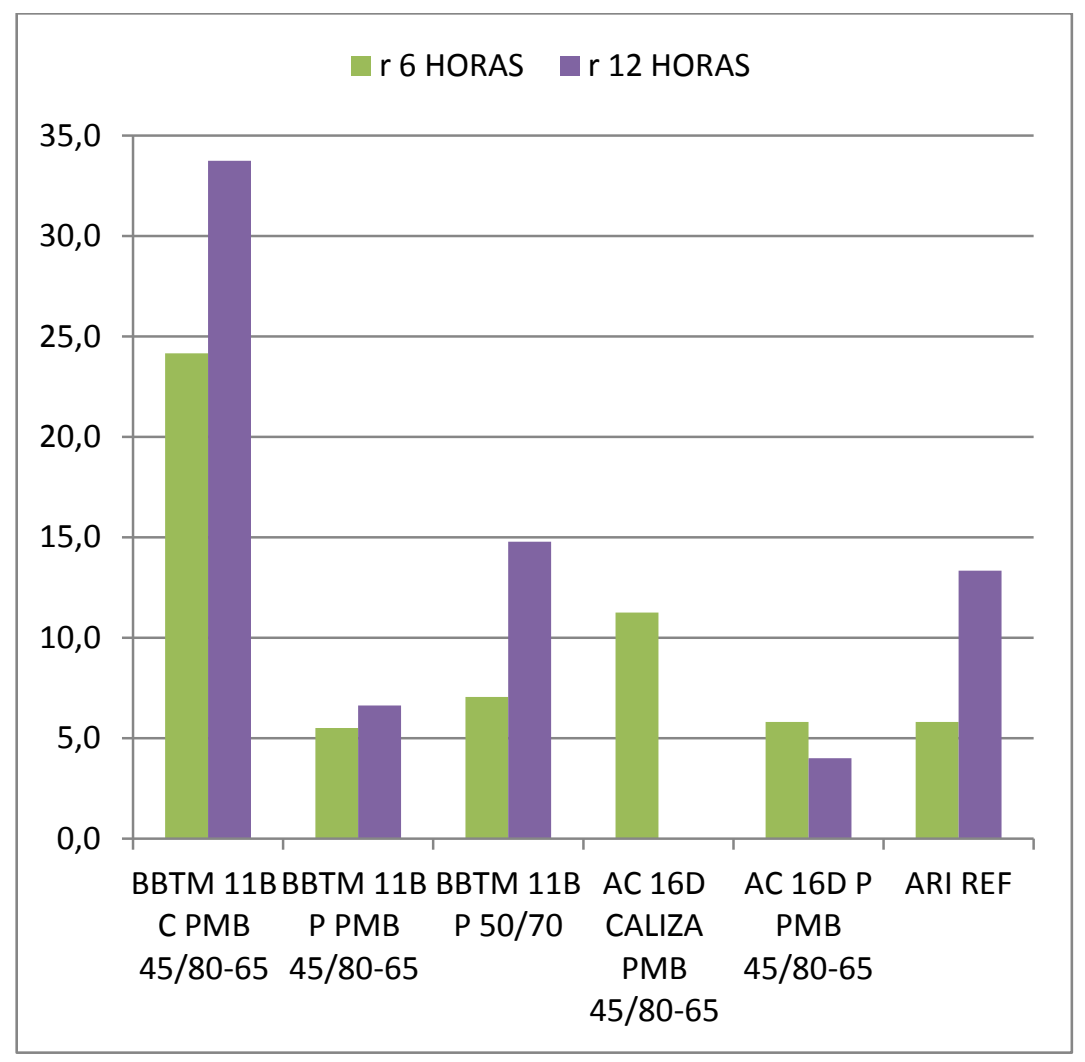

Figura 5.23. Repetibilidad a 6 y 12 horas. Pulimento según UNE-EN 1097-8. 
Los resultados conseguidos en la repetibilidad, junto con el hecho de que las probetas fabricadas con árido calizo, y algunas con pórfido, no pudiesen terminarse de pulir y la presencia de valores anómalos en las curvas que se obtuvieron, confirmaron la necesidad de modificar el proceso de pulimento de las mezclas.

Como se observa en las figura 5.24, en la mayoría de las mezclas estudiadas los valores de CPM a 12 horas eran mayores que a 6 horas lo cual se explicaba porque los defectos introducidos por el pulimento en las probetas de mezcla hacían que éstas presentasen una superficie irregular donde el péndulo TRRL se quedaba "enganchado" dando valores de resistencia al deslizamiento anómalos, (figura 5.25 y 5.26).

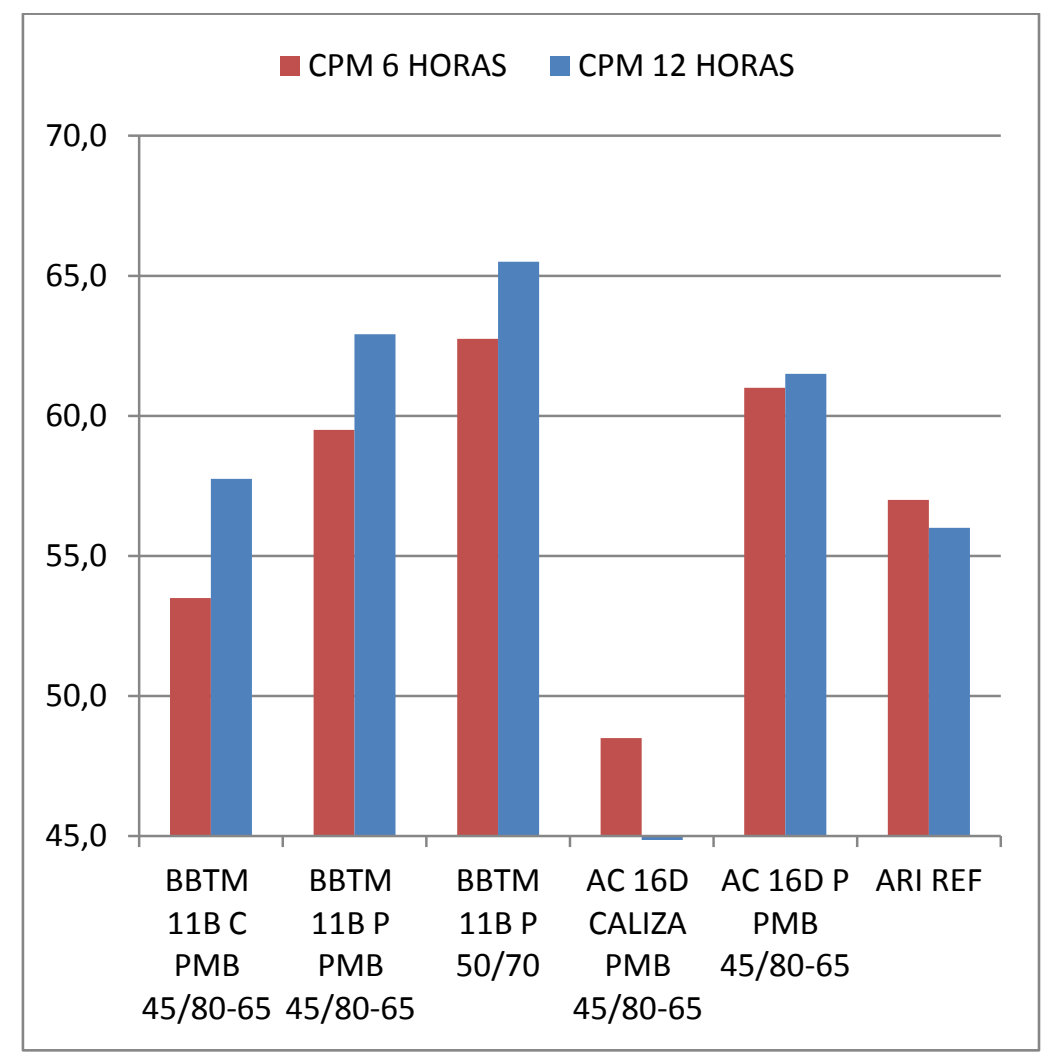

Figura 5.24. CPM a 6 y 12 horas. Pulimento según UNE-EN 1097-8. 


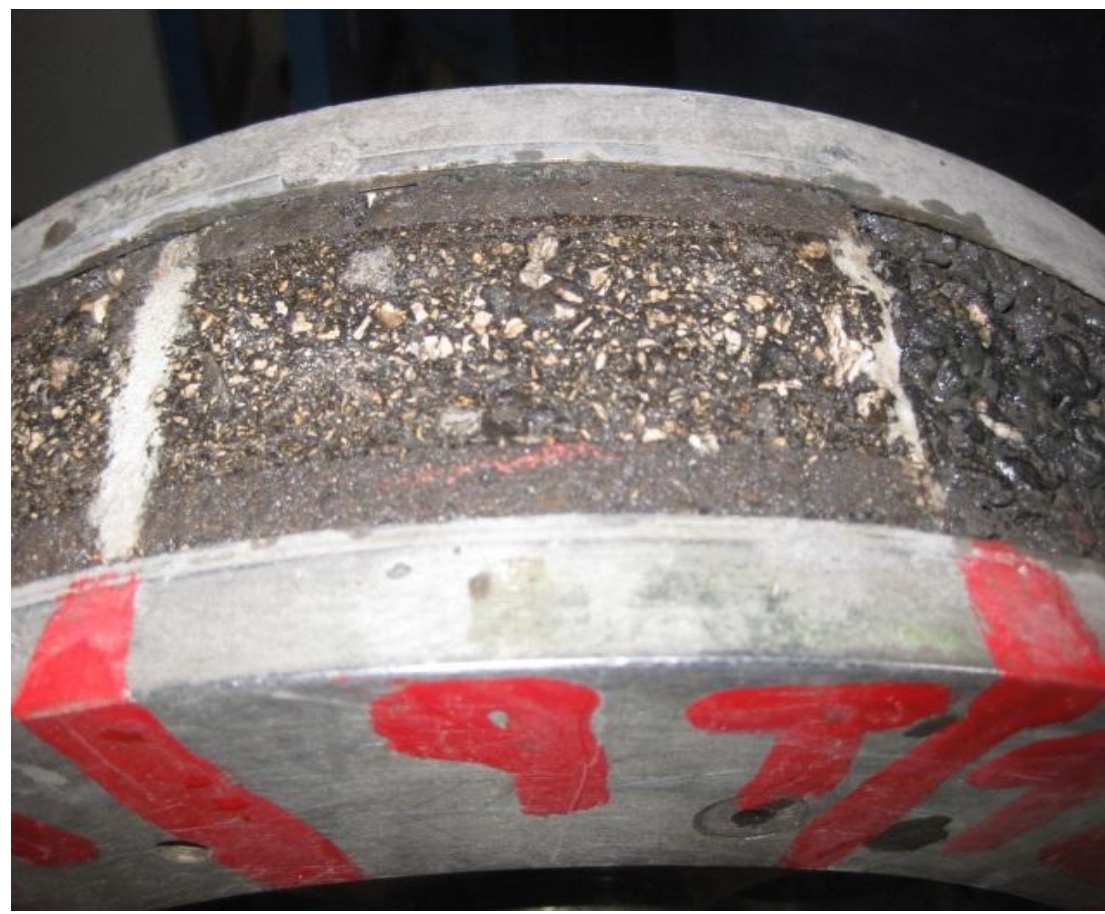

Figura 5.25. Probeta AC 16D caliza después de 5 horas de pulimento según UNE-EN 1097-8.

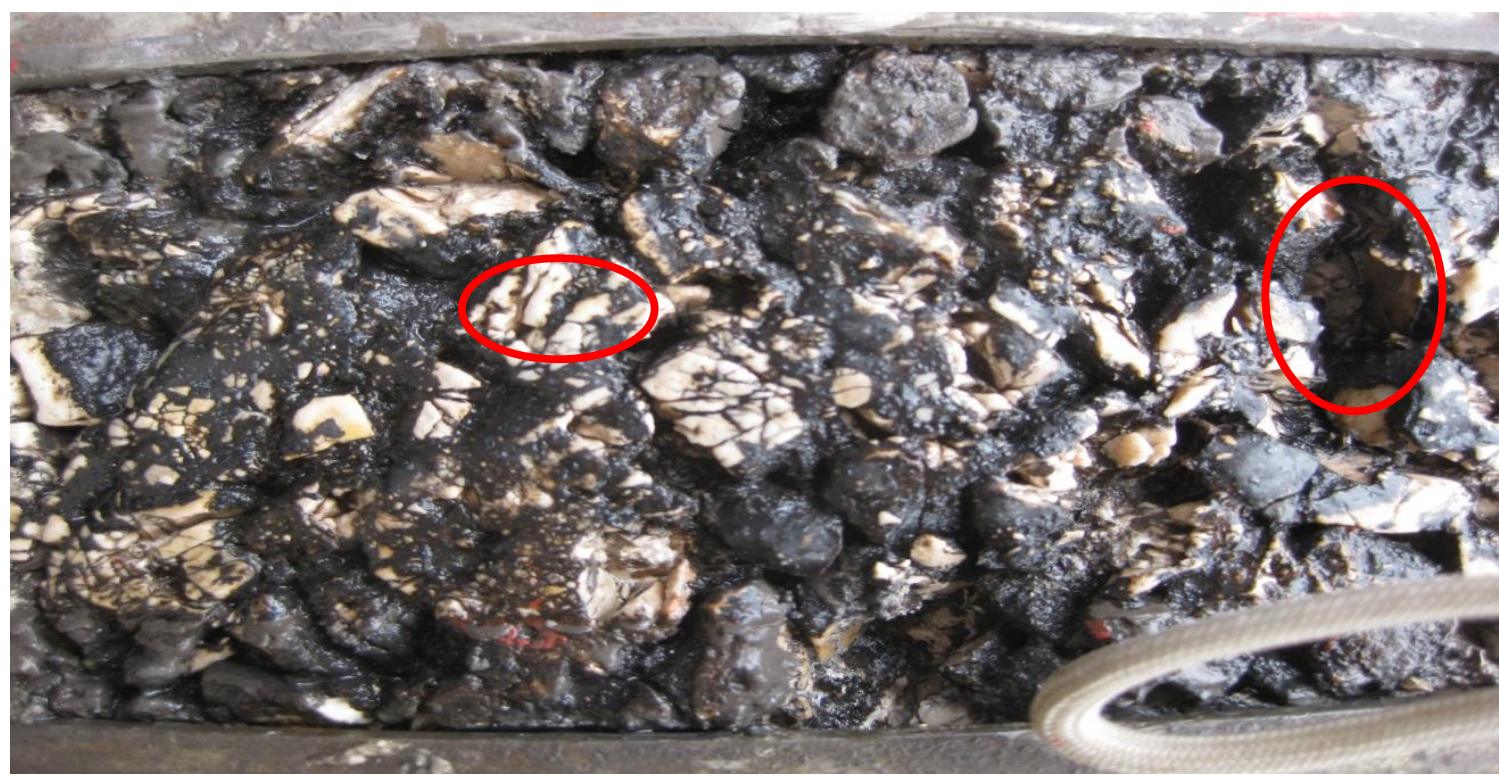

Figura 5.26. Probeta BBTM 11B caliza después de 5 horas de pulimento según UNE-EN 1097-8.

Por todo lo anterior se procedió a incorporar al equipo de pulimento un muelle de longitud $86 \mathrm{~mm}$ y una constante "k" de Young de $17.500 \mathrm{~N} / \mathrm{m}$, que uniese el peso responsable de la fuerza que la rueda de caucho rígido ejerce sobre las probetas de mezcla con el brazo de palanca de la máquina de pulimento, (figura 5.27). Tal y como se explicó en el capítulo 4 se probaron distintos tipos de muelle y se observó que era este el que conseguía amortiguar de forma más efectiva los golpes que la rueda de caucho rígido producía contra las probetas de mezcla durante el proceso de pulimento de éstas. 


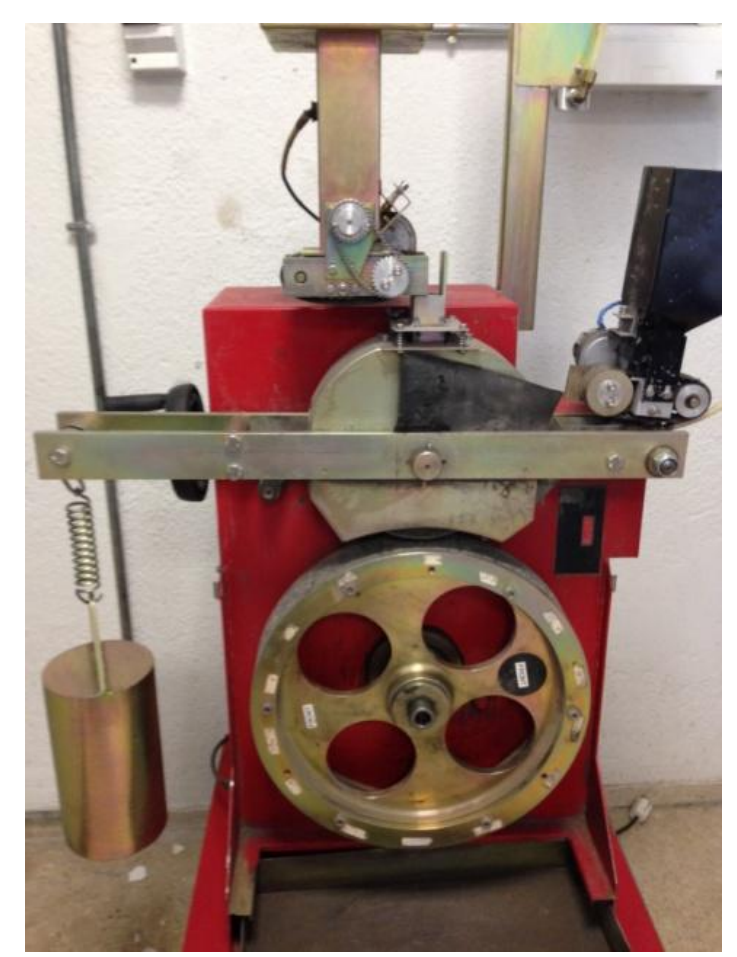

Figura 5. 27 . Detalle del equipo de pulimento con muelle.

Con el equipo de pulimento modificado se procedió a fabricar dos nuevas ruedas formadas por las mismas 5 mezclas que en la fase anterior y con el mismo árido de referencia. En las tablas 5.9 y 5.10 , se indican los resultados obtenidos y el estudio de repetibilidad que se llevó a cabo se muestra en las tablas A8 a A16 incluidas en el anexo 1. 
Tabla 5.9. Evolución del CRD de las mezclas fabricadas para la rueda 1. Pulimento según UNE-EN 1097-8 con muelle

\begin{tabular}{|c|c|c|c|c|c|c|c|c|c|c|c|}
\hline \multicolumn{12}{|c|}{ RUEDA 1} \\
\hline \multirow{2}{*}{ MEZCLA } & \multirow{2}{*}{ PROBETA } & \multicolumn{4}{|c|}{$\begin{array}{l}\text { Esmeril } \\
\text { Grueso }\end{array}$} & \multicolumn{6}{|c|}{ Esmeril Fino } \\
\hline & & 0 & 1 & 2 & 3 & 4 & 5 & 6 & 8 & 10 & 12 \\
\hline \multirow{2}{*}{$\begin{array}{l}\text { BBTM 11B CALIZO } \\
\text { PMB 45/80-65 }\end{array}$} & 11B C BM R 1,1 & 71 & 75 & 75 & 70 & 63 & 60 & 59 & 59 & 57 & 57 \\
\hline & 11B C BM R1,2 & 68 & 70 & 73 & 72 & 65 & 62 & 57 & 57 & 55 & 55 \\
\hline \multirow{2}{*}{$\begin{array}{c}\text { BBTM 11B } \\
\text { PÓRFIDO } \\
\text { PMB 45/80-65 }\end{array}$} & 11B P BM R1, 1 & 70 & 74 & 70 & 63 & 60 & 60 & 60 & 55 & 54 & 55 \\
\hline & 11B P BM R1,2 & 67 & 72 & 70 & 65 & 63 & 63 & 61 & 61 & 55 & 55 \\
\hline \multirow{2}{*}{$\begin{array}{l}\text { AC 16D CALIZA } \\
\text { PMB 45/80-65 }\end{array}$} & 16D C BM R 1,1 & 75 & 73 & 77 & 74 & 63 & 60 & 58 & 55 & 54 & 53 \\
\hline & 16D C BM R1,2 & 74 & 74 & 80 & 72 & 61 & 59 & 55 & 51 & 51 & 49 \\
\hline \multirow{2}{*}{$\begin{array}{l}\text { AC 16D PÓRFIDO } \\
\text { PMB 45/80-65 }\end{array}$} & 16D P BM R1,1 & 67 & 70 & 73 & 69 & 64 & 60 & 57 & 57 & 57 & 57 \\
\hline & 16D P BM R1,2 & 74 & 71 & 74 & 70 & 65 & 60 & 59 & 54 & 53 & 52 \\
\hline \multirow{2}{*}{$\begin{array}{c}\text { BBTM 11B } \\
\text { PÓRFIDO 50/70 }\end{array}$} & 11B P BC R1,1 & 68 & 70 & 70 & 70 & 65 & 64 & 55 & 55 & 52 & 50 \\
\hline & 11B P BC R1,2 & 70 & 70 & 70 & 70 & 65 & 60 & 57 & 56 & 55 & 54 \\
\hline \multirow{2}{*}{ ARI REF } & ARI R1,1 & 68 & 68 & 65 & 65 & 65 & 60 & 60 & 60 & 60 & 59 \\
\hline & ARI R1,2 & 69 & 68 & 65 & 65 & 64 & 61 & 60 & 60 & 60 & 58 \\
\hline
\end{tabular}

Tabla 5. 10. Evolución del CRD de las mezclas fabricadas para la rueda 2. Pulimento según UNE-EN 1097-8 con muelle

\begin{tabular}{|c|c|c|c|c|c|c|c|c|c|c|c|}
\hline \multicolumn{12}{|c|}{ RUEDA 2} \\
\hline \multirow{2}{*}{ MEZCLA } & \multirow{2}{*}{ PROBETA } & \multicolumn{4}{|c|}{$\begin{array}{l}\text { Esmeril } \\
\text { Grueso }\end{array}$} & \multicolumn{6}{|c|}{ Esmeril Fino } \\
\hline & & 0 & 1 & 2 & 3 & 4 & 5 & 6 & 8 & $\overline{10}$ & 12 \\
\hline \multirow{2}{*}{$\begin{array}{c}\text { BBTM 11B CALIZO } \\
\text { PMB 45/80-65 }\end{array}$} & 11B C BM R 1,1 & 68 & 70 & 72 & 70 & 63 & 60 & 57 & 57 & 56 & 54 \\
\hline & 11B C BM R1,2 & 75 & 77 & 75 & 73 & 65 & 62 & 56 & 55 & 55 & 52 \\
\hline \multirow{2}{*}{$\begin{array}{c}\text { BBTM 11B } \\
\text { PÓRFIDO } \\
\text { PMB 45/80-65 }\end{array}$} & 11B P BM R1,1 & 72 & 74 & 70 & 62 & 64 & 55 & 57 & 59 & 59 & 55 \\
\hline & 11B P BM R1,2 & 72 & 75 & 70 & 70 & 68 & 67 & 63 & 63 & 60 & 56 \\
\hline \multirow{2}{*}{$\begin{array}{l}\text { AC 16D CALIZA } \\
\text { PMB 45/80-65 }\end{array}$} & 16D C BM R1,1 & 71 & 74 & 75 & 73 & 60 & 58 & 56 & 55 & 51 & 52 \\
\hline & 16D C BM R1,2 & 71 & 73 & 70 & 72 & 60 & 55 & 55 & 52 & 51 & 50 \\
\hline \multirow{2}{*}{$\begin{array}{l}\text { AC 16D PÓRFIDO } \\
\text { PMB 45/80-65 }\end{array}$} & 16D P BM R1,1 & 70 & 72 & 74 & 69 & 66 & 65 & 59 & 59 & 55 & 55 \\
\hline & 16D P BM R1,2 & 72 & 75 & 74 & 70 & 67 & 65 & 57 & 57 & 55 & 5 \\
\hline \multirow{2}{*}{$\begin{array}{c}\text { BBTM 11B } \\
\text { PÓRFIDO } 50 / 70\end{array}$} & 11B P BC R1,1 & 72 & 72 & 70 & 70 & 65 & 64 & 62 & 60 & 55 & 54 \\
\hline & 11B P BC R1,2 & 73 & 74 & 71 & 67 & 65 & 61 & 60 & 60 & 54 & 53 \\
\hline \multirow{2}{*}{ ARI REF } & ARI R1,1 & 74 & 70 & 68 & 66 & 66 & 65 & 60 & 60 & 60 & 60 \\
\hline & ARI R1,2 & 73 & 70 & 67 & 66 & 63 & 62 & 56 & 56 & 55 & 55 \\
\hline
\end{tabular}

En la tabla 5.11 se incluye un resumen de los principales valores estadísticos obtenidos en este experimento. 
Tabla 5.11. Principales valores estadísticos a 6 y 12 horas. Pulimento según UNE-EN 1097-8 más muelle.

\begin{tabular}{|c|c|c|c|c|c|c|c|c|c|c|c|c|}
\hline \multicolumn{13}{|c|}{ CONDICIONES ENSAYOS EN 1097-8 + MUELLE } \\
\hline \multirow{2}{*}{$\begin{array}{l}\text { TIPO DE } \\
\text { MEZCLA }\end{array}$} & \multicolumn{6}{|c|}{6 HORAS } & \multicolumn{6}{|c|}{12 HORAS } \\
\hline & $\begin{array}{l}\text { MÁX.- } \\
\text { MÍN. }\end{array}$ & MEDIA & $\begin{array}{c}\text { DESV. } \\
\text { TÍPICA }\end{array}$ & CV & $\mathbf{r}$ & CPM & $\begin{array}{l}\text { MÁX.- } \\
\text { MÍN. }\end{array}$ & MEDIA & $\begin{array}{l}\text { DESV. } \\
\text { TÍPICA }\end{array}$ & CV & $\mathbf{r}$ & CPM \\
\hline $\begin{array}{c}\text { BBTM 11B } \\
\text { C PMB } \\
45 / 80-65\end{array}$ & 3 & 57 & 1,3 & $2,2 \%$ & 4,0 & 55,3 & 5 & 55 & 2,1 & $3,8 \%$ & 6,6 & 52,5 \\
\hline $\begin{array}{l}\text { BBTM 11B } \\
\text { P PMB } \\
45 / 80-65\end{array}$ & 6 & 60 & 2,5 & $4,1 \%$ & 8,0 & 58,3 & 1 & 55 & 0,5 & $0,9 \%$ & 1,6 & 53,3 \\
\hline $\begin{array}{l}\text { BBTM 11B } \\
\text { P 50/70 }\end{array}$ & 7 & 59 & 3,1 & $5,3 \%$ & 9,9 & 56,5 & 4 & 53 & 1,9 & $3,6 \%$ & 6,0 & 50,8 \\
\hline $\begin{array}{c}\text { AC 16D } \\
\text { CALIZA } \\
\text { PMB } \\
45 / 80-65\end{array}$ & 3 & 56 & 1,4 & $2,5 \%$ & 4,5 & 54,0 & 4 & 51 & 1,8 & $3,6 \%$ & 5,8 & 49,0 \\
\hline $\begin{array}{c}\text { AC 16D P } \\
\text { PMB } \\
45 / 80-65\end{array}$ & 2 & 58 & 1,2 & $2,0 \%$ & 3,7 & 56,0 & 5 & 55 & 2,1 & $3,8 \%$ & 6,6 & 52,8 \\
\hline ARI REF & 4 & 59 & 2,0 & $3,4 \%$ & 6,4 & 57,0 & 5 & 58 & 2,2 & $3,7 \%$ & 6,9 & 56,0 \\
\hline
\end{tabular}

Como se puede observar los valores de rango, coeficiente de variación y repetibilidad alcanzados suelen ser menores, tanto a 6 como a 12 horas, para los mismos tipos de mezcla, con la modificación introducida en el equipo de pulimento, (figuras 5.28 a 5.30 ).

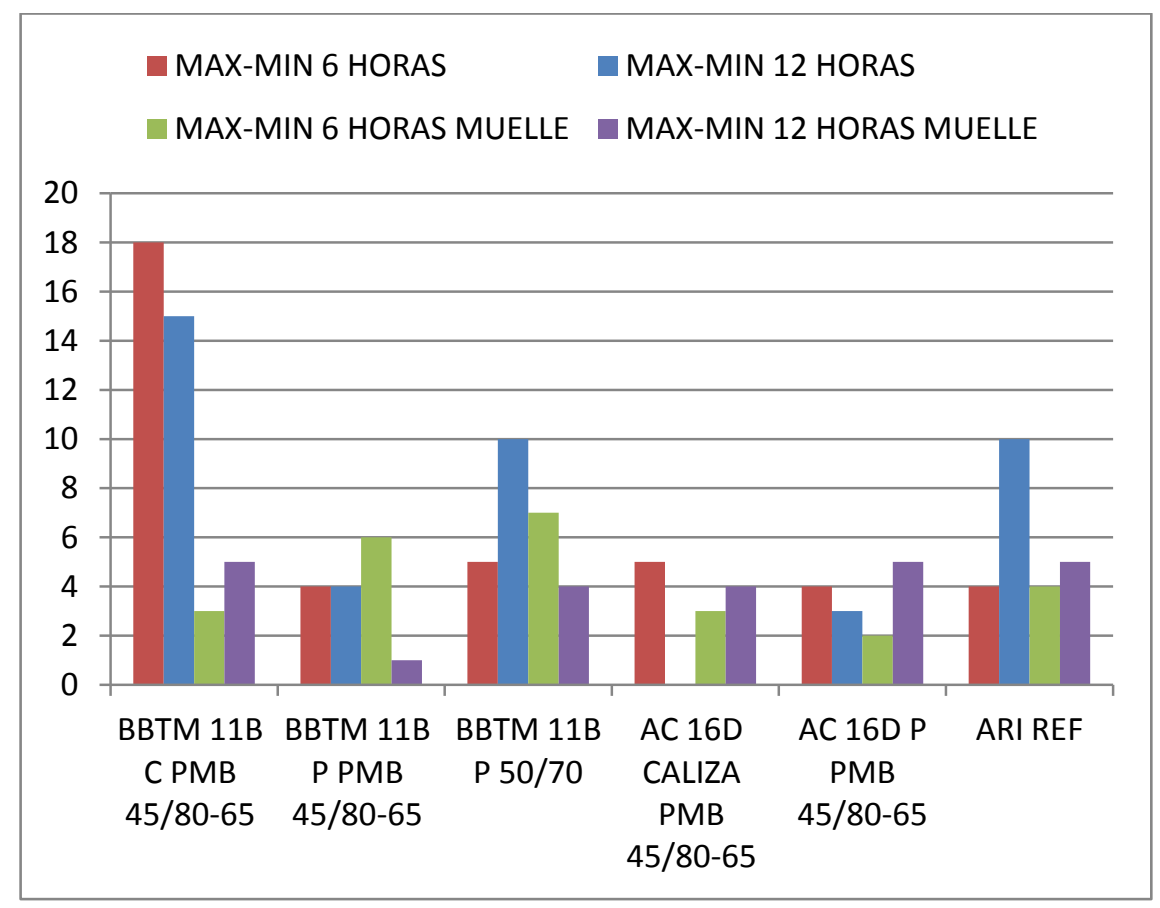

Figura 5. 28. Rango a 6 y 12 horas. Pulimento según UNE-EN 1097-8 más muelle. 


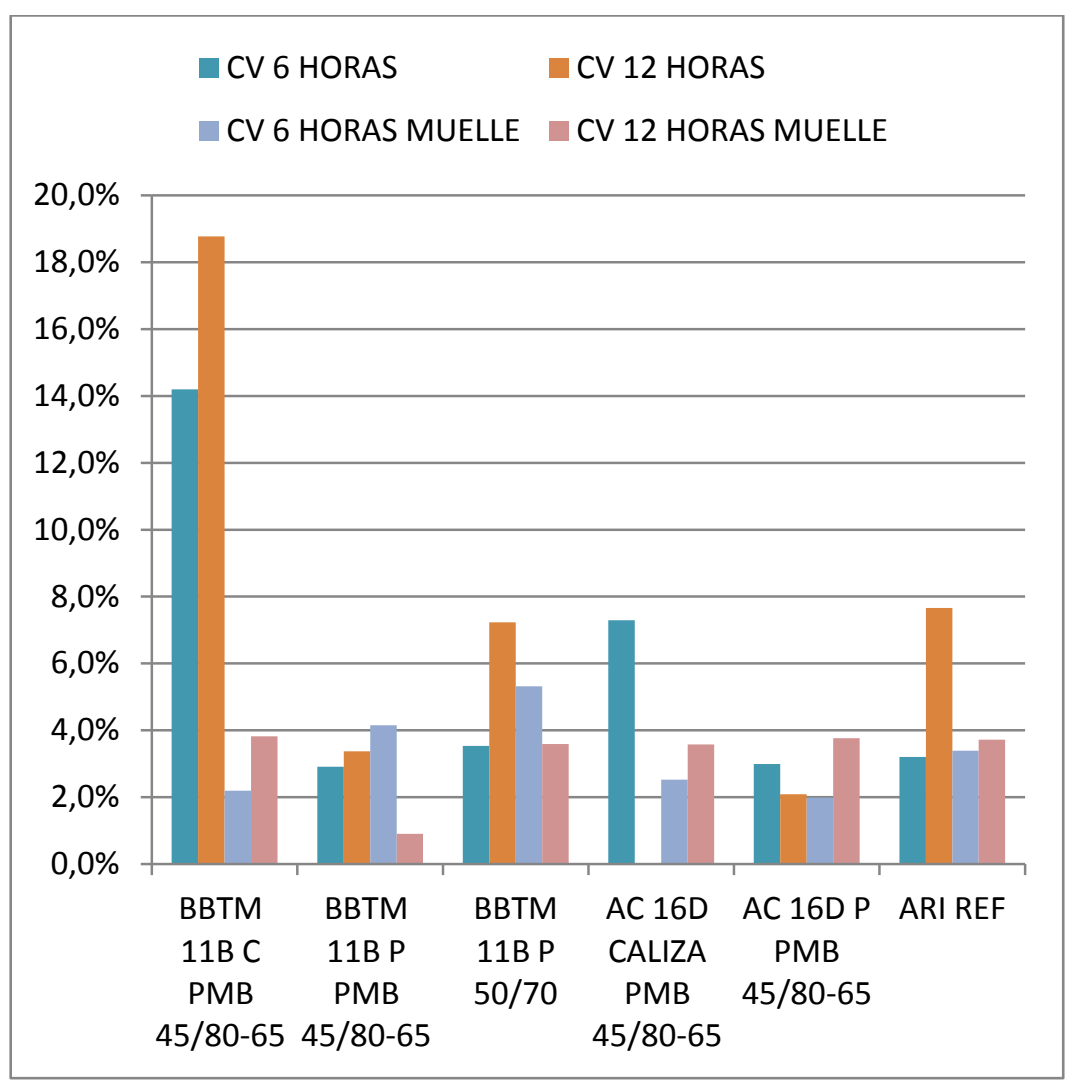

Figura 5.29. Coeficientes de variación a 6 y 12 horas. Pulimento según UNE-EN 1097-8 más muelle.

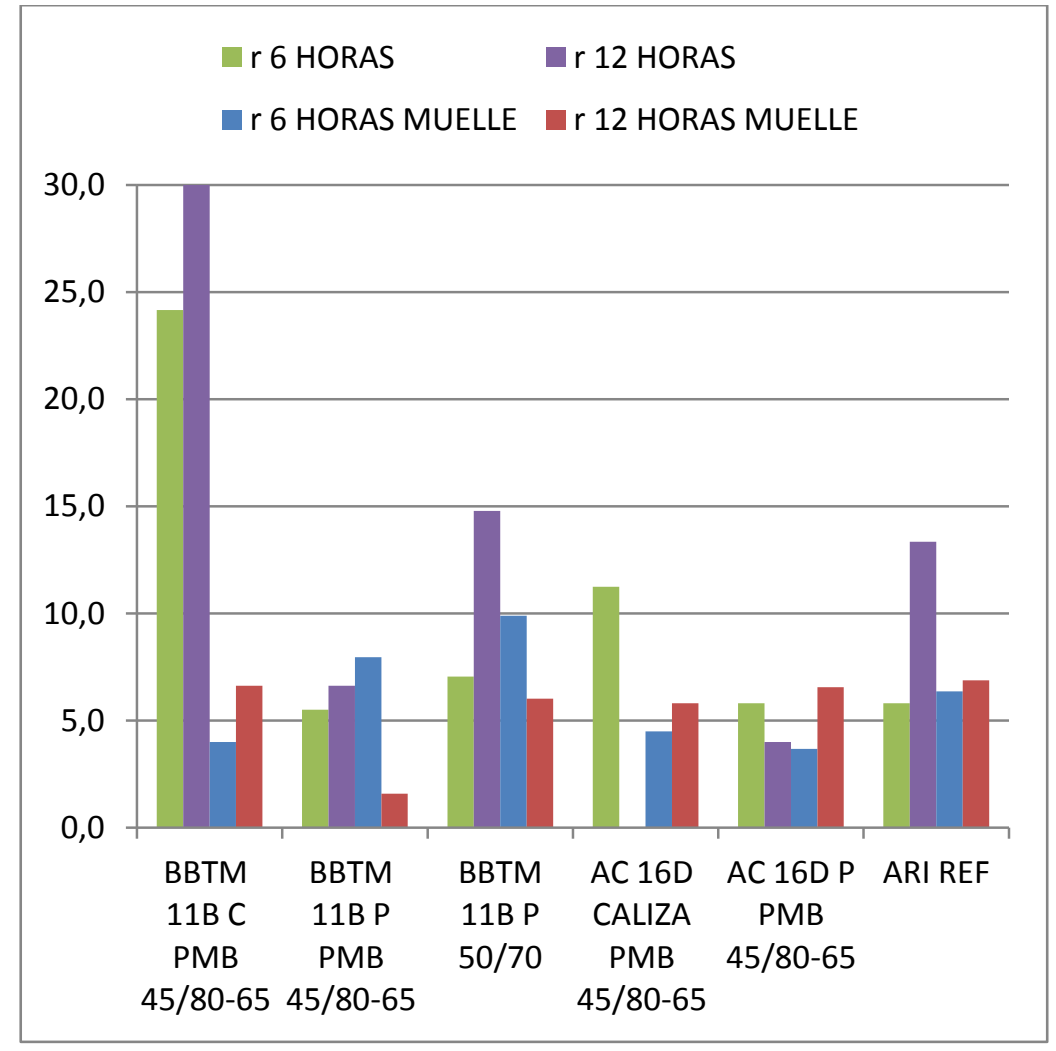

Figura 5.30. Repetibilidad a 6 y 12 horas. Pulimento según UNE-EN 1097-8 más muelle. 
Además los valores de coeficiente de pulimento acelerado de mezclas a las 12 horas del ensayo son menores que los obtenidos a 6 horas, cosa que no ocurría cuando el peso se unía directamente al brazo palanca del equipo sin muelle, (figura 5.31). Todo esto da a entender que con las modificaciones introducidas en el proceso de pulimento, se consigue que éste se haga de forma más uniforme, limitando los golpes que se producían en las probetas de mezcla con el proceso de pulimento de acuerdo a la norma UNE-EN 1097-8, evitando dañar éstas y permitiendo que el péndulo midiera sobre superficies de mezcla regulares y sin dañar.

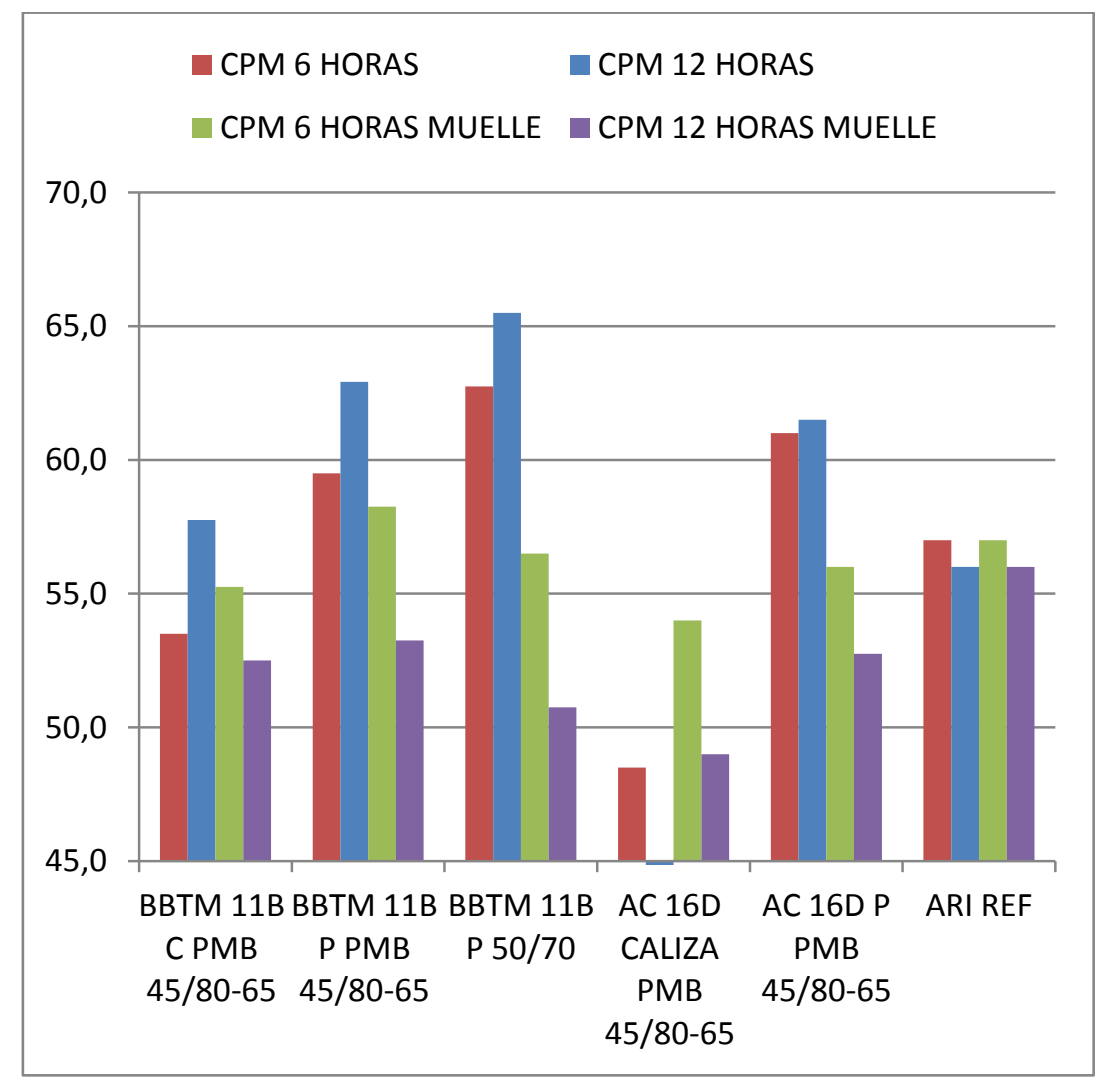

Figura 5.31. CPM a 6 y 12 horas. Pulimento según UNE-EN 1097-8 más muelle.

Por último comentar que se hizo una comprobación del cumplimento de los criterios de rechazo que se establecieron en el capítulo 4 para verificar si con el procedimiento de pulimento con muelle se cumplían. En la tabla 5.24 se han incluido para cada mezcla las diferencias entre los valores medios de resistencia al deslizamiento de las dos probetas ensayadas en cada rueda a lo largo de tiempo. Como puede verse, a 6 horas las diferencias son inferiores a 5 unidades por lo que uno de los dos criterios de rechazo establecidos se cumplía. Además en el caso de las probetas de árido de referencia a 6 horas las diferencias entre el valor medio de las dos probetas de árido ensayadas en la rueda 1 y en la rueda 2 fueron menores de 3 unidades por lo que el segundo y último criterio de rechazo considerado 
también se cumplían dando por bueno el ensayo para la totalidad de las mezclas ensayadas, (tabla 5.12)

Tabla 5. 12. Criterio rechazo. Diferencias entre valores medios de cada rueda. Pulimento según UNE-EN 1097-8 más muelle.

\begin{tabular}{|c|c|c|c|c|c|c|c|c|c|c|c|}
\hline \multirow[t]{2}{*}{ MEZCLA } & \multirow[t]{2}{*}{ RECHAZO } & \multicolumn{4}{|c|}{$\begin{array}{c}\text { Esmeril } \\
\text { Grueso }\end{array}$} & \multicolumn{6}{|c|}{ Esmeril Fino } \\
\hline & & 0 & 1 & 2 & 3 & 4 & 5 & 6 & 8 & 10 & 12 \\
\hline $\begin{array}{c}\text { BBTM11B } \\
\text { CALIZO PMB } \\
45 / 80-65\end{array}$ & \multirow{6}{*}{$\begin{array}{l}\text { MEDIA } \\
\text { R1- } \\
\text { MEDIA } \\
\text { R2 }\end{array}$} & $-2,0$ & $-1,0$ & 0,5 & $-0,5$ & 0,0 & 0,0 & 1,5 & 2,0 & 0,5 & 3,0 \\
\hline $\begin{array}{c}\text { BBTM11B } \\
\text { PÓRFIDO PMB } \\
45 / 80-65\end{array}$ & & $-3,5$ & $-1,5$ & 0,0 & $-2,0$ & $-4,5$ & 0,5 & 0,5 & $-3,0$ & $-5,0$ & $-0,5$ \\
\hline $\begin{array}{c}\text { AC 16D } \\
\text { CALIZA PMB } \\
45 / 80-65\end{array}$ & & 3,5 & 0,0 & 6,0 & 0,5 & 2,0 & 3,0 & 1,0 & $-0,5$ & 1,5 & 0,0 \\
\hline $\begin{array}{c}\text { AC 16D } \\
\text { PÓRFIDO PMB } \\
45 / 80-65\end{array}$ & & $-0,5$ & $-3,0$ & $-0,5$ & 0,0 & $-2,0$ & $-5,0$ & 0,0 & $-2,5$ & 0,0 & $-0,5$ \\
\hline $\begin{array}{l}\text { BBTM11B } \\
\text { PÓRFIDO } \\
50 / 70\end{array}$ & & $-3,5$ & $-3,0$ & $-0,5$ & 1,5 & 0,0 & $-0,5$ & $-5,0$ & $-4,5$ & $-1,0$ & $-1,5$ \\
\hline ARI REF & & $-5,0$ & $-2,0$ & $-2,5$ & $-1,0$ & 0,0 & $-3,0$ & 2,0 & 2,0 & 2,5 & 1,0 \\
\hline
\end{tabular}

\subsubsection{Análisis de la sensibilidad del ensayo a los materiales evaluados.}

Para que este método de ensayo sea efectivo en el diseño de mezclas bituminosas es necesario que sus resultados muestren valores diferentes cuando los materiales que componen las mezclas ensayadas cambian. En lo que sigue se exponen los resultados obtenidos en una serie de estudios en los que se evalúa la sensibilidad del ensayo CPM frente al tipo de mezcla y los materiales con que ésta se fabrica. El primer estudio se centra en el análisis del comportamiento frente a deslizamiento del mismo tipo de mezcla bituminosa, esto es, con la misma granulometría y macrotextura y con los mismos tipos de árido pero fabricada con distintos tipos de betún. El segundo analiza la respuesta frente a deslizamiento de mezclas bituminosas fabricadas con misma macrotextura y ligante pero distintos tipos de árido. Por último, en el tercer estudio se investiga cómo varía el comportamiento frente a deslizamiento en mezclas fabricadas con mismo tipo de árido y ligante pero con distintas macrotexturas.

\subsubsection{Sensibilidad del ensayo CPM frente al tipo de ligante}

Para estudiar la influencia que tiene el ligante de una mezcla en el comportamiento frente a deslizamiento de la misma se emplearon dos mezclas tipo BBTM 11B 
fabricadas con la misma granulometría y mismo tipo de áridos, pórfido para el grueso y silíceo para el fino. En ambos casos se utilizó como filler carbonato cálcico. Lo único que cambió fue el tipo de ligante empleado. Una mezcla se fabricó con betún modificado, tipo PMB 45/80-65, y la otra con un betún convencional 50/70.

La figura 5.32 muestra los resultados obtenidos en las pruebas llevadas a cabo utilizando como sistema de pulimento el de la UNE-EN 1097-8 con muelle. Los valores representados corresponden a las medias obtenidas de 4 probetas de cada tipo de mezcla ensayadas dos en una rueda y otras dos en otra.

Como se puede observar la curva en ambos casos es bastante parecida. Sin embargo, hay un pico en la mezcla fabricada con betún modificado en la hora 1 , dónde esta mezcla da valores más altos de resistencia al deslizamiento. Parece que el betún modificado tarda más tiempo en desprenderse del árido, por lo que éste tarda más tiempo en pulimentarse, de ahí el pico en la curva. Pero una vez eliminado el betún de la superficie del árido en contacto con la rueda que desgasta las probetas, el árido se pulimenta de la misma forma que en la mezcla fabricada con betún normal. El dato es interesante por cuanto el ensayo podría utilizarse para, en función del tipo de betún empleado en la fabricación de las mezclas, determinar el momento más adecuado a la hora de medir el coeficiente de resistencia al deslizamiento en carreteras a través del SCRIM, actualmente establecido en un mes desde la puesta en servicio de la carretera. Bastaría con intensificar las medidas tomadas en el intervalo de 0 a 2 horas, cada 15 min por ejemplo, para monitorizar de forma más detallada este proceso.

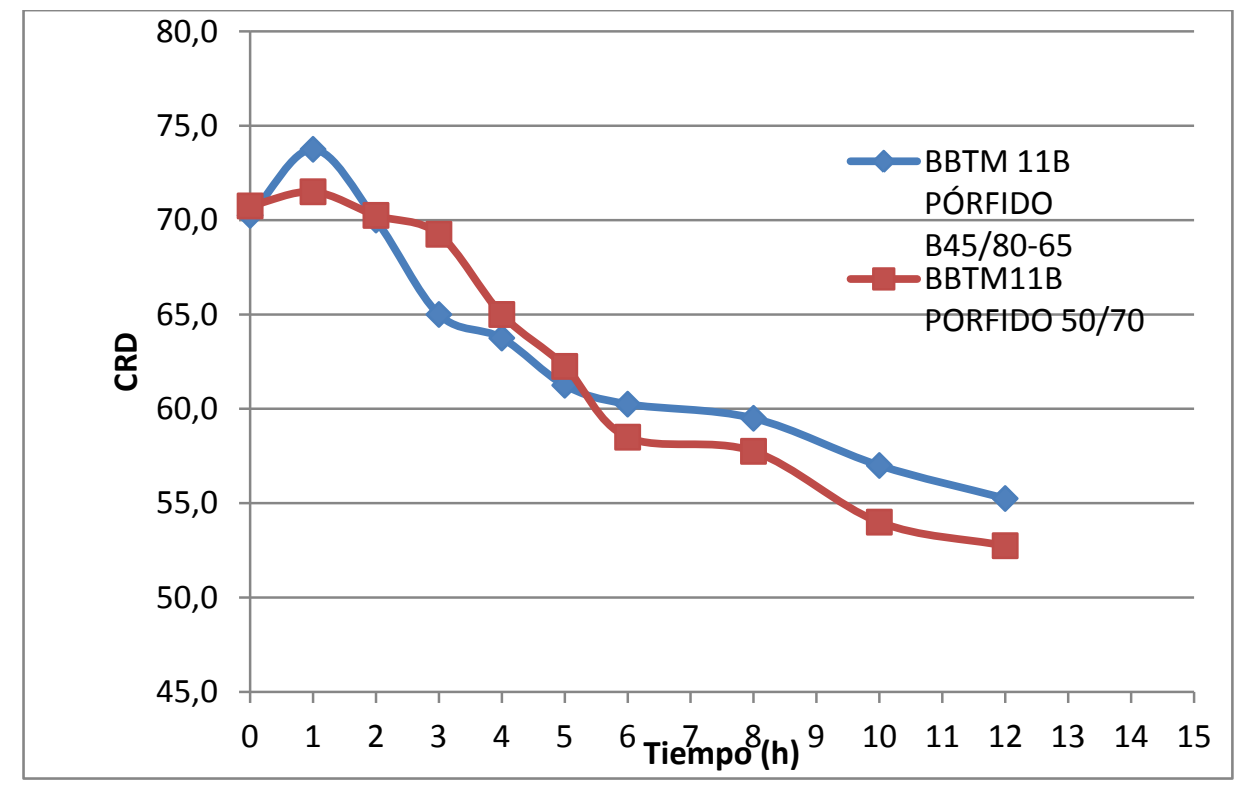

Figura 5.32. Sensibilidad del ensayo CPM frente al tipo de betún con que se fabrica la mezcla. Pulimento según la UNE-EN 1097:8 más muelle. 


\subsubsection{Sensibilidad del ensayo CPM frente al tipo de árido}

Para el estudio de la influencia de la naturaleza del árido en el comportamiento de una mezcla bituminosa frente a la resistencia al deslizamiento, en una primera fase, se emplearon dos mezclas de similares características, del tipo BBTM 11B, una fabricada con áridos gruesos andesíticos, (CPA 57), y otra con áridos gruesos porfídicos, (CPA 47). En ambos casos el árido fino fue del tipo silíceo, el filler de aportación carbonato cálcico y el betún modificado, del tipo PMB 45/80-65.

Las figura 5.33 muestra los resultados obtenidos en las pruebas llevadas a cabo, utilizando como sistema de pulimento el de la UNE-EN 1097-8 sin muelle. Los valores representados corresponden a las medias obtenidas de 12 probetas de cada tipo de mezcla.

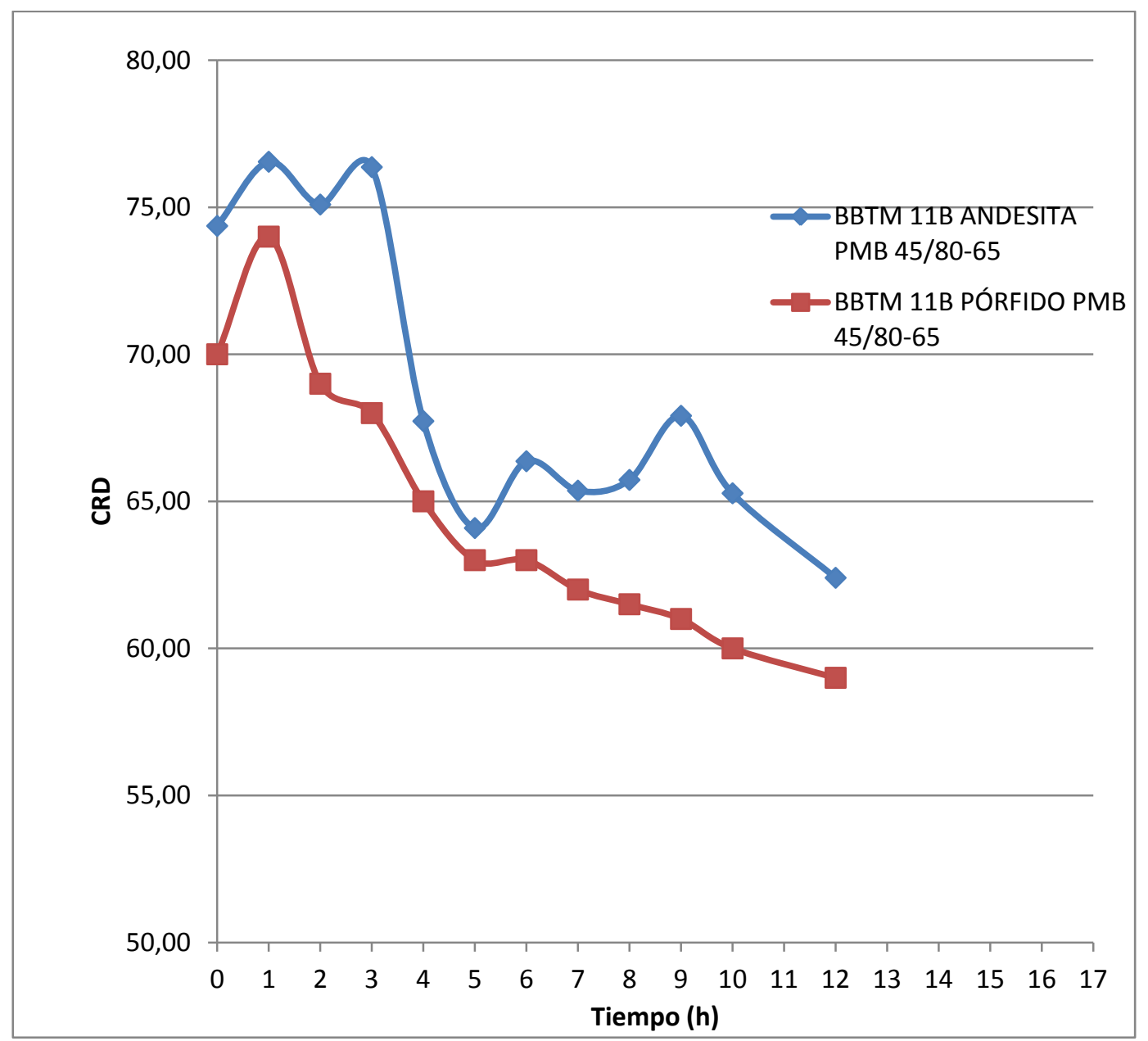

Figura 5.33. Sensibilidad del ensayo CPM frente al tipo de árido con que se fabrica la mezcla. Pulimento según UNE-EN 1097-8. 
Como puede verse, el valor de resistencia al deslizamiento de la mezcla fabricada con áridos con mayor CPA está dando valores de resistencia al deslizamiento más altos en todo el intervalo temporal estudiado.

Las irregularidades que se observan en la curva que representa el comportamiento frente al deslizamiento de la BBTM 11B fabricada con andesita se deben a un proceso de pulimento demasiado agresivo, sobre una de las primeras ruedas que se fabricaron para la presente investigación, con probetas con ciertas irregularidades en su espesor, donde los efectos dinámicos del proceso de pulimento se veían acrecentados.

En una segunda fase se emplearon dos mezclas de similares características. Una AC 16D fabricada con árido grueso y fino calizo de CPA 43 y una AC 16D fabricada con árido grueso porfídico, de CPA 47, y árido fino de tipo silíceo. También se fabricaron una BBTM 11B, con el mismo tipo de árido grueso porfídico y árido fino silíceo y el mismo tipo de mezcla fabricada con los mismos áridos calizos con los que se fabricó la AC16D caliza. En todos los casos se utilizó como filler de aportación carbonato cálcico y como ligante, un betún modificado tipo PMB 45/80-65.

Las figura 5.34 y 5.35 muestran los resultados obtenidos en las pruebas llevadas a cabo utilizando como sistema de pulimento el de la UNE-EN 1097-8 con muelle. Los valores representados corresponden a las medias obtenidas de 4 probetas de cada tipo de mezcla ensayadas dos en una rueda y otras dos en otra.

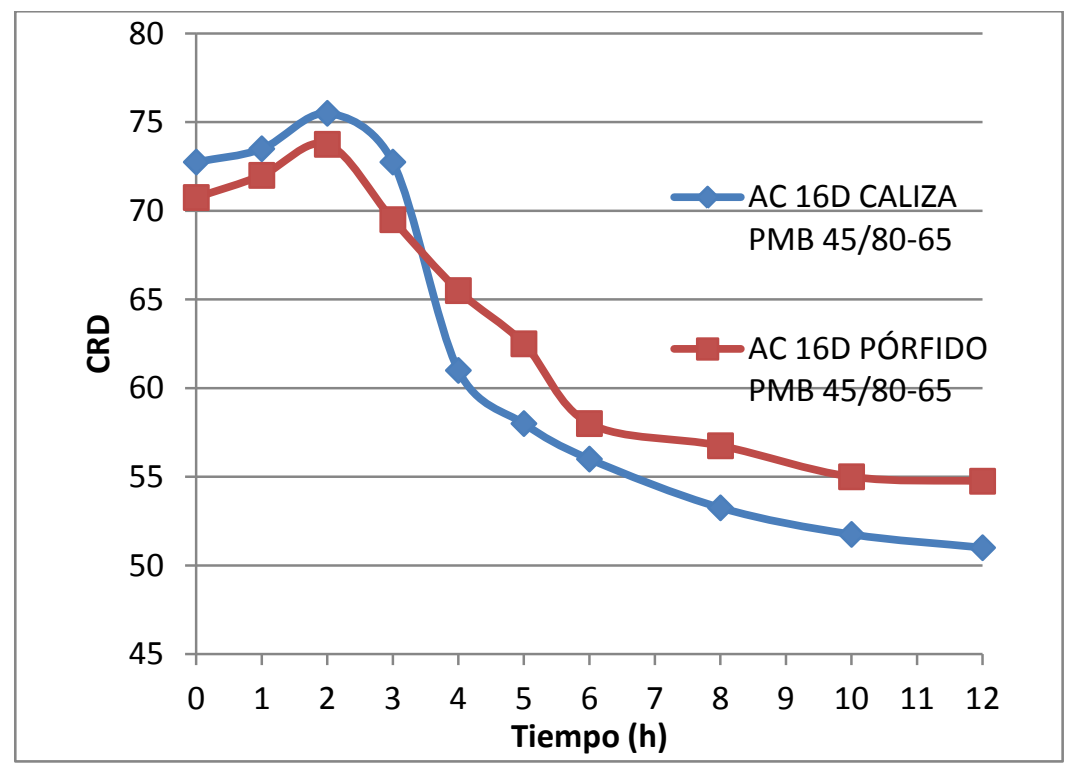

Figura 5.34. Sensibilidad del ensayo CPM frente al tipo de árido con que se fabrica la mezcla. AC 16D caliza versus pórfido. Pulimento según UNE-EN 1097-8 más muelle. 


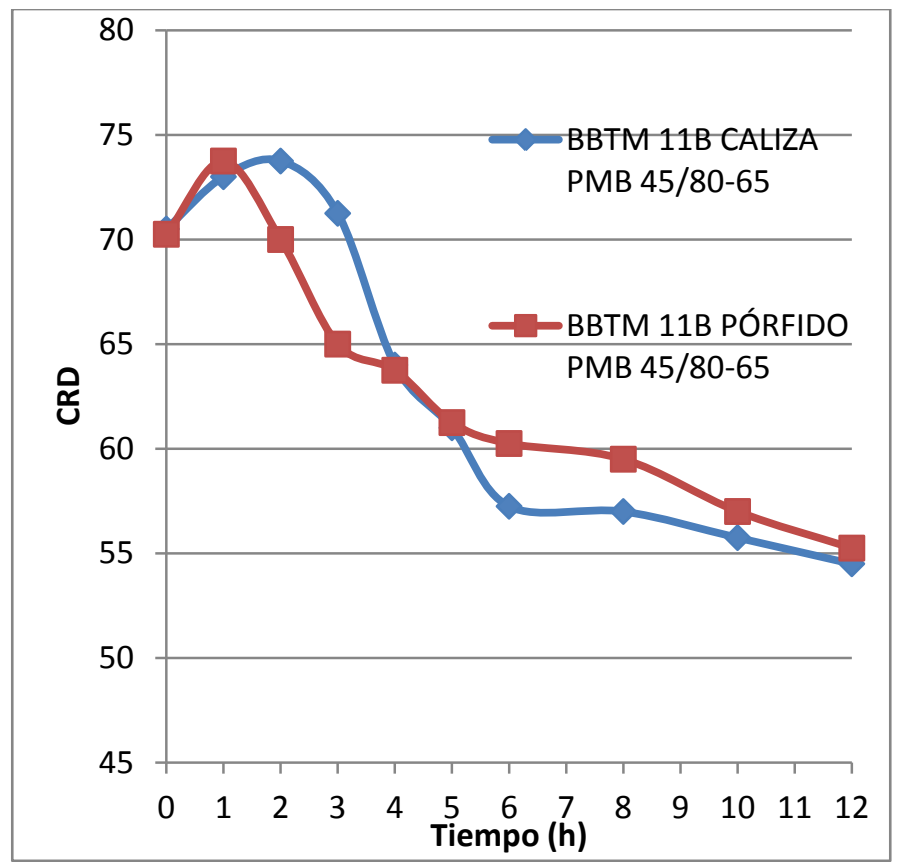

Figura 5.35. Sensibilidad del ensayo CPM frente al tipo de árido con que se fabrica la mezcla. BBTM 11B caliza versus pórfido. Pulimento según UNE-EN 1097-8 más muelle.

En el caso de las mezclas tipo AC 16D, (figura 5.36), la influencia del árido de mayor CPA empieza a apreciarse a partir de la hora 4 de pulimento al igual que ocurre en el caso de las mezclas tipo BBTM 11B, (figura 5.37).

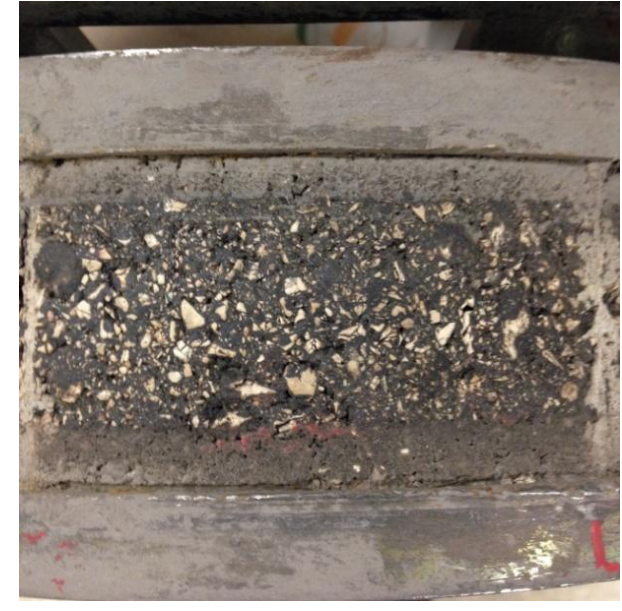

Figura 5.36. Probeta de AC 16D caliza tras 12 horas de pulimento con muelle.

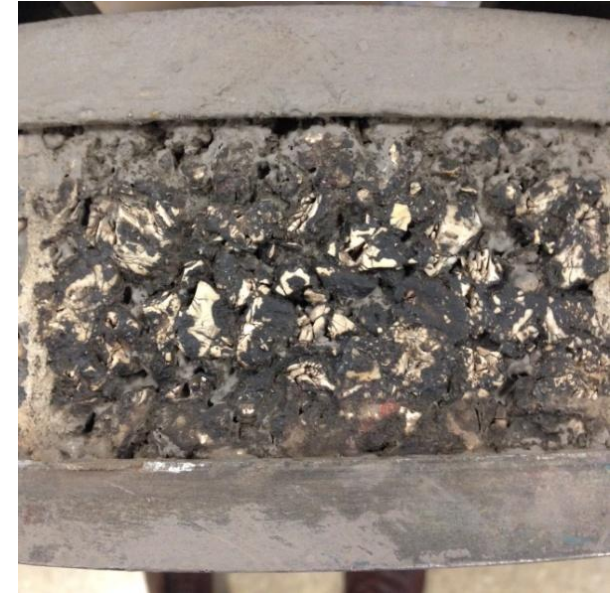

Figura 5.37. Probeta BBTM 11B caliza tras 12 horas de pulimento con muelle

A pesar de la gran similitud de características entre mezclas en las que se utilizó el mismo tipo de betún y esqueleto mineral, el ensayo desarrollado en esta investigación ha demostrado tener la precisión suficiente para poder poner de manifiesto cuál de ellas ofrece un comportamiento más favorable frente al fenómeno de resistencia al deslizamiento en función del tipo de árido con el que se fabrican. 


\subsubsection{Sensibilidad del ensayo CPM frente al tipo de mezcla}

Para el estudio de la influencia de la macrotextura en el comportamiento frente a deslizamiento de una mezcla, en una primera fase se empleó una mezcla tipo BBTM 11B fabricada con áridos gruesos porfídicos de CPA 47. El árido fino fue del tipo silíceo, el filler de aportación carbonato cálcico y el betún modificado del tipo PMB 45/80-65.

Con esta mezcla se fabricaron 12 probetas hasta completar una rueda que se pulió de acuerdo al procedimiento que marca la UNE-EN 1097-8. Se hicieron macrotexturas de las 12 probetas con el procedimiento adaptado del círculo de arena explicado en el capítulo 4 y se obtuvieron los valores medios de resistencia al deslizamiento de dos grupos de 6 probetas: los que tenían una macrotextura mayor a $1,5 \mathrm{~mm}$ y los que tenían una macrotextura menor a $1,5 \mathrm{~mm}$.

La figura 5.38 muestra los resultados obtenidos en las pruebas llevadas a cabo.

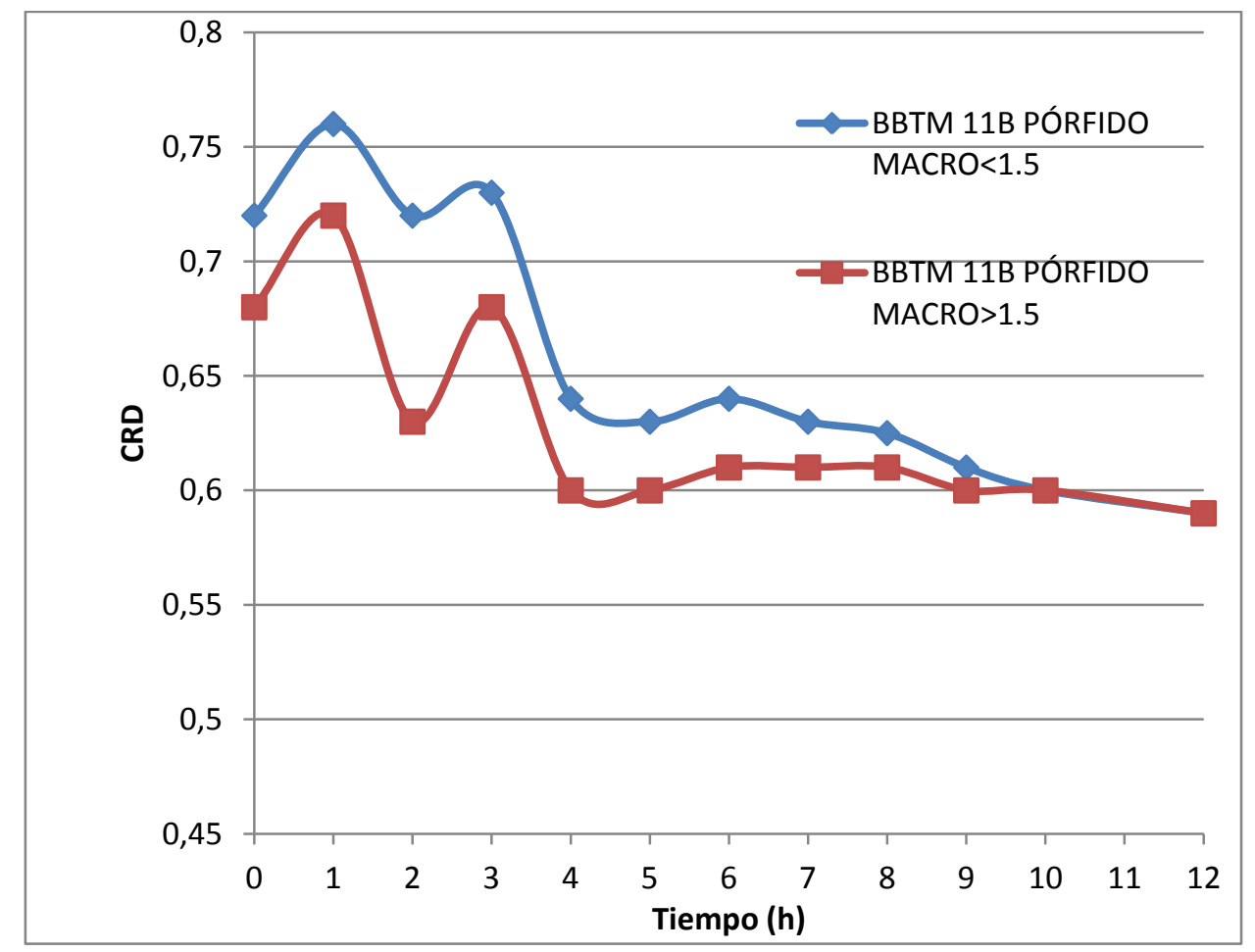

Figura 5. 38. Sensibilidad del ensayo CPM frente a la macrotextura. Pulimento según UNE-EN 1097-8.

Las probetas se han pulido de acuerdo a la UNE-EN 1097-8 lo que puede explicar los valores anómalos de resistencia al deslizamiento que se tienen a las dos horas. Del análisis de estas dos curvas se aprecia que se consiguen mayores resistencias al deslizamiento con macrotexturas menores y que a partir de las 8 horas de 
pulimento las diferencias dejan de ser apreciables porque el proceso de pulimento llevado a cabo hace que las probetas pierdan algo de la macrotextura inicial.

A la vista de los resultados anteriores en una segunda fase, con el equipo de pulimento de mezclas modificado con el muelle, se estudió la evolución del coeficiente de resistencia al deslizamiento de mezclas fabricadas con los mismos áridos y ligante pero con husos granulométricos muy diferentes. En concreto se compararon los resultados obtenidos de mezclas tipo BBTM 11B, de mayor macrotextura, con mezclas tipo AC 16D, de macrotextura menor. Se fabricaron 4 probetas de BBTM 11B, con árido grueso y fino calizo de CPA 43, que se compararon con los resultados de 4 probetas AC 16D fabricadas con el mismo tipo de árido. Por otro lado, se compararon los resultados de 4 probetas de BBTM 11B, fabricadas con árido grueso pórfido con CPA 50 y un árido fino de tipo silíceo, con los resultados obtenidos en 4 probetas de AC 16D fabricadas con los mismos tipos de árido. En todos los casos el filler de aportación fue el mismo, carbonato cálcico, y el betún también, PMB 45/80-65.

En la tabla 5.13 se incluyen los valores de macrotextura conseguidos para las probetas ensayadas. En las mezclas tipo BBTM 11B fabricadas con árido porfídico, se han conseguido texturas propias de mezclas de este tipo. Con el resto, las macros obtenidas están por debajo de su valor deseado por lo que habrá que revisar el procedimiento de compactación empleado de cara al futuro.

Tabla 5. 13. Macrotextura de las mezclas fabricadas

\begin{tabular}{|c|c|c|c|c|c|c|}
\hline & \multirow[b]{2}{*}{ PROBETA } & \multicolumn{5}{|c|}{ TIPO DE MEZCLA } \\
\hline & & $\begin{array}{c}\text { BBTM 11B } \\
\text { CALIZO PMB } \\
45 / 80-65\end{array}$ & $\begin{array}{c}\text { BBTM 11B } \\
\text { PÓRFIDO } \\
\text { PMB 45/80-65 }\end{array}$ & $\begin{array}{c}\text { AC 16D } \\
\text { CALIZA } \\
\text { PMB } \\
45 / 80-65\end{array}$ & $\begin{array}{l}\text { AC 16D } \\
\text { PÓRFIDO } \\
\text { PMB } \\
\text { 45/80-65 }\end{array}$ & $\begin{array}{c}\text { BBTM 11B } \\
\text { PÓRFIDO } \\
50 / 70\end{array}$ \\
\hline \multirow{4}{*}{$\begin{array}{c}\text { MACRO } \\
(\mathrm{mm})\end{array}$} & 1,1 & 0,7 & 1,6 & 0,3 & 0,5 & 1,6 \\
\hline & 1,2 & 1,1 & 1,5 & 0,3 & 0,4 & 2,0 \\
\hline & 2,1 & 1,1 & 1,5 & 0,3 & 0,5 & 2,4 \\
\hline & 2,2 & 1,0 & 1,4 & 0,3 & 0,4 & 2,0 \\
\hline \multirow{7}{*}{ 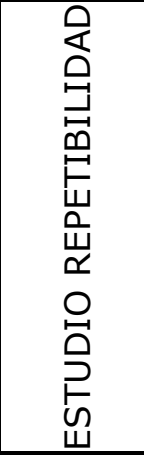 } & MAX & 1,1 & 1,6 & 0,3 & 0,5 & 2,4 \\
\hline & MIN & 0,7 & 1,4 & 0,3 & 0,4 & 1,6 \\
\hline & $\begin{array}{l}\text { MÁX.- } \\
\text { MÍN. }\end{array}$ & 0,4 & 0,2 & 0,0 & 0,1 & 0,8 \\
\hline & MEDIA & 1,0 & 1,5 & 0,3 & 0,5 & 2,0 \\
\hline & DESV & 0,2 & 0,1 & 0,0 & 0,0 & 0,3 \\
\hline & $\mathrm{CV}$ & $19,4 \%$ & $4,4 \%$ & $0,0 \%$ & $10,3 \%$ & $15,4 \%$ \\
\hline & $r$ & 0,6 & 0,2 & 0,0 & 0,2 & 1,0 \\
\hline
\end{tabular}


En las figuras 5.39 y 5.40 se pueden comparar el comportamiento frente al deslizamiento de estos tipos de mezclas. Las gráficas corresponden a los valores medios obtenidos de las 4 probetas que se pulieron en parejas de dos en ruedas independientes con el proceso de pulimento de la UNE-EN 1097-8 modificado con muelle.

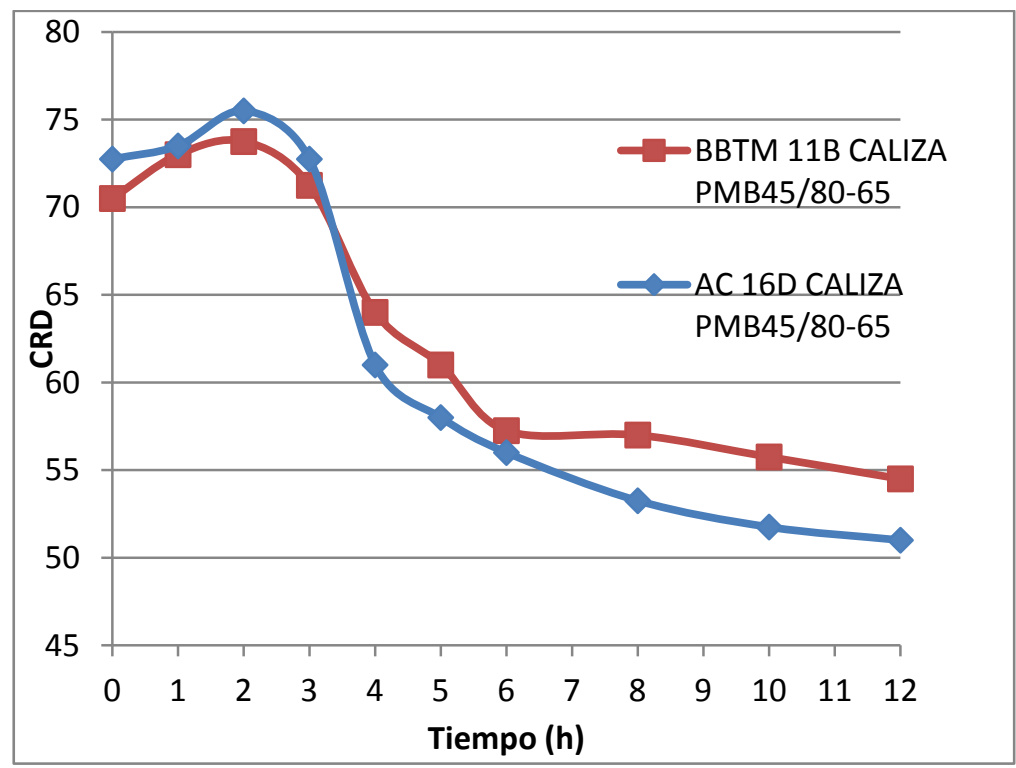

Figura 5.39. Sensibilidad del ensayo CPM frente a la macrotextura. BBTM 11B caliza versus AC 16D caliza. Pulimento según UNE-EN 1097-8 más muelle

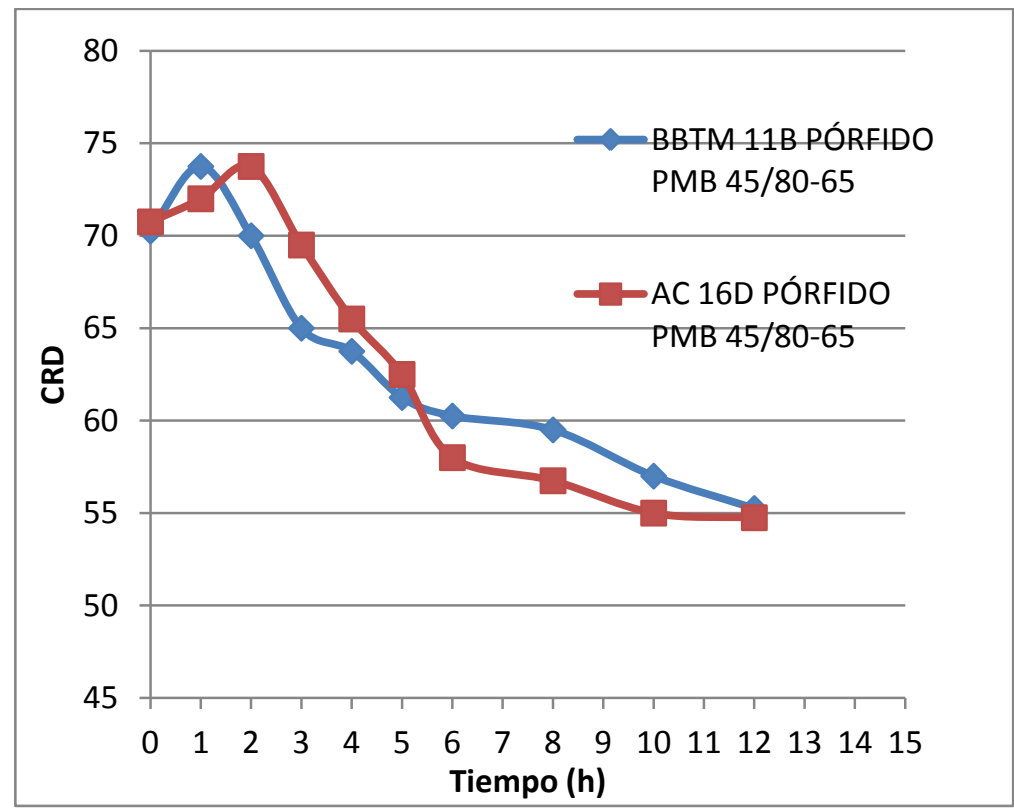

Figura 5.40. Sensibilidad del ensayo CPM frente a la macrotextura. BBTM 11B Pórfido versus AC 16D Pórfido. Pulimento según UNE-EN 1097-8 más muelle. 
En ambos casos las mezclas discontinuas, con mayor macrotextura, presentan un peor comportamiento al deslizamiento hasta las 4 o 5 horas que las mezclas tipo AC fabricadas con el mimos tipo de betún y áridos. A partir de ahí los valores de resistencia al deslizamiento son ligeramente mayores en las mezclas con mayor macrotextura lo cual va en contra de lo esperado.

La bibliografía consultada ya indicaba que la macrotextura es una propiedad de las mezclas que tiene influencia en el comportamiento de éstas frente a la resistencia al deslizamiento para velocidades mayores de $60 \mathrm{~km} / \mathrm{h}$. La medida de resistencia al deslizamiento en el ensayo desarrollado se hace con el péndulo de fricción TRRL, que sólo es capaz de proporcionar medidas de resistencia al deslizamiento a bajas velocidades. El parámetro que más influencia tiene en la resistencia al deslizamiento a bajas velocidades es la microtextura de la mezcla, que está muy influenciada por las características del árido, sobre todo por su CPA, y aunque hay investigaciones que concluyen que las medidas del péndulo se ven afectadas por la macrotextura de la mezcla, otras apuntan que las medidas que da el péndulo son poco fiables en este tipo de texturas.

Por otro lado, de la inspección visual de las mezclas pulimentadas se puede observar que, aunque la inclusión del muelle ha servido para suavizar el proceso de desgaste de las probetas de mezcla, las fabricadas con una granulometría discontinua siguen siendo sensibles al proceso de pulimento incluso con muelle, por lo que es posible que los valores de resistencia al deslizamiento en este tipo de mezclas estén influenciados por defectos localizados provocados en las probetas durante su pulimento, que den lugar a valores de resistencia al deslizamiento algo superiores a los esperados. 


\section{CONCLUSIONES}

A continuación pasamos a exponer las principales conclusiones a las que se ha llegado en el presente trabajo siguiendo la misma estructura metodológica que se ha seguido en la tesis.

\subsection{Dispositivo de ensayo}

Se ha conseguido desarrollar un procedimiento de ensayo basado en el equipo que actualmente se utiliza para medir el coeficiente de pulimento acelerado de los áridos de acuerdo a la norma UNE-EN 1097-8, (Ensayos para determinar las propiedades mecánicas y físicas de los áridos. Parte 8: Determinación del coeficiente de pulimento acelerado).

Las modificaciones introducidas en el equipo son fácilmente replicables en cualquier máquina de pulimento de áridos y con bajo coste. Básicamente han consistido en una modificación de la rueda porta-muestras, que es capaz de albergar hasta 12 probetas de mezcla bituminosa con forma de dovela, del eje que la soporta, en el empleo de un motor de mayor potencia y en la colocación de un muelle o resorte de $86 \mathrm{~mm}$ de longitud y una constante "k" de Young de $17.500 \mathrm{~N} / \mathrm{m}$, entre el peso y el brazo palanca, con el objeto de conseguir un pulimento más uniforme y menos agresivo que el que se produce cuando se quiere obtener el coeficiente de pulimento acelerado de los áridos.

El personal de laboratorio encargado de la realización del ensayo CPA con poco entrenamiento será capaz de llevar a cabo el ensayo propuesto con el equipo modificado desarrollado en este trabajo. Esto facilitará la futura normalización del ensayo y su utilización por otros laboratorios de control de calidad, universidades y centro tecnológicos especializados en el diseño y control de calidad de mezclas bituminosas.

El proceso de pulimento permite reproducir con fiabilidad, de forma controlada y en un corto periodo de tiempo, el desgaste por abrasión que sufren las mezclas bituminosas en capa de rodadura cuando son sometidas a la acción del tráfico rodado.

El dispositivo de ensayo permite evaluar mezclas con tamaño máximo de árido 8, $11 \mathrm{~mm}$ e incluso $16 \mathrm{~mm}$ si, como en el caso de las mezclas AC diseñadas para este trabajo, el $100 \%$ de los áridos pasan por el tamiz $16 \mathrm{~mm}$. Sin embargo, para poder evaluar mezclas con tamaño máximo $22 \mathrm{~mm}$ deberíamos utilizar probetas de mayor espesor, por lo que habría que modificar la rueda porta-muestras desarrollada en el presente trabajo y los moldes y útiles de compactación empleados. 


\subsection{Características del ensayo}

La forma y dimensiones de las probetas a ensayar no presentan dificultades en su fabricación para no tener que emplear excesivo tiempo en su elaboración y tener garantías de que se pueden repetir con características homogéneas. Sus dimensiones, dovelas de $30 \mathrm{~mm}$ de espesor, $80 \mathrm{~mm}$ de ancho, $107 \mathrm{~mm}$ de longitud en la cara externa y $91 \mathrm{~mm}$ en la cara interna, permiten una buena trabajabilidad sin incurrir en tamaños de probeta demasiado grandes que incrementen el consumo de material a utilizar. El operador deber ser estricto con los espesores finales conseguidos para no tener problemas durante la colocación de las probetas en la rueda porta-muestras y en la fase de pulimento posterior, estableciéndose en 29,3 $\mathrm{mm}$ el espesor de probeta óptimo.

Se han desarrollado moldes y útiles de compactación específicos para la fabricación de este tipo de probetas fácilmente replicables y que no requieren de una excesiva inversión.

Se ha desarrollado un procedimiento de compactación para la fabricación de las probetas que permite garantizar que la densidad y porcentaje de huecos, en las muestras fabricadas en laboratorio, sean representativas de las que se obtendrán sobre la misma mezcla puesta en el pavimento de una carretera. El procedimiento de compactación empleado fue el de aplicar una compresión simple de 170 KN durante 6 segundos. Tiempos mayores de aplicación de carga terminaban por romper los áridos calizos utilizados en la presente investigación. La macrotextura conseguida con este procedimiento en las mezclas tipo BBTM 11B fabricadas con árido porfídico superaba los valores de 1,5 mm típicos de este tipo de mezclas. En cambio, la macrotextura conseguida en la misma mezcla discontinua fabricada con árido calizo se encontraba entre 0,7 y $1 \mathrm{~mm}$. La conseguida en las probetas de mezclas tipo $A C 16 \mathrm{D}$ fue de unos $0,3 \mathrm{~mm}$, para las fabricadas con árido calizo, y entre 0,4 y $0,5 \mathrm{~mm}$ para las $A C$ fabricadas con pórfido, valores que están por debajo del valor de 0,7 mm que se pide a este tipo de mezclas. Se debe revisar el procedimiento de compactación a emplear para este tipo de mezclas de forma que se garantice una macrotextura más representativa de la que se obtendrá cuando se coloquen en obra.

Las probetas con forma de dovela se fabrican con la curvatura de ensayo necesaria como para que puedan colocarse en una rueda porta-muestras similar a la empleada en el ensayo para pulimento de áridos pero modificada para poder albergar las probetas de mezcla de $30 \mathrm{~mm}$ de espesor y $80 \mathrm{~mm}$ de ancho. 
Las condiciones de ensayo han quedado definidas y son las indicadas por la UNE-EN 1097-8 que trata de reproducir el efecto de pulimento que tiene el árido de las mezclas por efecto del tráfico.

El procedimiento de ensayo permite conocer el comportamiento de las mezclas en cuanto a su resistencia al deslizamiento a lo largo del tiempo. La medición con el péndulo TRRL de la resistencia al deslizamiento de las probetas de mezcla se hará antes de empezar el pulimento de éstas y, una vez iniciado el pulimento, con una frecuencia horaria. Se da por buena la duración del ensayo de 12 horas porque se ha comprobado que el CPM de las mezclas apenas sufre variación a partir de ese tiempo. El proceso de pulimento se hará de acuerdo a la UNE-EN 1097-8 pero utilizando durante las tres primeras horas como abrasivo el grano de esmeril y durante las nueve restantes, el polvo de esmeril de granulometría más fina.

Se han definido los criterios de rechazo del ensayo que permiten detectar si el proceso de pulimento ha sido adecuado. Se han adoptado de manera conservadora criterios de rechazo similares a los que marca la UNE-EN 1097-8 aunque los valores obtenidos, cuando el pulimento de las probetas de mezcla se hace con muelle, permitirían criterios de rechazo incluso más estrictos. Con los resultados obtenidos podemos concluir que no se darán por buenos aquellos ensayos en los que el valor medio de resistencia al deslizamiento a 6 horas y 12 horas, medidos con el péndulo TRRL, de cada pareja de probetas del mismo tipo de mezcla en una rueda, difiera en más de 5 unidades del obtenido en la otra rueda para los mismos tipos de mezcla. También se rechazará el ensayo si el valor medio a 6 horas y a 12 horas, de cualquiera de las parejas de árido de referencia pulidas en cada una de las dos ruedas, difiere en más de 3 unidades de su valor.

\subsection{Medida del coeficiente de resistencia al deslizamiento sobre mezclas bituminosas.}

Se ha definido un parámetro, el coeficiente de pulimento acelerado de mezclas o CPM, que permite caracterizar la resistencia de una mezcla frente al fenómeno de resistencia al deslizamiento. Dicho parámetro no sólo tiene en cuenta la resistencia del árido grueso de la mezcla a pulimentarse, sino también la del árido fino, la macrotextura de la mezcla y el contenido y tipo de ligante empleado.

Se calcula de acuerdo a la siguiente ecuación:

$$
\mathrm{CPM}_{\mathrm{t}}=\mathrm{S}_{\mathrm{t}}+\mathrm{CPA}_{\mathrm{t}}-\mathrm{C}_{\mathrm{t}}
$$

Donde: 
$\mathrm{CPM}_{\mathrm{t}}$ es el coeficiente de pulimento acelerado de la mezcla estudiada en el tiempo t.

$\mathrm{S}_{\mathrm{t}}$ es el valor medio en el tiempo t de resistencia al deslizamiento, medido con el péndulo TRRL, de las cuatro probetas de mezcla pulimentadas, (dos en cada una de las dos ruedas porta-probetas ensayadas).

$\mathrm{CPA}_{t}$ es valor estimado del coeficiente de pulimento acelerado del árido de referencia utilizado en el tiempo $t$.

$\mathrm{C}_{\mathrm{t}}$ es el valor medio obtenido en el tiempo t de resistencia al deslizamiento, medido con el péndulo TRRL, de las cuatro probetas de árido pulimentadas, (dos en cada una de las dos ruedas porta-probetas ensayadas).

Como puede verse, el valor CPM se podrá calcular para el intervalo de tiempo t que se desee aunque interesará, sobre todo, el valor de CPM correspondiente al final del ensayo, (12 horas), siendo las mezclas con mayor CPM las que presentarán un mejor comportamiento frente a la resistencia al deslizamiento.

\subsection{Validación del método de ensayo}

Los rangos, desviaciones típicas y coeficientes de variación conseguidos en el ensayo para medir el coeficiente de pulimento acelerado de mezclas asfálticas, son suficientemente buenos como para que el ensayo se pueda aplicar en la caracterización de mezclas asfálticas, con el método de pulimento seguido por la UNE-EN 1097-8, (sin resorte). Sin embargo, se obtenían valores de repetibilidad muy altos. Con este procedimiento de ensayo algunas probetas, sobre todo las fabricadas con áridos más blandos, no terminaban de desgastarse, porque el proceso de pulimento, adecuado para probetas de árido, era excesivamente agresivo para probetas de mezcla y terminaba dañando alguna de las probetas fabricadas antes de que el ensayo pudiera darse por concluido.

Con la introducción del resorte en el procedimiento de pulimento, todas las variables estadísticas que miden la precisión del ensayo se han mejorado, obteniéndose repetibilidades entre 3,7 y 9,9 a 6 horas y entre 1,6 y 6,9 a 12 horas. Los valores del coeficiente de variación han oscilado entre un $2 \%$ y un 5,3\%, a 6 horas y entre un $0,9 \%$ y un $3,8 \%$ a 12 horas. Estos valores, que dan idea de la precisión del ensayo, son adecuados y se encuentra por debajo de los obtenidos para otros ensayos de carreteras.

El método de ensayo desarrollado permite hacer estudios comparativos sobre el comportamiento a deslizamiento de distintos tipos de mezclas bituminosas. Durante la investigación llevada a cabo se ha podido comprobar que el ensayo parece que 
es sensible, durante las primeras horas de ensayo, a los cambios en los tipos de ligante con los que se fabrican las mezclas y a los cambios en los tipos de árido con los que se fabrican, (microtextura).

Sin embargo los resultados obtenidos muestran que a partir de la cuarta o quinta hora del ensayo los valores del coeficiente de pulimento acelerado de las mezclas con mayor macrotextura son superiores a los de mezclas con menor macrotextura, lo cual va en contra de lo esperado. La forma de medir la resistencia al deslizamiento con el péndulo TRRL, que sólo es capaz de medir a bajas velocidades, o pequeños defectos que a pesar del uso del resorte se pueden producir durante el proceso de pulimento en la superficie de las probetas fabricadas, pueden ser los motivos por los que se hayan obtenido mayores valores de resistencia al deslizamiento de los esperados en las mezclas con mayor macrotextura. 


\section{FUTURAS LÍNEAS DE INVESTIGACIÓN}

Durante el desarrollo del presente trabajo han surgido nuevas línea de investigación que podrían servir para mejorar el procedimiento de ensayo desarrollado y ampliar los conocimientos sobre el comportamiento de las mezclas bituminosas frente al deslizamiento.

Se proponen como futuras líneas de investigación las siguientes:

1. Estudiar la reproducibildad del método de ensayo desarrollado. Para ello habría que adaptar otros equipos de ensayo CPA para que se pudieran pulir probetas de mezclas como las diseñadas en este trabajo, por otros operadores distintos, siguiendo el mismo método de ensayo.

2. Intentar mejorar aún más la precisión del ensayo mediante procesos de pulimento alternativos al propuesto. Sustituir la rueda de caucho rígida, que se utilizada en la UNE-EN 1097-8, por otra más blanda o inflada podría ser una línea a estudiar. Aumentar la superficie de pulimento, mediante el empleo de zapatas y probetas de mayores dimensiones, o la disminución de la velocidad de giro del equipo de pulimento serían otros posibles caminos a seguir. En cualquier caso, convendría estudiar cómo varía la macrotextura de la mezcla conforme ésta se va puliendo y si la evolución de textura se puede relacionar con las medidas de resistencia al deslizamiento obtenidas en cada momento.

3. Estudiar otros procedimientos de compactación que permitan reproducir mejor la macrotextura en las mezclas fabricadas con áridos calizos. El empleo de cargas de compresión menores durante menos tiempo, junto con el empleo de vibración de la mezcla en el molde y el empleo de moldes de mayores dimensiones en las mezclas de mayor tamaño máximo de árido, podría ser el camino a seguir.

4. Investigar cómo medir el coeficiente de resistencia al deslizamiento de la mezcla a velocidades mayores de lo que se hace con el péndulo TRRL, con el objeto de estudiar con más detalle la influencia de la macrotextura en esta propiedad. El desarrollo de algún sistema a pequeña escala de rueda parcialmente bloqueada, que apoyase sobre la rueda porta-muestras girando a gran velocidad midiendo el rozamiento que se genera después de cada intervalo de pulimento, podría ser otra de las líneas de investigación a seguir. 
5. Investigar si las modificaciones introducidas en el proceso de pulimento tienen influencia en los valores de coeficiente de pulimento acelerado de distintos tipos de árido. Comprobar si la repetibilidad y reproducibilidad del ensayo descrito en la UNE-EN 1097-8 se ve mejorada con el empleo de un resorte de las mismas características que el utilizado en la presente investigación.

6. Ampliar el campo de aplicación del equipo a mezclas con mayor tamaño máximo de árido mediante nuevos moldes de probetas de mayores dimensiones y una nueva rueda porta-muestra capaz de albergar dichas probetas.

7. Analizar la correlación que puede haber entre este ensayo y otros que se están empezando a utilizar en laboratorio para conocer el comportamiento frente a deslizamiento de mezclas bituminosas, como el que utiliza la máquina Wehner Schulze, o los que usan una pulidora de mezclas similar a la desarrollada por el NCAT basada en tres ruedas neumáticas infladas.

8. Investigar la relación que pueda existir entre el pulimento producido con el equipo desarrollado en el presente trabajo en mezclas que luego se colocan en el pavimento de carreteras y el pulimento que realmente sufren éstas por la acción del tráfico. En base a esta relación, intentar elaborar un modelo matemático basado en el equipo de ensayo desarrollado, que sea capaz de predecir en laboratorio el comportamiento a futuro de las mezclas frente al deslizamiento. 


\section{REFERENCIAS}

American Association of State Highway and Transportation Officials, AASHTO. 2008. Guide for pavement friction. Washington, D.C., USA.

Asociación Española de Normalización y Certificación, AENOR. 1999. UNE-EN 1097-

3. Ensayos para determinar las propiedades mecánicas y físicas de los áridos. Parte

3: Determinación de la densidad aparente y la porosidad.

Asociación Española de Normalización y Certificación, AENOR. 2006. UNE-EN ISO 13473-1. Caracterización de la textura de los pavimentos mediante el uso de perfiles de superficie. Parte 1: Determinación de la profundidad media del perfil (ISO 13473-1:1997)

Asociación Española de Normalización y Certificación, AENOR. 2008. UNE-EN 13108-1. Mezclas bituminosas. Especificaciones de materiales. Parte 1: Hormigón bituminoso.

Asociación Española de Normalización y Certificación, AENOR. 2010a. UNE-CEN/TS 15901-7 IN. Características superficiales de carreteras y aeropuertos. Parte 7: Procedimiento para determinar la resistencia al deslizamiento de la superficie de un pavimento utilizando un equipo con el ratio de deslizamiento longitudinal fijo (CRLG): GripTester®.

Asociación Española de Normalización y Certificación, AENOR. 2010b. UNE-EN 1097-8. Ensayos para determinar las prestaciones mecánicas y físicas de los áridos. Parte 8: Determinación del coeficiente de pulimento acelerado.

Asociación Española de Normalización y Certificación, AENOR. 2010c. UNE 41201 IN. Características superficiales de carreteras y aeropuertos. Procedimiento para determinar la resistencia al deslizamiento de la superficie de un pavimento a través de la medición del coeficiente de rozamiento transversal (CRTS): SCRIM.

Asociación Española de Normalización y Certificación, AENOR. 2012a. UNE-EN 13036-1. Características superficiales de carreteras y aeropuertos. Parte 1: Medicioón de la macrotextura superficial del pavimento mediante el método volumétrico.

Asociación Española de Normalización y Certificación, AENOR. 2012b. UNE-EN 13036-4. Características superficiales de carreteras y aeropuertos. Parte 4: Método de ensayo para la medición de la resistencia al deslizamiento/derrape. Ensayo del péndulo. 
Asociación Española de Normalización y Certificación, AENOR. 2014. UNE-EN 12697-49. Mezclas bituminosas. Métodos de ensayo para mezclas bituminosas en caliente. Parte 49: Determinación del rozamiento tras el pulido.

Arampamoorthy, H. and Patrick, J. 2011. Potential of the Wehner-Schulze test to predict the on-road friction performance of aggregate. New Zealand Transport Agency research report 443.

Asi, I. 2005. Evaluating skid resistance of different asphalt concrete mixes. Building and Environment 42 (1): 325-29. doi:10.1016/j.buildenv.2005.08.020.

American Society for Testing and Materials, ASTM. 2002. ASTM E707-90. Standard test method for skid resistance measurements using the North Carolina State University Variable-Speed Friction Tester.

American Society for Testing and Materials, ASTM. 2009a. ASTM E1911-09a. Standard test method for measuring paved surface frictional properties using the Dynamic Friction Tester. doi:10.1520/E1911-09AE01.2.

American Society for Testing and Materials, ASTM. 2009b. ASTM E2157-09. Standard test method for measuring pavement macrotexture. Properties using the Circular Track Meter.

American Society for Testing and Materials, ASTM. 2011. ASTM D3319-11. Standard Practice for Accelerated Polishing of Aggregates Using the British Wheel

American Society for Testing and Materials, ASTM. 2013. ASTM E303-93. Standard test method for measuring surface frictional properties using the British Pendulum Tester. doi:10.1520/E0303-93R13.2.

American Society for Testing and Materials, ASTM. 2015. ASTM E1960-07. Standard practice for calculating International Friction Index of a pavement surface

Austroads. 2011a. Review of skid resistance and measurement methods. Austroad technical report No. AP-T177/11. Sydney, Australia.

Austroads. 2011b.Guidance for the development of policy to manage skid resistance. Austroads research report AP-R374/11. Sydney, Australia.

British Standard Institute, BSI. 2002a. BS 7976-1. Pendulum testers. Specification. British Standard Institute, BSI. 2002b. BS 7976-2. Pendulum testers. Method in operation. 
Bullas, J.C. 2005. Slippery when DRY? Low dry friction and binder rich road surfaces. International surface friction conference, 19. Christchurch, New Zealand.

Cairney, P. 1997. Skid resistance and crashes - a review of the literature. ARR 311. Vermont, South Victoria, Australia.

Cenek, P.D, Jamieson, N.J. and Towler, J.I. 2000. The influence of texture depth on skidding resistance. New Zealand.

Centro de Estudios y Experimentación de Obras Públicas, CEDEX. 1987. NLT 33587. Medida de la textura superficial de un pavimento por el método del círculo de arena.

Centro de Estudios y Experimentación de Obras Públicas, CEDEX. 1992. NLT 33692. Determinación de la resistencia al deslizamiento con el equipo de medida del rozamiento transversal.

Centro de Estudios y Experimentación de Obras Públicas, CEDEX. 1998. NLT 17598. Coeficiente de resistencia al deslizamiento con el péndulo del TRRL.

Del Val, M.A. 2010. La resistencia al deslizamiento de los pavimentos. Monografía 11 de la Asociación Española de Fabricantes de Mezclas Asfálticas (Asefma).

Dirección General de Carreteras, DGC. 2015: Pliego de Prescripciones Técnicas Generales para Obras de Carreteras y Puentes PG-3. Ministerio de Fomento. Ediciones Liteam. Madrid.

Do, M.-T, Tang, Z., Kane, M. and de Larrard, F. 2007. Pavement polishingdevelopment of a dedicated laboratory test and its correlation with road results. Wear 263 (1-6): 36-42. doi:10.1016/j.wear.2006.12.086.

Do, M.-T., Tang, Z., Kane, M. and de Larrard, F. 2009. Evolution of road-surface skid-resistance and texture due to polishing. Wear 266 (5-6): 574-77. doi:10.1016/j.wear.2008.04.060.

Do, M.T. and Roe, P. 2008. Transport report on state of the art of test surfaces for skid resistance, Seventh Framework Programme: Theme 7: Transport.

Dunford, A. 2008. The Wehner Schulze machine and its potential use to improve aggregate specifications. Transportation Research Board, no. 002. Cheltenham, UK.

Ech, M., Yotte, S., Morel, S., Breysse, D. and Pouteau, B. 2012. Qualification of wearing course material surface evolution after durability test. Construction and 
Building Materials 35 (October). Elsevier Ltd: 313-20. doi:10.1016/j.conbuildmat.2012.02.081.

Fricke, L.B. 1990. Traffic accident reconstruction. Edited by Evanston III. Vol. 2. Northwestern University Traffic Institute.

Golden, J.M. 1981. A theory of wet road-tyre friction. Journal of Wear 71: 307-31.

Hartley, A. 1974. A review of the geological factors influencing the mechanical properties of road surface aggregates. Quarterly Journal of Engineering Geology and Hydrogeology. 7 (1): 69-100.

Harwood, D.W, Mason, J.M., Glauz, W.D., Kulakowski, B.T. and Fitzpatrick, B. 1989. Truck characteristics for use in highway design and operation. FHWA-RD-89227. Kansas City, USA.

Henry, J.J. 2000. Evaluation of pavement friction characteristics. Washington, D.C., USA.

Highways Agency. 2001. Design manual for roads and bridges: Vol. 7: Pavement design and maintenance.

Hill, B.J. and Henry J.J. 1981. Short term weather related skid resistance variations. 60th Annual Meeting of the Transportation Research Board, edited by University Park: Pennsylvania Transportation Institute, 76-81. Washington, D.C., USA: Transportation Research Board.

Hosking, J. R. 1976. Aggregates for skid-resistant roads. (No. TRRL Rep). Edited by England Crowthorne. Transport and Road Research Laboratory, (TRRL).

Hosking, J.R. 1970. Synthetic aggregates of high resistance to polishing 1: Gritty aggregates. Edited by Crowthorne Berkshire. Transport and Road Research laboratory. Report LR350:1.

Irvine, F. 2010. Highways- GripTester MK2 Skid Resistance Tester.

James, D. 2006. An analysis of the seasonal and short-term variation of road pavement skid resistance. Doctoral tesis, University of Auckland, New Zealand.

Jellie, J.H. 2003. A study of factors affecting skid resistance characteristics. Doctoral tesis, University of Ulster, Northern Ireland.

Kane, M., Artamendi, I. and Scarpas,T. 2013. Long-term skid resistance of asphalt surfacings: Correlation between Wehner-Schulze friction values and the 
mineralogical composition of the aggregates. Wear 303 (1-2). Elsevier: 235-43. doi:10.1016/j.wear.2013.03.022.

Kane, M., Do, M.-T. and Piau, J.M. 2010. On the Study of polishing of road surface under traffic load. Journal of Transportation Engineering 136 (1): 45-51. doi: 10.1061/(ASCE)0733-947X(2010)136:1(45)

Kraemer, H.C, Pardillo, J.M., Rocci,S., Romana, G.M., Blanco, S.V. and Del Val, M.A. 2009. Ingenieria de Carreteras (Vol. 1). Edited by McGraw- Hill Interamericana de España. 2 edición. Madrid, España.

Lamm, R., Psarianos, B. and Mailaender, T. 1999. Highway Design and Traffic Safety Engineering Handbook. Edited by McGraw Hill. New York, USA.

Lees, G. and Kennedy, C.K. 1975. Quality, shape and degradation of aggregates. Quarterly Journal of Engineering Geology and Hydrogeology. 8 (1): 193-205.

Leu, M.C. and Henry, J.J. 1978. Prediction of skid resistance as a function of speed from pavement texture measurements. Transportation Research Record., no. 666: 7-13.

Mcdaniel, R.S. and Coree, B.J. 2003. Identification of laboratory technique to optimize superpave HMA surface friction characteristics. Transportation Research Board. SQDH 2003-6. Phase 1: Final Report. HL 2003-19.

Millard, R. S. and Transport Research Laboratory. 1993. Road building in the tropics. Edited by HMSO: London. doi:10.1002/jctb.5010120803.

Miró, J.R. 1994. Metodologia para la caracterizacion de ligantes asfalticos mediante el empleo del ensayo cantabro.Tesis doctoral, Universidad Politécnica de Barcelona, Barcelona, España

Moreno, F. 2013. Diseño de un método de ensayo de laboratorio para el análisis de la resistencia a fisuración de mezclas bituminosas. Tesis doctoral, Universidad de Granada, España.

Neville, G. 1974. A study of the mechanism of polishing of roadstones by traffic. Edited by Transport and Road Research Laboratory (TRRL). Crowthorne, England.

Oliver, J. W. H. 2003. Skid resistance presentation. Road Engineering Association of Asia and Australasia, (REAAA). 
Owusu, S. 1995. Modeling skid resistance for flexible pavements: A comparison between regression and neural network models. Transportation Research Record., no. 1501: 60-71.

Permanent International Association of Road Congress, PIARC. 1987. Technical Committee Reports 1-12. 18th World Road Congress, Brussels, Belgium.

Permanent International Association of Road Congress, PIARC. 1995. Inventory of road surface characteristics measuring equipment. Technical committee $\mathrm{C} 1$, on surface characteristics. Paris, France.

Permanent International Association of Road Congress, PIARC. 2003. Road Safety Manual: recommendations from the World Road Association. Switzerland: road to market.

Prowell, B.D, Xie, H., Cooley, A.L., Powell, R.B. and Hanson, D. 2003. Relationships between pavement friction and material properties at NCAT Test Track. 82 anual meeting of the Transportation Research Board, (TRB). Washington, D.C., USA.

Rado, Z. 1994. Analysis of texture profiles. PTI Report 9510. Pennsylvania, USA.

Roe, P.G. and Hartshorne, S.A. 1998. The Polished Stone Value of aggregates inservice skidding resistance. Transport Research Laboratory report 322.

Rogers, M.P. and Gargett, T. 1991. Skidding resistance standard for the national road network. Transportation Research Board 38 (4): 10-13.

Sandberg, U. 1999. Influence of road surface texture on traffic characteristics related to environment, economy and safety: a state of the art regarding measures and measuring methods. Swedish National Road and Transport Research Institute, 94.

Smith, M. R., Collis, L. and Fookes, P.G. 2001. Aggregates: sand, gravel and crushed rock aggregates for construction purposes. Edited by Geological Society. 3er ed. London, United Kingdom.

Transit New Zealand, Roading Controlling Authorities and Roading New Zealand. 2005. Chipsealing in New Zealand. Wellington, New Zealand.

Valdés, V.G., Botella, R., Pérez, F. y Miró, R. 2011. Aplicación del ensayo fénix para dosificar mezclas resistentes al fallo por fatiga. Comunicación 11, jornada nacional Asociación Española de Fabricación de Mezclas Asfálticas, (ASEFMA). 
Vollor, W.T. and Hanson, I.D. 2006. Development of laboratory procedure for measuring friction of HMA mixtures - Phase I. NCAT Report 06-06. Auburn, Alabama, USA.

Walsh, I. 2000. Out of the Skid Pan. Transport Research Board 187 (5607): 4-12.

Wambold, J. C. and Henry, J.J. 1995. International PIARC experiment to compare and harmonize texture and skid resistance measurement. Nordic Road \& Transport Research 6 (2): 28-31.

Wang, H. and Wang, Z. 2013. Evaluation of pavement surface friction subject to various pavement preservation treatments. Construction and Building Materials 48 (November). Elsevier Ltd: 194-202. doi:10.1016/j.conbuildmat.2013.06.048.

Woodward, W.D.H., Woodside, A.R. and Jellie, J.H. 2002. Development of early life skid resistance for high stone content asphalt mixes. 3rd International conference of bituminous mixtures and pavements. Transport Research Board, 895-903.

Woodward, W.D.H., Woodside, A.R., and Jellie, J.H. 2005. Early and mid life SMA skid resistance. In International Surface Friction Conference, 4:1-10. Christchurch, New Zealand. 
ANEXO 1. CÁLCULO DE LA REPETIBILIDAD DEL ENSAYO

Tabla A1. Repetibilidad BBTM 11B Caliza con PMB 45/80-65. Pulimento según UNE-EN 1097-8.

\begin{tabular}{|c|c|c|c|c|c|c|c|c|c|c|}
\hline \multirow{2}{*}{ MEZCLA } & \multirow{2}{*}{ PROBETA } & & \multicolumn{3}{|c|}{ Esmeril Grueso } & \multicolumn{5}{|c|}{ Esmeril Fino } \\
\hline & & 0 & 1 & 2 & 3 & 4 & 5 & 6 & 9 & 12 \\
\hline \multirow{4}{*}{$\begin{array}{c}\text { BBTM } \\
11 B \\
\text { CALIZO } \\
\text { PMB } \\
45 / 80- \\
65\end{array}$} & $\begin{array}{l}11 B C \\
\text { BM } \\
S M 1,1\end{array}$ & 65 & 67 & 70 & 60 & 53 & 45 & 46 & 45 & \\
\hline & $\begin{array}{l}\text { 11B C } \\
\text { BM } \\
\text { SM1,2 }\end{array}$ & 71 & 69 & 70 & 67 & 57 & 45 & 51 & & \\
\hline & $\begin{array}{l}11 \mathrm{~B} \mathrm{C} \\
\text { BM } \\
\text { SM2,1 }\end{array}$ & 62 & 66 & 70 & 70 & 64 & 55 & 53 & 50 & 49 \\
\hline & $\begin{array}{c}11 B C \\
\text { BM } \\
\text { SM2,2 }\end{array}$ & 65 & 63 & 64 & 64 & 69 & 67 & 64 & 64 & 64 \\
\hline \multirow{7}{*}{ 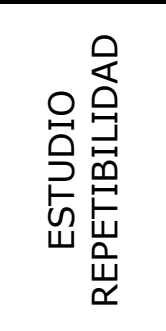 } & MÁX & 71 & 69 & 70 & 70 & 69 & 67 & 64 & 64 & 64 \\
\hline & MÍN & 62 & 63 & 64 & 60 & 53 & 45 & 46 & 45 & 49 \\
\hline & MÁX-MÍN & 9 & 6 & 6 & 10 & 16 & 22 & 18 & 19 & 15 \\
\hline & MEDIA & 66 & 66 & 69 & 65 & 61 & 53 & 54 & 53 & 57 \\
\hline & DESV & 3,8 & 2,5 & 3,0 & 4,3 & 7,1 & 10,5 & 7,6 & 9,8 & 10,6 \\
\hline & $\mathrm{CV}$ & $5,7 \%$ & $3,8 \%$ & $4,4 \%$ & $6,5 \%$ & $11,7 \%$ & $19,7 \%$ & $14,2 \%$ & $18,6 \%$ & $18,8 \%$ \\
\hline & $r$ & 12,0 & 8,0 & 9,5 & 13,6 & 22,7 & 33,3 & 24,2 & 31,3 & 33,8 \\
\hline
\end{tabular}

Tabla A2. Repetibilidad BBTM 11B Pórfido con PMB 45/80-65. Pulimento según UNE-EN 1097-8.

\begin{tabular}{|c|c|c|c|c|c|c|c|c|c|c|}
\hline \multirow{2}{*}{ MEZCLA } & \multirow{2}{*}{ PROBETA } & & \multicolumn{3}{|c|}{ Esmeril Grueso } & \multicolumn{5}{|c|}{ Esmeril Fino } \\
\hline & & $\mathbf{0}$ & 1 & 2 & 3 & 4 & 5 & 6 & 9 & 12 \\
\hline \multirow{4}{*}{$\begin{array}{c}\text { BBTM 11B } \\
\text { PÓRFIDO } \\
\text { PMB } \\
45 / 80-65\end{array}$} & $\begin{array}{l}11 \mathrm{~B} P \\
\text { BM } \\
\text { SM } 1,1\end{array}$ & 60 & 70 & 74 & 65 & 64 & 60 & 60 & 60 & 64 \\
\hline & $\begin{array}{l}11 \mathrm{~B} P \\
\mathrm{BM} \\
\mathrm{SM} 1,2\end{array}$ & 60 & 71 & 70 & 62 & 64 & 55 & 57 & 57 & 60 \\
\hline & $\begin{array}{c}11 B \quad P \\
\text { BM } \\
\text { SM2,1 }\end{array}$ & 57 & 64 & 66 & 66 & 65 & 60 & 60 & 60 & \\
\hline & $\begin{array}{c}\text { 11B P BM } \\
\text { SM2,2 }\end{array}$ & 60 & 64 & 65 & 65 & 64 & 61 & 61 & 61 & 61 \\
\hline \multirow{7}{*}{ 虽 } & MÁX & 60 & 71 & 74 & 66 & 65 & 61 & 61 & 61 & 64 \\
\hline & MÍN & 57 & 64 & 65 & 62 & 64 & 55 & 57 & 57 & 60 \\
\hline & MÁX-MÍN & 3 & 7 & 9 & 4 & 1 & 6 & 4 & 4 & 4 \\
\hline & MEDIA & 59 & 67 & 69 & 65 & 64 & 59 & 60 & 60 & 62 \\
\hline & DESV & 1,5 & 3,8 & 4,1 & 1,7 & 0,5 & 2,7 & 1,7 & 1,7 & 2,1 \\
\hline & $\mathrm{CV}$ & $2,5 \%$ & $5,6 \%$ & $6,0 \%$ & $2,7 \%$ & $0,8 \%$ & $4,6 \%$ & $2,9 \%$ & $2,9 \%$ & $3,4 \%$ \\
\hline & $r$ & 4,8 & 12,0 & 13,1 & 5,5 & 1,6 & 8,6 & 5,5 & 5,5 & 6,6 \\
\hline
\end{tabular}


Tabla A3. Repetibilidad AC 16D Caliza con B 45/80-65. Pulimento según UNE-EN 1097-8.

\begin{tabular}{|c|c|c|c|c|c|c|c|c|c|c|}
\hline \multirow{2}{*}{ MEZCLA } & \multirow{2}{*}{ PROBETA } & \multirow[b]{2}{*}{0} & \multicolumn{3}{|c|}{ Esmeril Grueso } & \multicolumn{5}{|c|}{ Esmeril Fino } \\
\hline & & & 1 & 2 & 3 & 4 & 5 & 6 & 9 & 12 \\
\hline \multirow{4}{*}{$\begin{array}{c}\text { AC 16D } \\
\text { CALIZA } \\
\text { PMB } \\
45 / 80-65\end{array}$} & $\begin{array}{c}\text { 16D C } \\
\text { BM } \\
\text { SM1,1 }\end{array}$ & 65 & 67 & 70 & 60 & 53 & 45 & 46 & 45 & \\
\hline & $\begin{array}{c}\text { 16D C } \\
\text { BM } \\
\text { SM1,2 }\end{array}$ & 71 & 69 & 70 & 67 & 57 & 45 & 51 & & \\
\hline & $\begin{array}{l}\text { 16D C } \\
\text { BM } \\
\text { SM2,1 }\end{array}$ & 74 & 65 & 66 & 66 & 66 & 58 & & & \\
\hline & $\begin{array}{l}16 D C \\
\text { BM } \\
\text { SM2,2 }\end{array}$ & 73 & 65 & 65 & 65 & 70 & 56 & & & \\
\hline \multirow{7}{*}{ 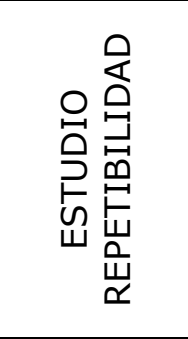 } & MÁX & 74 & 69 & 70 & 67 & 70 & 58 & 51 & & \\
\hline & MÍN & 65 & 65 & 65 & 60 & 53 & 45 & 46 & & \\
\hline & MÁX-MÍN & 9 & 4 & 5 & 7 & 17 & 13 & 5 & & \\
\hline & MEDIA & 71 & 67 & 68 & 65 & 62 & 51 & 49 & 45 & \\
\hline & DESV & 4,0 & 1,9 & 2,6 & 3,1 & 7,9 & 7,0 & 3,5 & & \\
\hline & $\mathrm{CV}$ & $5,7 \%$ & $2,9 \%$ & $3,9 \%$ & $4,8 \%$ & $12,8 \%$ & $13,7 \%$ & $7,3 \%$ & & \\
\hline & $r$ & 12,8 & 6,1 & 8,4 & 9,9 & 25,0 & 22,2 & 11,3 & & \\
\hline
\end{tabular}

Tabla A4. Repetibilidad AC 16D Pórfido con B 45/80-65. Pulimento según UNE-EN 1097-8.

\begin{tabular}{|c|c|c|c|c|c|c|c|c|c|c|}
\hline \multirow{2}{*}{ MEZCLA } & \multirow{2}{*}{ PROBETA } & \multirow[b]{2}{*}{$\mathbf{0}$} & \multicolumn{3}{|c|}{ Esmeril Grueso } & \multicolumn{5}{|c|}{ Esmeril Fino } \\
\hline & & & 1 & 2 & 3 & 4 & 5 & 6 & 9 & 12 \\
\hline \multirow{4}{*}{$\begin{array}{c}\text { AC 16D } \\
\text { PÓRFIDO } \\
\text { PMB } \\
45 / 80-65\end{array}$} & $\begin{array}{c}\text { 16D P BM } \\
\text { SM } 1,1\end{array}$ & 69,0 & 65,0 & 64,0 & 65,0 & 61,0 & 57,0 & 60,0 & 55,0 & 59,0 \\
\hline & $\begin{array}{c}\text { 16D P BM } \\
\text { SM1,2 }\end{array}$ & 65,0 & 66,0 & 70,0 & 65,0 & 65,0 & 59,0 & 59,0 & 57,0 & 60,0 \\
\hline & $\begin{array}{c}\text { 16D P BM } \\
\text { SM2,1 }\end{array}$ & 68,0 & 65,0 & 65,0 & 65,0 & 65,0 & 62,0 & 63,0 & 63,0 & 62,0 \\
\hline & $\begin{array}{c}\text { 16D P BM } \\
\text { SM2,2 }\end{array}$ & 67,0 & 65,0 & 69,0 & 69,0 & 69,0 & 65,0 & 62,0 & 61,0 & 60,0 \\
\hline \multirow{7}{*}{ 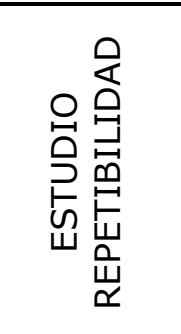 } & MÁX & 69,0 & 66,0 & 70,0 & 69,0 & 69,0 & 65,0 & 63,0 & 63,0 & 62,0 \\
\hline & MÍN & 65,0 & 65,0 & 64,0 & 65,0 & 61,0 & 57,0 & 59,0 & 55,0 & 59,0 \\
\hline & MÁX-MÍN & 4,00 & 1,00 & 6,00 & 4,00 & 8,00 & 8,00 & 4,00 & 8,00 & 3,00 \\
\hline & MEDIA & 67,3 & 65,3 & 67,0 & 66,0 & 65,0 & 60,8 & 61,0 & 59,0 & 60,3 \\
\hline & DESV & 1,7 & 0,5 & 2,9 & 2,0 & 3,3 & 3,5 & 1,8 & 3,7 & 1,3 \\
\hline & $\mathrm{CV}$ & $2,5 \%$ & $0,8 \%$ & $4,4 \%$ & $3,0 \%$ & $5,0 \%$ & $5,8 \%$ & $3,0 \%$ & $6,2 \%$ & $2,1 \%$ \\
\hline & $r$ & 5,4 & 1,6 & 9,4 & 6,4 & 10,4 & 11,1 & 5,8 & 11,6 & 4,0 \\
\hline
\end{tabular}


Tabla A5. Repetibilidad BBTM 11B Pórfido con 50/70. Pulimento según UNE-EN 1097-8.

\begin{tabular}{|c|c|c|c|c|c|c|c|c|c|c|}
\hline \multirow{2}{*}{ MEZCLA } & \multirow{2}{*}{ PROBETA } & \multirow[b]{2}{*}{0} & \multicolumn{3}{|c|}{ Esmeril Grueso } & \multicolumn{5}{|c|}{ Esmeril Fino } \\
\hline & & & 1 & 2 & 3 & 4 & 5 & 6 & 9 & 12 \\
\hline \multirow{4}{*}{$\begin{array}{l}\text { BBTM 11B } \\
\text { PÓRFIDO } \\
50 / 70\end{array}$} & $\begin{array}{l}11 B \quad P \\
50 / 70 \\
\text { SM1,1 }\end{array}$ & 73,0 & 74,0 & 71,0 & 67,0 & 65,0 & 61,0 & 60,0 & 60,0 & 66,0 \\
\hline & $\begin{array}{l}11 B \quad P \\
50 / 70 \\
S M 1,2\end{array}$ & 72,0 & 65,0 & 69,0 & 66,0 & 64,0 & 55,0 & 62,0 & 57,0 & 60,0 \\
\hline & $\begin{array}{l}11 B \quad P \\
50 / 70 \\
\text { SM2,1 }\end{array}$ & 72,0 & 61,0 & 61,0 & 61,0 & 65,0 & 64,0 & 64,0 & 62,0 & 61,0 \\
\hline & $\begin{array}{l}11 B \text { P } \\
50 / 70 \\
\text { SM2,2 }\end{array}$ & 73,0 & 65,0 & 69,0 & 69,0 & 74,0 & 68,0 & 65,0 & 63,0 & 70,0 \\
\hline \multirow{7}{*}{ 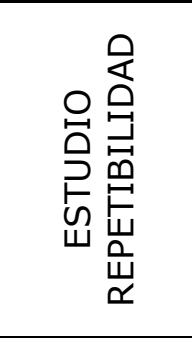 } & MÁX & 73,0 & 74,0 & 71,0 & 69,0 & 74,0 & 68,0 & 65,0 & 63,0 & 70,0 \\
\hline & MÍN & 72,0 & 61,0 & 61,0 & 61,0 & 64,0 & 55,0 & 60,0 & 57,0 & 60,0 \\
\hline & MÁX-MÍN & 1,00 & 13,00 & 10,00 & 8,00 & 10,00 & 13,00 & 5,00 & 6,00 & 10,00 \\
\hline & MEDIA & 72,5 & 66,3 & 67,5 & 65,8 & 67,0 & 62,0 & 62,8 & 60,5 & 64,3 \\
\hline & DESV & 0,6 & 5,5 & 4,4 & 3,4 & 4,7 & 5,5 & 2,2 & 2,6 & 4,6 \\
\hline & $\mathrm{CV}$ & $0,8 \%$ & $8,3 \%$ & $6,6 \%$ & $5,2 \%$ & $7,0 \%$ & $8,8 \%$ & $3,5 \%$ & $4,4 \%$ & $7,2 \%$ \\
\hline & $r$ & 1,8 & 17,5 & 14,1 & 10,8 & 14,9 & 17,4 & 7,1 & 8,4 & 14,8 \\
\hline
\end{tabular}

Tabla A6. Repetibilidad árido de referencia. Pulimento según UNE-EN 1097-8.

\begin{tabular}{|c|c|c|c|c|c|c|c|c|c|c|}
\hline \multirow{2}{*}{ MEZCLA } & \multirow{2}{*}{ PROBETA } & \multirow[b]{2}{*}{0} & \multicolumn{3}{|c|}{ Esmeril Grueso } & \multicolumn{5}{|c|}{ Esmeril Fino } \\
\hline & & & 1 & 2 & 3 & 4 & 5 & 6 & 9 & 12 \\
\hline \multirow{4}{*}{ ARI REF } & $\begin{array}{c}\text { ARI SM } \\
1,1\end{array}$ & 54,0 & 60,0 & 55,0 & 55,0 & 60,0 & 55,0 & 55,0 & 50,0 & 49,0 \\
\hline & $\begin{array}{c}\text { ARI SM } \\
1,2 \\
\end{array}$ & 63,0 & 63,0 & 60,0 & 59,0 & 60,0 & 57,0 & 56,0 & 55,0 & 55,0 \\
\hline & $\begin{array}{c}\text { ARI SM } \\
2,1\end{array}$ & 63,0 & 65,0 & 60,0 & 60,0 & 60,0 & 60,0 & 58,0 & 57,0 & 56,0 \\
\hline & $\begin{array}{c}\text { ARI SM } \\
2,2\end{array}$ & 67,0 & 65,0 & 62,0 & 62,0 & 61,0 & 61,0 & 59,0 & 60,0 & 59,0 \\
\hline \multirow{7}{*}{ 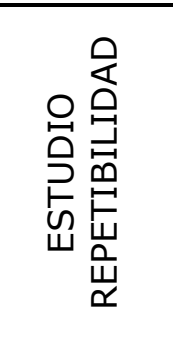 } & MÁX & 67,0 & 65,0 & 62,0 & 62,0 & 61,0 & 61,0 & 59,0 & 60,0 & 59,0 \\
\hline & MÍN & 54,0 & 60,0 & 55,0 & 55,0 & 60,0 & 55,0 & 55,0 & 50,0 & 49,0 \\
\hline & MÁX-MÍN & 13,00 & 5,00 & 7,00 & 7,00 & 1,00 & 6,00 & 4,00 & 10,00 & 10,00 \\
\hline & MEDIA & 61,8 & 63,3 & 59,3 & 59,0 & 60,3 & 58,3 & 57,0 & 55,5 & 54,8 \\
\hline & DESV & 5,5 & 2,4 & 3,0 & 2,9 & 0,5 & 2,8 & 1,8 & 4,2 & 4,2 \\
\hline & $\mathrm{CV}$ & $8,9 \%$ & $3,7 \%$ & $5,0 \%$ & $5,0 \%$ & $0,8 \%$ & $4,7 \%$ & $3,2 \%$ & $7,6 \%$ & $7,7 \%$ \\
\hline & $r$ & 17,5 & 7,5 & 9,5 & 9,4 & 1,6 & 8,8 & 5,8 & 13,4 & 13,3 \\
\hline
\end{tabular}


Tabla A7. Repetibilidad BBTM 11B Caliza con PMB 45/80-65. Pulimento según UNE-EN 1097-8 más muelle

\begin{tabular}{|c|c|c|c|c|c|c|c|c|c|c|c|}
\hline \multirow{2}{*}{ MEZCLA } & \multirow{2}{*}{ PROBETA } & & \multicolumn{3}{|c|}{ Esmeril Grueso } & \multicolumn{6}{|c|}{ Esmeril Fino } \\
\hline & & 0 & 1 & 2 & 3 & 4 & 5 & 6 & 8 & 10 & 12 \\
\hline \multirow{4}{*}{ 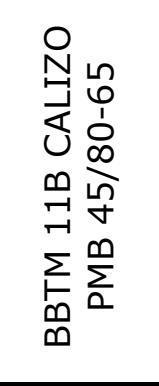 } & $\begin{array}{c}11 \mathrm{~B} \mathrm{C} \\
\mathrm{BM} \mathrm{R} 1,1\end{array}$ & 71 & 75 & 75 & 70 & 63 & 60 & 59 & 59 & 57 & 57 \\
\hline & $\begin{array}{c}11 \mathrm{~B} \mathrm{C} \\
\mathrm{BM} \mathrm{R} 1,2\end{array}$ & 68 & 70 & 73 & 72 & 65 & 62 & 57 & 57 & 55 & 55 \\
\hline & $\begin{array}{c}11 \mathrm{~B} \mathrm{C} \\
\mathrm{BM} R 2,1\end{array}$ & 68 & 70 & 72 & 70 & 63 & 60 & 57 & 57 & 56 & 54 \\
\hline & $\begin{array}{c}11 \mathrm{~B} \mathrm{C} \\
\mathrm{BM} \mathrm{R} 2,1\end{array}$ & 75 & 77 & 75 & 73 & 65 & 62 & 56 & 55 & 55 & 52 \\
\hline \multirow{7}{*}{ 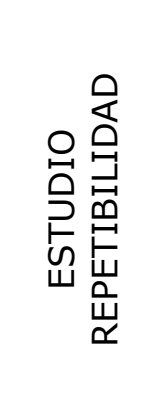 } & MÁX & 75 & 77 & 75 & 73 & 65 & 62 & 59 & 59 & 57 & 57 \\
\hline & MÍN & 68 & 70 & 72 & 70 & 63 & 60 & 56 & 55 & 55 & 52 \\
\hline & MÁX-MÍN & 7 & 7 & 3 & 3 & 2 & 2 & 3 & 4 & 2 & 5 \\
\hline & MEDIA & 71 & 73 & 74 & 71 & 64 & 61 & 57 & 57 & 56 & 55 \\
\hline & DESV & 3,3 & 3,6 & 1,5 & 1,5 & 1,2 & 1,2 & 1,3 & 1,6 & 1,0 & 2,1 \\
\hline & CV & $4,7 \%$ & $4,9 \%$ & $2,0 \%$ & $2,1 \%$ & $1,8 \%$ & $1,9 \%$ & $2,2 \%$ & $2,9 \%$ & $1,7 \%$ & $3,8 \%$ \\
\hline & $r$ & 10,6 & 11,3 & 4,8 & 4,8 & 3,7 & 3,7 & 4,0 & 5,2 & 3,0 & 6,6 \\
\hline
\end{tabular}

Tabla A8. Repetibilidad BBTM 11B Pórfido con PMB 45/80-65. Pulimento según UNE-EN 1097-8 más muelle.

\begin{tabular}{|c|c|c|c|c|c|c|c|c|c|c|c|}
\hline \multirow{2}{*}{ MEZCLA } & \multirow{2}{*}{ PROBETA } & & \multicolumn{3}{|c|}{ Esmeril Grueso } & \multicolumn{6}{|c|}{ Esmeril Fino } \\
\hline & & $\mathbf{0}$ & 1 & 2 & 3 & 4 & 5 & 6 & 8 & 10 & 12 \\
\hline \multirow{4}{*}{ 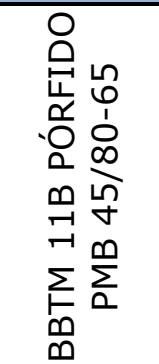 } & \begin{tabular}{|c|}
$11 \mathrm{~B} P$ \\
$\mathrm{BM} \mathrm{R} 1,1$ \\
\end{tabular} & 70 & 74 & 70 & 63 & 60 & 60 & 60 & 55 & 54 & 55 \\
\hline & $\begin{array}{c}11 \mathrm{~B} P \\
\mathrm{BM} \mathrm{R} 1,2\end{array}$ & 67 & 72 & 70 & 65 & 63 & 63 & 61 & 61 & 55 & 55 \\
\hline & $\begin{array}{c}11 \mathrm{~B} P \\
\mathrm{BM} \mathrm{R} 2,1 \\
\end{array}$ & 72 & 74 & 70 & 62 & 64 & 55 & 57 & 59 & 59 & 55 \\
\hline & $\begin{array}{c}11 \mathrm{~B} \mathrm{P} \\
\mathrm{BM} \mathrm{R} 2,2\end{array}$ & 72 & 75 & 70 & 70 & 68 & 67 & 63 & 63 & 60 & 56 \\
\hline \multirow{7}{*}{ 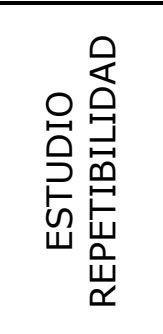 } & MÁX & 72 & 75 & 70 & 70 & 68 & 67 & 63 & 63 & 60 & 56 \\
\hline & MÍN & 67 & 72 & 70 & 62 & 60 & 55 & 57 & 55 & 54 & 55 \\
\hline & MÁX-MÍN & 5 & 3 & 0 & 8 & 8 & 12 & 6 & 8 & 6 & 1 \\
\hline & MEDIA & 70 & 74 & 70 & 65 & 64 & 61 & 60 & 60 & 57 & 55 \\
\hline & DESV & 2,4 & 1,3 & 0,0 & 3,6 & 3,3 & 5,1 & 2,5 & 3,4 & 2,9 & 0,5 \\
\hline & $\mathrm{CV}$ & $3,4 \%$ & $1,7 \%$ & $0,0 \%$ & $5,5 \%$ & $5,2 \%$ & $8,3 \%$ & $4,1 \%$ & $5,7 \%$ & $5,2 \%$ & $0,9 \%$ \\
\hline & $r$ & 7,5 & 4,0 & 0,0 & 11,3 & 10,5 & 16,1 & 8,0 & 10,9 & 9,4 & 1,6 \\
\hline
\end{tabular}


Tabla A9. Repetibilidad AC 16D Caliza con PMB 45/80-65. Pulimento según UNE-EN 1097-8 más muelle.

\begin{tabular}{|c|c|c|c|c|c|c|c|c|c|c|c|}
\hline \multirow[b]{2}{*}{ MEZCLA } & \multirow[b]{2}{*}{ PROBETA } & \multirow[b]{2}{*}{0} & \multicolumn{3}{|c|}{ Esmeril Grueso } & \multicolumn{6}{|c|}{ Esmeril Fino } \\
\hline & & & 1 & 2 & 3 & 4 & 5 & 6 & 8 & 10 & 12 \\
\hline \multirow{4}{*}{ 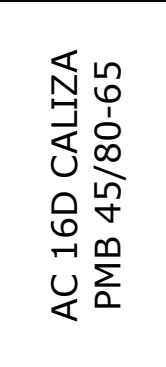 } & $\begin{array}{c}16 \mathrm{D} \text { C BM } \\
\mathrm{R} 1,1\end{array}$ & 75 & 73 & 77 & 74 & 63 & 60 & 58 & 55 & 54 & 53 \\
\hline & $\begin{array}{c}16 \mathrm{D} \text { C BM } \\
\mathrm{R} 1,2 \\
\end{array}$ & 74 & 74 & 80 & 72 & 61 & 59 & 55 & 51 & 51 & 49 \\
\hline & $\begin{array}{c}16 \mathrm{D} \mathrm{C} \mathrm{BM} \\
\mathrm{R} 2,1\end{array}$ & 71 & 74 & 75 & 73 & 60 & 58 & 56 & 55 & 51 & 52 \\
\hline & $\begin{array}{c}16 \mathrm{D} \mathrm{C} \mathrm{BM} \\
\mathrm{R} 2,2 \\
\end{array}$ & 71 & 73 & 70 & 72 & 60 & 55 & 55 & 52 & 51 & 50 \\
\hline \multirow{7}{*}{ 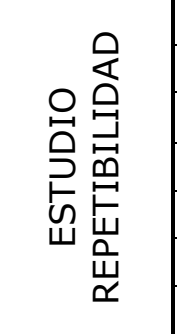 } & MÁX & 75 & 74 & 80 & 74 & 63 & 60 & 58 & 55 & 54 & 53 \\
\hline & MÍN & 71 & 73 & 70 & 72 & 60 & 55 & 55 & 51 & 51 & 49 \\
\hline & MÁX-MÍN & 4 & 1 & 10 & 2 & 3 & 5 & 3 & 4 & 3 & 4 \\
\hline & MEDIA & 73 & 74 & 76 & 73 & 61 & 58 & 56 & 53 & 52 & 51 \\
\hline & DESV & 2,1 & 0,6 & 4,2 & 1,0 & 1,4 & 2,2 & 1,4 & 2,1 & 1,5 & 1,8 \\
\hline & $\mathrm{CV}$ & $2,8 \%$ & $0,8 \%$ & $5,6 \%$ & $1,3 \%$ & $2,3 \%$ & $3,7 \%$ & $2,5 \%$ & $3,9 \%$ & $2,9 \%$ & $3,6 \%$ \\
\hline & $r$ & 6,6 & 1,8 & 13,4 & 3,0 & 4,5 & 6,9 & 4,5 & 6,6 & 4,8 & 5,8 \\
\hline
\end{tabular}

Tabla A10. Repetibilidad AC 16D Pórfido con PMB 45/80-65. Pulimento según UNE-EN 1097-8 más muelle.

\begin{tabular}{|c|c|c|c|c|c|c|c|c|c|c|c|}
\hline \multirow{2}{*}{ MEZCLA } & \multirow{2}{*}{ PROBETA } & \multirow[b]{2}{*}{0} & \multicolumn{3}{|c|}{ Esmeril Grueso } & \multicolumn{6}{|c|}{ Esmeril Fino } \\
\hline & & & 1 & 2 & 3 & 4 & 5 & 6 & 8 & 10 & 12 \\
\hline \multirow{4}{*}{ 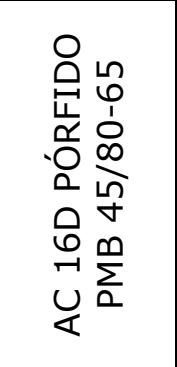 } & $\begin{array}{c}\text { 16D P BM } \\
\text { R } 1,1\end{array}$ & 67 & 70 & 73 & 69 & 64 & 60 & 57 & 57 & 57 & 57 \\
\hline & \begin{tabular}{|c|} 
16D P BM \\
R1,2 \\
\end{tabular} & 74 & 71 & 74 & 70 & 65 & 60 & 59 & 54 & 53 & 52 \\
\hline & $\begin{array}{c}\text { 16D P BM } \\
\text { R2,1 }\end{array}$ & 70 & 72 & 74 & 69 & 66 & 65 & 59 & 59 & 55 & 55 \\
\hline & $\begin{array}{c}\text { 16D P BM } \\
\text { R2,2 }\end{array}$ & 72 & 75 & 74 & 70 & 67 & 65 & 57 & 57 & 55 & 55 \\
\hline \multirow{7}{*}{ 虽 } & MÁX & 74 & 75 & 74 & 70 & 67 & 65 & 59 & 59 & 57 & 57 \\
\hline & MÍN & 67 & 70 & 73 & 69 & 64 & 60 & 57 & 54 & 53 & 52 \\
\hline & MÁX-MÍN & 7 & 5 & 1 & 1 & 3 & 5 & 2 & 5 & 4 & 5 \\
\hline & MEDIA & 71 & 72 & 74 & 70 & 66 & 63 & 58 & 57 & 55 & 55 \\
\hline & DESV & 3,0 & 2,2 & 0,5 & 0,6 & 1,3 & 2,9 & 1,2 & 2,1 & 1,6 & 2,1 \\
\hline & $\mathrm{CV}$ & $4,2 \%$ & $3,0 \%$ & $0,7 \%$ & $0,8 \%$ & $2,0 \%$ & $4,6 \%$ & $2,0 \%$ & $3,6 \%$ & $3,0 \%$ & $3,8 \%$ \\
\hline & $r$ & 9,5 & 6,9 & 1,6 & 1,8 & 4,1 & 9,2 & 3,7 & 6,6 & 5,2 & 6,6 \\
\hline
\end{tabular}


Tabla A11. Repetibilidad BBTM 11B Pórfido con 50/70. Pulimento según UNE-EN 1097-8 más muelle.

\begin{tabular}{|c|c|c|c|c|c|c|c|c|c|c|c|}
\hline \multirow{2}{*}{ MEZCLA } & \multirow{2}{*}{ PROBETA } & & \multicolumn{3}{|c|}{ Esmeril Grueso } & \multicolumn{6}{|c|}{ Esmeril Fino } \\
\hline & & $\mathbf{0}$ & 1 & 2 & 3 & 4 & 5 & 6 & 8 & 10 & 12 \\
\hline \multirow{4}{*}{ 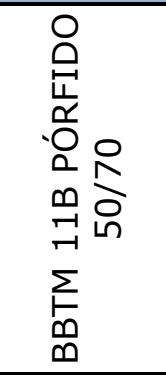 } & $\begin{array}{c}\text { 11B P BC } \\
\text { R } 1,1\end{array}$ & 68 & 70 & 70 & 70 & 65 & 64 & 55 & 55 & 52 & 50 \\
\hline & $\begin{array}{c}11 \mathrm{~B} P \text { P BC } \\
\mathrm{R} 1,2\end{array}$ & 70 & 70 & 70 & 70 & 65 & 60 & 57 & 56 & 55 & 54 \\
\hline & $\begin{array}{c}11 \mathrm{~B} \mathrm{P} \mathrm{BC} \\
\mathrm{R} 2,1\end{array}$ & 72 & 72 & 70 & 70 & 65 & 64 & 62 & 60 & 55 & 54 \\
\hline & $\begin{array}{c}\text { 11B P BC } \\
\text { R2,2 }\end{array}$ & 73 & 74 & 71 & 67 & 65 & 61 & 60 & 60 & 54 & 53 \\
\hline \multirow{7}{*}{ 空 } & MÁX & 73 & 74 & 71 & 70 & 65 & 64 & 62 & 60 & 55 & 54 \\
\hline & MÍN & 68 & 70 & 70 & 67 & 65 & 60 & 55 & 55 & 52 & 50 \\
\hline & MÁX-MÍN & 5 & 4 & 1 & 3 & 0 & 4 & 7 & 5 & 3 & 4 \\
\hline & MEDIA & 71 & 72 & 70 & 69 & 65 & 62 & 59 & 58 & 54 & 53 \\
\hline & DESV & 2,2 & 1,9 & 0,5 & 1,5 & 0,0 & 2,1 & 3,1 & 2,6 & 1,4 & 1,9 \\
\hline & CV & $3,1 \%$ & $2,7 \%$ & $0,7 \%$ & $2,2 \%$ & $0,0 \%$ & $3,3 \%$ & $5,3 \%$ & $4,6 \%$ & $2,6 \%$ & $3,6 \%$ \\
\hline & $r$ & 7,1 & 6,1 & 1,6 & 4,8 & 0,0 & 6,6 & 9,9 & 8,4 & 4,5 & 6,0 \\
\hline
\end{tabular}

Tabla A12. Repetibilidad árido de referencia. Pulimento según UNE-EN 1097-8 más muelle.

\begin{tabular}{|c|c|c|c|c|c|c|c|c|c|c|c|}
\hline \multirow{2}{*}{ MEZCLA } & \multirow{2}{*}{ PROBETA } & & \multicolumn{3}{|c|}{ Esmeril Grueso } & \multicolumn{6}{|c|}{ Esmeril Fino } \\
\hline & & $\mathbf{0}$ & 1 & 2 & 3 & 4 & 5 & 6 & 8 & 10 & 12 \\
\hline \multirow{4}{*}{ 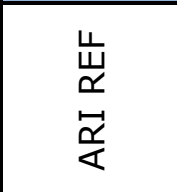 } & ARI R1,1 & 68,0 & 68,0 & 65,0 & 65,0 & 65,0 & 60,0 & 60,0 & 60,0 & 60,0 & 59,0 \\
\hline & ARI R1,2 & 69,0 & 68,0 & 65,0 & 65,0 & 64,0 & 61,0 & 60,0 & 60,0 & 60,0 & 58,0 \\
\hline & ARI R2,1 & 74,0 & 70,0 & 68,0 & 66,0 & 66,0 & 65,0 & 60,0 & 60,0 & 60,0 & 60,0 \\
\hline & ARI R2,2 & 73 & 70 & 67 & 66 & 63 & 62 & 56 & 56 & 55 & 55 \\
\hline \multirow{7}{*}{ 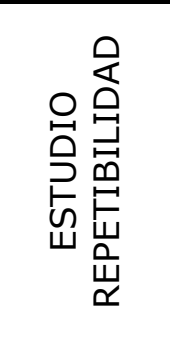 } & MÁX & 74 & 70 & 68 & 66 & 66 & 65 & 60 & 60 & 60 & 60 \\
\hline & MÍN & 68 & 68 & 65 & 65 & 63 & 60 & 56 & 56 & 55 & 55 \\
\hline & MÁX-MÍN & 6 & 2 & 3 & 1 & 3 & 5 & 4 & 4 & 5 & 5 \\
\hline & MEDIA & 71 & 69 & 66 & 66 & 65 & 62 & 59 & 59 & 59 & 58 \\
\hline & DESV & 2,9 & 1,2 & 1,5 & 0,6 & 1,3 & 2,2 & 2,0 & 2,0 & 2,5 & 2,2 \\
\hline & $\mathrm{CV}$ & $4,1 \%$ & $1,7 \%$ & $2,3 \%$ & $0,9 \%$ & $2,0 \%$ & $3,5 \%$ & $3,4 \%$ & $3,4 \%$ & $4,3 \%$ & $3,7 \%$ \\
\hline & $r$ & 9,4 & 3,7 & 4,8 & 1,8 & 4,1 & 6,9 & 6,4 & 6,4 & 8,0 & 6,9 \\
\hline
\end{tabular}

